Louisiana State University

LSU Digital Commons

1972

\title{
Health Care Patterns, Attitudes, and Resource Utilization of a Predominantly Indigent Population in Three Communities.
}

\author{
Robert Allen Perkins \\ Louisiana State University and Agricultural \& Mechanical College
}

Follow this and additional works at: https://digitalcommons.Isu.edu/gradschool_disstheses

\begin{abstract}
Recommended Citation
Perkins, Robert Allen, "Health Care Patterns, Attitudes, and Resource Utilization of a Predominantly Indigent Population in Three Communities." (1972). LSU Historical Dissertations and Theses. 2232.

https://digitalcommons.Isu.edu/gradschool_disstheses/2232
\end{abstract}

This Dissertation is brought to you for free and open access by the Graduate School at LSU Digital Commons. It has been accepted for inclusion in LSU Historical Dissertations and Theses by an authorized administrator of LSU Digital Commons. For more information, please contact gradetd@lsu.edu. 


\section{INFORMATION TO USERS}

This dissertation was produced from a microfilm copy of the original document. While the most advanced technological means to photograph and reproduce this document have been used, the quality is heavily dependent upon the quality of the original submitted.

The following explanation of techniques is provided to help you understand markings or patterns which may appear on this reproduction.

1. The sign or "target" for pages apparently lacking from the document photographed is "Missing Page(s)". If it was possible to obtain the missing page(s) or section, they are spliced into the film along with adjacent pages. This may have necessitated cutting thru an image and duplicating adjacent pages to insure you complete continuity.

2. When an image on the film is obliterated with a large round black mark, it is an indication that the photographer suspected that the copy may have moved during exposure and thus cause a blurred image. You will find a good image of the page in the adjacent frame.

3. When a map, drawing or chart, etc., was part of the material being photographed the photographer followed a definite method in "sectioning" the material. It is customary to begin photoing at the upper left hand corner of a large sheet and to continue photoing from left to right in equal sections with a small overlap. If necessary, sectioning is continued again - beginning below the first row and continuing on until complete.

4. The majority of users indicate that the textual content is of greatest value, however, a somewhat higher quality reproduction could be made from "photographs" if essential to the understanding of the dissertation. Silver prints of "photographs" may be ordered at additional charge by writing the Order Department, giving the catalog number, title, author and specific pages you wish reproduced.

\section{University Microfilms}


PERKINS, Robert Allen, 1928-

HEALTH CARE PATTERNS, ATTITUDES, AND RESOURCE

UTILIZATION OF A PREDOMINANTLY INDIGENT

POPULATION IN THREE COMMNITIES.

The Louisiana State University and Agricultural and Mechanical College, Ph.D., 1972

Sociology, public welfare

University Microfilms, A XEROX Company , Ann Arbor, Michigan 
HEALTH CARE PATTERNS, ATTITUDES, AND RESOURCE

UTILIZATION OF A PREDOMINANTLY INDIGENT

POPULATION IN THREE COMMUNITIES

A Dissertation

Submitted to the Graduate Faculty of the

Louisiana State University and

Agricultural and Mechanical College

in partial fulfillment of the

requirements for the degree of

Doctor of Philosophy

in

The Department of Sociology

by

Robert Allen Perkins

B.S., Loulsiana State University, 1956

M.S.W., Louisiana State University, 1960

May, 1972 
PLEASE NOTE:

Some pages may have

indistinct print.

Filmed as received.

University Microfilms, A Xerox Education Company 


\section{ACKNOWLEDGMENTS}

This dissertation was completed only because of the valuable and unselfish contributions of many persons. Among these persons the writer is especially indebted to the members of his committee: Alvin L. Bertrand, Ph.D., Chairman, V. K. Andreasen, Ph.D., Perry H. Howard, Ph.D., Nell Paterson, Vernon J. Parenton, Ph.D., and Hilliard E. Chesteen, Ph.D. Not only did these persons offer knowledge and skill, but, in many instances, they provided encouragement and reassurance which contributed greatly to the completion of the study.

Deep appreciation must also be expressed to my wife, Flo, and my children, Allen, Patsy, Becky, and Cathy, who unswervingly endured the restructuring of their life styles to accommodate the pursult of this study. 
TABLE OF CONTENTS

Page

ACKNOWLEDGMENTS. . . . . . . . . . . . . . . . . . . . 11

LIST OF TABLES . . . . . . . . . . . . . . . . . . . v v

LIST OF FIGURES. . . . . . . . . . . . . . . . . . . . xi1

ABSTRACT ............................. x111

Chapter

I. THE PROBLEM AND REVIEW OF THE LITERATURE . . . . . . . . . 1

The Problem. . . . . . . . . . . . . . . . . 1

Statement of the Problem............... 1

Purposes of the Study................. 2

Significance of the Study. . . . . . . . . . . 2

Review of the Literature............... . 5

Social Epidemiology. . . . . . . . . . . 6

Social Etiology... . . . . . . . . . . . . 11

Health Care Resource Utilization........... 21

Summary. . . . . . . . . . . . . . 32

II. GENERAL SOCIOLOGICAL FRAMEWORK AND METHODOLOGY . . . . . . 34

General Sociological Framework . . . . . . . . . 34

Medical Sociology. . . . . . . . . . . . . 34

Social Organization. . . . . . . . . . . . 34

Methodology. . . . . . . . . . . . . . 50

Hypotheses .................. . 50

Research Procedures................. 51

Method of Data Gathering . . . . . . . . . . 52

Sampling Procedures.............. . . 55

Methods of Analysis. . . . . . . . . . . . 58

Limitations of this Study. . . . . . . . . . . 58

III. THE SETTINGS AND POPULATIONS . . . . . . . . . . . 60

The Intent........ . . . . . . . . . . 60

The Settings... . . . . . . . . . . . . . 60

New Roads..................... . 60

Geographic Features............... . 60

Economy. .................... 61

Hammond. . . . . . . . . . . . . . . 62

Geographic Features. . . . . . . . . . 62

Economy. . . . . . . . . . . . . . . 63 
III. (Continued)

South Baton Rouge Neighborhood Area. . . . . . . 64

Geographic Features. . . . . . . . . . . . 64

Economy. . . . . . . . . . . . . . . 65

IV. PERCEIVED MORBIDITY BY A PREDOMINANTLY INDIGENT

POPULATION. . . . . . . . . . . . . . . . . . . . . 76

Perceived Seriousness of Symptoms. . . . . . . . . 76

Morbidity. . . . . . . . . . . . . . . . . . 87

Anomie and Percelved Morbidity .. . . . . . . 87

Summary. . . . . . . . . . . . . . . . 110

V. HEALTH CARE UTILIZATION. . . . . . . . . . . . . . . 127

Normative Utilization. . . . . . . . . . . . . . 127

Quality of Medical Doctor Utilization. . . . . . . . 131

Reasons for Use of Medical Care. . . . . . . . . 156

Summary. . . . . . . . . . . . . . . 165

vI. ATTITUDE TOWARD HEALTH CARE FACILITIES . . . . . . . . . 168

Summary. . . . . . . . . . . . . . . . . 185

VII. SUMMARY AND CONCLUSIONS. . . . . . . . . . . . . . . 194

Background .. . . . . . . . . . . . . . . 194

Pathology. . . . . . . . . . . . . . . 200

Health Care Utilization................ 203

Attitudes. . . . . . . . . . . . . . . 206

Limitations of the study ............... 209

Recommendations.................. 212

BIBLIOGRAPHY ......................... . 216

APPENDICES . • . • • . • . . . . . . . . . . . . . 222

VITA . . . . . . . . . . . . . . . . . . . . 234 


\section{LIST OF TABLES}

Table

Page

I Distribution of Labor Force Among Occupational

Categories in the Parishes of East Baton Rouge, Tangipahoa and Pointe Coupee, 1968 . . . . . .

II Ethnic and Race Distribution of the Sample Populations for South Baton Rouge, Hammond, and New Roads, 1971.................

III A Comparison of the Sex Ratio of the Sample Populations of South Baton Rouge, Hammond, and New Roads, 1971....................

IV Age Distribution of the Sample Populations for South Baton Rouge, Hammond, and New Roads, 1971. .

V Distribution of Families by Functiona 1 Dwelling Type in the Sample Populations for South Baton Rouge, Hammond, and New Roads, 1971. . . . . .

VI Distribution by Religious Affiliation of the Sample Populations for South Baton Rouge, Hammond, and New Roads, 1971 . . . . . . . 74

VII Income Distributions of the Sample Populations for South Baton Rouge, Hammond, and New Roads, 1971. .

VIII Extent to which Selected Symptoms are Perceived as Serious Enough to Require Treatment by a Medical Doctor among a Predominantly Indigent Population of South Baton Rouge, Hammond, and New Roads, 1971

IX

Difference in Perception of Selected Symptoms as Serious Enough to Require Treatment by a Medical Doct or in a Predominantly Indigent Population of South Baton Rouge, Hammond, and New Roads, Shown by Religious Affiliation, 1971 . . . . . . .

Income Differential and the Perception of Selected Symptoms as Serious Enough to Require Treatment by a Medical Doct or in a Predominantly Indigent Population of South Baton Rouge, Hammond, and New Roads, 1971. . . . . . . . . . . . . 
XI Ethnic Differential in the Perception of Selected Symptoms as Serious Enough to Require Treatment by a Medical Doctor in a Predominant ly Indigent Population of South Baton Rouge, Hammond, and New Roads, 1971................

XII Rates of Perceived Morbidity for Selected Disease Categories Shown by Levels of Anomie in a Predominantly Indigent Population of South Baton Rouge, Hammond, and New Roads, 1971. . . . . .

XIII Rates of Perceived Morbidity for Selected Disease Categories as Shown by Geographic Stability of Families in a Predominantly Indigent Population of South Baton Rouge, Hammond, and New Roads, 1971. .

XIV Rates of Perceived Morbidity for Selected Disease Categories as Shown by Family Composition in a Predominantly Indigent Population of South Baton Rouge, Hammond, and New Roads, 1971. . . . . .

XV Perceived Morbidity Rates for Head of Household Shown by Sex in a Predominantly Indigent Population of South Baton Rouge, Hammond, and New Roads, 1971. .

XVI Perceived Morbidity Rates for Husband and Wife, NonHead of Household in a Predominantly Indigent Population of South Baton Rouge, Hammond, and New Roads, 1971...................

XVII Perceived Morbidity Rates for Atypical and Normal Children in a Predominantly Indigent Population of South Baton Rouge, Hammond and New Roads, 1971 . .

XVIII Percelved Morbidity Rates Shown by Quality of Church Participation of a Predominantly Indigent Population of South Baton Rouge, Hammond, and New Roads, 1971 ...................

XIX Rates of Perceived Morbidity for Selected Disease Categories among the Medically Indigent of the Sample Populations in a Predominantly Indigent Population for South Baton Rouge, Hammond, and New Roads, 1971. . . . . . . . . . . . . . Identity in a Predominantly Indigent Population for South Baton Rouge, Hammond, and New Roads, 1971. . 
Table

Page

XXI Differential Rates of Perceived Morbidity among an Indigent Population for Selected Disease Categories as Shown by Religious Affiliation in a Predominantly Indigent Population for South Baton Rouge, Hammond, and New Roads, 1971............... 108

XXII Rates of Perceived Morbidity for Selected Disease Categories as Shown by Annual Family Income in a Predominantly Indigent Population for South Baton Rouge, Hammond, and New Roads, 1971. . . . . . 109

XXIII Overall Morbidity Rates Shown by Level of Anomie for a Predominantly Indigent Population of South Baton Rouge, Hammond, and New Roads, 1971. . . . . . 111

XXIV Overal1 Morbidity Rates Shown by Completeness of Composition in a Predominantly Indigent Population of South Baton Rouge, Hammond, and New Roads, 1971 . 112

XXV Overal1 Morbidity Rates for Atypical and Normal Children in a Predominently Indigent Population of South Baton Rouge, Hammond, and New Roads, 1971. . . 114

XXVI Overall Morbidity Rates for Head of Household Shown by Sex in a Predominantly Indigent Population of South Baton Rouge, Hammond, and New Roads, 1971. . . 115

XXVII Overall Morbidity Rates for Adult Females Shown by Household Position in a Predominantly Indigent Population of South Baton Rouge, Hammond, and New Roads, 1971.................. 116

XXVIII Overa11 Morbidity Rates for Husband and Wife NonHead of Household in a Predominent ly Indigent Population of South Baton Rouge, Hammond, and New Roads, 1971....................

$\mathrm{XXIX}$

Overall Morbidity Rates for Husbands shown by Household Position in a Predominant ly Indigent Population of South Baton Rouge, Hammond, and New Roads, 1971..................

$\mathrm{XXX}$

Overall Morbidity Rates Shown by Geographic Stability of Families in a Predominantly Indigent Population of South Baton Rouge, Hammond, and New Roads, 1971 . 118 
XXXI Overall Morbidity Rates Shown by Quality of Church Attendance in a Predominantly Indigent Population of South Baton Rouge, Hammond, and New Roads,

XXXII Overall Morbidity Rates Shown by Quality of Church Contribution in a Predominently Indigent Population of South Bat on Rouge, Hammond, and New Roads, 1971...................

XXXIII Overal1 Morbidity Rates Shown by Level of Income in a Predominantly Indigent Population of South Baton Rouge, Hammond, and New Roads, 1971. . . . . 120

XXXIV Overal1 Morbidity Rates Shown by Race in a Predominantly Indigent Population of South Baton Rouge, Hammond and New Roads, 1971 ........

XXXV Quality of Utilization of Medica1 Doctors of a Predominantly Indigent Population as Shown by Community of Residence and Race, 1971. . . . .

XXXVI Quality of Utilization of Medical Doctors of a Predominantly Indigent Population of South Baton Rouge, Hammond, and New Roads as Shown by Religious Affiliation, 1971........... . 134

XXXVII Quality of Utilization of Medical Doctors as Shown by Age in a Predominantly Indigent Population of South Baton Rouge, Hammond, and New Roads, 1971. . 136

XXXVIII Quality of Utilization of Medical Doctors as Shown by Levels of Income in a Predominantly Indigent Population of South Baton Rouge, Hammond, and New Roads, 1971................. . 138

XXXIX Rate of Use of Various Community Caretakers as First or Second Choices by Persons of Different Income Ranges in a Predominantly Indigent Population of South Baton Rouge, Hammond, and New Roads, 1971. . . 140

XL Rates of Use of Selected Community Caretakers During Course of Illness by Persons of Different Income Ranges in a Predominantly Indigent Population of South Baton Rouge, Hammond, and New Roads, 1971. . . 141 
XLI Rate of Use of Selected Community Caretakers by Persons of Different Income Ranges in a Predominently Indigent Population of Baton Rouge, Hammond, and New Roads, 1971. . . . . .

XIII Rates of Use of Various Community Caretakers as First or Second Choice by Predominantly Indigent Populations of Three Communities Shown by Race, 1971 . . . . . . . . . . . . . .

XLIII Rate of Use of Various Community Caretakers during Course of Illness by the Indigent Populations of Three Communities shown by Race, 1971. . . . .

XLIV Rate of Use of Various Community Caretakers by Predominantly Indigent Populations of Three Communities shown by Race, 1971. . . . . . .

XLV Rates of Use of Various Caretakers as First or Second Choice by Persons of Varying Levels of Anomie in a Predominantly Indigent Population of South Baton Rouge, Hammond, and New Roads, 1971. .

XLVI Rates of Use of Various Caretakers during Course of Illness by Persons of Varying Levels of Anomie in a Predominant ly Indigent Population of South Baton Rouge, Hammond, and New Roads, 1971. . . . . .

XLVII Rates of Various Caretakers by Persons of Varying Levels of Anomie in a Predominantly Indigent Population of South Baton Rouge, Hammond, and New Roads, 1971..................

XLVIII Reasons for Non Use of Medical Doctor by Symptom Bearing Persons shown by Rank Order. . . . . . .

XLIX Reasons for Use of Medical Doctor by Symptom Bearing Persons shown by Rank Order........

Rotated Factor Matrix of Reasons for not Seeking Medical Care................

Attitudes Toward Public and Private Hospital Care shown by Range of Income in a Predominantly Indigent Population of Baton Rouge, Hammond, and New Roads, 1971.................. 
LIII Attitudes Toward Public and Private Hospital Among the Predominantly Indigent Population of Three Communities, 1971. . . . . . . . . . . .

LIV Attitudes Toward Public and Private Hospital Care Shown by Age Range in a Predominant ly Indigent Population for South Baton Rouge, Hammond, and New Roads, 1971. . . . . . . . . . . . .

LV Attitudes Toward Public and Private Hospital Care Shown by Race and Ethnic Group in a Predominantly Indigent Population for South Baton Rouge, Hammond, and New Roads, 1971 . . . . . . . .

LVI Attitudes Toward Public and Private Hospital Shown by Level of Anomie in a Predominantly Indigent Population for South Baton Rouge, Hammond, and New Roads, 1971.................

LVII Attitudes Toward Public and Private Hospital Care Shown by Manner of Payment in a Predominantly Indigent Population for South Baton Rouge, Hammond, and New Roads, 1971 . . . . . . . .

LVIII Type of Payment for Hospital Care Shown in Rank Order for Private and Public Hospitals . . . . .

LIX

Ranks of Positive Response Rates Toward Public and Private Hospital Care of a Predominant 1y Indigent Population of South Baton Rouge, Hammond, and New Roads Shown by Leve 1 of Income, 1971 . . . . . .

LX

Frequency of Positive and Negative Attitude Responses for Public and Private Hospital Care in a Predominantly Indigent Population for South Baton Rouge, and Hammond, 1971 . . . . . . . . .

LXI

Frequency of Positive and Negative Attitude Responses for Public and Private Hospital Care in a Predominant1y Indigent Population for New Roads, 1971

LXII Ranks of Positive Response Rates Toward Public and Private Hospital Care of a Predominantly Indigent Population of South Baton Rouge, Hammond, and New Roads Shown by Age Categories, 1971. . . . .

LXIII Frequency of Positive and Negative Attitude Responses of Non Whites for Public and Private Hospital Care in a Predominant $1 y$ Indigent Population for South Bat on Rouge, Hammond and New Roads, 1971 . . . . 
LXIV Frequency of Positive and Negative Attitude Responses of Whites for Public and Private Hospital Care in a Predominant ly Indigent Population for South Baton Rouge, Hammond and New Roads, 1971 . . . 190

LXV Rate of Positive Attitude Response for Public Hospital and Private Hospital Care Shown by Level of Anomie in a Predominantly Indigent Population of South Baton Rouge, Hammond and New Roads, 1971 . .

LXVI Ranks of Positive Attitude Response to Hospital Care Shown by Type of Payment for Public and Private Hospitals in a Predominantly Indigent Population of South Baton Rouge, Hammond and New Roads, 1971. 


\section{LIST OF FIGURES}

Figure

Page

1. Four Member Social System . . . . . . . . . . 43

2. Conditions at the Severa 1 System Levels Found to be Related to Illness. . . . . . . . . . . . 123

3. Relationship of Conditions Found to be Possitively Associated with Morbidity to System Paradigm. . . . . 125

4. Medica 1 Doctor Utilization Paradygm . . . . . . . . 167 


\section{ABSTRACT}

This study represents an attempt to explore the health care patterns of persons living in predominently indigent areas of three communities, New Roads, Hammond, and a neighborhood in South Baton Rouge. These communities were selected, because it was felt that they might represent three positions on the urbanization and industrialization continuums. One is a trade center depending on an agricultural economy and having little industry which is not farm related. A second community is somewhat larger and provides a second relevant quality. Formerly, it was a farming area and produce shipping center. At the present time, however, this city is beginning to address itself to industry. The third population source is located in an industrial, urban area.

The sample selection procedure varied slightly for each community as field adaptations had to be made to accommodate variations in population concentrations. In each instance, however, a geographic based sampling procedure was utilized which provided for a two stage sampling frame. The second stage was the family unit while the first stage was a geographic unit approximately the size of a city block. In addressing the research problem attention was directed to the areas of perceived morbidity, health care utilization, and attitudes toward health care facilities. Each of these areas were operationalized as a dependent variable and their relationship to several selected, socio-economic characteristics was explored. 
In the area of morbidity it was reasoned that, because of the interpenetration of system levels, it could be expected that disease, or a disruption of the homeostases of the organismic system level, would be accompanied by a disruption of equilibrium on the several other system levels. This proved to be the case, with gross morbidity found to be related significantly to feelings of alienation at the personality system, while at the social system level morbidity rates were found to be related significantly to incomplete family structure, position of atypical child, position of female head of household, and irregular church attendance and contribution. Finally, at the culturaleconomic system level a relationship with income was determined to exist.

Health care resource utilization proved to be a complex phenomenon reflecting multiple influences. The most frequently utilized health care resource proved to be the medical doctor. However, many differences were found in the quality of the relationship between the medical doctor and various types of patients. It was also found that the decision to seek treatment from the medical doctor was not simply a function of the symptom. This decision making process was explored through factor analysis. This analysis yielded factors which were compatible with the possibility of multiple system level influences on the decision to either go or not go to a medical doctor.

When attitudes toward public hospital and private hospital care were examined it was again found that such attitudes are not a simple function of the proprietorship of the hospital. There is some cause for concern about these attitudes, as almost $20 \%$ of the sample 
responded with less than a "good" attitude toward hospital care. Adding to this concern are the facts that the urban population and the younger age groups tended to have less positive attitudes. Both of these conditions may forebode trends which should be watched.

The absence of builtin feedback channels in the health care delivery system make such a surveilance even more imperative. In addition, the findings of this study suggest that it may be productive to explore further the relationship between individual pathologies and social structure and the decision making process. Because of the former relationship there are indications that morbidity rates can be expected to increase. The latter condition may prove to be a mechanism through which health care cost might be reduced. 
CHAPTER I

THE PROBLEM AND REVIEW OF THE LITERATURE

\section{THE PROBLEM}

\section{Statement of the Problem}

This study represents an attempt to explore the health care patterns of the medically indigent persons in a circumscribed geographic area. Such an effort is much more complex than it might appear, for health care patterns are much more than a response to a simple equation such as:

awareness of symptom $\longrightarrow$ purchase of treatment. The perception of symptoms as a medically significant event is not always a deterministic response to a universally held belief or to ubiquitous knowledge. It can, on occasion, be influenced by personality traits of the affected individual, by previous experiences of this individual, or by cultural nuances of reference groups to which he might belong. Additionally, before an awareness of a medically significant symptom is translated into the purchase of health care services the decision must be reconciled with a set of priorities involving other behavior making simultaneous demands on the time, energy and financial resources of the individual. Finally, once the decision to purchase health care services is made, the manner and effectiveness with which this decision is executed is, to some extent, a function of the individual's knowledge and belief systems. 
The problem, then, becomes that of exploring the prevalence of diagnostic, disease categories in the medically indigent population, the perception of symptoms as it relates to various socio-economiccultural variables, and the patterns of health care consumption as they, too, relate to these variables.

\section{Purposes of the Study}

The purposes of this study are both pragmatic and heuristic. Pragmatically, it is hoped that the findings of this study will provide the Louisiana Capital Area Health Planning Council with data that will enhance its ability to plan more effectively for the health care needs existing in the geographic area for which it has the planning responsibility. In addition, it is hoped that the study will provide insights that will lead to the development of feedback mechanisms to facilitate on going planning in the future. Heuristically, it is the intent of this study to explore illness and the response to illness as a manifestation of social structure intrinsically related to such social groups as the family, religious groups, ethnic groups, and income groupings.

\section{Significance of the Study}

The importance of health problems in contemporary society is well established. When expressed in monetary terms alone, the impact of the problem is staggering. In 1970, the national personal health care expenditure in the United States amounted to 63.7 billion dollars with 40 per cent of these funds coming from tax sources. That the problem is not one that has peaked and entered into decline can be 
The problem, then, becomes that of exploring the prevalence of diagnostic, disease categories in the medically indigent population, the perception of symptoms as it relates to various socio-economiccultural variables, and the patterns of health care consumption as they, too, relate to these variables.

Purposes of the Study

The purposes of this study are both pragmatic and heuristic. Pragmatically, it is hoped that the findings of this study will provide the Louisiana Capital Area Health Planning Council with data that will enhance its ability to plan more effectively for the health care needs existing in the geographic area for which it has the planning responsibility. In addition, it is hoped that the study will provide insights that will lead to the development of feedback mechanisms to facilitate on going planning in the future. Heuristically, it is the intent of this study to explore illness and the response to illness as a manifestation of social structure intrinsically related to such social groups as the family, religious groups, ethnic groups, and income groupings.

\section{Significance of the Study}

The importance of health problems in contemporary society is well established. When expressed in monetary terms alone, the impact of the problem is staggering. In 1970, the national personal health care expenditure in the United States amounted to 63.7 billion dollars with 40 per cent of these funds coming from tax sources. That the problem is not one that has peaked and entered into decline can be 
seen from the fact that in 1950, the national personal health care expenditure was only 11.1 billion dollars. In 1968 , it reached 49.8 billion dollars and since 1965, it has increased at a rate of 5 billion dollars annually. 1

Dollar figures do not adequately portray the true significance of the problem, however, for they ignore the social costs. Since many of the pathological conditions, especially chronic disease conditions, tend to strike middle aged and older persons they kill or disable those persons who have mastered their occupations and who are among the most productive members of society.

A 1954 survey conducted in Butler County, Pennsylvania, to discover the extent of disability in the population of this mexed urban and rural area, indicated that 16 persons per 1,000 population were disabled. The survey also revealed that a total of 141.4 man years per 1,000 population was lost because of disability with three diseases, arthritis, diabetes, and circulatory disorders accounting for almost 40 per cent of the disabilities found. 2

In addition to a deterioration in their work role, disabled persons might, a priori, be assumed to suffer some liability in other social roles. It is conceivable that a father who does not adequately fulfill his role of bread winner in the home may also abdicate a part of his role in the socialization of his children or that any parent

$1_{H}$. P. Hampton, Report of Governors' Conference on Health Care Cost, Austin, Texas: Governor's Office of Comprehensive Health Planning.

${ }^{2}$ S. Graham, "Disability in Butler County," Public Health Reports, LXXI (November, 1956), pp. 115-118. 
suffering from a chronic disease condition may use this condition to influence the behavior of the other members of the family. Thus, illness may influencr the fundamental fabric of social control in a society.

Another quality of ill health, viewed from a sociological perspective, that adds significance to this study is the fact that populations are differentially affected by health problems. It has been empirically established that the poor are sicker than the non-poor and yet, receive fewer health services. ${ }^{3}$ This relationship, however, is more complex than it might appear, for it cannot be assumed that it is the lack of money that produces pathology or dictates an inefficient utilization of treatment resources. Culturally determined perceptions of disease or misconceptions of treatment might also influence this relationship and attitudes toward medical care can mitigate the effective utilization of health care resources.

In notable contrast to the importance of health to the social and economic welfare of our society and to the vast sums expended for health care, is the scarcity of centralized, valid health data. On the national level, the establishment of the United States National Health Survey in 1956 was a major step. Unfortunately, at the state level, death certificates remain the basic source of information, since the sample used in the national survey is too small for reliable

3William C. Richardson, "Poverty, Illness, and Use of Health Services in the United States," Hospitals, Journal of the American Hospital Association, XLIII (July 1, 1969), p. 34. 
measures of illness and disability. ${ }^{4}$ However, there are many pathological conditions that do not result in death. Consequently, mortality data provide only a partial and biased portrayal of morbidity trends and distributions.

This condition produces grievous problems in planning for adequate health services for any population. Yet the unremitting rise in health care costs dictates that comprehensive health care planning must become a reality. It is this paradox that provided the stimulation to undertake this project to gain a better understanding of the perceived health needs, patterns of health care, and attitudes toward health care in several population centers.

It is hoped that this study will provide the beginning insights required to initiate health care planning for the populations surveyed. It is also hoped that this study will provide insights into more sociologically relevant areas such as the relationship of illness and health care to social structure.

\section{REVIEW OF THE LITERATURE}

Attesting to the importance of health as an area of investigation is the large amount of professional and popular literature devoted to it. This literature covers a rather wide range of health related topics. In reviewing the professional literature those topics related to social epidemiology, social etiology, health care resource

${ }^{4}$ Thomas R. Ford, Health and Demography in Kentucky, Lexington: University of Kentucky Press, 1964, p. 102. 
utilization, and methods of approach were given particular attention.

\section{Social Epidemiology}

In considering the epidemiology of illness, attention must be directed to an interesting question. That is, what conditions are to be considered pathological. There is evidence that conditions considered pathologica 1 by some groups are accepted as normal by other groups. For example, dyschromic spirochetosis, a disease characterized by spots of various colors that appear on the skin, is so common in a particular South American tribe that indians who do not have them are regarded as abnormal and are even excluded from marriage. ${ }^{5}$ Mechanic points out that a wide variety of diseases are not defined by particular groups as illness conditions because they occur frequently and are regarded as the common state of man. In some countries, the obese woman is an object of envy and desire. Other groups define obesity as a physical and emotional disease. In some societies supernatural powers are attributed to the epileptic, while in others, the epileptic is not only regarded as $i 11$, but also as the object of scorn and social prejudice. 6

Parsons suggests that society may determine, to some extent, the conditions to be considered pathological. 7 This position is

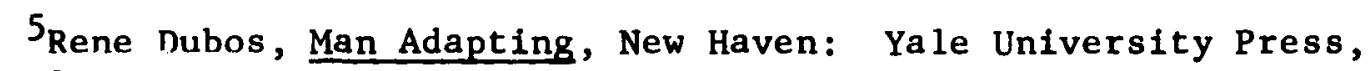
1965, p. 251 .

6David Mechanic, Medical Sociology, New York: Free Press of Glencoe, 1968, pp. 16-17.

7 Talcott Parsons, "Definitions of Health and Illness in the Light of American Values and Social Structure," in E. G. Jaco, ed., Patients, Physicians, and Illness, New York: The Free Press of Glencoe, 1958, P.186. 
supported by Zborowski who attempts to specify varying culture orientations to pain among persons in different ethnic groups. He notes that Italians have a present-oriented apprehension with regard to the actual experience of pain, while Jews show a future-oriented anxiety as to the meaning of the pain experienced. Further, he notes that Jewish and Italian culture allow for free expression of feeling and emotions, while "old American" patients try to take a detached and unemotional view of their symptoms. 8

Some observers claim that the poor perceive more episodes as nonserious than do the nonpoor. This suggests that the perceptual threshold, beyond which an event is judged to be a symptom, is higher in the poor than in other classes. It is Kosa's opinion that this might be true in the case of medically unsophisticated people, but that the present-day American poor, particularly the urban poor, cannot be characterized with such a lack of sophistication. Moreover, he points out that the observed differences in the morbidity of social classes show up in the serious illnesses where the likelihood that a symptom would not reach the perceptual threshold is great ly diminished by the nature of the illness. 9

Accepting the fact that the apparent difference in the distribution of illness among social groups may be inflated by nuances in

8. Zoborowski, "Cultural Components in Responses to Pain," Journal of Social Issues, VIII, 非 (1952), 16-30.

${ }^{9} \mathrm{John}$ Kosa et a1., "Health and Poverty Reconsidered," in John Kosa et al., eds. Poverty and Health: A Sociological Analysis, Cambridge: Harvard University Press, 1969, p. 321. 
perception of illness there remains the propensity for some populations to be afflicted by disease to a greater extent than others. Early studies in France demonstrated that mortality rates in that nation were closely linked to the living conditions of the different social classes and revealed a clear relationship between poverty and disease. 10,11 Sydenstricker reported an earlier study completed in 1924, in the United States in which Emmet classified the members of a workmans' sick and death benefit fund into broad occupational classes that were really differentiated according to economic status, and computed temporary sickness and accident rates for each. A consistent and definite association of disability with poor economic status was shown. 12

A more recent study, utilizing data from the National Center for Health Statistics for the fiscal year 1965, explored the relationship of income and both acute and chronic illnesses for a 11 age groups. The findings relative to chronic, activity limiting conditions were impressive, revealing that the low income family members experienced a higher rate of such chronic conditions in all age categories. 13

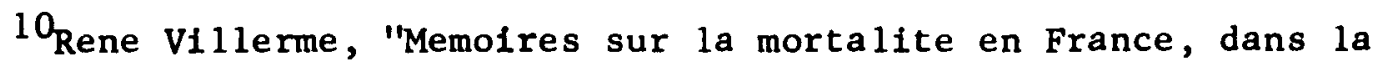
classe aisee et dan la class indigente," Memoires de l'Academie royale de Medecine, I (1828), 51-99.

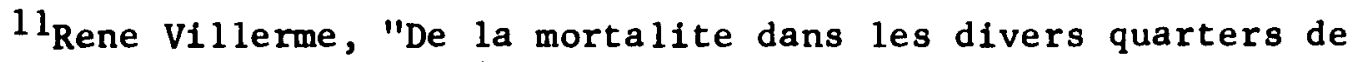
la ville de Paris," Annales d'hygiene publique, III (1830), 294-341.

12 Edgar Sydenstricker, Health and Environment, New York: McGraw-Hil1 Book Company, Inc., 1933, p. 85 .

13 William C. Richardson, "Poverty, Illness, and Use of Health Services in the United States," Hospitals, Journal of the American Hospital Association, XLII (July 1, 1969), 34. 
While it appears incontestable that gross illness rates are higher in lower socio-economic groups there is evidence in the literature that there may be some specificity of illness to socio-economic class with certain illnesses appearing more frequently in specific social classes. For example, the lowest social classes have the highest rates of severe psychiatric disorder in our society. 14

In physical health the social distribution of morbidity shows some diseases to be more prevalent in the wealthier classes. Among these diseases are coronary problems and lung cancer. Other diseases, such as contagious diseases and diseases resulting in infant mortality, are known to be more prevalent in the poverty classes.

There is no discernible sign that the morbidity gap between the poor and non-poor is narrowing in the field of mental health. The question of the morbidity gap in physical health, however, is more complex. There is no question that differences among social classes above the poverty line have narrowed considerably. There is strong evidence, too, that in those disease areas which are open to control by public health measures the poor are not as relatively disadvantaged as they once were. 15

A review of the literature also brings out that the distribution of illness in society is characterized by differential prevalence in categories other than social class. Calabresi found differences in the

${ }^{14} \mathrm{John}$ Kosa et a1., Op. cit., p. 321.

${ }^{15}$ Ibid. 
pneumonia, tuberculosis, heart disease, and diabetes rates among Irish, Italians, Germans, British, Canadians, and Poles in the United States. 16 Smith found differences in the frequency with which persons of differ.. ent nationa 1 background in America are afflicted with cancer at various sites. 17 Emerson, exploring rates of communicable diseases found variation in prevalence among different nationality groups ${ }^{18}$ while Aycock and Hawkins report a similar relationship with leprosy. 19

The most frequently reported disease in our society, heart disease, has yielded reluctantly to sociological investigation. Incidence, the number of new cases occurring at a given time, is very difficult to determine. Consequently, prevalence rates, the number of cases current in a population at a given time, are usually the unit of inquiry. Low prevalence rates may reflect high mortality rates from an illness rather than low incidence rates. However, the few studies made of ethnic background as related to prevalence of heart disease offer some interesting insights. One study concluded that Jews have a

${ }^{16}$ Massimo Calabresi, "The Relation of Country of Origin to Mortality for Various Causes in New York State," Human Biology, XVII (1945), 340-65.

17F. R. Smith, "Nationality and Carcinoma of the Cervix," American Journal of Obstetrics and Gynecology, XLI (March, 1941), 424-30.

${ }^{18}$ Haven Emerson, "Significant Differences in Racial Susceptibility to Measles, Diphtheria, and Scarlet Fever: Statistical Study of Case Incidence and Deaths Among Treatment Dwellers in New York City, 1921-1925, Inclusive," Journal of Preventive Medicine, V (September, 1931), 317-50.

19 W. L. Aycock and J. W. Hawkins, "Regiona1, Racial and Familial Relationships in Leprosy in the United States," Public Health Reports, LVI (June, 1941), 1323-36. 
higher prevalence of coronary artery disease than do Italians 20 while Sauer found that the Irish and Russians (native born) also have high mortality rates from the disease. 21

Saxon Graham reported a study in which an attempt was made to determine whether first generation ethnic groups were more disease prone than subsequent generations of the same ethnic groups. It was reasoned that the first generation members would tend to be "marginal men" especially prone to tensions in assimilation. It was found that the disease rates for rheumatism, arthritis, high blood pressure and diabetes showed a relatively low rate in the first generation, a sharp increase in the second and a decline in subsequent generations. Heart disease and hernia rates were found to increase with the number of generations in the United States. Only hardening of the arteries reached its highest incidence in the first generation. ${ }^{22}$

\section{Social Etiology}

Having established the fact that there is a positive correlation between disease and various socio-economic conditions, the question of causation arises. Do these socio-economic conditions cause

20 Frederick H. Epstein, et a1., "The Epidemiology of Atherosclerosis among a Random Sample of Clothing Workers of Different Ethnic Origins in New York City, I," Journal of Chronic Disease, V (September, 1957), 300-28.

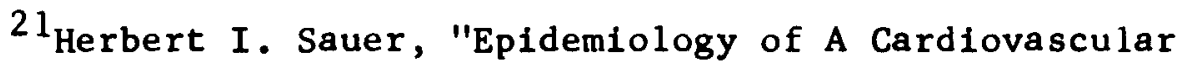
Mortality - Geographic and Ethnic," American Journal of Public Health, LII (January, 1962), 94-105.

${ }^{22}$ Saxon Graham, "Ethnic Background and Illness in a Pennsylvania County," Social Problems, IV (July, 1956), 76-82. 
or contribute to the cause of the diseases with which they are assoclated? Earlier, single causation theories, that developed following the discovery of the important role played by microorganisms in many diseases made it difficult to attribute disease causation to socioeconomic factors. Now, however, it is generally accepted that microorganisms may not be a sufficient cause even of the infectious diseases. A case in point is the common "fever blister" or "cold sore." This condition results from the herpes simplex virus. However, it is known that this virus infects the individual very early in life and remains within the individual throughout his life time. Yet, lesions do not occur unless certain other conditions first occur, upsetting the chemical balance of the body. These other conditions may include overexposure to ultraviolet light, infection with the common cold or emotional stress. The herpes virus, then, is a necessary but not a sufficient cause of the "fever blister."

Obviously, for socio-economic experiences to influence health, there must exist some bridging mechanism between them and tile physiological systems of the individual. When the socio-econoric experience resembles that of the match workers, studies by Rousse 1,23 in which the pathological condition, phosphorus necrosis, was directly traceable to working conditions, it is not difficult to see the influence that the social condition has on the physiological systems.

In many instances, where the relationship between the two is

23 George Rosen, "The Evolution of Social Medicine," In Howard E. Freeman, et al., (eds.), Handbook of Medical Sociology, Englewood C11ffs: Prentice-Hal1, Inc., 1963, p. 33. 
not so striking, it is more difficult to understand the bridging mechanism. The body's communication systems may provide this function. There are two major systems of communication in the body, the nervous system and the endocrine system. While the major characteristic of the nervous system lies in its ability to communicate complex messages with great alacrity and precision, the importance of the various endocrine systems lies in their pervasive influence upon many basic metabolic processes and upon the functioning of particular organ systems. These two systems do not operate independently of each other. Recent work has indicated that endocrine systems, rather than being entirely under the control of internal feedback mechanisms, can be influenced by the activity of the central nervous system as well.

It is conceivable, then, that socio-economic conditions producing an effect on the central nervous system may have this effect transferred to the endocrine system and, thus, exert a control on the body's physiologic systems. Research conducted by Hand 1 on $^{24}$ seemingly bears this out. In this research a group of students, faced with both financial and academic problems, were tested periodically for qualities of euphoria and dysphoria. Their urine was also tested periodically for 17-hydroxy corticosteroids, a product related to stress. It was found that the urine level of this compound did change with emotional change and also tended to be related to the social backgrounds of the students.

$24 \mathrm{Joseph} H$. Handlon, "Hormonal Activity and Individual Responses to Stresses and Easements in Everyday Living," in R. Roessler and $N$. Greenfield, eds., Physiological Correlates of Psychological Disorder, Madison: The University of Wisconsin Press, 1962, pp. 157-70. 
If this relationship does exist it suggests that social conditions producing prolonged stress are potentially pathogenic. One complicating factor in exploring this possibility is the lack of precision in the definition of the term "stress." This term has been used to refer to a situation which causes people to react as though they have been threatened. At times, it has been used to characterize physical, social, and cultural conditions likely to be upsetting to the average person. Such conditions would include battle conditions, impending surgery, rapid cultural or social change, anomie, and a variety of life crises. When used in this way, the designation of certain circumstances as stress situations is based on assumption. The term stress is also used to refer to the emotional response to stressful situations. Thus, various emotions such as anxiety, fear, depression, and general discomfort are frequently referred to as stress. Mechanic suggests that it is useful to conceive of stress as characterizing a discrepancy between the demands impinging on a person-whether these demands be external or internal, whether challenges or goals--and the individual's potential responses to these demands. 25 From this perspective, stress can be thought of as an interaction between a situation and an individual's capacity to meet the situation. Assuming that stress is related to social situations, it follows that it must be, at least partially, a function of social organization. If this is true and if it is also true that prolonged stress is

25 David Mechanic, Medical Sociology, New York: Free Press of Glencoe, 1968, p. 301 . 
pathogenic, there should be a relationship between types of social organization and disease. More specifically, stress producing social structure should exhibit some degree of pathogenesis while stress inhibiting social structure should generate some degree of prophylaxis. There is some indication in the literature that such a relationship does obtain. Durkheim successfully demonstrated a positive relationship between suicide and anomie. 26 Actually, this relationship had been suggested earlier by de Boismont. 27 Horton found a positive correlation between the level of anxiety in a society and the rate of alcoholism and it has also been found that in the United States the rate of alcoholism is significant $1 \mathrm{y}$ higher in urban areas than in rural. Indeed, the rate of increase in alcoholism in the United States more nearly approximates the rate of urbanization than any other single parameter. ${ }^{28}$ If we assume that the urban social structure is characterized by a relatively greater condition of anomie than the rural area, Horton's findings are not at all inconsistent with Durkheim's.

Anomie may be produced by the larger society and it is probably in this perspective that we tend to think of the concept. The

${ }^{26}$ Emile Durkheim, Suicide, A Study in Sociology, translated by John A. Spaulding and George Simpson, Glencoe: Free Press, 1951.

27 Brierre de Boismont, "De l'influence de la civilization sur le suicide," Annales d'hygiene publique (1835)

${ }^{28}$ Peter B. Field, "A New Cross-cultural Study of Drunkenness," and John R. Seeley, "The Ecology of Alcoholism: A Beginning," In David J. Pittman and Charles R. Snyder (eds.), Society, Culture, and Drinking Patterns, New York: John Wiley and Sons, Inc., 1962, Pp. 48-74 and 330-44. 
interpenetration of systems, however, dictates that if it exists on the societal level it must have its correlates at the lower system levels such as the family and even at the level of the personality system. It may exist at this latter level in a circumscribed number of people without emerging into the societal level. Individuals who experience geographic relocation and remain marginal to the new social structure may experience a higher degree of anomie than that characteristic of the larger society. If this is true then these marginal persons may experience a higher disease rate than either those members of the new social structure or those members of their own group who did not make the migration.

Mechanic described a study that seemingly supports this possibility. 29 In this study, it was found that the Bantu Africans who were transported from the vicinity of Johannesburg into the outskirts of the city itself and employed in industry continued to experience the same tuberculosis morbidity rate as in the tribal villages, but the mortality rate from this disease increased greatly. This was true despite the fact that living conditions were improved. This finding is similar to one reported by Wolff, that, during the relocations of Navajo and Sioux Indians within the same climate and geographic area, the tuberculosis mortality rate greatly increased. 30 In still another report data are presented for a large rural population who migrated from Ireland to the United States between 1840 and the early $1900^{\prime} \mathrm{s}$.

29 David Mechanic, op. cit., p. 274.

$30 \mathrm{H}$. Wolff, Stress and Disease, Springfield, Illinois: Thomas, 1968, p. 8. 
This rural population left Ireland because of severe economic stresses. They settled primarily in urban areas in the United States where economic conditions were probably better and more food was probably available than in the area that they migrated from. Yet, the tuberculosis mortality rate among those Irish in the United States was twice as high as among those who remained in Ireland. 31

It can be shown that even in geographically stable populations social change is associated with increases in certain diseases. Halliday reported that between 1931-1936 in Scotland, during a period of serious economic depression, there was a marked increase in those illnesses lasting more than one year. Peptic ulcer increased by $130 \%$ to $140 \%$ and rheumatism increased by $50-60 \% .^{32}$ Dubos suggests a relationship between tuberculosis mortality and social change. He argues that the peak incidence of tuberculosis mortality occurs within ten to twenty years after industrialization has been established in a society. Thereafter, it declines sharply. ${ }^{33}$

There is some apparent inconsistency in the findings of studies of the relationship of geographic relocation to morbidity reported in the literature. The study by S. Graham, cited earlier, indicated only hardening of the arteries tended to be over-represented

${ }^{31}$ David Mechanic, op. cit., p. 274 .

${ }^{32} \mathrm{D}$. T. Graham and I. Stevenson, "Disease as Response to Life Stress," in H. I. Lief et al., (eds.), The Psychological Basis of Medical Practice, New York: Harper and Row, 1963, p. 123.

${ }^{33}$ Rene Dubos, Mirage of Hea1th, New York: Harper, 1959, p. 127. 
in first generation immigrant families. Several diseases, rheumatism, arthritis, high blood pressure, and diabetes, were found to have low morbidity rates in the first generation, high rates in the second generation, and successively lower rates in subsequent generations. 34

It has been suggested by Danish researchers that hard physical labor may be a cause of hardening of the arteries. Since it might be expected that first generation immigrants would have to work harder than upward mobile later generations, even this single high disease rate does not confirm the other studies cited. However, there is a possible explanation for the apparent inconsistency of the finding of this study. It is possible that the first generation of these immigrants brought with them their stable family structure and behavioral norms from the old country. This may have protected the migrating generation from anomie while the second generation, being exposed to conflicting norms in their socialization, may have become the marginal generation with the accompanying condition of anomie.

Although this is entirely speculation, there is some support in the literature for the assumption that stable family structure can provide some degree of immunity to certain diseases. In Norway, a community-wide study of blood pressures was conducted. It was found that unmarried women had a higher rate of hypertension than any other group of females. In addition, among married women there was an inverse relationship between the rate of hypertension and the number of

${ }^{34}$ S. Graham, op. cit., p. 79. 
children in the family. ${ }^{35}$ In a study of tuberculosis in Seattle, Hawkins divided the city into four socio-economic districts; skid row, working class, middle class, and well-to-do. The rate of tuberculosis was determined in each. As might be expected, the highest rate was found in the skid row section. However, when a further analysis of the data was made, it was found that the morbidity rate for each race was highest in that sector where the race was in a minority, thus, expcriencing a dearth of interpersonal interaction. The highest rate was found to be among the single room lodgers who lived without fami $1 y .36$

Not all stress can be attributed to anomie. Separation can be a contributing factor and it, too, has been found to be associated with illness. Lindeman reported that bereavement preceded the onset of ulcerative colitis in 75 of 87 patients. In 56 of these instances, the bereavement was by death. 37 Schmale studied a group of 42 hospital patients having a wide variety of disorders and found that 41 had experienced recently an actual or threatened separation from a significant object in their lives. Seventy-five per cent of these separations had occurred within the week preceding the onset of the

${ }^{35}$ Saxon Graham, "Social Factors in Relation to the Chronic I11nesses," in H. E. Freeman, et al., (eds.), Handbook of Medical Sociology, op. cit., p. 81 .

$36 \mathrm{~N}$. G. Hawkins and T. H. Holmes, "Environmental Considerations in Tuberculosis: Ecologic Factors in Tuberculosis Morbidity," Transactions of the Fiftieth Anniversary Meeting of the National Tuberculosos Association, 1954, PP. 223-38.

${ }^{37} \mathrm{D}$. T. Graham and I. Stevenson, "Disease as Response to Life Stress," op. cit., p. 118 . 
patient's disease and included marital separation, death of a sibling, a wife's returning to work, a failing grade on a report card, and the delayed arrival of a friend. 38

Social stress has also been reported in heart disease although there is some inconsistency in the findings. Vernon found emotional factors important in 83 per cent of 30 patients with congestive heart failure that he studied. Chambers and Reiser found social stresses to be precipitating events in $76 \%$ of 25 cases they studied. On the other hand, Sodeman and Burch found that emotional disturbances occurred significantly in only 2 per cent of 100 patients with congestive heart failure whom they studied and Boyer determined emotions to be a precipitating factor in on $1 y 1$ patient out of 1,000 whom he examined. Graham reviewed these studies and formed the opinion that the difference in findings between these studies was due to differences in the techniques of observations and that the former techniques were better. 39

There are socio-economic conditions which are not stress related in the ordinary sense, but have been found to be positively associated with illness. Cultural traits such as diet, housing and sanitation have been suggested as contributing factors to illness. Since the presence of disease in an individual depends partly on his ineffectiveness in employing preventive practices, lack of knowledge of preventive measures may contribute to the morbidity rate. Supporting this contention is the fact that it has been established that the

$$
{ }^{38} \text { Ibid., p. } 119 . \quad{ }^{39} \text { Ibid., p. } 123 .
$$


education level of the mother is the most important factor in prenatal morbidity. 40

The authors of one clinical study investigated the factors found to result in overeating in 500 obese persons who requested treatment for obesity. Eight conditions were determined to have resulted in overeating among this group. These conditions included: environment, economics, monotony, occupation, organic disease, nervousness, glandular imbalance, and subconscious factors. Among these conditions the first four are clearly socio-economic. 41

Despite the apparent importance of socio-economic factors in illness the interrelatedness of these factors, their stochastic nature, the absence of "necessary causes" among them, and the difficulty of establishing temporal sequences between their occurrence and the onset of disease, make it very difficult to attribute definite causation to them.

Health Care Resource Utilization

Even the role of emotions, which has often been seen as an etiological or precipitating factor in illness, has been questioned by some authorities. Mechanic and Volkart advanced the possibility that emotion, induced by stress, may be more significant in its influence on p. 328 .

40 John Kasa et a1., "Health and Poverty Reconsidered," op. cit.,

41 Albert Stunkard, "Research on a Disease: Strategies in the Study of Obesity," in R. Roessler and N. Greenfield (eds.), Physiological Correlates of Psychological Disorder, Madison, Wisconsin: The University of Wisconsin Press, $1962, \mathrm{p} .212$. 
health seeking and on the expression of 11 lness than on the actual occurrence of the condition. They then preceded to examine this problem by an investigation of more than 600 students at a major university. A major focus of the study was the relationship between measures of "stress," and measures of illness behavior, and their joint effect on the use of medical facilities. Analysis of the data indicated that perceived stress, as measured by indices of loneliness and nervousness, and 11 lness behavior were clearly related to the use of a college health service during a one year period. Among students with a high inclination to use medical facilities and high "stress," 73 per cent were frequent users of medical services, while among the low-inclinationlow "stress" group, only 30 per cent were frequent users of such services. When illness behavior patterns were controlled statistically it was found that the influence of "stress" was somewhat different among persons with a high receptivity to medical services than among those with a low receptivity. In the high inclination group, "stress" was a rather significant factor in bringing people to the physician. The researchers felt that these data supported the interpretation that "stress" leads to an attempt to cope. Those who are inclined to adopt the patient role tend to adopt this particular method of coping more frequently than those who are not so inclined. 42

Rather than disprove the influence of emotions on the occurrence of disease this study seems simply to have recognized the role of stress in inducing behavior. However, an overlooked finding of this study is

\footnotetext{
${ }^{42}$ David Mechanic, op. cit., p. 129.
} 
that some people suffering the conditions of illness and stress may not be inclined to seek medical care while others may. It seems that this "inclination" may be of greater sociological relevance than is the role of "emotion." The implication is that even among a group as affluent and sophisticated as college students, the utilization of health care resources cannot be explained by the simple equation:

awareness of significant symptom $\longrightarrow$ search for diagnosis and treatment

If the utilization of health care resources is differentially executed, the question arises whether this differential utilization is idiosyncratic or patterned.

Parsons points out that the behavior of the sick person is constrained or limited by the role expectations of the society in which he lives. According to him, in Western societies the sick role consists of two rights and two duties. The rights are exemptions from normal social responsibilities and the recognition that the $i 11$ person is not to blame for his state. The obligations are a desire to get well and to seek technically competent help to achieve that end. 43

This is obviously an ideal type construct and it is probably not possible to reduce illness behavior to such a simple mode1. Other authorities agree with the concept of the ordering of illness behavior by social influences. Anderson suggests that it is reasonable to assume that patterns of utilization are not quixotic. It appears that in different contexts there are patterns of utilization dependent on such

${ }^{43}$ Talcott Parsons, The Social System, New York: The Free Press of Glencoe, Inc., 1951, p. 85 . 
factors as illness levels, age and sex composition of the population, presence or absence of health facilities, family income, residence, and the perceptions of providers and recipients of health services. 44 The dynamics of the patterning of health care behavior is not clearly brought out in the literature and is probably not completely understood at this time. Simmons states that the therapeutic relationship should function at its optimum where professional and patient are of the same social class. ${ }^{45}$ This position appears compatible with studies of the psychotherapeutic relationship in the United States which indicated that the patients who most nearly approached the therapist's status were accorded the best treatment and the most sympathy. 46 Roth also affirms this position in pointing out that Negroes at any income and occupational level are less likely to have a continuing relationship with a physician than whites of the same income and occupational level. He suggests that this may result from the somewhat elusive psychological factor of social distance: the Negro at any income level may feel more distant from the white, upper-class physician than the white of the same income level, hence, the Negro tends to eschew the offices of private physicians and instead prefers the public clinics

${ }^{44}$ Odin W. Anderson, "The Utilization of Health Services," in Howard E. Freeman et al. (ex.), Handbook of Medical Sociology, Englewood Cliffs: Prentice-Ha11, Inc., 1965, Pp. 349-50.

${ }^{45}$ Ozzie Simmons, "Implications of Social class for Public Hea 1th," Human Organization, XVI (Fa11, 1957), 9.

${ }^{46}$ F. C. Redlich, et al., "Social Class Differences in Attitudes Toward Psychiatry," American Journal of Orthopsychlatry, XXV (1955), 60-70. 
where the institutional setting works to protect against the feeling of social distance. 47

In the study of Regionville there was considerable feeling on the part of lower status people that physicians did not want them as patients. However, this antagonism may, in turn, have been related to an incompatibility of values. The lower status person, getting negative sanction for exhibiting norms inconsistent with those of the professional, may have perceived this as a rejection of him as a patient. This possibility is somewhat borne out by Kosa who recognized that specific anxiety shows a variation between socio-economic classes. In the well-to-do class it tends to conform on the whole with the expectations of the medical profession, while in the poor class it tends to deviate from such expectations. This situation produces certain negative consequences for the poor. It possesses serious obstacles in the line of effective communication between the physician and the poor patient and creates difficulties in the professional treatment of the anxiety component of the poor patient's illness. 48

Anthropologists consider the cultural differences in attitudes toward the use of services to be an important factor in the utilization of health care resources. ${ }^{49}$ This position is strengthened by a

47Julius A. Roth, "The Treatment of the Sick," in J. Kosa, et al., Poverty and Health: A Sociological Analysis, op. cit., pp. 217-218. p. 322 .

48 John Kosa, et al., "Health and Poverty Reconsidered," op. c1t.,

${ }^{49}$ Lyle Saunders, Cultural Difference and Medical Care: The Care of the Spanish-Speaking People of the Southwest, New York: Russe11 Sage Foundation, 1954. 
study indicating that positive attitudes on the part of parents toward dental care had a positive effect on their provision of dental care to their children. 50 Accepting the importance of attitudes leads immediately to the question of whether antagonistic attitudes toward medical doctors, other health professionals, and health care produce a tendency to utilize health services less. Feldman correlated attitudes toward medical doctors by a group of subjects with the number of times a doctor was seen during the previous year, controlling by a rather refined index of perceived medical needs. The resulting partial correlation approached zero. From this, he concluded that, in general, it seems that if a person recognizes that he is 111 , he will generally consult a doctor no matter what he thinks of the profession as a whole. 51

Regardless of the dynamics there is ample evidence in the literature of the existence of differential patterns of health care resource utilization. It has been said that there are two distinct kinds of medical service in the United States. The middle class uses physicians in private practice and the low-income class utilizes public clinics. In terms of volume the literature seems to contradict this assessment. The authors of one study relying on data obtained from the national health survey found no significant difference in the gross number of

50 Alvin L. Bertrand and Homer L. Hitt, Parental Attitudes and Dental Care for Children in Selected Rural Areas of Louisiana, Baton Rouge: Louisiana State University Press, 1948, p. 31.

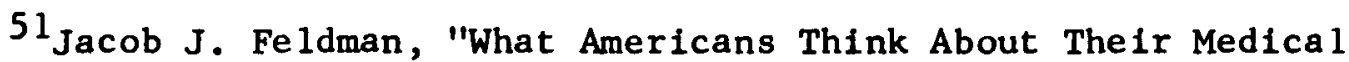
Care," Paper read at the annual meeting of the American Statistical Association, Chicago, December 27-30, 1958. 
doctor visits between social classes, but did find qualitative differences. Members of families with an income of less than $\$ 3,000.00$ annually appeared to be twice as likely to see the doctor in a hospital clinic or emergency room and only one half as likely to make initial contact over the phone. The higher income group was more inclined to utilize specialists. This was most true for obstetrics-gynecology and pediatric specialties. The proportion of the high income group seeing a dentist during the previous year was three times as great as that of the low income group. Twenty-two percent of the low income group and seven percent of the high income group had never seen a dentist and the higher the income the less was the likelihood that dental visits were for extractions. 52

Alpert found evidence that the designation of a particular doctor as a family doctor or "regular" doctor is a function of income. When 4,320 families with children in the pediatric age group were asked whether they had a doctor who usually looked after the children, the proportion of affirmative responses increased dramatically from the lowest to the highest income group. Only $16 \%$ of the families receiving public assistance had such a doctor while $85 \%$ of the families with an income of more than $\$ 10,000.00$ per year did.53

Predicated on the premise that there is basically a dichotomy

52 William C. Richard, "Poverty, Illness, and Use of Health Services in the United States," Hospitals, Journal of the American Hospital Association, XLIII (July 1, 1969), 34.

53 Joel J. Alpert et a1., "Types of Families That Use an Emergency Clinic," Medical Care, VII (Jan. - Feb., 1969), 57. 
in health care utilization of private physician vs. public clinic, Roth described four typical utilization patterns:

(1) A stable relationship with a private practice physician implying that such a physician is used for total primary care and that the public clinic is visited only at the recommendation of the usual physician.

(2) An unstable relationship with a private physician implying that such a physician is named and is used intermittantly with a public clinic.

(3) A stable relationship with a clinic implying that the family uses one public clinic and approaches other sources of medical care only occasionally.

(4) An unstable relationship with a clinic implying that the family uses several public clinics, indiscriminately, without a discernable pattern, and presumably in accordance with monetary convenience.

Comparing these utilization patterns with income, Roth

found that the highest socio-economic status group tended to have stable physician relationships. The status of the group decreased for each of the utilization patterns reaching the lowest level among those who have unstable relationships with a clinic. 54

Roth's paradyme overly simplifies health care utilization reducing its value in examining the wide range of behavior appropriately considered to fall into this category. Actually, patients use a variety of medical services and each type of service may have a different pattern of utilization by each social class, age category, ethnic group or any number of other population attributes.

As an example, it is rather widely accepted that the lower

54 Julius A. Roth, "The Treatment of the Sick," op. cit., p. 222. 
socio-economic classes are "present oriented." If this quality is carried over into health care utilization, it would be expected that the lower socio-economic groups would tend to underutilize future oriented medical services such as programs of prevention. The 11terature suggests that this is the case. In fact, one of the earliest utilization studies reported was an effort to determine why the working class population and the peasants did not readily accept vaccination against smallpox in France. 55 This study has a contemporary American counterpart in an effort to explore the relationship of socioeconomic status to participation in a poliomyelitis vaccine trial. In this study of a random sample of 160 mothers of second grade children in five public schools, a clear relationship was found between socioeconomic status and participation in the trial. The reason for participation or non-participation did not vary significantly between classes. 56

Although income can be expected to be an important variable in determining patterns of health care utilization the fact that the services offered in the above studies were without cost dictates that income cannot be the determining factor in all cases. An additional

55 Annuaire des cig de' partments de 1 'ancienne Normandie. caen: 1835. Reviewed in Annales d'hygience publique (1835), p. 233.

56Leila C. Deasy, "Socio-economic Status and Participation in the Poliomyelitis Vaccine Trial," in D. Apple, ed., Sociological Studies of Health and Sickness, New York: McGraw-Hill Book Company, Inc., 1960, Pp. 15-24. 
study revealed that low income groups failed to take advantage of free, conveniently located specialty clinics for emotional problems also. 57

Health care resource utilization must be complex and any effort directed toward developing a utilization paradyme must accommodate this complexity. Zola made an initial attempt in this direction when he delineated five tuning "triggers" in patients' decisions to seek medical care. These "triggers" are:

1. Interpersonal crisis: the situation calls attention to the symptoms and causes the patient to dwell on them.

2. Social Interference: the symptoms do not change, but come to threaten a valued social activity.

3. The presence of sanctioning: the person is told to seek care.

4. Perceived threat.

5. Nature and quality of the symptoms: symptoms are related to previous experiences or to those of friends. 58

Mechanic suggests a more detailed model of the help-seeking process. His model is composed of ten conditions as follows:

1. Visibility recognizability, or perceptual salience of deviant signs and symptoms.

2. The extent to which the symptoms are perceived as serious. That is, the person's estimate of the present and future possibilities of danger.

3. The extent to which symptoms disrupt family, work, and other social activities.

57 John Kosa, et al., "Crisis and stress in Family Life," Wisconsin Sociologist, IV (Summer, 1965), 11-19.

${ }^{58}$ I. Zola, "Illness Behavior of the Working Class," in A. Shostak and W. Gomberg (eds.), Blue-Color World: Studies of the American Worker, Englewood Cliffs: Prentice-Ha11, pp. 353-54. 
4. The frequency of the appearance of the deviant signs or symptoms, their persistence, or their frequency of recurrence.

5. The tolerance threshold of those who are exposed to and evaluate the deviant signs and symptoms.

6. Available information, knowledge, and cultural assumptions and understandings of the evaluator.

7. Basic needs which lead to autistic psychological processes. (i.e., perceptual processes that distort reality).

8. Needs competing with illness responses.

9. Competing possible interpretations that can be assigned to the symptoms once they are recognized.

10. Availability of treatment resources, physical proximity, and psychological and monetary costs of taking action (included are not only physical distance and costs of time, money, and effort, but also such costs as stigma, social distance, feelings of humiliation, and the like). 59

This is a rather comprehensive coverage of those factors affecting health care utilization. It includes personality factors as well as social, economic, and cultural factors. However, this complexity also makes the operationalization of this model difficult. One distinct advantage of this model is that it incorporates aspects of the delivery system. While the nature of the delivery system can be expected to influence the utilization of health services the literature does not contain a great deal of information in this area. Some attention has been directed to the differential utilization associated with different prepayment plans. In regard to this quality of the delivery system, Health Information Foundation and National Opinion Research

${ }^{59}$ David Mechanic, op. cit., pp. 130-31. 
Center surveyed two populations in the same area that were enrolled in different comprehensive physicians' service plans. One of the plans was based on group practice methods and the other on traditional free choice of physician and fee-for-service method of payment. Both consulted physicians at an equal rate although there was a difference in the rate of hospital admissions. 60 Thus, when alternative forms of health care were available at the same cost to a population there was a difference in the pattern of utilization.

\section{$\underline{\text { Summary }}$}

Health and health care behavior, both on the part of consumers and providers, are vitally important to contemporary society and have probably been so since the beginning of society. Any collection of behaviors that has endured for such an extended length of time in such a prominent position can be expected to have achieved an intricate interpenetration into a wide range of social, economic, and cultural systems.

This interpenetration results in a strong bilateral influence between illness and health care behavior and those systems into which they have interpenetrated. Studies suggest that cultural systems determine, to some extent, those conditions to be considered pathological as well as many of the habits, such as eating, that might increase

60 Odin W. Anderson and Paul B. Sheatsley, Comprehensive Medical Insurance - A Study of Costs, Use, and Attitudes Under Two Plans, Hea1th Information Foundation Research Series No. 9, New York: Health Information Foundation, 1959. 
susceptibility to some diseases. Social systems at various levels prescribe and constrain sickness behavior. In addition, to the extent that social systems influence anomie and other stress producing conditions, they contribute to one of the established causes of some disease. Each of these several systems influence health care resource utilization and there are also epidemiological relationships within each of these sets of systems.

To explore these complex relationships is difficult and cannot be accomplished effectively without the guidance of a theoretical frame of reference and the utilization of a variety of variables and statistical techniques. 
CHAPTER II

GENERAL SOCIOLOGICAL FRAMEWORK AND METHODOLOGY

I. GENERAL SOCIOLOGICAL FRAMEWORK

\section{Medical Sociology}

The complexity of the problem being explored in this study makes it improbable that the immediate findings exhaust the knowledge potential of the data. If this knowledge potential is to be maximally exploited it is necessary to relate these data, along with relationships that have been determined to exist among them, to a more fundamental theoretical framework.

An obviously appropriate theoretical framework to relate these types of data to is that of medical sociology. Unfortunately, this cannot be done without encountering some difficulty because of the present nature of the field of medical sociology. McIntire defines this field as:

the science of the social phenomena of the physicians themselves as a class apart and separate; and the science which investigates the laws regulating the relations between the medical profession and human society as a whole; treating of the structure of both, how the present conditions came about, what progress civilization has affected and indeed everything relating to the subject. 1

Since this definition was formulated the sociology of health and medical care has experienced a remarkable growth. The field has

${ }^{1}$ Charles McIntire, "The Importance of the Study of Medical Sociology," Bulletin American Academy of Medicine, I (February, 1894), 425-34. 
become formally designated and systematically elaborated in the past two decades. However, medical sociology has not become analytically defined. It must be regarded as a loosely interrelated collection of investigations in which many of the theories and findings of sociology are applied to the specific problems of health and medical practice. Viewed from this perspective, medical sociology offers neither a unified definition nor a distinctive theoretical focus. In fact, theory in medical sociology is at present only in a very rudimentary stage of development. 2 obviously, when viewed in the context of the larger body of sociological theory, medical sociology does not constitute a completely discrete subset of knowledge nor does it provide long range theory to which to relate empirical findings.

Consequently, the conceptual framework of this study also incorporates concepts indigenous to other areas of sociological knowledge. Social organization is one such area. The review of the literature revealed that health care behavior, including perception of illness and acting out the sick role, are basically determined by social and cultural norms. In addition it appears that the existence of some types of disease is, at least partially, related to a breakdown in social system structure at the family as we 11 as at the societal levels.

\section{Social Organization}

This study is an attempt by the writer to approach 11 lness and

${ }^{2}$ Neil J. Smelser and James A. Davis, eds., Sociology, Englewood Cliffs: New Jersey, Prentice-Ha 11, Inc., 1969, pp. 94-95. 
illness behavior as aspects of social structure and, to the extent possible, from a system perspective. One advantage of using a systems approach in examining social structure is that it provides a set-subset type of relationship. Such an approach has been employed effectively in other disciplines. Examples of this are the solar system in astronomy and the various system concepts in biology. Essentially, the basic assumption in the system concept is that within the universe of data there are certain subgroups which bear a stronger relationship among themselves than they do to other data in the universe. In social systems the data universe consists of social facts and more specifically of social interactional facts; that is, in all of the social interaction occurring there are groupings in which the interacting elements are significantly more strongly related to each other than they are to elements outside of the group.

Despite the apparent, potential advantages offered by social system theory, there are disadvantages also. Not the least of these is the fact that social system theory is not yet a fully matured body of theory. Walter Buckley ${ }^{3}$ mentions the importance to sociology of three system models: the mechanical, the organic model and the process model. The mechanical model originated in the "social physics" of the 17 th century in which man was regarded as a physical object whose actions and psychic processes could be analyzed in terms of the principles of mechanics. By the 19th century, Pareto had forged a concept

Walter Buckley, Sociology and Modern Systems Theory, Englewood Cliffs, New Jersey: Prentice-Hal1, Inc., 1967, p. 384. 
of systems from this knowledge base. This mechanical model embraced the idea of a group of elements in mutual interrelations resulting in a state of equilibrium. Moderate changes in these elements or their interactions away from the equilibrium position are counterbalanced by changes tending to restore it. This conception is reflected to a large degree in the ideas of Burkharin, Sorokin, Zaniecki, Lewin, Homans and Parsons. Central to this model is a mechanistic type of equilibrium. It is this equilibrium which is perhaps the most vulnerable aspect of the mechanistic model, as its rigid nature does not permit an explanation of the constant change that occurs in social structure.

Serious scientific usage of organic analogizing is usually traced back to Herbert Spencer. Similar to the rise of the mechanistic model in an era of physical science advances, the organic model of society was inspired by the advances in biology. In biological systems the static connotations of equilibrium give way. Substituted is the term "homeostasis" to bring out the dynamic processual, potentialmaintaining properties of basically unstable physiological systems. Thus, system models constructed on organic foundations offer a more viable concept to accommodate to notions of change. 4

It is argued, however, that even the extension of the equilibrium concept is not sufficient to account for the type of system maintenance activity occurring in social structure. In this respect, Karl Deutsch observes that homeostasis is not a broad enough concept to

${ }^{4} \operatorname{Kar} 1 \mathrm{~W}$. Deutsch, in Toward a Unified Theory of Human Behavior, ed. Roy Grinker, New York: Basic Books, Inc., 1956, pp. 161-62. 
describe either the internal restructuring of learning systems or the combinational findings of the solutions. It is too narrow a concept because it is change rather than stability which we must account for. This handicap is not as pronounced in the "process" model. This model was a predominate point of view in American sociology of the early twentieth century. In essence, the process model typically views society as a complex, multifaceted fluid interplay of widely varying degrees and intensities of association and disassociation. The "structure" is an abstract construct, not something distinct from the ongoing interactive process, but rather a temporary accomodative representation of it at any one time. These considerations lead to the fundamental insight that sociocultural systems are inherently structure-elaborating and changing. Societies and groups continually shift their structures as adaptations to internal or external conditions are required. Process, then, focuses on the actions and interactions of the components of an ongoing system, such that varying degrees of structuring arise, persist, dissolve, or change. 5

This brief summary of three types of system models does not exhaust the possible types. It does serve to demonstrate that system theory is not a unified body of theory. In the face of this condition, this study takes an eclectic approach and draws from the several orientations of system theory. It is recognized that there are various levels of systems involving people. Among these are the organismic

${ }^{5}$ Buckley, op. cit. 
system level, the personality system level, the social system level, and the cultural system level.

Illness and the concomitant health care behavior exist at each of the several levels of systems. However, it is the social system and cultural system levels which have the greatest relevance for this study. Although there is no categorical typology of social systems it is obvious that they, too, exist at different levels of complexity each with unique characteristics. All may have a common, basic, bonding mechanism accounting for their stable quality. Many explanations have been advanced for this mechanism. Smith, Spencer, Marx and Durkheim suggest the division of labor in society as the quality tending to produce this solidarity.

Durkheim observed that difference, as we 11 as likeness, can be a cause of mutual attraction. However, certain differences do not produce this effect. We do not find pleasure in those completely different from us. Spendthrifts do not seek the company of misers, nor moral and honest people that of hypocrites and pretenders. Only certain kinds of differences attract each other. They are those which, instead of opposing and excluding, complement each other. As richly endowed as we may be, we always lack something, and the best of us realize our own insufficiency. That is why we seek in our friends the qualities that we lack, since in joining with them, we participate in some measure in their nature and thus, feel less incomplete. So it is that small friendly associations are formed wherein each one plays a role conformable to his character, where there is a true exchange of services. 
We are thus, led to consider the division of labor in a new light. In this instance, the economic services are insignificant compared to the morale effect that it produces, and its true function is to create in two or more persons a feeling of solidarity. In whatever manner the result is obtained, its aim is to cause coherence among friends and to stamp them with its sea 1.6

It was further observed by Durkheim that, although the conjugal group requires a certain harmony of thought and sentiment, it is not the similarity that imparts to this relationship its peculiar character and energy. It is, instead, the sexual division of labor that provides the source of conjugal solidarity. ${ }^{7}$ This solidarity based on a division of labor resembles that of higher order animals in which each organ has its special physiognomy, its autonomy. Because of this analogy, Durkheim refers to this type of solidarity as organic. 8 Herbert Spencer also compares the division of labor or of function in social structure to the specialization of function in a living organism. According to him as social structure grows its parts become unlike producing an increase of structure. This produces a progressive differentiation of social functions in which the functions are not simply different, but their differences are related in such a way as to make one another possible. This reciprocal aid causes mutual dependence of the parts. In turn, the mutually-dependent parts, living

${ }^{6}$ Emile Durkheim, The Division of Labor in Society, Translated by George Simpson, New York: The Free Press, 1933, pp. 54-56. 
by and for one another, form an aggregate constituted on the same general principles as in an individual organizm. ${ }^{9}$ Although Spencer established his organic analogy and consequent coherence of function at the societal level, there is ample evidence that he considered this quality ubiquitous to all but the most primitive social structure. In order to place illness and health care behavior in some sort of perspective to social structure it is necessary to make some assumptions reconciling these several concepts. If it is assumed that social structure is made up of social systems and that these social systems are composed of differentiated, integrated, interdependent parts whose composite functioning accomplishes the vital functions required to sustain the system, it remains to articulate these assumptions into some type of model that captures the dynamics of system interaction.

Several types of such models exist, including Loomis' P.A.S. model and Parsons' scheme of functional imperatives. Loomis' P.A.S. model is more appropriate to a macro level of analysis while the functional imperatives when not used along with some other structural quality lacks applicability to individuals. This latter characteristic is an essential requirement for this study. In fact, two tasks are required for the structural model used in this study. First, it must account for the patterning of relationships between culturally defined structural units including norms, roles, and status-positions.

${ }^{9}$ Herbert Spencer, The Principles of Sociology. New York: D. Applet on and Co., 1898, Vol. II. 
Secondly, since such concepts enter the cultural structure only after first originating in the interactional arena of social organization, the model must also be able to account for structuring patterns that have not yet become a part of the cultural structure.

Unfortunately, a single model possessing both of these features apparent ly is not readily available. Consequently, two system models are relied upon. One of these is a modification of a cybernetic type described by Holder. ${ }^{10}$ This model is diagramed in figure 1 , depicting a four member social system. The greatest modification in this model is the inclusion of three social system monitors, the cultural system monitor, the personality system monitor, and the organismic system monitor.

These three system concepts have been somewhat loosely drawn from Parsons. 11 The organismic system exists at the level of the various cells, tissues, and organs of the body. Together they form a system whose vital functions must be achieved if it is to endure. Since its existence is prerequisite to the survival of a social system there must be a compatibility in their functions. This can only occur if the social system is sensitive to the outputs of the organismic system. Together with the personality system the organismic system

10 Harold D. Holder, "Evaluation Methods and Dynamics in Program Planning," (Source unknown-reprint on file at the L.S.U. School of Social Welfare), p. 36 .

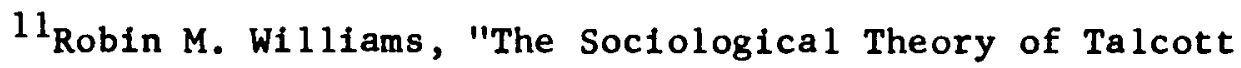
Parsons," in Max Black (ed.), The Social Theorles of Talcott Parsons: A Critical Examination, Englewood Cliffs: Prentice-Ha11, Inc., 1961, pp. 69-72. 


\section{FIGURE I}

FOUR MEMBER SOCLAL SYSTEM

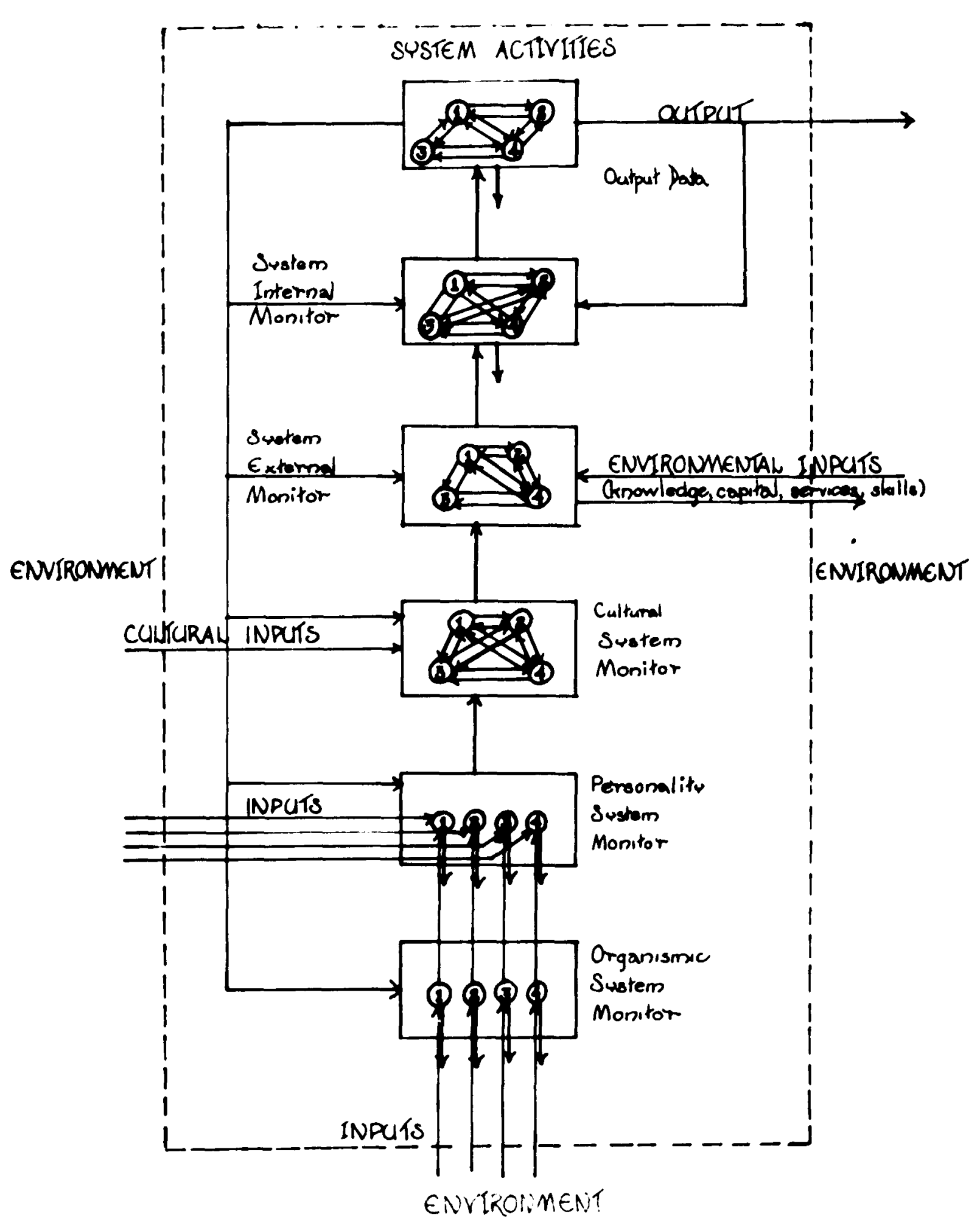


helps to determine the need predisposition of the members of the social system. The personality system is a higher level emergence than the organismic system and represents the addition of the individual's mental processes. The cultural system actually represents a higher level system which emerges from the interaction occurring in the social system. As the interacting individuals in a social system begin to evolve rules and norms representing the ideal behavior, the resulting blueprint of behavior represents the emergence of the cultural system. The cultural system then exists in the artifacts that express it as well as in the minds of individuals. It influences the system in two ways, then. Existing in the minds of the individual, the cultural system contributes to the need predisposition of individuals influencing their interaction. Since these individuals are members of multiple systems and the introjected cultural norms are carried with them from system to system they at times represent an inclusion of exogenous content into the system. However, cultural norms are also transmitted through cultural artifacts such as literature, journalism, plays, and broadcasts as well as by the reporting of court decisions. Such transmissions are picked up by the cultural system monitor and brought into the system.

Since a social system is composed of people as well as artifacts and resources its component parts must be similarly constituted. These individuals must be ordered into the required system components and status-positions and roles must be assigned or negotiated. Among the components apparently necessary to a social system are a system external 
monitor, a system internal monitor, and an activity implementing subsystem. The system external monitor scans, evaluates and selectively admits inputs from the environment. These inputs may be data, know1edge, skills, capital, equipment or services. The system internal monitor determines when these resources are to be used in system activity as we 11 as the adequacy of system activity. This latter determination is made partly from a comparison of the output of the activity implementing subsystem with some predetermined goal. This constitutes an internal feedback loop. The assessment of the adequacy of system activity is also made partly from data channeled into the system through the external monitor, constituting an external feedback loop. The activity implementing subsystem produces the output of the system. However, not all the output actually leaves the system. Some is channeled back into the system internal monitor. Other output of this subsystem is directed toward the other system components and might be regarded as expressive or system maintenance activity while that directed outside the system can be regarded as instrumenta1 activity.

In final analysis, it is not the Individuals, but the functions that are ordered in a social system. Since these functions must be performed by people then the people, too, must be ordered. Ordinarily, the positioning of system members into the various subsystems is accomplished largely through the cultural structure with its normative prescriptions but norms such as internal or external system monitoring are not visibly articulated in the cultural structure. Therefore, the 
negotiation for status-positions and roles in the cybernetic system structure is probably partly determined by the individuals' need predispositions and is accomplished through the sanctioning process, apparently often without conscious intent.

Most social system structure is more visible, with norms rooted in the cultural structure achieving a high degree of institutionalization through the processes of validation and legitimation. The family is an example of such a visible, institutionalized social system. The positions of mother, father, son, and daughter are relatively well defined containing culturally articulated norms. This does not mean that such a system is completely free of stress, however, as there appears to be a permanent process of disorganization in every system. 12 There are many reasons for this condition. Among some of those which have been recognized are the facts that no single individual perceives or interprets the situation the same as do others and the socialization process, which accounts for the transmission of norms from the cultural structure to the personality system, is not a monolithic process. Instead, it is accomplished through a wide range of agents which frequently describe identical social roles and positions difierently. Consequently, even after social structural units achieve validation and legitimation in the cultural structure they remain less than precise and an individual's impression of such structural units varies with the particular socializing agents to which he has greatest exposure.

12 Alvin L. Bertrand, "The Stress-Strain Element of Social Systems: A Micro Theory of Conflict and Change," Social Forces, Vol. XLII (October, 1963), 1-9. 
One other significant source of stress in social structure has relevance to this research. This results from the fact that the legitimated, culturally articulated system structure and the less visible, emergent, cybernetic system structure must exist simultaneously and be reconciled to each other. A complication is produced by the fact that there is not a one to one correspondence between the status-positions in the legitimated system and the cybernetic functions. There does appear to be a possibility that particular individuals tend to specialize in certain types of functions, as Bales determined that there was a tendency for social-emotional specialists and instrumental specialists to evolve in problem solving groups that he observed. 13 This tendency toward specialization of function is extended to the sexual roles by Parsons who points out that in the family the adult male tends to perform instrumental functions and the adult female tends to perform expressive functions and through the socialization process this division of function is communicated to the children forming their prototype of social organization. 14

$$
\text { of the many obvious sources and types of stress existing in }
$$
social structure the particular manifestation of relevance to this study is those several conditions that have been defined as anomie. Durkheim envisioned this condition as a breakdown in social norms

13 Robert A. Bales, Interaction Process Analysis: A Method for the Study of Small Groups, Cambridge, Mass .: Addison-Wesley, 1949.

${ }^{14}$ Talcott Parsons and Robert F. Bales, Family, Socialization and Interaction Process, New York: The Free Press, 1955, pp. 74-94 and 113 . 
especially in a manner that produces a visible gap between individuals' aspirations and their achievement. 15 This condition approaches the limit in the expanding economy of an open society where the state of crisis and anomie is constant. MacIver interprets anomie somewhat differently, defining it as "the breakdown of the individual's sense of attachment to society."16 This ego centered definition of anomie is also embraced by Lasswe 11 who describes the condition as a lack of identification on the part of the primary ego of the individual with a 'self' that includes others. He observed that modern man appears to be suffering from psychi isolation, feeling alone, cut off, unwanted, unloved, and unvalued. 17

A high level of anomie appears to be characteristic of an open class, industrial society such as we have in the United States. Within this frame of reference, however, anomie can be expected to be differentially related to reference social structures. It would be expected that population groups presenting a dearth of reference group memberships would tend to have a higher level of anomie than those having an abundance of such memberships. Rural populations might be expected to have a lower level than urban populations and geographic stable populations would seem to be less vulnerable to anomie than nomadic persons.

15Emile Durkheim, Le Suicide: Etude de Sociology (Paris: Alcan, 1897). Translated by John A. Spaulding and George Simpson in Suicide, New York: The Free Press of Glencoe, 1951, pp. 148-49.

${ }^{16}$ Robert M. MacIver, The Ramparts We Guard, New York: The Macmillan Co., 1950, pp. 84-92.

17 Harold Lasswe11, "The Threat to Privacy" in Robert M. MacIver (ed.), Conflict of Loyalties, New York: Harper and Bros., 1952, PP. $132 \mathrm{ff}$. 
If anomie is reflected in the individual's ego, it can probably be induced at a structural level other than that of the society. In fact, if the definition of anomie is extended only slightly, to include any condition of social structure that tends to produce an uncertainty of norms, then it becomes apparent that micro structure can be conducive to anomie. The vagueness of the cybernetic structure should itself contribute to anomie of the system members. In addition, it might be expected that those members of the system who occupy components exposing them to other systems and therefore, other value systems will be more susceptible to anomie than those occupying components associated with internal system structure. A greater possibility is that those system members relegated to a system substructure for which their socialization should not have been expected to prepare them adequately will experience a high level of anomie. Thus, a wife cast into the wage earner role, the husband thrown into the home maker role, and an immature child filling the position of parent surrogate would fall into this category.

In summary, an attempt has been made to establish that human beings are simultaneously influenced by multiple systems at four system levels, the organismic, the personality, the social, and the cultural. Each tends to exist in some type of dynamic, patterned change resembling an equilibrium. These systems are linked through interpenetration so that a disruption of the ordered change in one transmits stresses throughout the others, demanding adjustive behavior. Disease is a manifestation of this phenomenon. Obviously a disruption of the homeostasises of the organismic system, may partially result from 
psychological stress, interactional stress, or debilitating, culturally determined behavior. Once in existence, this disruption of the organismic homeostasis is capable of inducing stress (anxiety) in the personality system. This anxiety, once it achieves sufficient intensity, may stimulate behavior at the level of social organization such as the acting out of the sick role. Nuances in the acting out of this role may, in turn, contribute to change in the cultural structure.

\section{METHODOLOGY}

\section{Hypotheses}

The relationship between disease and social structure is seen to be intricate with both apparently influencing each other in various ways. The relationship of social structure to disease is especially intriguing because it is apparently a significant factor in both the existence and the amelioration of many forms of pathology. Such a relationship suggests that at least some diseases may be a manifestation of maladaptation of the social system structure to the vital requirements of the personality and organismic systems. Such a lack of responsiveness on the part of the social system to the lower system levels might be the result of several types of structural defects. Among these is the condition of anomie which has been shown to be positively correlated with such mortality rates as suicide. Since anomie represents the degree to which the personality system is integrated into the social and cultural systems, it has implications for 11 iness behavior as well as illness. 
In order to explore these relationships as well as the more esoteric demographic relationships in morbidity the several hypotheses addressed are to provide direction to the exploration rather than to set a limit to the study. These hypotheses are:

1. Morbidity rates are related, either generically or differentially, in a positive direction to anomie.

2. Morbidity rates are related, either generically or differentially, in a positive direction to those several social conditions that can be considered conducive to anomie including :

a) lack of participation in the church

b) geographic mobility

c) urban residence

d) occupation of a social status-position for which socialization can be expected to be inadequate

e) marginality within the family structure

f) incompleteness of family structure

3. The occurrence of perceived pathology among the sampled populations will fall into patterns related to age, sex, income, education, and ethnicity.

4. Selected attitudes toward health care by these populations will fall into patterns related to age, sex, income, education, residence, and ethnicity.

5. The perception of symptoms as requiring medical care will vary with ethnicity, income, religion, and education.

6. The utilization of health care resources by these populations will fall into patterns related to age, sex, income, education, ethnicity, and anomie.

\section{Research Procedure}

\section{Operationalization of Concepts}

Indigent: Those persons falling below the O.E.0. Income criteria for poverty. 


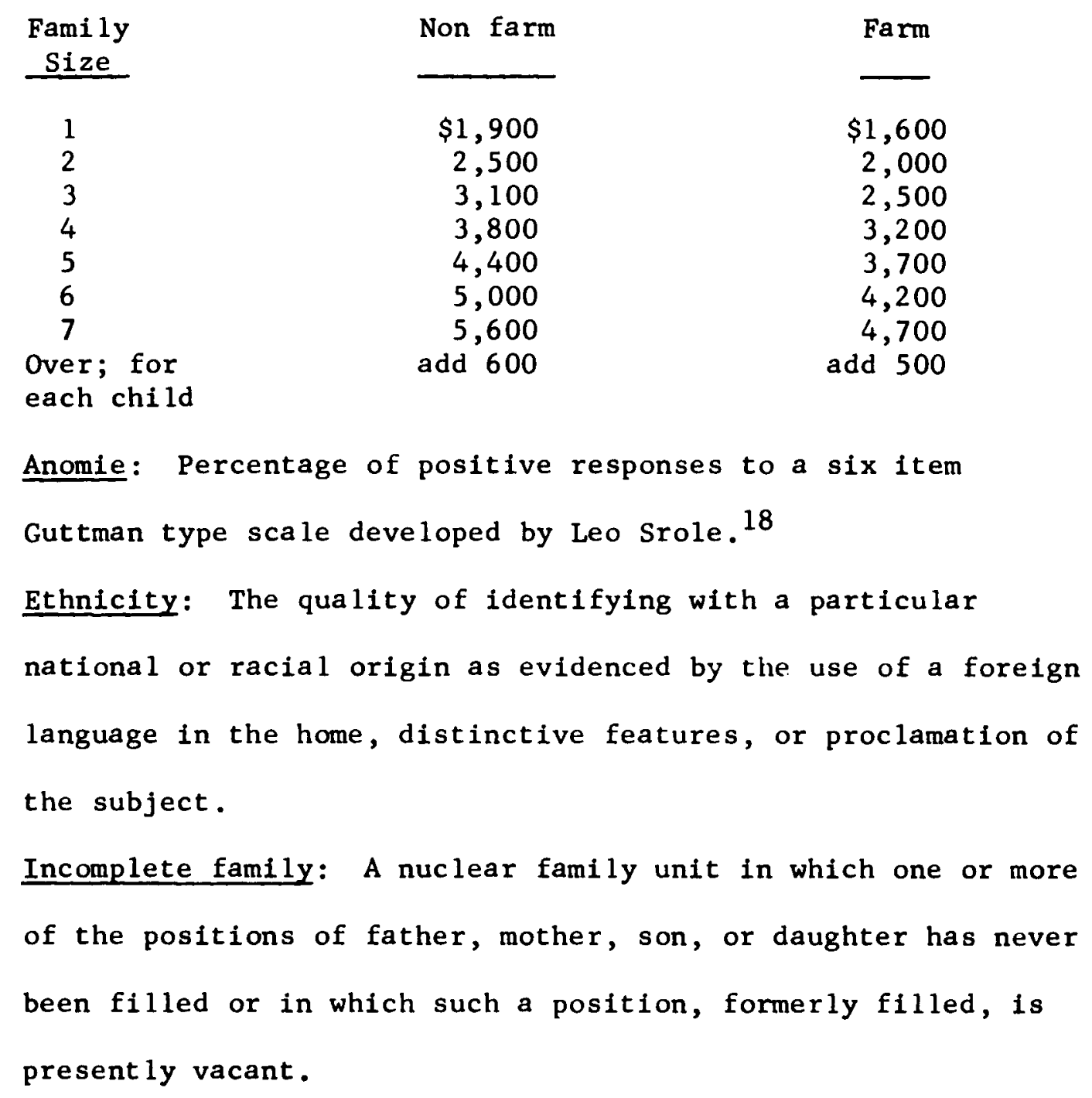

\section{Method of Data Gathering}

The method of data gathering for this study was decided upon with pragmatic objectives in mind. These were to gather data and explore relationships that would facilitate health care planning in three specified communities. Among the data required were morbidity

${ }^{18}$ Leo Srole, "Social Integration and Certain Corollaries: An Exploratory Study," American Sociological Review, XXI, (December, 1956), 709-16. 
rates, epidemiology, attitudes toward health care, and patterns of health care of the indigent populations.

To accomplish the gathering of these data, a consumer survey approach was decided upon. It is true that this type of approach contains certain inherent limitations, especially in gathering data related to morbidity. Among the alleged limitations is the lack of accuracy in gathering morbidity data because of its reliance on subjective responses. The disadvantages of the survey approach, although somewhat discouraging, are not readily eliminated by the selection of alternate approaches. The diagnostic team approach, for example, has been found to produce inaccurate data also. ${ }^{19}$ In addition, it introduces unique logistical problems due to the need to recruit and mobilize volunteer subjects to submit to physical examinations.

Dorn suggests that, although clinical examinations do yield, morbidity data closer to reality than do household interviews, examinations of a general populations sample have had poorer response rates than interview surveys resulting in a greater problem of nonresponse bias. But even in household morbidity surveys, the most important methodological problem has been the extent of unreported disease. 20 Haberman indicates that in considering morbidity survey techniques the

${ }^{19}$ Harold F. Dorn, "Method of Measuring Incidence and Prevalence of Disease," American Journal of Public Health, XLI (March, 1951), $271-78$.

20 Ibid. 
one which elicits more positive responses about the presence is apt to be the more accurate. 21

It appears then that the ideal morbidity study technique does not exist. The problem, thus, becomes one of selecting the technique most appropriate for the objectives and conditions at hand. Since our objectives were not limited to obtaining morbidity data, but included the determination of health care practices and attitudes, it was felt that at least part of the required information could best be obtained through the use of trained interviewers. In addition, since the morbidity data gathered was to serve the function of determining the nature of services to be provided to the target populations, any person believing himself to be 111 should be considered a potential receiver of health services. Because of these considerations a survey technique was selected to gather these data.

A copy of the interview schedule appears in Appendix "A." The basic morbidity items were drawn from an instrument developed by Mulford at the University of Iowa Medical Center. To these items were added symptom eliciting items used in the Regionville study, ${ }^{22}$ items suggested by Mechanic's model of the help-seeking process, ${ }^{23}$ items

$21_{M}$. B. Bailey, et a1., "The Epidemiology of Alcoholism in an Urban Residential Area," Quarterly Journal of Studies on Alcohol, XXVI, (March, 1965), 19-40.

22 Earl L. Koos, The Health of Regionvi11e, New York: Columbia University Press, 1954.

23 Mechanic, op. cit., Ch. 4, pp. 130-31. 
developed by Srole to quantify anomie, ${ }^{24}$ and finally severa 1 items eliciting attitudes toward health care arrived at through several meetings of indigenous persons and a pre-test of the instrument.

\section{Sampling Procedures}

The geographic areas surveyed included the towns of Hammond and New Roads and a South Baton Rouge Neighborhood area. The procedural task was not to obtain a representative sample of each of the geographic areas but to obtain a sample that would provide insights into the illness and health care characteristics of the poverty populations of these areas. In Baton Rouge, the objectives were slightly different as the neighborhood selected was one that was under consideration for the establishment of a more effective health care delivery system. Time and money were also critical factors dictating that the sampling procedures utilized had to provide for optimum speed in data gathering .

Taking these factors into consideration the following procedures were decided upon. The three geographic areas were determined by the Louisiana Capital Area Health Planning Council and represented three types of residential centers under their planning jurisdiction. New Roads represents a market community still closely associated with an agrarian economy offering a high concentration of population with a French ethnic origin. Hammond presents a more cosmopolitan population with more ethnic diversity, but with a relatively high

$$
{ }^{24} \text { Leo srole, op. cit. }
$$


concentration of its population maintaining an Italian ethnic identity. The economy is moving away from its original agricultural base toward a commuting pattern of reliance on accessible industrial areas such as Baton Rouge and New Orleans. Baton Rouge provides an industrial community setting.

The sampling procedure varied somewhat in each of the geographic areas. In Baton Rouge, the neighborhood sampled approximated three census tracts located in a poverty area containing a representative number of both the black and white races. Because of this concentration of population the serpentine, two stage sampling method described by $\mathrm{Kish}^{25}$ was employed with some modifications. First, the entire geographic area was outlined. It was then divided into blocks which were numbered. The sampling interval was calculated by determining the number of dwelling units to be included in the sample. In this instance, it was determined to be .05 of the number of households with an income lower than that considered to constitute medical indigency or approximately 330. This figure was divided by the approximate number of single household dwelling units in the area, which was 6,591, giving the probability of selection for each dwelling unit. The product of the probabilities of selection for each of the two stages must equal the overall probability ratio. The first stage, the city block, was generated by randomly selecting a border block in each of the three census tracts and from this point generating a sine curve 
over the combined census tracts. Each block that was intersected by this line was included in the sample and the probability of the first stage was computed by dividing the total number of blocks in the sample by the total number of blocks in the combined census tracts area. This value remained constant and the interviewers adjusted the probability of selection of each dwelling unit, the second stage, in order to achieve the established overall probability ratio. 26

In New Roads economic data gathered by the Office of Economic Opportunity were used. The city was divided into small geographic areas with income data available for each of these areas. These data were examined and a sufficient number of the areas with a concentration of medical indigency of $75 \%$ or greater were selected randomly to provide a total sample representing .07 of the medically indigent of the town. Saturation surveying was then utilized in each of the se areas. In Hammond a windshield survey was conducted to locate likely poverty dwellings. These were recorded on the census enumeration

${ }^{26}$ These several values were determined to be as follows:

Overall sampling probability ratio

$A=$ approximate number of dwelling units in the neighborhood geographic area $=6,591$

$B=$ approximate number of dwelling units in the sample $=267$

$C=$ overall sampling ratio $=B / A=.05$ or $1 / 20$

First stage (city block)

$D=$ Number of city blocks in the neighborhood geographic area $=267$

$E=$ number of city blocks in the sample $=54$

$F=$ probability of the selection of each block $=E / D=.20$

Second stage (dwelling unit)

$G$ = approximate number of dwelling units in a specific city block

$\mathrm{H}=$ probability of selecting each dwelling unit: since $\mathrm{H} \times \mathrm{F}$ must $=\mathrm{C}$ and $\mathrm{F}$ is constant and $\mathrm{C}$ is constant then $\mathrm{E}$ must $=\mathrm{C} / \mathrm{F}=.05 / .20=.25$ or $1 / 4$. 
district maps and the sample was drawn from them.

\section{Methods of Analysis}

The statistical analysis of these data is relatively straight forward. The Product Moment Coefficient of Correlation is used to explore those correlations between variables measured in interval scales. These include the correlation between morbidity rates and age, income, education an anomie. This latter variable is quantified by a modification of the Alleger method of scoring the Srole Anomie Scale. 27 For those data expressed as frequencies among dichotomized categories, chi square is employed. These data include the relative frequencies of morbidity in rural and urban settings as well as the relationship of morbidity to church participation, mobility, social status-position, incomplete family structure and sex. Comparisons of rank order variables is accomplished with the Kendall Rank Correlation Coefficient.

In view of the exploratory nature of this study and the large number of variables involved, the question of spuriousness arises. An effort was made to control for possible invalidating factors through refinement of variables and a constant search for relevant controls. 28

\section{Limitations of this Study}

One of the most serious limitations of this study is the

27 Daniel Alleger, "A Southern Rural Paradox: Social Change and Despair," (Tallahassee: Florida State University, Agricultural Experiment Station, Research Report, Vol. II, No. 1, January, 1966), p. 7.

${ }^{28}$ Herbert Hyman, Survey Design and Analysis (Glencoe, Illinois: The Free Press, 1955), pp. 244-74. 
absence of a time sequence making it impossible to employ elaboration techniques and to arrive at cause and effect relationships. Relationships which are determined to exist can be related to the three geographic areas sampled. Thus, ethnic nuances in sickness and health care determined to exist in this sample cannot be generalized to national populations. This is true also of the relationship between other attributes and illness or patterns of health care.

There is also a possibility that the contrived complex variables may not validly portray the qualities which they are purported to. The Srole Scale, for example, measures anomie, which is a social system phenomenon, at the level of the personality system. Similarly, a paradigm of health care utilization contrived to reflect the relative influence of various factors on the decision to seek treatment can only apriorily be assumed to exhaust these factors. The intent of the study is exploratory, however. As an exploratory study it detects relationships and suggests areas for future research. 
CHAPTER III

THE SETTINGS AND POPULATIONS

I. THE INTENT

In the selection of the geographic areas from which the sample populations were drawn it was hoped to obtain population concentrations with varying degrees of industrialization and urbanization and with a representative number of the two major ethnic groups in the planning jurisdiction of the Capital Area Health Planning Council and of the black population. To accomplish this, three population centers were chosen. One of these, New Roads, is a trade center depending on a farm economy and having little industry that is not farm related. There is a prominent French ethnic population in the area. A dearth of transportation ingress and egress contributes to a quality of isolation. A second community, Hammond, is somewhat larger. Formally a farming area and produce shipping center, it is now beginning to address itself to industry. The town is situated at a rail and interstate highway crossroads. In this community, there is a large Italian ethnic population. The third population concentration is located in Baton Rouge, an industrial, urban area.

The intent of this study is not to compare three "ideal type" communities representing urban, transitional, and rural trade centers, but to compare health data and health care data related to a range of economic and population characteristics. The specific communities are important to the study only to the extent that they contain these 
economic and population characteristics. Accepting the fact that these communities do not represent ideal types, the degree to which they approximate ideal types, as well as the extent to which they contrast with each other, can be seen only by comparing a description of the three.

\section{THE SETTINGS}

$\underline{\text { New Roads }}$

\section{Geographic Features}

New Roads is located about thirty-five miles from Baton Rouge on a horseshoe shaped lake approximately twelve miles in length. Although it is situated near the Mississippi River, the river provides neither a means of transportation nor industry for the town other than a single, small ferry boat that crosses to the town of Saint Francisville. Neither is the town served by train or plane, nor is it located on a federal highway. Access is provided to the town by two black topped, state highways. The land is flat, alluvial and rich. The only known mineral deposits in the area are natural gas and ofl.

\section{Economy}

The rich land, abundant rainfa 11 and mild climate of the area is conducive to agriculture while the lack of resources and transportation as well as a limited sophisticated labor reservoir mitigate industrial development. The proximity of industry in Baton Rouge has enticed some residents from New Roads and a limited number commute daily. Despite this current influence, Pointe Coupee Parish and New 
Roads have retained the tradition of being primarily an agricultural area and the residents take pride in this fact. 1

of the parish's 360,960 acres, 240,000 are in farms on which 100,000 acres of crops are harvested and 140,000 are devoted to pasture land, both open and woodland. In 1968, the gross revenues from the major crops for the parish were as follows: (1) soybeans, $\$ 3,072,000$; (2) sugar cane, $\$ 2,975,000$; (3) beef cattle, $\$ 2,520,000$; (4) corn, $\$ 1,487,000 ;$ (5) pecans and other horticulture crops, $\$ 1,337,000 ;$ (6) cotton, \$770,200; (7) dairying, \$350,000; (8) swine, $\$ 252,000$; (9) Forestry, $\$ 250,000$; (10) Miscellaneous, $\$ 150,000$; (11) Poultry, $\$ 170,000$. Industry in the area around New Roads is largely agricultural related and includes a chip mill employing 16 full-time workers, cotton gins, a single sugar factory with 125 employees and a pecan shelling plant providing approximately seven months employment each year for about 35 persons. Oil was discovered in the parish in 1948 . Although New Roads is not located in a producing oil field there are 185 oil wells in 11 oil fields in the parish. ${ }^{2}$

An indication of the nature of employment in the parish is found in the fact that only 11.6 per cent of the work force was employed in manufacturing in 1960. At that time the unemployment rate stood at 7.8 per cent. The median family income was $\$ 3,875$ for the

1Bernard Curet, "Pointe Coupee: Her Economic Progress," Acadiana Profile - A Magazine for Bi-Lingual Louisiana, I (September and October, 1969), P. 28 .

\section{Ibid.}


parish with 40 per cent of the families earning less than $\$ 3,000$ and 8.8 per cent earning $\$ 10,000$ or over. The median education in the parish was 8.9 years in 1960 with 34.1 per cent of the population over twenty-five years having completed four years of high school or more. 3

$\underline{\text { Hammond }}$

\section{Geographic Features}

Hammond is located approximately forty-five miles East of Baton Rouge in a flat plain of relatively high P.H. soll. Although the town is not located on a navigable stream some of its citizens took the initiative in forming a port authority to develop the potential of a stream some sixteen miles distant. The town is also served by other forms of transportation as it is located at the intersection of two interstate highways and two rail lines. One of these rail lines is the trunk line of the Illinois Central Railroad. Regular bus service is provided by the Greyhound Bus Lines and local and area carriers. Six motor freight lines operate in and out of the city. The town also has a three runway airport, but no scheduled air flights.

The only known mineral deposit in the area is gravel. Five rivers and numerous creeks are located in the immediate vicinity of Hammond. None of these streams provide a commercial source of fish. Game also exists in the area, but, again does not provide a source of industry other than recreation.

${ }^{3}$ U.S. Department of Commerce: Bureau of the Census, Census of Population: 1960, Volume I: Characteristics of the Population, Part 20, Louisiana, U.S. Government Printing Office: Washington, D.C., 1961, 113. 


\section{Economy}

The quality of the land around Hammond along with early settlement patterns on small plots of land is not conducive to large scale farming. The proximity of the urban markets of New Orleans and Baton Rouge and the accessibility of such markets as Chicago encourage some truck farming. Dairy farming and poultry farming are also carried on. However, the most important crop to the area historically, both in terms of value and cultural impact, is strawberries. During the past two years, the acreage devoted to this crop has declined from 10,000 acres to some 1,300 acres. Despite this large decline the city continues to designate itself as "the Strawberry Capital of the World." Another agricultural related industry that is in decline in the area is lumbering, but logging operations continue to be carried on to supply several soft wood saw mills and a nearby paper mill.

Conconmitant with the decline of agriculture in the area, there has developed an awareness of industry as an alternative for economic growth. The city advertises the fact that it is located in close proximity to the great industrial-science complex of Louisiana. Recent efforts were made to attract several industries including a multi-million dollar steel foundry, machine shop, and rolling mill, a plywood plant, a plastic bonding manufacturer, and a candy company. Although none of these companies actually located in Hammond, all located nearby. In addition, the town contains a company manufacturing industrial valves, a brick company and a garment company. A 276 acre industrial park is in the planning stages and has been approved 
by the U.S. Economic Development Administration for a participaing grant for site development. ${ }^{4}$

The education level of the residents of Hammond is higher than those of Pointe Coupee Parish with 9.5 years being the median years attained and with 40 per cent of the population having completed four years of high school or more. A slightiy larger proportion of the population in Hammond is involved in manufacturing with 11.7 per cent being thus employed in 1960. The unemployment rate was lower in that year than was the rate for Pointe Coupee Parish with only 5.3 of the work force being unemployed in Hammond. The median income was $\$ 4,142$ per family with 36 per cent of the families earning under $\$ 3,000$ annually and 11.7 earning 10,000 or more. 5 Each of these statistics is slightly more favorable for Hammond than for Pointe Coupee Parish.

\section{South Baton Rouge Neighborhood Area}

\section{Geographic Features}

The South Baton Rouge Neighborhood Area is comprised essentially of census tracts $21,22,24$ and 25 . It is bordered on the North by South Boulevard, on the South by Roosevelt and State Streets, on the West by the Mississippi River, and on the East by Dalrymple Drive. Access to and from the area on the West and East sides is somewhat

\footnotetext{
4"Economic Facts About Haimond," An unpublished report with aceograph copies on file in the office of the Hammond Chamber of Commerce.

${ }^{5} \mathrm{U} . \mathrm{S}$. Department of Commerce, op. cit., p. 111.
} 
limited by natural geographic formations. On the West lies the Mississippi River with a single bridge accessible to South Baton Rouge Neighborhood. This bridge does not accommodate pedestrian traffic. On the East lies a recreation area containing several lakes and a golf course transected by a single local road. As a result of these natural barriers most traffic tends to move in a North-South direction although it may first move in an East or West direction to reach one of four major North-South traffic arteries. In addition to these natural formations the area itself was recently transected by an interstate highway which has made it difficult to travel from one side of the area to the other except by using a limited number of routes. The area is served effectively by city bus transportation.

Baton Rouge, the city in which the neighborhood is located, is well served by transportation including ship, barge, rail, air, bus, and truck. Three major air lines serve the local airport. Nine major, regularly scheduled motor freight lines have terminals in the city, which is located on Interstate Highway 10. To the North of Baton Rouge, are 14,000 miles of commercially navigable water routes.

\section{Economy}

Although there is an absence of industry in the immediate area of the South Baton Rouge Neighborhood, the city in which the neighborhood is located is highly industrialized. From 1960 to 1970, the per capita income increased from $\$ 1,887$ to $\$ 2,907$ and the mean per family income increased from $\$ 6,788$ to $\$ 10,548$ in the city. ${ }^{6}$ Industrial

${ }^{6}$ Baton Rouge Area Chamber of Commerce, A Decade of Progress: Economic Resume, Baton Rouge, Loulsiana, Baton Rouge: Chamber of Commerce, 1971. 
production accounted for $\$ 173,857,671$ in wages and salaries in Baton Rouge in 1970. These wages and salaries were generated by 126 manufacturing firms. Prominent among these industries are petrochemical, alumina reduction, plastics, building supplies, and janitorial chemicals.

The city is served by the nation's seventh largest port. Imports through this port include: coffee, stee 1, automobiles, motorcycles, lead, plywood and fluorspar. Exports include: rice, flour, powdered milk, petroleum, soda ash, motor fuel additives, fertilizers, lumber, and scrap iron. 7

Several other factors exert an influence on the economy of the area. Among these are the presence of state government offices and Louisiana State University. A second university, Southern University, is located outside the incorporated limits of Baton Rouge, but the presence of this university probably also influences the area.

In $1960,18.2$ per cent of the work force in Baton Rouge were employed in manufacturing. This was much higher than either of the other two towns included in the survey. Unemployment, in 1960, stood at 6.1 per cent. The median family income was $\$ 5,789$ in that year with 22.1 per cent of the families earning less than $\$ 3,000$ and 18.3 per cent earning over $\$ 10,000$.

A comparison of the economic structure of the three areas can be made from the following table:

${ }^{7}$ Gulf States Utilities Company, Via Port of Baton Rouge, Gulf States Utilities Company, p. 2 . 
TABLE I

DISTRIBUTION OF LABOR FORCE AMONG OCCUPATIONAL CATEGORIES IN THE PARISHES OF EAST BATON ROUGE TANGIPAHOA AND POINTE COUPEE, $1968^{8}$

\begin{tabular}{|c|c|c|c|c|c|c|}
\hline \multirow{3}{*}{ Occupational Category } & \multicolumn{6}{|c|}{ Parishes } \\
\hline & \multirow{2}{*}{$\begin{array}{c}\text { East Baton } \\
\text { number }\end{array}$} & \multirow{2}{*}{$\begin{array}{l}\text { Rouge } \\
\text { rate }\end{array}$} & \multicolumn{2}{|c|}{ Tangipahoa } & \multirow{2}{*}{$\begin{array}{l}\text { Pointe } \\
\text { number }\end{array}$} & \multirow{2}{*}{$\begin{array}{r}\text { Coupee } \\
\text { rate }\end{array}$} \\
\hline & & & number & rate & & \\
\hline Agricultural sources & 247 & .3 & 138 & 1.6 & (D)* & -- \\
\hline Mining & 414 & & 78 & & 206 & \\
\hline oil and gas & 229 & & -- & & (D)* & \\
\hline Nonmetallic minerals & 185 & & 78 & & -- & \\
\hline Contract Construction & 19,036 & & 575 & & 166 & \\
\hline Manufacturing & 18,061 & 21.7 & 2,012 & 23.8 & 213 & 13.5 \\
\hline Food & 2,202 & & 576 & & -- & \\
\hline Lumber and wood & 325 & & 999 & & 128 & \\
\hline Printing and & & & & & & \\
\hline Publishing & 1,042 & & -- & & -- & \\
\hline Chemicals & 7,649 & & -- & & - & \\
\hline Petroleum & (D) & & -- & & -- & \\
\hline Stone, clay, glass & 810 & & 151 & & -- & \\
\hline Metals, primary & (D) & & -- & & - & \\
\hline Metals, fabrication & 1,330 & & -- & & -- & \\
\hline Machinery & 249 & & -- & & -- & \\
\hline Transportation & & & & & & \\
\hline equipment & 117 & & -- & & -- & \\
\hline Administrative & 217 & & -- & & -- & \\
\hline Transportation \& & & & & & & \\
\hline Utilities & 4,955 & & 270 & & (D)* & \\
\hline Wholesale sales & 5,610 & & 759 & & 104 & \\
\hline Retail sales & 14,981 & & 2,762 & & 480 & \\
\hline Finance, Insurance, R.E. & 5,384 & & 374 & & 99 & \\
\hline Services & 14,092 & & 1,407 & & 192 & \\
\hline Health Services & 3,217 & & 472 & & 44 & \\
\hline Unclassified & 284 & & 79 & & (D)* & \\
\hline TOTAL & 83,064 & & 8,444 & & 1,575 & \\
\hline
\end{tabular}

*Information withheld to respect confidentiality.

${ }^{8}$ U.S. Department of Commerce: Bureau of the Census, 1968 County Business Patterns, Louisiana, U.S. Government Printing office: Washington, D. C., 1969, pp. 31-34, 70-72, 59-60. 
These data suggest that by 1968 , the trend toward industrialization in Tangipahoa Parish had proceeded to the point that a larger portion of its work force was engaged in manufacturing than was true of East Baton Rouge Parish. This is somewhat misleading, however, as Tangipahoa Parish also has a higher percentage of its work force in agricultural services and in agriculture related manufacturing such as food processing and lumber and wood products. Baton Rouge, on the other hand, has larger proportions of its work force deployed in other industry related and urban related categories.

These data do not appear to be inconsistent with the initial intent to select three communities representing three relatively distinct stages in the urbanization--industrialization or, perhaps, the gemienschaft-gesellshaft continuum. One community is sma11, rural, isolated and agriculture oriented. The second community is somewhat larger with a significant agricultural past, but with an apparent ly increasing industrial awareness. The third community is clearly an established urban and industrial center.

\section{THE POPULATIONS}

It was also hoped that the sample would yield relatively larger proportions of three minority groups: Negroes in Baton Rouge, Italians in Hammond, and French in New Roads. This hope was only partially realized. As seen in Table II, the sample drawn in Baton Rouge did yield a large proportion of Negroes and the New Roads sample yielded a large proportion of French ethnic subjects, as expected. Although the sample drawn in Hammond did produce a larger proportion of persons with 
an Italian ethnic identity than did either of the other two samples, this ethnic group still accounted for only 1.4 per cent of the Hammond sample. This condition apparently resulted from the fact that the Italian population of Hammond tends to settle outside the city limits and thus is outside the sample area.

TABLE II

ETHNIC AND RACE DISTRIBUTION OF THE SAMPLE POPULATIONS

FOR SOUTH BATON ROUGE, HAMMOND, AND NEW ROADS, 1971

\begin{tabular}{|c|c|c|c|c|c|c|c|c|}
\hline \multirow{3}{*}{$\begin{array}{l}\text { Ethnic } \\
\text { Group } \\
\text { and Race } \\
\end{array}$} & \multicolumn{6}{|c|}{ SAMPLE POPULATIONS } & \multirow{2}{*}{\multicolumn{2}{|c|}{ OVERALL TOTAI }} \\
\hline & South Baton & Rouge & Ham & nond & & w Roads & & \\
\hline & Number $P$ & ercent & Number & Percent & Number & Percent & $t$ Number & Percent \\
\hline American & 43 & 4.9 & 161 & 21.9 & 82 & 15.0 & 286 & 13.3 \\
\hline French & 18 & 2.0 & 10 & 1.4 & 106 & 19.4 & 134 & 6.2 \\
\hline Italian & 9 & 1.0 & 10 & 1.4 & $-0-$ & 0.0 & 19 & .9 \\
\hline Negro & 792 & 89.5 & 547 & 74.3 & 352 & 64.4 & 1,691 & 78.4 \\
\hline German & 9 & 1.0 & 6 & 0.8 & $-0-$ & 0.0 & 15 & .7 \\
\hline other & 8 & 0.9 & 0 & 0.0 & 5 & 0.9 & 13 & .6 \\
\hline TOTAL & 879 & & 734 & & 545 & & 2,158 & 100.1 \\
\hline
\end{tabular}

The breakdown of the sample population by sex in Table III shows a higher proportion of females in all three sample populations. This characteristic is most pronounced in South Baton Rouge Neighborhood and least pronounced in Hammond. The sex ratio in New Roads approximates that of Hammond. 


\section{TABLE III}

A COMPARISON OF THE SEX RATIO OF THE SAMPLE POPULATIONS OF SOUTH BATON ROUGE, HAMMOND, AND NEW ROADS, 1971

\begin{tabular}{|c|c|c|c|c|c|c|c|c|}
\hline \multirow{3}{*}{ SEX } & \multicolumn{6}{|c|}{ SAMPLE POPULATIONS } & \multirow[b]{2}{*}{ OVERALL } & \multirow[b]{2}{*}{ TOTAL } \\
\hline & \multicolumn{2}{|c|}{ South Bat on Rouge } & \multicolumn{2}{|c|}{ Hammond } & \multicolumn{2}{|c|}{ New Roads } & & \\
\hline & Number & Percent & Number & Percent & Number & Percent & Number & Percent \\
\hline Ma le & 353 & 39.9 & 358 & 48.6 & 256 & 46.8 & 967 & 45.1 \\
\hline Fema le & 524 & 59.2 & 373 & 50.7 & 280 & 51.2 & 1,177 & 54.9 \\
\hline TOTAL & 877 & & 731 & & 536 & & 2,144 & 100.0 \\
\hline
\end{tabular}

The age distribution of the samples is shown in Table IV. Very nearly $50 \%$ of the total sample falls in the age range from $0-20$ years. The actual percentage falling in this range is 49.5. This distribution is very nearly the same in each community. In Baton Rouge 48.3 per cent of the population falls in this category while in Hammond 49.7 per cent falls into this category. The New Roads sample has the highest percentage falling in the 20 years and below range with 51.5 per cent. In the age range between 20 years and 65 years, which might be considered the range of maximum industrial employability, the difference in distribution is a little greater. South Baton Rouge and Hammond are very similar with 40.3 per cent of the South Baton Rouge sample falling in this range and 39.6 of the Hammond sample also falling into this range. Only 35.6 of the New Roads sample is within these limits. At the other extreme Hammond more closely resembles New Roads in that 8.7 per cent of the Hammond sample is 70 years or over and 8.6 per cent of 
the New Roads sample falls within this range. In the South Baton Rouge sample only 5.8 per cent of the sample is within this range. That portion of the Hammond sample falling from 70 and below has a mean of 23.2 , the lowest of the three communities. New Roads is next with a mean of 24.2 and South Baton Rouge is highest with a mean of 26.1.

TABLE IV

AGE DISTRIBUTION OF THE SAMPLE POPULATIONS FOR SOUTH

BATON ROUGE, HAMMOND, AND NEW ROADS, 1971

\begin{tabular}{|c|c|c|c|c|c|c|c|c|}
\hline \multirow{3}{*}{$\begin{array}{r}\text { AGE } \\
\text { IN } \\
\text { YEARS } \\
\end{array}$} & \multicolumn{6}{|c|}{ SAMPLE POPULATIONS } & \multirow{2}{*}{\multicolumn{2}{|c|}{ OVERALL TOTAL }} \\
\hline & \multicolumn{2}{|c|}{ South Baton Rouge } & \multicolumn{2}{|c|}{ Hammond } & \multicolumn{2}{|c|}{ New Roads } & & \\
\hline & Number & Percent & Number & Percent & Number & Percent & Number & Percent \\
\hline $0-5$ & 106 & 12.0 & 104 & 14.1 & 58 & 10.6 & 268 & 12.5 \\
\hline $5-10$ & 110 & 12.4 & 108 & 14.7 & 84 & 15.4 & 302 & 14.0 \\
\hline $10-15$ & 111 & 12.5 & 83 & 11.3 & 73 & 13.3 & 267 & 12.4 \\
\hline $15-20$ & 101 & 11.4 & 71 & 9.6 & 57 & 12.2 & 229 & 10.7 \\
\hline $20-25$ & 68 & 7.7 & 72 & 9.8 & 25 & 4.6 & 165 & 7.7 \\
\hline $25-30$ & 51 & 5.8 & 37 & 5.0 & 29 & 5.3 & 117 & 5.4 \\
\hline $30-35$ & 30 & 3.4 & 32 & 4.3 & 26 & 4.8 & 88 & 4.1 \\
\hline $35-40$ & 35 & 4.0 & 18 & 2.4 & 29 & 5.3 & 82 & 3.8 \\
\hline $40-45$ & 34 & 3.8 & 28 & 3.8 & 20 & 3.7 & 82 & 3.8 \\
\hline $45-50$ & 28 & 3.2 & 24 & 3.3 & 16 & 2.9 & 68 & 3.2 \\
\hline $50-55$ & 37 & 4.2 & 36 & 4.9 & 24 & 4.4 & 97 & 4.5 \\
\hline $55-60$ & 32 & 3.6 & 19 & 2.6 & 8 & 1.5 & 59 & 2.7 \\
\hline $60-65$ & 41 & 4.6 & 26 & 3.5 & 17 & 3.1 & 84 & 3.9 \\
\hline $65-70$ & 45 & 5.1 & 14 & 1.9 & 21 & 3.8 & 80 & 3.7 \\
\hline 70- & & & & & & & & \\
\hline over & 51 & 5.8 & 64 & 8.7 & 47 & 8.6 & 162 & 7.5 \\
\hline TOTAL & 880 & & 736 & & 534 & & 2,150 & 99.9 \\
\hline
\end{tabular}

There is not a great deal of difference in the types of dwe11ings occupied by the three sample populations. Table $V$ reveals that in each community there is a strong tendency for the indigent population to live in single family dwellings. This tendency is greatest in New 
Roads, only slightly less strong in Hammond and noticeably less strong in South Baton Rouge Neighborhood. This latter area tended to have the most persons living in dwelling types associated with transiency, including rooming houses and apartment houses. Only 1.1 per cent of the Hammond sample live in apartments while this type of dwelling is not represented in the New Roads sample.

TABLE V

DISTRIBUTION OF FAMILIES BY FUNCTIONAL DWELLING TYPE

IN THE SAMPLE POPULATIONS FOR SOUTH BATON

ROUGE, HAMMOND, AND NEW ROADS, 1971

\begin{tabular}{|c|c|c|c|c|c|c|c|c|}
\hline \multirow{3}{*}{$\begin{array}{l}\text { FUNCTIONAL } \\
\text { DWELLING } \\
\text { TYPE } \\
\end{array}$} & \multicolumn{6}{|c|}{ SAMPLE POPULATIONS } & \multirow{2}{*}{\multicolumn{2}{|c|}{ OVERALL TOTAL }} \\
\hline & \multicolumn{2}{|c|}{ South Baton Bouge } & \multicolumn{2}{|c|}{ Hammond } & \multicolumn{2}{|c|}{ New Roads } & & \\
\hline & Number & Percent & Number & Percent & Number & Percent & Number & Percent \\
\hline Single & & & & & & & & \\
\hline Family & 716 & 80.9 & 682 & 92.7 & 536 & 98.0 & 1,934 & 90.4 \\
\hline Duplex & 66 & 7.5 & 35 & 4.8 & 8 & 1.5 & 109 & 5.1 \\
\hline Rooming & & & & & & & & \\
\hline House & 5 & 0.6 & 1 & 0.1 & 1 & 0.2 & 7 & .3 \\
\hline Apartment & 82 & 9.3 & 8 & 1.1 & 0 & 0.0 & 90 & 4.2 \\
\hline Hote 1 & 0 & 0.0 & 0 & 0.0 & 0 & 0.0 & 0 & 0.0 \\
\hline TOTAL & 869 & & 726 & & 545 & & 2,140 & 100.0 \\
\hline
\end{tabular}

The three samples present differences in religious affiliation. Table VI shows that the Hammond sample contains the largest proportion of Protestants followed by South Baton Rouge Neighborhood. New Roads contains the largest proportion of Catholics, again followed by South Baton Rouge Neighborhood. The Hammond sample has the largest proportion 
of medically constricted religious groups, while the New Roads sample has no one in this category.

TABLE VI

DISTRIBUTION BY RELIGIOUS AFFILIATION OF THE SAMPLE

POPULATIONS FOR SOUTH BATON ROUGE, HAMMOND,

AND NEW ROADS, 1971

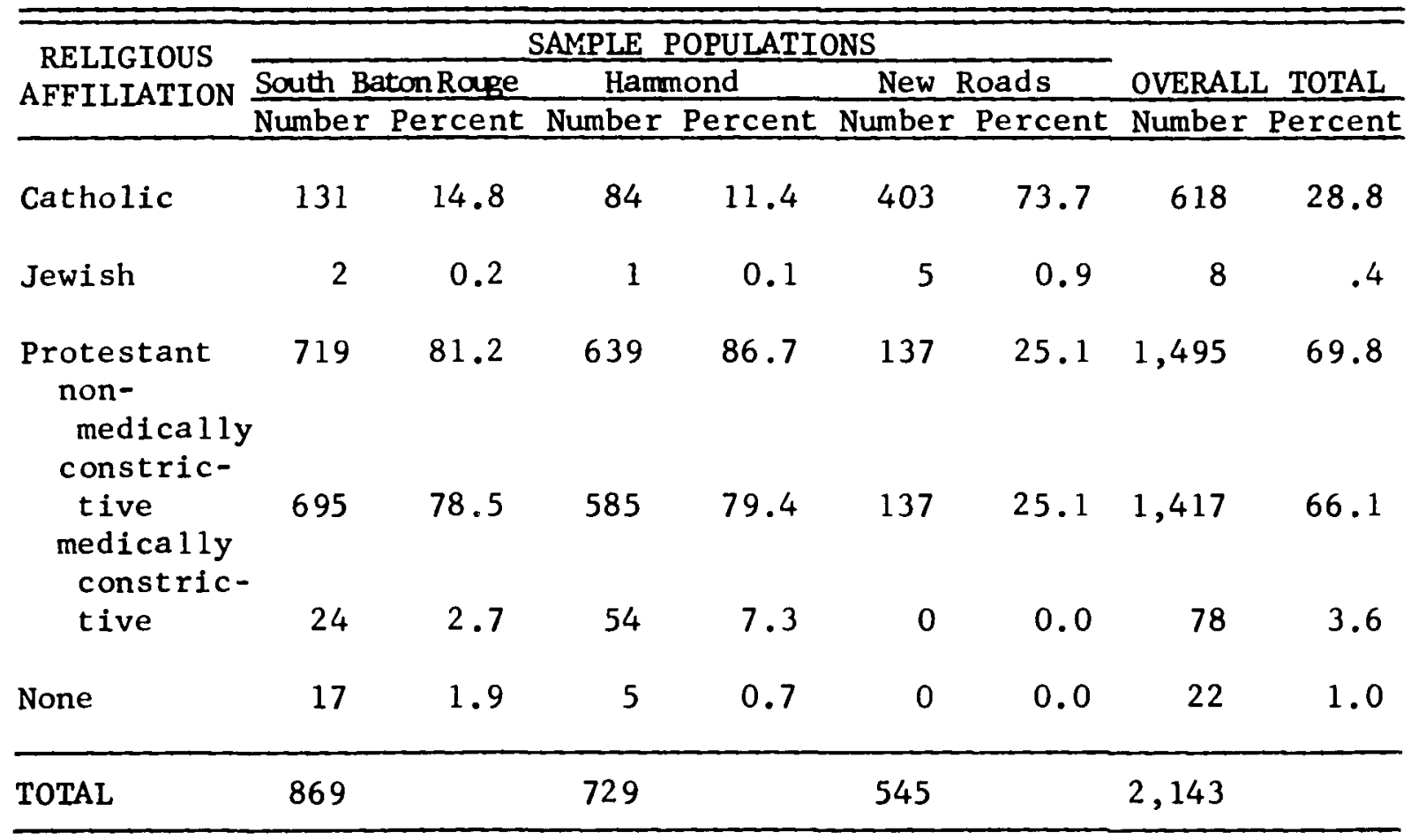

The income of the Hammond sample is lower than both the New Roads and South Baton Rouge Neighborhood samples. Of perhaps, most importance is the fact that 64.3 per cent of the Hammond sample have a family income of $\$ 4,000$ or less per year. In the New Roads sample 58.5 per cent of the families have an annual income within this range while 55.5 per cent of the families in the South Baton Rouge sample fall within these limits. Table VII shows the income distribution of the three samples. 
TABLE VII

INCOME DISTRIBUTIONS OF THE SAMPLE POPULATIONS FOR SOUTH BATON ROUGE, HAMMOND, AND NEW ROADS, 1971

\begin{tabular}{|c|c|c|c|c|c|c|c|c|}
\hline \multirow{3}{*}{$\begin{array}{l}\text { INCOME } \\
\text { CATEGORIES }\end{array}$} & \multicolumn{6}{|c|}{ SAMPLE POPULATIONS } & \multirow{2}{*}{\multicolumn{2}{|c|}{ OVERALL TOTAL }} \\
\hline & \multicolumn{2}{|c|}{ South Baton Rouge } & \multicolumn{2}{|c|}{ Hammond } & \multicolumn{2}{|c|}{ New Roads } & & \\
\hline & Number & Percent & Number & Percent & Number & Percent & Number & Percent \\
\hline$\$ 0-1,000$ & 57 & 6.4 & 38 & 5.2 & 15 & 2.7 & 110 & 5.2 \\
\hline $1,001-2,000$ & 136 & 15.4 & 187 & 25.4 & 118 & 21.6 & 441 & 20.9 \\
\hline $2,001-3,000$ & 170 & 19.2 & 172 & 23.4 & 145 & 26.5 & 487 & 23.1 \\
\hline $3,001-4,000$ & 128 & 14.5 & 76 & 10.3 & 42 & 7.7 & 246 & 11.7 \\
\hline $4,001-5,000$ & 118 & 13.3 & 58 & 7.9 & 39 & 7.1 & 215 & 10.2 \\
\hline $5,001-6,000$ & 46 & 5.2 & 75 & 10.2 & 23 & 4.2 & 144 & 6.8 \\
\hline $6,001-7,000$ & 38 & 4.3 & 35 & 4.8 & 22 & 4.0 & 95 & 4.5 \\
\hline $7,001-8,000$ & 68 & 7.7 & 42 & 5.7 & 21 & 3.8 & 131 & 6.2 \\
\hline 8,001 -over & 95 & 10.7 & 38 & 5.2 & 106 & 19.4 & 239 & 11.3 \\
\hline TOTAL & 856 & & 721 & & 531 & & 2,108 & 99.9 \\
\hline
\end{tabular}

$\underline{\text { Summary }}$

The three sample populations present rather distinctive characteristics. The Negro race predominates in all three, but is much more numerous in the South Baton Rouge Neighborhood and Hammond samples. New Roads offers the fewest number of types of ethnic identities. The female sex exceeds the male sex in all three communities. However, this quality is most pronounced in South Baton Rouge while the Hammond and New Roads samples closely resemble each other in this respect. In age distribution Hammond and South Baton Rouge tend to resemble each other more in the below 20 years and 20 to 65 years ranges, while Hammond and New Roads are more similar in the above 70 years range. There appears to be more similarity between the functional dwelling types of the Hammond and Baton Rouge samples as well as between the overall religious affiliations. 
CHAPTER IV

PERCEIVED MORBIDITY BY A PREDOMINENTLY

INDIGENT POPULATION

\section{Perceived Seriousness of Symptoms}

Since a survey approach was used to determine morbidity rates in this study, it must be considered a possibility that subjective feelings may influence the subjects' perception of themselves as having pathology. Pathological conditions that are manifested in symptoms which are considered not to be serious enough to require medical treatment may go untreated or even unnoticed while similar conditions, when existing with persons who interpret the manifested symptoms as serious, should result in the subjects' considering themselves sick. Thus, to some extent the difference in reaction to pathology may reflect a difference in sensitivity to symptoms. The extent to which this is true of groups or classes of people is important to health planning and offers a clearer understanding of perceived morbidity rates.

In the Resionville study, an effort was made to determine the extent to which members of different family income ranges considered various symptoms to be serious enough to require treatment by a medical doctor. ${ }^{1}$ With only one addition the list of symptoms used in the Regionville study was submitted to the subjects of the present study. The results are tabulated according to community, race and ethnic identity, income and religion. Table VIII presents this information by community.

${ }^{1}$ Earl L. Koos, The Health of Regionville, New York: Columbia University Press, 1954, p. 32 . 
TABLE VIII

EXTENT TO WHICH SELECTED SYMPTOMS ARE PERCEIVED AS SERIOUS ENOUGH TO REQUIRE TREATMENT BY A MEDICAL DOCTOR AMONG

A PREDOMINANTLY INDIGENT POPULATION OF SOUTH BATON ROUGE, HAMMOND, AND NEW ROADS, 1971

\begin{tabular}{|c|c|c|c|c|c|c|c|c|}
\hline \multirow{4}{*}{ SYMPTOM } & \multicolumn{8}{|c|}{ COMMUNITIES } \\
\hline & \multicolumn{2}{|c|}{ South } & \multirow{2}{*}{\multicolumn{2}{|c|}{$\begin{array}{l}\text { Hammond } \\
\mathrm{N}=231\end{array}$}} & \multirow{2}{*}{\multicolumn{2}{|c|}{$\begin{array}{r}\text { New Roads } \\
N=159\end{array}$}} & \multirow{2}{*}{\multicolumn{2}{|c|}{ Tota 1}} \\
\hline & $\begin{array}{l}\text { Baton } \\
\mathrm{N}=301\end{array}$ & Rouge & & & & & & \\
\hline & $\mathrm{N}$ & $\%$ & $\mathrm{~N}$ & $\%$ & $\mathrm{~N}$ & $\%$ & $\mathbf{N}$ & $\%$ \\
\hline Loss of appetite & 147 & 48.8 & 155 & 69.1 & 87 & 54.7 & 389 & 56.2 \\
\hline $\begin{array}{c}\text { Persistent } \\
\text { Backache } \\
\end{array}$ & 218 & 72.4 & 200 & 86.6 & 116 & 78.0 & 534 & 77.2 \\
\hline $\begin{array}{l}\text { Continued } \\
\text { Coughing } \\
\end{array}$ & 225 & 74.8 & 208 & 90.0 & 113 & 71.1 & 546 & 79.0 \\
\hline $\begin{array}{r}\text { Persistent Joint } \\
\text { \& Muscle Pains }\end{array}$ & 199 & 66.1 & 180 & 77.9 & 97 & 61.0 & 476 & 68.8 \\
\hline Bloody Stool & 259 & 86.1 & 220 & 95.2 & 138 & 86.8 & 617 & 89.2 \\
\hline Bloody Urine & 261 & 86.7 & 222 & 96.1 & 135 & 84.9 & 618 & 89.4 \\
\hline $\begin{array}{l}\text { Excessive Vagi- } \\
\text { nal Bleeding }\end{array}$ & 229 & 76.1 & 213 & 92.2 & 120 & 75.5 & 562 & 81.3 \\
\hline Swelling of & & & & & & & & \\
\hline Ankles & 192 & 63.8 & 185 & 80.1 & 107 & 67.3 & 484 & 70.0 \\
\hline Loss of Weight & 178 & 59.1 & 170 & 73.6 & 98 & 61.6 & 446 & 64.5 \\
\hline Bleeding Gums & 207 & 68.7 & 189 & 81.8 & 116 & 73.0 & 512 & 74.0 \\
\hline Chronic Fatigue & 195 & 61.5 & 185 & 80.1 & 102 & 64.2 & 482 & 69.7 \\
\hline $\begin{array}{l}\begin{array}{c}\text { Shortness of } \\
\text { Breath }\end{array} \\
\end{array}$ & 234 & 77.8 & 212 & 91.8 & 133 & 83.7 & 579 & 83.7 \\
\hline $\begin{array}{l}\text { Persistent } \\
\text { Headaches }\end{array}$ & 230 & 76.4 & 210 & 90.9 & 116 & 73.0 & 556 & 80.4 \\
\hline Fainting Spe 11s & 236 & 78.4 & 215 & 93.1 & 126 & 79.3 & 577 & 83.5 \\
\hline Pain in Chest & 239 & 79.4 & 215 & 93.1 & 136 & 85.5 & 590 & 85.3 \\
\hline Lump in Breast & 253 & 64.1 & 221 & 95.7 & 140 & 88.1 & 614 & 88.8 \\
\hline Lump in Abdomen & 242 & 60.5 & 216 & 93.5 & 130 & 81.8 & 588 & 85.0 \\
\hline Fever & 207 & 68.8 & 190 & 82.3 & 110 & 69.2 & 507 & 73.3 \\
\hline $\begin{array}{l}\text { Persistent } \\
\text { Stomach Cramps }\end{array}$ & 236 & 78.4 & 204 & 88.3 & 116 & 73.0 & 556 & 80.4 \\
\hline TOTAL & 4,187 & $1,390.0$ & 3,810 & & 2,236 & $1,406.3$ & 0,233 &, 480.8 \\
\hline
\end{tabular}


This table reveals very little difference in the perception of symptoms as serious enough to require treatment by a medical doctor among the three communities. Loss of appetite is considered serious by the least number of people in all three communities while bloody stool is considered serious by the largest number of subjects in both South Baton Rouge and Hammond and by the second to largest number in New Roads. The rate of perception of symptoms as important is greatest in Hammond at 16.45 symptoms per person, lowest for Baton Rouge at 13.90 symptoms per person and is 14.06 per person in New Roads.

It is reasonable to expect a relationship between religious affiliation and symptom sensitivity. Religion and medicine were virtually inseparable through many centuries of man's history with some physicians actually being deified. With such a close relationship existing in the past it might be expected that the residual influence of these disciplines on each other would continue to be great. of the religions found to exist among the subjects in this study it was found, in fact, that such an influence does exist. of these religions, all were found to have clear statements on their relationship to illness and medical care contained within their doctrine.

The extent to which religion exerts an influence on health care varies greatly and affects the perception of disease, permissible diet, permissible treatment, and physician-patient relationship. Since the perception of illness might be expected, in turn, to affect the perception of symptoms, it may be worthwhile to explore, very briefly, the positions of the several religions encountered in this study on the nature of disease. 
These religions include: Catholic, Baptist, Methodist, Church of the Latter Day Saints, Christian Scientist, Seventh Day Adventist, and several Pentecostal sects. Of these religions, the Catholic apparent ly has the most benign perception of disease. According to its doctrine, man is subject to disease and death because the "gift of immortality," given to Adam upon his creation was lost as part of the punishment for his disobedience. Illnesses are considered to be trials sent by God but not necessarily punishment. 2

of the protestant churches encountered in the study, the Baptist and Methodist also assume a benign position on 11 lness feeling that it is neither punishment nor unreal. Originally, the leaders of the Church of Latter-Day Saints taught that disease resulted from defilement of the person. Today, however, the attitude of the members of this church is that sickness is real, sometimes inevitable or unavoidable, but to be cured or endured according to God's will. The members of another church of American origin, Jehovah's Witness, believe that all sickness resulted from the original violation of God's law concerning physical well-being, but sickness also has normal causes such as inherited constitutional liability factors. The Seventh-Day Adventist is an ultraconservative denomination of the Protestant Church. According to their doctrine, pain, sickness, and death are the transgressions of our first parents. Similarly specific diseases may be vested upon a sinner because of his sins. Members do not believe all disease results from such

2 Patrick 0'Brien, Mora1 Problems in Hospital Practice, St. Louis: B. Herder Book Co., 1956, P. 111 . 
a cause, however. ${ }^{3}$ There is some variation among the subscribers to Pentecostal religions ranging from the more moderate Holiness Church to the more conservative Church of God and Holy Roller sect. All, however, feel that disease resulted from the original sin and its presence, to a greater or lesser extent, reflects a lack of faith. ${ }^{4}$ The final religion represented in this study, Christian Science, whose followers deny the existence of disease as a real condition. Instead, it is felt to be a manifestation of internal feelings. 5

In view of this relationship between religion and 11 lness, it appears potentially productive to explore the possible influence of religion on symptom sensitivity. For the purposes of this study the protestant religions were divided into two categories, non-medically constricted and medically constricted. Since all religions take some doctrinal position on illness and medical care, the distinction made between these two groups is relative rather than absolute. Essentially, the basis for the classification is the extent to which the religion embraces generally accepted medical procedures. Those that reject even a single such procedure are considered to be medically constricted. Those that allow the medical profession to make this determination are considered to be non-medically constricted. Mormans, Jehovah's Witnesses, Pentecostal Churches, and Christian Scientists are included in

${ }^{3}$ Richard T. Barton, Religious Doctrine and Medical Practice, Springfield: Charles C. Thomas, 1958, Pp. 64, 71, 74, and 77.

${ }^{4} \mathrm{H}$. Black, The Pentecostal Movement, New York: Humanities Press, 1964, P. 149 .

${ }^{5}$ Barton, op. cit., p. 83 . 
the first category. Baptists and Methodists comprise the second category.

The most difficult decision was encountered in the classification of Jehovah's Witnesses. Although the formal doctrine of this church permits its members to decide individually on the type of medical treatment they may seek, there is a strong feeling against blood transfusion. Because this position is defended so strongly by the members of the church, it was classified among the medically constrictive.

The data pertaining to the relationship between religious affiliation and the perception of symptoms as being serious enough to require treatment by a medical doctor are presented in Table IX. A rather marked difference is found among these data. Among the Jews and the Medically Constricted Protestants, there is a somewhat greater overall tendency to view the enumerated symptoms as indicating the need for treatment by a medical doctor. All religious groups tend to view loss of appetite as the least serious symptom. A lower percentage of Jews and Medically Constricted Protestants consider persistent backache as serious enough to require medical treatment than do Catholics or non-Medically Constricted Protestants. This is also true of swelling ankles, bleeding gums, bloody stool, and bloody urine with the medically constricted Protestants also responding at a higher rate to the latter symptom. The Jews are unique in having a higher rate of response to fever and persistent stomach cramps as being serious enough to require treatment. 
TABLE IX

DIFFERENCE IN PERCEPTION OF SELECTED SYMPTOMS AS SERIOUS ENOUGH TO REQUIRE TREATMENT BY A MEDICAL DOCTOR IN A PREDOMINANTLY INDIGENT POPULATION OF SOUTH BATON ROUGE, HAMMOND, AND NEW ROADS, SHOWN BY RELIGIOUS AFFILIATION, 1971

\begin{tabular}{|c|c|c|c|c|c|c|c|c|}
\hline \multirow{3}{*}{ SYMPTOM } & \multicolumn{8}{|c|}{ RELIGIOUS AFFILIATION } \\
\hline & Catholic & Jewish & \multicolumn{2}{|c|}{ Protestant } & \multirow[b]{2}{*}{ Tota $\frac{1}{\%}$} & None & Other & \multirow{2}{*}{$\begin{array}{r}\text { Grand } \\
\text { Tota } 1 \\
\%\end{array}$} \\
\hline & & $\mathrm{N}=3$ & $\%$ Constrict & $\begin{array}{l}\text { Constricted } \\
\mathrm{N}=27\end{array}$ & & $\mathrm{~N}=8$ & $\mathrm{~N}=2 \%$ & \\
\hline Loss of Appetite & 57.9 & 6.7 & $2 \quad 57.1$ & 77.7 & 58.2 & 25.0 & 50.0 & 36.4 \\
\hline Persistent Backache & 69.5 & 6.7 & 80.1 & 85.1 & 80.4 & 50.0 & 100.0 & 77.1 \\
\hline Continued Coughing & 67.3 & 100.0 & 81.8 & 96.2 & 82.6 & 87.5 & 50.0 & 78.5 \\
\hline Persistent Joint \& Muscle Pains & 60.9 & 100.0 & 71.5 & 77.7 & 71.8 & 50.0 & 50.0 & 68.7 \\
\hline Bloody Stool & 82.8 & 100.0 & 90.7 & 100.0 & 91.2 & 87.5 & 50.0 & 88.8 \\
\hline Bloody Urine & 82.3 & 100.0 & 91.1 & 100.0 & 91.6 & 87.5 & 50.0 & 89.0 \\
\hline Excessive Vaginal Bleeding & 74.3 & 100.0 & 82.9 & 100.0 & 83.9 & 62.5 & 50.0 & 94.7 \\
\hline Swe11ing of Ankles & 61.4 & 6.7 & 73.2 & 85.1 & 73.9 & 25.0 & 0.0 & 69.7 \\
\hline Loss of Weight & 56.6 & 6.7 & 66.5 & 88.8 & 67.8 & 25.0 & 50.0 & 64.2 \\
\hline Bleeding Gums & 68.4 & 6.7 & 75.6 & 92.5 & 76.5 & 75.0 & 0.0 & 74.0 \\
\hline Chronic Fatigue & 62.5 & 100.0 & 71.5 & 96.2 & 72.9 & 37.5 & 0.0 & 69.6 \\
\hline Shortness of Breath & 76.4 & 100.0 & 85.1 & 96.2 & 85.7 & 87.5 & 100.0 & 83.3 \\
\hline Persistent Headaches & 69.5 & 100.0 & 84.2 & 92.5 & 84.7 & 62.5 & 0.0 & 80.1 \\
\hline Fainting Spe11s & 75.9 & 100.0 & 85.3 & 92.5 & 85.7 & 87.5 & 50.0 & 83.0 \\
\hline Pain in Chest & 80.2 & 100.0 & 85.9 & 96.2 & 86.5 & 87.5 & 100.0 & 84.9 \\
\hline Lump in Breast & 83.9 & 100.0 & 89.6 & 100.0 & 90.2 & 75.0 & 100.0 & 88.4 \\
\hline Lump in Abdomen & 77.5 & 100.0 & 86.8 & 100.0 & 87.5 & 75.0 & 50.0 & 84.6 \\
\hline Fever & 64.7 & 100.0 & 75.6 & 92.5 & 76.5 & 62.5 & 0.0 & 73.0 \\
\hline Persistent Stomach Cramps & 72.1 & 100.0 & 82.3 & 92.5 & 82.8 & 87.5 & 50.0 & 80.0 \\
\hline TOTAL & $1,340.1$ & $1,833.3$ & $1,517.8$ & $1,762.9$ & $1,531.3$ & $1,237.5$ & 225.0 & $1,475.6$ \\
\hline
\end{tabular}


In exploring the relationship between level of family income and perceived importance of symptoms an unexpected quality is found. The literature suggests that members of the lowest income range tend to assign less importance to symptoms overall. In the Regionville Study mentioned earlier the subjects were divided into three income classes with ranges of: $\$ 3,000-\$ 11,000 ; \$ 1,800-\$ 4,200$; and $\$ 700-\$ 2,000$. The members of the lowest income range tended to assign less importance to symptoms overa 11 and to grossly undervalue symptoms such as chronic fatigue, bleeding gums, loss of weight, persistent joint and muscle pain, and shortness of breath. 6

The data presented in Table $X$ reveal that in the sample population surveyed for this study a somewhat different relationship obtains. The highest rate of perception of symptoms as serious enough to require medical care is found in the highest income group. However, the second highest rate occurs in the lowest income range. In fact, the percentage of such responses for the four lowest classes combined exceed that for the four highest income classes combined. The percentage of responses of the lowest class to the symptom of chronic fatigue was higher than that of al1 but two other income groups. There is, however, a great deal of similarity in the relative importance assigned to each symptom as evidenced by the percentage of responses of each income group. Although there has long been a recognition of the subjectivity and variability of patients' description of their symptoms, there has

\footnotetext{
${ }^{6}$ Koos, op. cit.
} 
TABLE X

INCOME DIFFERENTIAL AND THE PERCEPTION OF SELECTED SYMPTOMS AS SERIOUS ENOUGH

TO REQUIRE TREATMENT BY A MEDICAL DOCTOR IN A PREDOMINENTLY INDIGENT POPULATION OF SOUTH BATON ROUGE, HAMMOND, AND NEW ROADS, 1971

\begin{tabular}{|c|c|c|c|c|c|c|c|c|c|c|}
\hline \multirow{3}{*}{ SYMPTOM } & \multicolumn{10}{|c|}{ INCOME RANGE } \\
\hline & $\begin{array}{l}0- \\
1,000 \\
\end{array}$ & $\begin{array}{r}, 001- \\
2,000 \\
\end{array}$ & $\begin{array}{r}, 001- \\
3,000 \\
\end{array}$ & $\begin{array}{r}3,001- \\
4,000 \\
\end{array}$ & $\begin{array}{r}4,001- \\
5,000\end{array}$ & $\begin{array}{r}5,001- \\
6,000 \\
\end{array}$ & $\begin{array}{r}6,001- \\
7,000 \\
\end{array}$ & $\begin{array}{r}7,001- \\
8,000 \\
\end{array}$ & $\begin{array}{l}\text { over } \\
\quad 8,000 \\
\end{array}$ & TOTAL \\
\hline & $N=54$ & $\mathrm{~N}=181$ & $N=144$ & $\mathrm{~N}=75$ & $\mathrm{~N}=53$ & $\mathrm{~N}=35$ & $\mathrm{~N}=33$ & $\mathrm{~N}=48$ & $\mathrm{~N}=61$ & \\
\hline Loss of Appetite & 70.3 & 48.6 & 59.0 & 62.6 & 47.1 & 57.1 & 36.3 & 50.0 & 72.1 & 55.9 \\
\hline Persistent Backache & 87.0 & 69.0 & 78.4 & 76.0 & 71.6 & 85.7 & 66.6 & 72.9 & 88.5 & 76.1 \\
\hline Cont inued Coughing & 90.7 & 75.1 & 75.0 & 82.6 & 81.1 & 82.8 & 63.6 & 66.6 & 86.8 & 77.9 \\
\hline Bloody Urine & 92.5 & 83.4 & 94.4 & 98.0 & 90.5 & 94.2 & 69.6 & 79.1 & 90.1 & 88.3 \\
\hline Excess. Vag. Bleeding & 79.6 & 74.0 & 84.0 & 88.0 & 79.2 & 91.4 & 66.6 & 68.7 & 91.8 & 80.2 \\
\hline Swe lling of Ankles & 72.2 & 70.7 & 68.7 & 74.6 & 56.6 & 68.5 & 51.5 & 68.7 & 81.9 & 69.2 \\
\hline Loss of Weight & 66.6 & 55.8 & 63.1 & 76.0 & 56.6 & 71.4 & 51.5 & 58.3 & 80.3 & 63.4 \\
\hline Bleeding Gums & 72.2 & 67.9 & 77.0 & 82.6 & 71.6 & 82.8 & 54.5 & 66.6 & 78.6 & 73.0 \\
\hline Chronic Fatigue & 74.0 & 64.0 & 70.1 & 72.0 & 67.9 & 77.1 & 57.5 & 66.6 & 77.0 & 69.0 \\
\hline Lump in Breast & 92.5 & 86.7 & 91.6 & 88.0 & 88.6 & 94.2 & 66.6 & 75.0 & 93.4 & 87.7 \\
\hline Lump in Abdomen & 92.5 & 79.5 & 88.8 & 86.0 & 84.9 & 88.5 & 63.6 & 70.8 & 91.8 & 83.9 \\
\hline Fever & 81.4 & 66.8 & 76.3 & 74.6 & 66.0 & 80.0 & 60.6 & 62.5 & 83.6 & 72.3 \\
\hline Persistent Stomach Cramps & 90.7 & 72.9 & 84.0 & 74.6 & 84.9 & 91.4 & 63.6 & 62.5 & 91.8 & 79.2 \\
\hline TOTAL & $1,594.4$ &, 376.2 & $1,520.1$ &, 533.3 & $1,411.3$ & $1,594.2$ & $1,151.5$ & $1,287.5$ & $1,640.9$ &, 461.4 \\
\hline
\end{tabular}


been little attention directed to the fact that this discrepancy in reporting may be influenced by systematic social factors such as race and ethnicity. It is possible that the patient is inclined to emphasize those symptoms which they consider important and to de-emphasize, perhaps, to the point of omitting, those symptoms which they deem to be unimportant. Zola reports different ethnic perceptions of essentially identical illnesses among groups of Irish and Italians. He felt this difference to be striking in view of the absence of know $n$ physiological difference between the ethnic groups. 7

In Table XI, we see the difference in the perception of importance of relatively common symptoms among the various racial and ethnic groups included in this study. These data suggest that the Negro race tends to react at a lower overall rate to the enumerated symptoms than does the white race. There is a rather wide variation in the overall responses among the various ethnic groups of the white race. The Germans tend to respond at a lower rate to the symptoms overall. However, with only four subjects of this ethnic group included in the sample, it is impossible to make generalizations. The French also tend to respond at a lower rate to the symptoms overall while the Italians and Americans tend to respond at higher rates. The Italian ethnic group is the only class examined in which the highest proportion of members rate loss of appetite as a symptom serious enough to require treatment by a medical doctor. Other than this there appears to be little striking difference.

7 Irving K. Zola, "Culture and Symptoms - An Analysis of Patients" Presenting Complaints," American Sociological Review, XXXI (October, 1966), 615-30. 
TABLE XI

ETHNIC DIFFERENTIAL IN THE PERCEPTION OF SELECTED SYMPTOMS AS SERIOUS ENOUGH

TO REQUIRE TREATMENT BY A MEDICAL DOCTOR IN A PREDOMINENTLY INDIGENT POPULATION OF SOUTH BATON ROUGE, HAMMOND, AND NEW ROADS, 1971

\begin{tabular}{|c|c|c|c|c|c|c|c|c|}
\hline \multirow{3}{*}{ SYMPTOM } & \multicolumn{8}{|c|}{ RACE AND ETHNIC IDENTITY } \\
\hline & $N=507$ & $(\mathrm{~N}=52)$ & $(\mathrm{N}=12)$ & $(\mathrm{N}=108)$ & $(\mathrm{N}=4)$ & $(\mathrm{N}=8)$ & $\mathrm{N}=184$ & $(N=691)$ \\
\hline & NEGRO & FRENCH & ITALIAN & AMERICAN & GERMAN & OTHER & TOTAL & $\begin{array}{l}\text { GRAND } \\
\text { TOTAL }\end{array}$ \\
\hline Loss of Appetite & 58.1 & 42.3 & 75.0 & 54.6 & 25.0 & 37.5 & 51.0 & 56.2 \\
\hline Persistent Backache & 78.1 & 65.3 & 58.3 & 83.3 & 75.0 & 37.5 & 74.4 & 77.1 \\
\hline Continued Coughing & 80.0 & 55.7 & 66.7 & 87.0 & 75.0 & 62.5 & 75.5 & 78.8 \\
\hline Bloody Urine & 90.7 & 73.0 & 75.0 & 91.6 & 75.0 & 100.0 & 85.3 & $\overline{89.2}$ \\
\hline Excess. Vaginal Bleeding & 82.0 & 71.1 & 58.3 & 86.1 & 75.0 & 62.5 & 78.8 & 81.1 \\
\hline Swelling of the Ankles & 72.7 & 53.8 & 58.3 & 67.5 & 25.0 & 62.5 & 61.9 & 69.8 \\
\hline Loss of Weight & 66.7 & 48.0 & 50.0 & 62.9 & 25.0 & 87.5 & 58.1 & 64.3 \\
\hline Bleeding Gums & 75.9 & 55.7 & 58.3 & 75.9 & 75.0 & 62.5 & 68.4 & 73.9 \\
\hline Chronic Fatigue & 69.4 & 59.6 & 66.7 & 75.0 & 75.0 & 75.0 & 70.1 & 69.6 \\
\hline Lump in Breast & 89.9 & 75.0 & 66.7 & 90.7 & 100.0 & 100.0 & 85.3 & 88.7 \\
\hline Lump in Abdomen & 86.5 & 67.3 & 58.3 & 87.0 & 100.0 & 100.0 & 80.4 & 84.9 \\
\hline Fever & 74.9 & 53.8 & 66.7 & 75.9 & 25.0 & 87.5 & 68.4 & 73.2 \\
\hline Persistent Stomach Cramps & 81.0 & 61.5 & 66.7 & 86.1 & 100.0 & 87.5 & 78.2 & 80.3 \\
\hline TOTAL & $1,506.5$ & $1,163.4$ & $1,208.3$ & $1,541.6$ & $1,175.0$ & $1,437.5$ & $1,400.5$ & $1,478.2$ \\
\hline
\end{tabular}




\section{Morbidity}

Although, perhaps not to the extent expected, it is established by these data that there does exist in the sample examined, a variation in the degree to which members of various groups perceive symptoms as serious enough to require treatment by a medical doctor. Apparently, then, something other than the physical presence of the symptom influences an individual's awareness of pathological conditions. Thus, groups tending to inflate the seriousness of symptoms may tend to over report pathology while those tending to minimize symptoms may tend to under report pathology. It is with this reservation that the data on morbidity should be examined.

These data were obtained by asking the subjects to respond to an inventory of pathological conditions. A copy of this inventory is found in Appendix B. For the purpose of analysis, these conditions were collapsed into the fourteen categories found in the following tables.

\section{Anomie and Perceived Morbidity}

The system model selected for this study assumes an interpenetration of system levels at the level of the social system. That is to say that a social system is simultaneously influenced by the organismic systems of its members, the personality system of its members, the social system that arises once a consensus is established and endures as long as the functional imperatives are continuously resolved, and the cultural system which arises as desired or ideal norms are defined and recorded or introjected. 
If such an interpenetration of system levels does, indeed, exist, influences existing at one system level might be expected to be accompanied by corollaries at other system levels. Pathology might be viewed as a disruption of the integrated functioning of the organismic system. If this is the case and if interpenetration of system levels occurs then it is possible that analogous disintegration may exist at higher system levels. Although the precise nature of this analogous disintegration cannot be known, it is possible that anomie is a manifestation of it.

Although anomie is not a difficult concept to recognize it has been defined in various ways and has proven to be an elusive concept to operationalize. In this study anomie at the personality system level, is considered to be reflected by positive responses to items on the Srole Scale. 8 A review of the items on this scale suggests that it probably is more appropriate to MacIver's conceptualization of anomie than to Durkheim's. As mentioned in Chapter II, MacIver views anomie as "the breakdown of the individual's sense of attachment to society." 9 To determine the subjects' level of anomie they were asked to respond to the six items of the Srole Scale. A score of one was given for each positive response. A score of 0 , then, represents an absence of anomie while a score of 6 represents maximum anomie.

${ }^{8}$ Leo Srole, "Social Integration and Certain Corollaries: An Exploratory Study," American Sociological Review, XXI (December, 1956), 709-16.

${ }^{9}$ Robert M. MacIver, The Ramparts We Guard, New York: The Macmillan Company, 1950, pp. 84-92. 
To explore the relationship between anomie and morbidity the relationship between anomie scores and morbidity rates was determined. However, since this provides insights only into the relationship between morbidity and "psychological" anomie, there remains a need to examine the relationship between "structural" anomie. This is done by selecting those social conditions, such as incomplete family structure, geographic instability and marginal position in the family, which can intuitively be considered to be characterized by a lack of clarity of norms or a feeling of alienation. Table XII presents data on the rate of perceived morbidity as it relates to the level of anomie.

The literature indicates the possibility of a relationship between morbidity and anomie. In one study, Thorton found that among a sample of sick or disabled people, a significant number manifested higher than expected feelings of loneliness, resentment, tedium, restlessness, anxiety and depression. 10 Although these feelings cannot be considered identical to anomie, they do seem to be related to the psychological manifestation of this condition. Further, they establish the fact that there can be a relationship between emotions and physical health.

The data in Table XII do indicate a positive relationship between level of anomie and overall pathology rate. The Product-Moment Coefficient of Correlation yielded a value of +.84 . This relationship is equally clear between cardiovascular diseases and anomie and arthritis and anomie.

10 Janet Thorton, The Social Component in Medical Care, New York: Morningside Heights: Columbia University Press, 1937, pp. 188-93. 
TABLE XII

RATES OF PERCEIVED MORBIDITY FOR SELECTED DISEASE CATEGORIES SHOWN BY LEVELS

OF ANOMIE IN A PREDOMINENTLY INDIGENT POPULATION OF SOUTH BATON ROUGE, HAMMOND, AND NEW ROADS, 1971

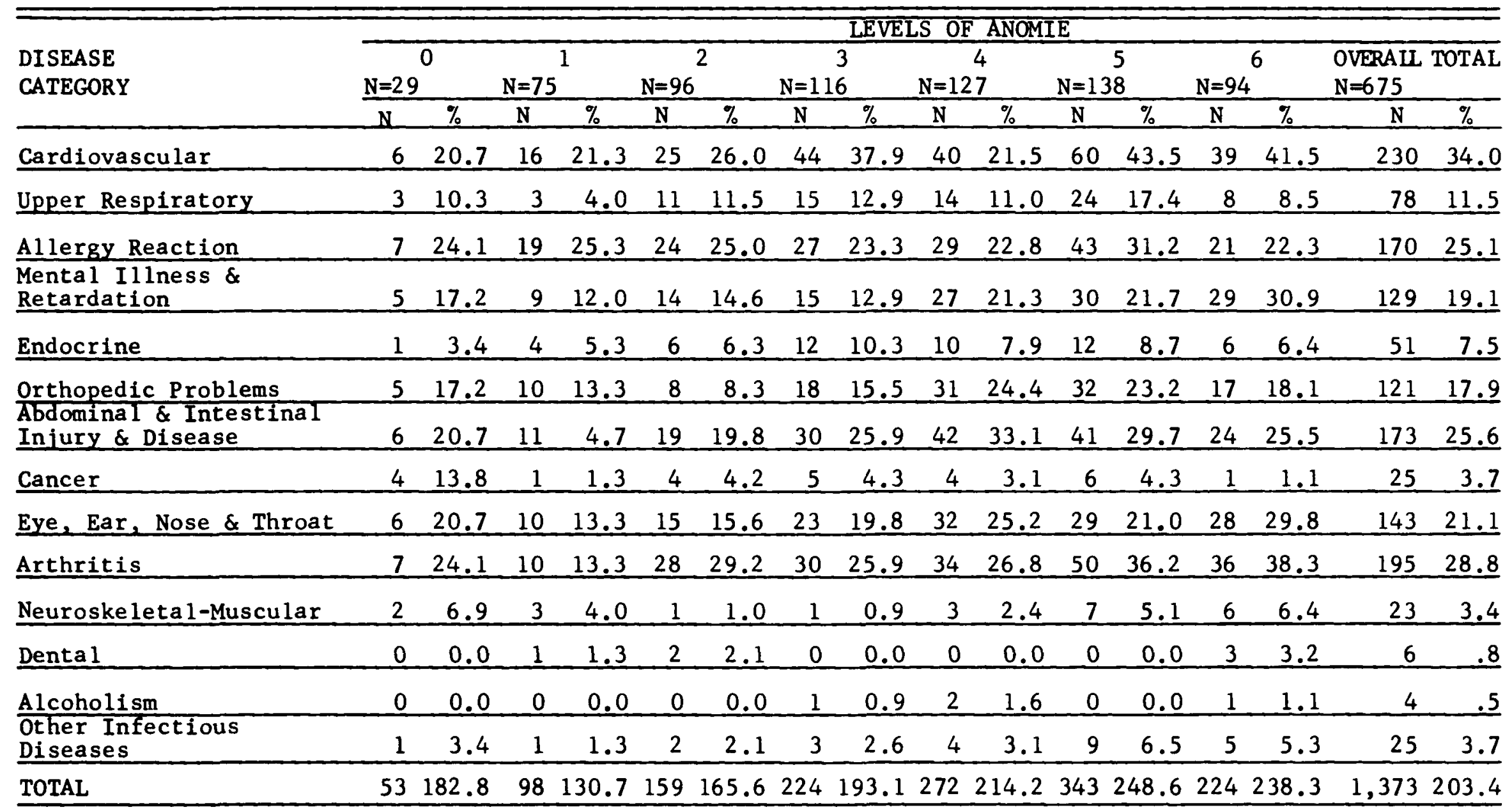


Having established that a positive correlation does indeed exist between perceived morbidity and anomie attention is next directed to those types of social conditions that might be associated with anomie. Since some sociologists interpret anomie as a feeling of isolation, alienation, or lack of belonging, it would seem that persons living a nomadic life characterized by frequent moving might be expected to experience a high level of anomie. In fact, even those families who move infrequently might be expected to experience an alienation immediately following such moves.

The literature is not entirely clear on this point. The study by Graham, mentioned earlier, brought out that it was not first generation immigrants, but subsequent generations who experienced increased morbidity. 11 studies of tuberculosis, on the other hand, bring out the fact that many of the victims of this disease are characterized by geographic instability and a poverty of human associations. 12

To explore this area the subjects were asked how many times they had moved during the past 3 years. These data were then compared to perceived morbidity rates. This relation is shown in Table XIII. The population proved to be very stable with only 4 people having moved over five times. Overall there appears to be no relationship between the number of times that a family moved and the rate of perceived

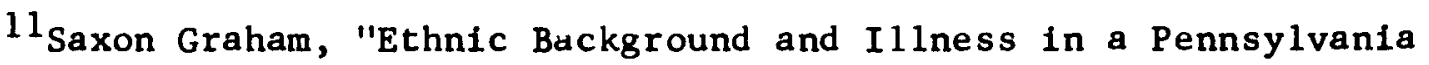
County," Socia1 Problems, IV (July, 1956), 79.

${ }^{12}$ Norman G. Hawkins, Medical Sociology, Springfield: Charles C. Thomas, 1958, p. 93. 
TABLE XIII

RATES OF PERCEIVED MORBIDITY FOR SELECTED DISEASE CATEGORIES AS SHOWN BY GEOGRAPHIC STABILITY OF FAMILIES IN A PREDOMINENTLY INDIGENT POPULATION OF SOUTH BATON ROUGE, HAMMOND, AND NEW ROADS, 1971

\begin{tabular}{|c|c|c|c|c|c|c|c|c|c|c|}
\hline \multirow{3}{*}{$\begin{array}{l}\text { DISEASE } \\
\text { CATEGORY }\end{array}$} & \multicolumn{10}{|c|}{ GEOGRAPHIC STABILITY OF FAMILIES } \\
\hline & \multicolumn{2}{|c|}{$\begin{array}{l}\bar{N}=600 \\
1 . \text { NO MOVES }\end{array}$} & \multicolumn{2}{|c|}{$\begin{array}{l}\mathrm{N}=126 \\
\text { 2. ONE OR } \\
\text { MOVES }\end{array}$} & \multicolumn{2}{|c|}{$\begin{array}{l}\mathrm{N}=36 \\
\text { 3. THREE TO } \\
\text { FIVE MOVES }\end{array}$} & \multicolumn{2}{|c|}{$\begin{array}{l}\text { N=4 } \\
\text { OVER FIVE } \\
\text { MOVES }\end{array}$} & $\mathrm{N}=766$ & OVERALL TOTAL \\
\hline & $\mathrm{N}$ & $\%$ & $\mathrm{~N}$ & $\%$ & $\mathrm{~N}$ & $\%$ & $\mathrm{~N}$ & $\%$ & $N$ & $\%$ \\
\hline Cardiovascular & 214 & 35.7 & 24 & 19.0 & 4 & 11.1 & 0 & 0.0 & 242 & 31.5 \\
\hline Upper Respiratory & 60 & 10.0 & 20 & 15.9 & 3 & 8.3 & $\underline{0}$ & 0.0 & 83 & 10.8 \\
\hline Allergy Reaction & 141 & 23.5 & 30 & 23.8 & 13 & 36.1 & 1 & 25.0 & 185 & 24.1 \\
\hline Mental Illness \& Retardation & 110 & 18.3 & 20 & 15.9 & 5 & 13.9 & 1 & 25.0 & 136 & 17.7 \\
\hline Endocrine & 44 & 7.3 & 6 & 4.8 & 4 & 11.1 & 0 & 0.0 & 54 & 7.0 \\
\hline Orthopedic Problems & 104 & 17.3 & 20 & 15.9 & 8 & 22.2 & 1 & 25.0 & 133 & 17.3 \\
\hline $\begin{array}{l}\text { Abdominal \& Intestinal } \\
\text { Injury \& Disease }\end{array}$ & 145 & 24.2 & 31 & 24.6 & 12 & 33.3 & 1 & 25.0 & 189 & 24.6 \\
\hline Cancer & 22 & 3.7 & 5 & 9.0 & 1 & 2.8 & 3 & 75.0 & 31 & 4.0 \\
\hline Eye, Ear, Nose \& Throat & 128 & 21.3 & 14 & 11.1 & 4 & 11.1 & 1 & 25.0 & 147 & 19.1 \\
\hline Arthritis & 182 & 30.3 & 13 & 10.3 & 2 & 5.6 & 0 & 0.0 & 197 & 25.7 \\
\hline Neuroskeletal-Muscular & 18 & 3.0 & 3 & 2.4 & 1 & 2.8 & 1 & 25.0 & 23 & 3.0 \\
\hline Denta l & 2 & .3 & 5 & 4.0 & 0 & 0.0 & 0 & 0.0 & 7 & .9 \\
\hline Alcoholism & 2 & .3 & 0 & 0.0 & 1 & 2.8 & 0 & 0.0 & 3 & .3 \\
\hline Other Infectious Diseases & 23 & 3.8 & 3 & 2.4 & 3 & 8.3 & 1 & 25.0 & 30 & 3.9 \\
\hline TOTAL & 1,196 & 199.3 & 194 & 153.9 & 61 & 169.4 & 10 & 250.0 & 1,461 & 190.7 \\
\hline
\end{tabular}


morbidity. There is a positive relationship between the number of family moves and abdominal and intestinal diseases. There is also a negative relationship with mental illness and with arthritis. This latter relationship suggests that the more stable population may tend to be the older population, since the rate of arthritis increases with age.

Observing that there is not a relationship between family mobility and disease rates, the question arises as to the explanation of the higher tuberculosis rates experienced by transient populations. Since these populations were also characterized by a poverty of human association it is possible that it may have been this latter quality which was positively associated with the incidence of the disease. To determine whether a similar influence might be operating in the present study, the subjects were broken down into five types of family composition: complete, mother absent, father absent, both parents absent, and single adults. The morbidity rates were determined for each type of family. These data are tabulated in Table XIV.

The lowest morbidity rate is experienced by the complete family type. This rate is exceeded by members of all types of incomplete families. The striking feature of these data is the fact that the adult living alone experiences about 2.45 the rate of morbidity than do members of complete families. Thus, the highest rate of illness is experienced by the single adult, who would be the person expected to have the least interpersonal interaction. Intuitively, it might be expected that the single adult would also be the person with the 
TABLE XIV

RATES OF PERCEIVED MORBIDITY FOR SELECTED DISEASE CATEGORIES AS SHOWN BY

FAMILY COMPOSITION IN A PREDOMINENTLY INDIGENT POPULATION OF

SOUTH BATON ROUGE, HAMMOND, AND NEW ROADS, 1971

\begin{tabular}{|c|c|c|c|c|c|c|c|c|c|c|c|c|}
\hline \multirow{3}{*}{$\begin{array}{l}\text { DISEASE } \\
\text { CATEGORY }\end{array}$} & \multicolumn{12}{|c|}{ FAMILY COMPOSITION } \\
\hline & \multirow{2}{*}{$\begin{array}{l}\text { Mother } \\
\frac{N=563}{N}\end{array}$} & Only & \multirow{2}{*}{$\begin{array}{l}\text { Father } \\
\frac{\mathrm{N}=30}{\mathrm{~N}}\end{array}$} & \multirow{2}{*}{$\begin{array}{l}\text { Only } \\
\%\end{array}$} & \multicolumn{2}{|c|}{$\begin{array}{l}\text { No Parent } \\
\mathrm{N}=82\end{array}$} & \multirow[t]{2}{*}{$\begin{array}{l}\text { Sing le } \\
N=148\end{array}$} & Adult & \multicolumn{2}{|c|}{$\begin{array}{l}\text { Complete } \\
\text { Family } \\
\mathrm{N}=1346\end{array}$} & \multicolumn{2}{|c|}{$\begin{array}{l}\text { Tota } 1 \\
\mathrm{~N}=2169\end{array}$} \\
\hline & & $\%$ & & & $\mathrm{~N}$ & $\%$ & & $\%$ & $\mathrm{~N}$ & $\%$ & $\mathrm{~N}$ & $\%$ \\
\hline Cardiovascular & 93 & 16.5 & 3 & 10.0 & 17 & 20.7 & 53 & 35.8 & 176 & 13.1 & 342 & 15.7 \\
\hline Upper Respiratory & 43 & 7.6 & 1 & 3.3 & 9 & 11.0 & 19 & 12.8 & 104 & 7.7 & 176 & 8.1 \\
\hline Allergy Reaction & 79 & 14.0 & 8 & 26.7 & 12 & 14.6 & 27 & 18.2 & 197 & 14.6 & 323 & 14.9 \\
\hline Mental Illness \& Retardation & 58 & 10.3 & 3 & 10.0 & 6 & 7.3 & 32 & 21.6 & 100 & 7.4 & 199 & 9.2 \\
\hline Endocrine & 23 & 4.1 & 0 & 0.0 & 2 & 2.4 & 19 & 12.8 & 32 & 2.4 & 76 & 3.5 \\
\hline Orthopedic Problems & 52 & 9.2 & 4 & 13.3 & 9 & 11.0 & 34 & 23.0 & 112 & 8.3 & 211 & 9.7 \\
\hline $\begin{array}{l}\text { Abdominal \& Intestinal } \\
\text { Injury \& Disease }\end{array}$ & 80 & 14.2 & 3 & 10.7 & 8 & 9.8 & 34 & 23.0 & 157 & 11.7 & 282 & 13.0 \\
\hline Cancer & 11 & 2.0 & 2 & 6.7 & $\underline{2}$ & 2.4 & 4 & 2.7 & 25 & 1.9 & 44 & 2.0 \\
\hline Eye, Ear, Nose \& Throat & 51 & 9.1 & 3 & 10.0 & 11 & 13.4 & 44 & 29.7 & 139 & 10.3 & 248 & 11.4 \\
\hline Arthritis & 68 & 12.1 & 1 & 3.3 & 7 & 8.5 & 52 & 35.1 & 124 & 9.2 & 252 & 11.6 \\
\hline Neuroskeleta1-Muscular & 27 & 4.8 & 0 & 0.0 & 1 & 1.2 & 7 & 4.7 & 32 & 2.4 & 67 & 3.1 \\
\hline Dental & 3 & .5 & 0 & 0.0 & 0 & 0.0 & 3 & 2.0 & 3 & .2 & 9 & .4 \\
\hline Alcoholism & 2 & .4 & 0 & 0.0 & $\underline{0}$ & 0.0 & 0 & 0.0 & 7 & .5 & 9 & .4 \\
\hline Other Infections \& Fevers & 23 & 4.1 & 2 & 6.7 & 1 & 1.2 & 12 & 8.1 & 56 & 4.2 & 94 & 4.3 \\
\hline TOTAL & 613 & 108.8 & 32 & 106.6 & 85 & 103.6 & 338 & 228.31 & 1,264 & 93.3 & 2,332 & 107.5 \\
\hline
\end{tabular}


strongest feelings of alienation. It is also possible, however, that the higher morbidity rate of the single adult is at least partially explained by the fact that the single adult population is also an older population.

Even in intact families there is a possibility that some members may be exposed to anomic conditions. For example, a person who has developed a particular set of norms over an extended period of time and finds that, because of changing circumstances, these norms can no longer be utilized may experience anomie as a result. This would appear to be especially likely if the culture did not clearly articulate acceptable norms for the changed circumstance. Such would seem to be the case with the husband who has lost his position as head of the household or the wife who has had to assume the position of head of household.

Tables XV and XVI provide data on Pathology rates of Male, head of household; female, head of household; male (husband), non-head of household; and female (wife), non-head of household.

In Table XV, it is seen that the overall morbidity rate for the female head of household is higher than that for the male head of household. This suggests that the female head of household, occupying a position for which she has not been socialized, may not feel comfortable with the required behavior and, thus, is vulnerable to anomie. of course, another explanation is that the female in this sample may experience a higher morbidity rate than the male, thus, explaining the difference in rates found in this table. 
TABLE XV

PERCEIVED MORBIDITY RATES FOR HEAD OF HOUSEHOLD SHOWN BY SEX IN A PREDOMINENTLY INDIGENT POPULATION OF SOUTH BATON ROUGE, HAMMOND, AND NEW ROADS, 1971

\begin{tabular}{|c|c|c|c|c|c|c|}
\hline \multirow{3}{*}{ PATHOLOGY CATEGORY } & \multicolumn{6}{|c|}{ HEAD OF HOUSEHOLD } \\
\hline & \multicolumn{2}{|c|}{$\begin{array}{l}\text { Male } \\
\mathrm{N}=330 \\
\end{array}$} & \multicolumn{2}{|c|}{$\begin{array}{l}\text { Fema le } \\
\mathrm{N}=235 \\
\end{array}$} & \multicolumn{2}{|c|}{ Total } \\
\hline & $\underline{N}$ & $\%$ & $\mathbf{N}$ & $\%$ & $\mathrm{~N}$ & $\%$ \\
\hline Cardiovascular & 90 & 27.3 & 107 & 45.5 & 197 & 34.9 \\
\hline Upper Respiratory & 38 & 11.5 & 29 & 12.3 & 67 & 11.9 \\
\hline Allergy Reaction & 52 & 15.8 & 54 & 23.0 & 106 & 18.8 \\
\hline Menta 1 Illness and Retardation & 34 & 10.3 & 59 & 25.1 & 93 & 16.5 \\
\hline Endocrine & 11 & 3.3 & 31 & 13.2 & 42 & 7.4 \\
\hline Orthopedic Problems & 68 & 20.6 & 49 & 20.9 & 117 & 20.7 \\
\hline $\begin{array}{l}\text { Abdominal and Intestinal } \\
\text { Disease and Injury }\end{array}$ & 74 & 22.4 & 73 & 31.1 & 147 & 26.0 \\
\hline Cancer & 9 & 2.7 & 9 & 3.8 & 18 & 3.2 \\
\hline Eye, Ear, Nose, and Throat & 58 & 17.6 & 58 & 24.7 & 116 & 20.5 \\
\hline Arthritis & 53 & 16.1 & 92 & 39.1 & 145 & 25.7 \\
\hline Neuroskeletal and Muscular & 12 & 3.6 & 5 & 2.1 & 17 & 3.0 \\
\hline Denta 1 & 1 & .3 & 4 & 1.7 & 5 & .9 \\
\hline Alcoholism & 5 & 1.5 & 0 & 0.0 & 5 & .9 \\
\hline Other Infections and Fevoral & 10 & 3.0 & 7 & 3.0 & 17 & 3.0 \\
\hline TOTAL & 515 & 156.1 & 577 & 245.5 & 1,092 & 193.3 \\
\hline
\end{tabular}




\section{TABLE XVI}

PERCEIVED MORBIDITY RATES FOR HUSBAND AND WIFE, NON-HEAD OF HOUSEHOLD, IN A PREDOMINENTLY INDIGENT POPULATION OF SOUTH BATON ROUGE, HAMMOND, AND NEW ROADS, 1971

\begin{tabular}{|c|c|c|c|c|c|c|}
\hline \multirow{3}{*}{ PATHOLOGY } & \multicolumn{6}{|c|}{ NON-HEAD OF HOUSEHOLD } \\
\hline & \multicolumn{2}{|c|}{$\begin{array}{l}\text { Husband } \\
\mathrm{N}=19\end{array}$} & \multicolumn{2}{|c|}{$\begin{array}{l}\text { Wife } \\
\mathrm{N}=296\end{array}$} & \multicolumn{2}{|c|}{ Total } \\
\hline & $\mathrm{N}$ & $\%$ & $\mathrm{~N}$ & $\%$ & $\mathrm{~N}$ & $\%$ \\
\hline Cardiovascular & 5 & 26.3 & 82 & 27.7 & 87 & 27.6 \\
\hline Upper Respiratory & 1 & 5.3 & 24 & 8.1 & 25 & 7.9 \\
\hline Allergy Reaction & 2 & 10.5 & 85 & 28.7 & 87 & 27.6 \\
\hline Mental Illness and Retardation & 3 & 15.8 & 55 & 18.6 & 58 & 18.4 \\
\hline Endocrine & $\underline{0}$ & 0.0 & 20 & 6.8 & 20 & 6.3 \\
\hline Orthopedic Problems & 4 & 21.1 & 31 & 10.5 & 35 & 11.1 \\
\hline $\begin{array}{l}\text { Abdominal and Intestinal } \\
\text { Di sease and Injury }\end{array}$ & 6 & 31.6 & 68 & 23.0 & 74 & 23.5 \\
\hline Cancer & 2 & 10.5 & 9 & 3.0 & 11 & 3.5 \\
\hline Eye, Ear, Nose, and Throat & 4 & 21.1 & 44 & 14.9 & 48 & 15.2 \\
\hline Arthritis & 6 & 31.6 & 69 & 23.3 & 75 & 23.8 \\
\hline Neuroskeletal and Muscular & $\underline{0}$ & 0.0 & 9 & 3.0 & 9 & 2.9 \\
\hline Denta 1 & 0 & 0.0 & 1 & .3 & 1 & .3 \\
\hline Alcoholism & 1 & 5.3 & 0 & .0 & 1 & .3 \\
\hline Other Infectious and Fevoral & 1 & 5.3 & 11 & 3.7 & 1 & .3 \\
\hline TOTAL & 35 & 184.2 & 508 & 171.6 & 532 & 168.9 \\
\hline
\end{tabular}


One way to explore this possibility further is to compare the morbidity rates for the female head of the household with the female non-head of household. This is possible by comparing the rates for females in both Tables XV and XVI. Such a comparison reveals that the housewife suffers a much lower morbidity rate than does the female head of household. This supports the contention that the higher morbidity rate is associated with the family status in question. The behavior of the morbidity rates of the male is not inconsistent with this contention, with the male head of household experiencing a lower rate of morbidity than the male non-head of household. This, however, might be explained by the fact that illness itself may account for the male losing the position of head of household.

In turning our attention to children it is assumed that there is a possibility that one child might be singled out by the family as being different. When this is the case, the child so designated might reasonably be considered to be in an anomic structure because of the resulting defective integration into the normative structure of the family. In an effort to explore this, the parents were asked which of their children, if any, they considered to be the most different from the rest of the family. If the apparent difference was due to an illness, the response was not accepted. For those responses which were accepted the rate of morbidity was determined and compared to the morbidity rates of children not designated as different. These data are recorded in Table XVII. According to these data, the overall morbidity rate for the children designated as atypical is much greater than the rate for normal children. 


\section{TABLE XVII}

PERCEIVED MORBIDITY RATES FOR ATYPICAL AND NORMAL CHILDREN IN A

PREDOMINENTLY INDIGENT POPULATION OF SOUTH BATON ROUGE, HAMMOND AND NEW ROADS, 1971

\begin{tabular}{|c|c|c|c|c|c|c|}
\hline \multirow{3}{*}{ PATHOLOGY } & \multicolumn{6}{|c|}{ STATUS OF CHILD } \\
\hline & \multicolumn{2}{|c|}{$\begin{array}{c}\text { Atypical } \\
\mathrm{N}=138\end{array}$} & \multicolumn{2}{|c|}{$\begin{array}{r}\text { Norma 1 } \\
\mathrm{N}=918 \\
\end{array}$} & \multicolumn{2}{|c|}{ Total } \\
\hline & $\mathrm{N}$ & $\%$ & $\mathrm{~N}$ & $\%$ & $\mathrm{~N}$ & $\%$ \\
\hline Cardiovascular & 3 & 2.2 & 17 & 1.9 & 20 & 1.9 \\
\hline Upper Respiratory & 9 & 6.5 & 60 & 6.5 & 69 & 6.5 \\
\hline Allergy Reaction & 20 & 14.5 & 82 & 8.9 & 102 & 9.7 \\
\hline Mental Illness and Retardation & 6 & 4.3 & 17 & 1.9 & 23 & 2.2 \\
\hline Endocrine & $\underline{0}$ & 0.0 & 5 & .5 & 5 & .5 \\
\hline Orthopedic Problems & 6 & 4.3 & 28 & 3.1 & 34 & 3.2 \\
\hline $\begin{array}{l}\text { Abdominal and Intestinal } \\
\text { Disease and Injury }\end{array}$ & 7 & 5.1 & 29 & 3.2 & 36 & 3.4 \\
\hline Cancer & 4 & 2.9 & 4 & .4 & 8 & .8 \\
\hline Eye, Ear, Nose, and Throat & 12 & 8.7 & 42 & 4.6 & 54 & 5.1 \\
\hline Arthritis & 0 & 0.0 & 9 & 1.0 & 9 & .9 \\
\hline Neuroskeletal and Muscular & 9 & 6.5 & 24 & 2.6 & 33 & 3.1 \\
\hline Denta 1 & $\underline{0}$ & 0.0 & $\underline{0}$ & 0.0 & 0 & 0.0 \\
\hline Alcoholism & 0 & 0.0 & 0 & 0.0 & 0 & 0.0 \\
\hline Other Infections and Fevoral & 7 & 5.1 & 47 & 5.1 & 54 & 5.1 \\
\hline TOTAL & 83 & 60.1 & 364 & 34.5 & 447 & 42.3 \\
\hline
\end{tabular}


Having established at this point that there is a relationship between anomie at the personality system leve1, as measured by the Srole Scale, and morbidity and that a similar relationship exists at the social system level, at least at the level of the family, it remains to explore the possibility of the relationship existing in the larger social structure. It has already been demonstrated that elevated morbidity rates do not accompany mobility within the larger social structure. Another interesting possibility is that persons who are members of formal social structures such as clubs and civic organizations might be considered in a less anomic structurai condition than nonmembers since such memberships may tend to affirm the individual's vital participation in the social structure.

The population with which we are working is largely indigent, however, limiting any formal organization memberships to those that are inexpensive and non-exclusive. Since the church is a formal organization that meets these two criteria, an effort was made to determine those subjects who actively participated in the church either by attending at least twice each month on the average or by contributing money or time at least once each month. Perceived morbidity rates were then determined for the active and inactive subjects in each category. These data are presented in Table XVIII.

According to these data these persons who participate actively in church either in attendance or in contributions tend to have a lower overall rate of morbidity. This relationship is a little stronger for those who attend regularly. For this population the morbidity rates of 
TABLE XVIII

PERCEIVED MORBIDITY RATES SHOWN BY QUALITY OF CHURCH PARTICIPATION

OF A PREDOMINENTLY INDIGENT POPULATION OF SOUTH

BATON ROUGE, HAMMOND, AND NEW ROADS, 1971

\begin{tabular}{|c|c|c|c|c|c|c|c|c|}
\hline \multirow{4}{*}{$\begin{array}{l}\text { DISEASE } \\
\text { CATEGORY }\end{array}$} & \multicolumn{8}{|c|}{ CHURCH PARTICIPATION } \\
\hline & \multicolumn{5}{|c|}{ Attendance } & \multicolumn{3}{|c|}{ Contribution } \\
\hline & \multicolumn{2}{|c|}{$\operatorname{Regular}(\mathrm{N}=1761)$} & \multicolumn{3}{|c|}{ Non-Regular $(\mathrm{N}=381)$} & Active (1084) & \multicolumn{2}{|c|}{ Inactive (461) } \\
\hline & $\mathrm{N}$ & $\%$ & $\mathbf{N}$ & $\%$ & $\mathbf{N}$ & $\%$ & $\mathrm{~N}$ & $\%$ \\
\hline Cardiovascular & 271 & 15.4 & 67 & 17.6 & 264 & 15.7 & 75 & 16.3 \\
\hline Upper Respiratory & 139 & 7.9 & 36 & 9.4 & 134 & 8.0 & 41 & 8.9 \\
\hline Allergy Reaction & 256 & 14.5 & 58 & 15.2 & 250 & 14.8 & 65 & 14.1 \\
\hline Mental Illness \& Retardation & 154 & 8.7 & 44 & 11.5 & 141 & 8.4 & 57 & 12.4 \\
\hline Endocrine & 60 & 3.4 & 16 & 4.2 & 54 & 3.2 & 21 & 4.6 \\
\hline Orthopedic Problems & 161 & 9.1 & 46 & 12.1 & 157 & 9.3 & 50 & 10.8 \\
\hline $\begin{array}{l}\text { Abdomina l and Intestina } 1 \\
\text { Disease and Injury }\end{array}$ & 226 & 12.8 & 53 & 13.9 & 223 & 13.2 & 57 & 12.4 \\
\hline Cancer & 34 & 1.9 & 10 & 2.6 & 33 & 2.0 & 10 & 2.2 \\
\hline Eye, Ear, Nose \& Throat & 182 & 10.3 & 63 & 16.5 & 180 & 10.7 & 65 & 14.1 \\
\hline Arthritis & 207 & 11.8 & 44 & 11.5 & 196 & 11.6 & 54 & 11.7 \\
\hline Neuroskeletal and Muscular & 53 & 13.0 & 11 & 2.9 & 52 & 3.1 & 13 & 2.8 \\
\hline Denta 1 & 8 & .5 & 1 & .3 & 4 & .2 & 5 & 1.1 \\
\hline Alcoholism & 7 & .4 & 2 & .5 & 7 & .4 & 2 & .4 \\
\hline Other Infections \& Diseases & 75 & 4.3 & 19 & 5.0 & 71 & 4.2 & 23 & 5.0 \\
\hline TOTAL & 1,833 & 104 & 470 & 123. & 1,766 & 105. & 538 & 117 \\
\hline
\end{tabular}


the non-regular attenders exceeded those of the regular attenders in all but three pathology categories: arthritis, neuroskeletal-muscular disorders, and dental conditions. None of these three differences are significant at the .05 level of confidence.

The three communities represented in the sample provide three levels of urbanization-industrialization. Assuming that there is a tendency for urbanization to produce anomie an opportunity is offered to investigate the relationship between this form of structural anomie and perceived morbidity. The literature is not very precise in this area. Some authorities argue a higher morbidity rate for rural, or less anomic, areas.13,14 However, this may not be true for all pathologies. Matt and Rosen concluded that whatever may be the pathogenesis of arteriosclerotic or hypertensive heart disease, there is much evidence to point to a relationship with the nervous strains more typically a part of urban than rural life. ${ }^{15}$ In a study by Hawkins, it was shown that tuberculosis rates correlate to population density and crowding. 16 Mott reveals that the rates of appendicitis, orthopedic impairments, diseases of the ear and mastoid, and hernia appear to be higher in urban areas. On the other hand, he mentioned that the most

13 E. G. Jaco, Patients, Physicians and Illness, Glencoe: The Free Press, 1958, p. 433.

${ }^{14}$ Frederick D. Mott and Milton I. Roemer, Rura1 Health and Medica 1 Care, New York: McGraw-Hil1 Book Co., Inc, 1948, pp. 75 and 80.

$15 \mathrm{Jaco}$, op. cit., p. 26.

${ }^{16}$ Norman G. Hawkins, Medical Sociology, Springfield: Charles C. Thomas, 1958, p. 93. 
striking features of the comparative rural and urban patterns of illness is their similarity. 17

In Table XIX are the pathology rates for the three communities included in the present study. Assuming that New Roads is the most rural community, Hammond is in transition, and Baton Rouge is the most urban, there is no remarkable difference in the overall perceived morbidity rates of the three. Hammond does have a slightly higher rate, but there is no indication of a rural-urban continuum influence. Addressing the individual categories of diseases, however, such a relationship may exist in alcoholism and neuroskeletalmuscular categories. In three other disease categories, upper respiratory, cancer and other infections and fevers, there tends to be a higher rate in the urban area. Assuming that atypical social structure is conducive to anomie, at least to the extent that it reduces the clarity with which norms are articulated, it would seem that the black race might be subjected to a greater amount of this type of structural anomie. This is logical because the black family tends to be partially dissolved at a higher rate than the white family. Also, many members of the black race continue to be denied entrance into the legitimate, visible modes of efficient goal achieving behavior patterns. of course, other potentially pathogenic qualities are also related to racial and ethnic differences. Such qualities may include diet, life styles, and incomes. Among established racial differences in morbidity rates, 
TABLE XIX

RATES OF PERCEIVED MORBIDITY FOR SELECTED DISEASE CATEGORIES AMONG THE MEDICALLY INDIGENT OF THE SAMPIE POPULATIONS IN A PREDOMINENTLY INDIGENT POPULATION
FOR SOUTH BATON ROUGE, HAMMOND, AND NEW ROADS, 1971 .

\begin{tabular}{|c|c|c|c|c|c|c|c|c|}
\hline \multirow{3}{*}{$\begin{array}{l}\text { DISEASE } \\
\text { CATEGORY }\end{array}$} & \multicolumn{8}{|c|}{ SAMPLE POPULATIONS } \\
\hline & \multicolumn{2}{|c|}{$\begin{array}{c}\text { South } \\
\text { Baton Rouge } \\
\mathrm{N}=885 \\
\end{array}$} & \multicolumn{2}{|r|}{$\begin{array}{l}\text { Hammond } \\
\mathrm{N}=736\end{array}$} & \multicolumn{2}{|c|}{$\begin{array}{c}\text { New Roads } \\
\mathrm{N}=547\end{array}$} & & \multirow{2}{*}{$\begin{array}{c}\begin{array}{c}\text { Overa } 11 \\
\text { Tota } 1\end{array} \\
\% \\
\end{array}$} \\
\hline & $\mathbf{N}$ & $\%$ & $\mathrm{~N}$ & $\%$ & $\mathrm{~N}$ & $\%$ & $\mathrm{~N}$ & \\
\hline Cardiovascular & 145 & 16.4 & 102 & 13.9 & 96 & 17.6 & 343 & 14.7 \\
\hline Upper Respiratory & 81 & 9.2 & 54 & 7.3 & 41 & 7.5 & 176 & 7.6 \\
\hline Allergy Reaction & 129 & 14.6 & 124 & 16.8 & 68 & 12.4 & 321 & 13.8 \\
\hline Menta1 Illness \& Retardation & 75 & 8.5 & 62 & 8.4 & 62 & 11.3 & 199 & 8.5 \\
\hline Endocrine & 30 & 3.4 & 25 & 3.4 & 21 & 3.8 & 76 & 3.3 \\
\hline \multirow{2}{*}{$\begin{array}{l}\text { Orthopedic Problems } \\
\text { Abdominal \& Intestina } \\
\text { Injury and Disease }\end{array}$} & 68 & 7.7 & 87 & 11.8 & 56 & 10.2 & 211 & 9.1 \\
\hline & 107 & 12.1 & 106 & 14.4 & 69 & 12.6 & 282 & 12.1 \\
\hline Cancer & 25 & 2.8 & 11 & 1.5 & 8 & 1.5 & 44 & 1.9 \\
\hline Eye, Ear, Nose \& Throat & 91 & 10.3 & 94 & 12.8 & 63 & 11.5 & 248 & 10.6 \\
\hline Arthritis & 97 & 11.0 & 93 & 12.6 & 63 & 11.5 & 253 & 10.6 \\
\hline Neuroskeletal \& Muscular & 31 & 3.5 & 22 & 3.0 & 13 & 2.4 & 66 & 2.8 \\
\hline Denta 1 & 2 & 0.2 & 6 & 0.8 & 1 & 0.2 & 9 & .4 \\
\hline Alcoholism & 7 & 0.8 & 2 & 0.3 & 0 & 0.0 & 9 & .4 \\
\hline Other Infections \& Fevers & 58 & 6.6 & 21 & 2.9 & 15 & 2.7 & 94 & 4.0 \\
\hline TOTAL & 946 & 106.9 & 809 & 109.9 & 576 & 105.3 & 2,331 & 107.5 \\
\hline
\end{tabular}


hypertension,diseases of the heart, arthritis, and nephritis were found to be more prevalent in the Negro race in one study. In the same study of public assistance recipients, diabetes, cholecystitis, and psychoneurosis were found to have higher rates among whites. 18 This is not entirely supported by a study of an urban population which found that age adjusted morbidity rates for heart disease indicated higher prevalence among whites. Also, in this study, diabetes rates were found to be higher in the black race. The two studies did agree on the rates of arthritis and mental disorders. 19 Cancer rates have been found to be higher in the white race, but some authorities are reluctant to conclude a lower predisposition by Negroes. These authorities feel that the lower reported rate among Negroes may be due to shorter 1 ife expectancy, lower living standards, and less accurate diagnoses of the Negro. 20

Table XX reveals that, although the non-white race has an overall pathology rate higher than that of the non-ethnic identified population and the French ethnic population, it has a lower pathology rate than any other ethnic group except German. The miscellaneous ethnic group has the distinction of having the highest overall pathology rate, followed by the Italians. However, the size of each of these ethnic

${ }^{18}$ American Public Health Association, The Maryland Medical Care Program, New York: American Public Health Association, 1948, p. 84.

${ }^{19}$ Commission on Chronic I1lness, Chronic Illness in the United States: Chronic Illness in a Large City, Cambridge: Harvard University Press, 1959, pp. 84 and 94.

20 Erwin Ackerknecht, History and Geography of the Most Important Diseases, New York: Hafner Publishing Co., Inc., 1965, p. 172. 
TABLE XX

PERCEIVED MORBIDITY RATES AS SHOWN BY RACE AND ETHNIC IDENTITY IN A PREDOMINENTLY INDIGENT POPULATION FOR SOUTH BATON ROUGE, HAMMOND, AND NEW ROADS, 1971

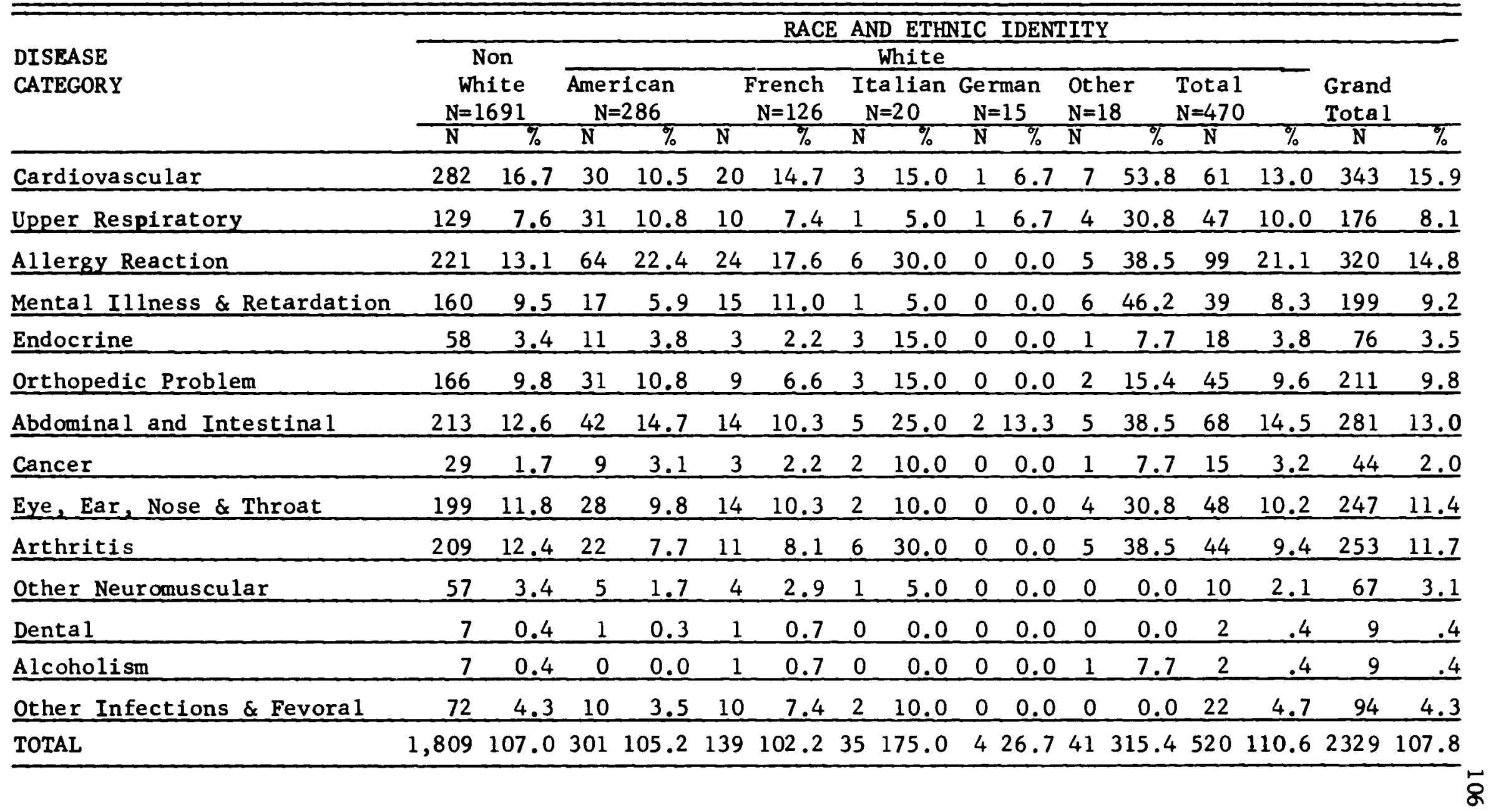


groups is so small that generalizations about them are unwarranted. The non-white population of the present sample tends to have higher rates of cardiovascular diseases, mental illness and retardation, eye, ear, nose and throat disorders, and arthritis. It tends to have a lower rate of allergy reaction, upper respiratory diseases, abdominal and intestina 1 disorders and cancer.

Intuitively, it seems reasonable to assume that religion might exert an influence on morbidity, as religion may sometimes dictate certain behavior patterns which might, in turn, exert an influence on health. Table XXI gives a breakdown of perceived morbidity rates by religious affiliation.

The Jewish tend to have the lowest perceived morbidity rate among this sample. However, the small number of this group makes generalizations impossible. The highest rate is that of the Protestant groups with those groups defined as non-medically constrictive being the highest of even this category.

Income, too, is a condition which exerts a large influence on life style, including diet, sanitation, and preventive medical care. It might be expected, then, to have an influence on health. Table XXII shows this relationship.

The relationship between family income and overall morbidity is striking with an apparent tendency for morbidity rates to vary inversely with income. The pathology patterns found in this sample tend to conform to those found in other studies. Heart disease tends to be over represented in the very low income ranges, but is somewhat higher in 
TABLE XXI

DIFFERENTIAL RATES OF PERCEIVED MORBIDITY AMONG AN INDIGENT POPULATION FOR SELECTED DISEASE CATEGORIES AS SHOWN BY RELIGIOUS AFFILIATION IN A

PREDOMINENTLY INDIGENT POPULATION FOR SOUTH BATON ROUGE HAMMOND, AND NEW ROADS, 1971

\begin{tabular}{|c|c|c|c|c|c|c|c|c|c|c|c|c|}
\hline \multirow{3}{*}{$\begin{array}{l}\text { DISEASE } \\
\text { CATEGORY }\end{array}$} & \multicolumn{12}{|c|}{ RELIGIOUS AFFILIATION } \\
\hline & $\begin{array}{r}\text { Catholic } \\
\mathrm{N}=620 \\
\end{array}$ & $\begin{array}{l}\text { Jewish } \\
\mathrm{N}=8\end{array}$ & \multicolumn{2}{|c|}{$\begin{array}{c}\text { Protestant } \\
\text { Total }\end{array}$} & \multicolumn{2}{|c|}{$\begin{array}{l}\text { Non-Medical1y } \\
\text { Con.Prot. } \\
N=1418\end{array}$} & \multicolumn{2}{|c|}{$\begin{array}{l}\text { Medical1y } \\
\text { Con.Prot. } \\
\mathrm{N}=78\end{array}$} & \multicolumn{2}{|c|}{$\begin{array}{l}\text { None } \\
\mathrm{N}=22\end{array}$} & \multicolumn{2}{|c|}{$\begin{array}{c}\text { Overa } 11 \\
\text { Tota } 1\end{array}$} \\
\hline & $\mathrm{N} \% \quad \%$ & $\mathrm{~N} \%$ & $\mathrm{~N}$ & $\%$ & $\mathbf{N}$ & $\%$ & $\mathbf{N}$ & $\%$ & $\mathbf{N}$ & $\%$ & $\mathrm{~N}$ & $\%$ \\
\hline Cardiovascular & $85 \quad 13.7$ & 112.5 & 251 & 16.8 & 238 & 16.8 & 13 & 16.7 & 1 & 4.5 & 338 & 15.7 \\
\hline Upper Respiratory & $49 \quad 7.9$ & $0 \quad 0.0$ & 124 & 8.3 & 119 & 8.4 & 5 & 6.4 & 3 & 13.6 & 176 & 8.2 \\
\hline Allergy Reaction & $86 \quad 13.9$ & $0 \quad 0.0$ & 231 & 15.4 & 222 & 15.7 & 9 & 11.5 & 1 & 4.5 & 318 & 14.8 \\
\hline Mental Illness \& Retardation & $53 \quad 8.5$ & 112.5 & 142 & 9.5 & 136 & 9.6 & 6 & 7.7 & 2 & 9.1 & 199 & 9.2 \\
\hline Endocrine & $24 \quad 3.9$ & $0 \quad 0.0$ & 52 & 3.5 & 50 & 3.5 & 2 & 2.6 & 0 & 0.0 & 76 & 3.5 \\
\hline Orthopedic Problems & $51 \quad 8.2$ & 112.5 & 155 & 10.4 & 148 & 10.4 & 7 & 9.0 & 4 & 18.2 & 211 & 9.8 \\
\hline $\begin{array}{l}\text { Abdominal \& Intestinal } \\
\text { Disease \& Injury }\end{array}$ & $65 \quad 10.5$ & 112.5 & 212 & 14.2 & 201 & 14.2 & 11 & 14.1 & 2 & 9.1 & 280 & 13.0 \\
\hline Cancer & $16 \quad 2.6$ & 112.5 & 27 & 1.8 & 27 & 1.9 & 0 & 0.0 & 0 & 0.0 & 44 & 2.0 \\
\hline Eye, Ear, Nose \& Throat & $59 \quad 9.5$ & $0 \quad 0.0$ & 183 & 12.2 & 175 & 12.3 & 8 & 10.3 & 3 & 13.6 & 246 & 11.4 \\
\hline Arthritis & $59 \quad 9.5$ & 225.0 & 188 & 12.6 & 173 & 12.2 & 15 & 19.2 & 2 & 9.1 & 250 & 11.6 \\
\hline Neuroskeletal - Muscular & $15 \quad 2.4$ & $0 \quad 0.0$ & 50 & 3.3 & 48 & 3.4 & 2 & 2.6 & 2 & 9.1 & 67 & 3.1 \\
\hline Denta 1 & $2 \quad 0.3$ & $0 \quad 0.0$ & 6 & .4 & 6 & .4 & 0 & 0.0 & 0 & 0.0 & 8 & .4 \\
\hline Alcoholism & 20.3 & 0.0 & 7 & .5 & 7 & .5 & $\underline{0}$ & 0.0 & 0 & 0.0 & 9 & .4 \\
\hline Other Infections \& Fevers & $24 \quad 3.9$ & $0 \quad 0.0$ & 68 & 4.5 & 66 & 4.7 & 2 & 2.6 & 2 & 9.1 & 94 & 4.4 \\
\hline TOTAL & 59095.2 & 787.5 & 1696 & 113.4 & 1616 & 114.0 & 80 & 102.6 & 22 & 100.0 & 2316 & 107.5 \\
\hline
\end{tabular}


TABLE XXII

RATES OF PERCEIVED MORBIDITY FOR SELECTED DISEASE CATEGORIES AS SHOWN BY ANNUAL FAMILY INCOME IN A PREDOMINENTLY INDIGENT POPULATION FOR SOUTH BATON ROUGE, HAMMOND, AND NEW ROADS, 1971

\begin{tabular}{|c|c|c|c|c|c|c|c|c|c|c|}
\hline \multirow[b]{2}{*}{$\begin{array}{l}\text { DISEASE } \\
\text { CATEGORY }\end{array}$} & \multicolumn{10}{|c|}{ LEVELS OF INCOME } \\
\hline & $\begin{array}{l}\text { Under } \\
\$ 1,000 \\
\mathrm{~N}=110 \\
\end{array}$ & $\begin{array}{r}1,001- \\
2,000 \\
\mathrm{~N}=441 \\
\end{array}$ & $\begin{array}{r}2,001- \\
3,000 \\
\mathrm{~N}=487 \\
\end{array}$ & $\begin{array}{r}3,001- \\
4,000 \\
\mathrm{~N}=246 \\
\end{array}$ & $\begin{array}{r}4,001- \\
5,000 \\
\mathrm{~N}=215 \\
\end{array}$ & $\begin{array}{r}5,001- \\
6,000 \\
\mathrm{~N}=144 \\
\end{array}$ & $\begin{array}{c}6,001- \\
7,000 \\
\mathrm{~N}=96 \\
\end{array}$ & $\begin{array}{r}7,001- \\
8,000 \\
\mathrm{~N}=133 \\
\end{array}$ & $\begin{array}{l}\text { Over } \\
8,000 \\
\mathrm{~N}=239 \\
\end{array}$ & $\begin{array}{c}\text { Overa } 11 \\
\text { Tota } 1\end{array}$ \\
\hline Cardiovascular & 27.3 & 22.4 & 19.1 & 15.9 & 8.8 & 7.6 & 5.2 & 9.8 & 9.6 & 15.7 \\
\hline Upper Respiratory & 11.8 & 10.0 & 6.8 & 8.1 & 10.7 & 6.3 & 6.3 & 4.5 & 7.5 & 8.1 \\
\hline \multirow{2}{*}{$\begin{array}{l}\text { Allergy Reaction } \\
\text { Mental IIness \& } \\
\text { Retardation }\end{array}$} & 17.3 & 13.8 & 13.3 & 11.4 & 19.1 & 16.7 & 15.6 & 14.3 & 15.9 & 14.7 \\
\hline & 16.4 & 16.1 & 9.2 & 8.1 & 6.5 & 3.5 & 3.1 & 3.8 & 6.3 & 9.3 \\
\hline Endocrine & 7.3 & 4.5 & 4.1 & 2.8 & 1.9 & 3.5 & 0.0 & 3.0 & 2.5 & 3.5 \\
\hline \multirow{2}{*}{$\begin{array}{l}\text { Orthopedic Problems } \\
\text { Abdomina1 \& Intestinal } \\
\text { Injury and Disease }\end{array}$} & 20.0 & 15.9 & 8.4 & 6.9 & 7.0 & 8.3 & 4.2 & 6.0 & 7.1 & 9.8 \\
\hline & 15.5 & 17.5 & 12.1 & 13.8 & 12.1 & 11.1 & 6.3 & 8.3 & 10.0 & 12.8 \\
\hline Cancer & 0.0 & 2.3 & 2.3 & 1.6 & 3.7 & 2.1 & 2.1 & 1.5 & 1.7 & 2.1 \\
\hline Eye, Ear, Nose \& Throat & 19.1 & 18.1 & 12.3 & 10.2 & 7.4 & 5.6 & 5.2 & 3.8 & 7.9 & 11.3 \\
\hline Arthritis & 24.5 & 22.0 & 10.7 & 11.8 & 6.5 & 3.5 & 1.0 & 8.3 & 3,8 & 11.6 \\
\hline Neuroskeletal - Muscular & 5.5 & 4.3 & 3.5 & 3.3 & .5 & 2.1 & 4.2 & 2.3 & 2.1 & 3.1 \\
\hline Denta 1 & 0.0 & .9 & .2 & 0.0 & .5 & .7 & 0.0 & 1.5 & 0.0 & .4 \\
\hline Other Infections \& Fevers & 5.5 & 3.2 & 2.3 & 2.4 & 7.9 & 6.3 & 8.3 & 7.5 & 4.2 & 4.3 \\
\hline Alcoholism & 1.8 & .2 & 0.0 & .4 & .9 & .7 & 0.0 & .8 & .4 & .4 \\
\hline TOTAL & 171.8 & 151.2 & 104.3 & 96.7 & 93.5 & 77.8 & 61.4 & 75.2 & 79.1 & 107.2 \\
\hline
\end{tabular}


the high income ranges than in the middle ranges. Mental illness tends to have a somewhat similar distribution while the rate of arthritis tends to vary inversely with income.

SUMMARY

Initially Durkheim approached anomie as a condition of social structure or, more specifically, as the anomic division of labor. 21 Later, he demonstrated a relationship between this condition and certain behavior on the part of individuals, namely suicide. Other authorities extended the concept to include certain feelings within the individual. Thus, it appears established that anomie is a condition that exists simultaneously on both the social system and personality system level. This is not incompatible with the concept of interpenetration of systems and leads to the speculation that the condition might also be manifested on other system levels. It is the intent of this chapter to determine whether the existence of anomie at either the personality system level or the social system level is associated with a disruption of the homeostasis of the organismic system. Should this be the case, the loss of homeostasis may be the organismic system level manifestation of anomie.

Anomie at the personality system level has been operationalized by the Srole Scale. The relationship between anomie at this level and disruption of homeostasis at the organismic system level is explored through the following hypothesis expressed in the null.

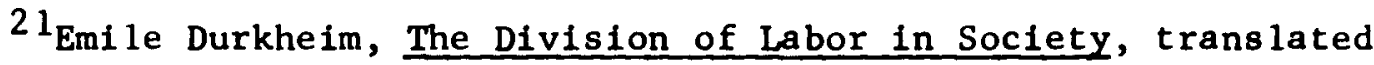
by George Simpson, New York: The Free Press, 1965, pp. 353ff. 
Hol: There is no positive linear relationship between morbidity rates and anomie.

TABLE XXIII

OVERALL MORBIDITY RATES SHOWN BY LEVEL OF ANOMIE FOR A PREDOMINENTLY INDIGENT POPULATION OF SOUTH BATON ROUGE, HAMMOND, AND NEW ROADS, 1971

\begin{tabular}{ccccccccc}
\hline \multicolumn{7}{c}{ Leve 1 of Anomie } \\
\hline & 0 & & 1 & & 2 & & 3 \\
\hline $\mathrm{N}$ & $\%$ & $\mathrm{~N}$ & $\%$ & $\mathrm{~N}$ & $\%$ & $\mathrm{~N}$ & $\%$ \\
\hline 53 & 182.8 & 98 & 130.7 & 159 & 165.6 & 224 & 193.1 \\
\hline
\end{tabular}

\begin{tabular}{ccccccccc}
\hline & 4 & & 5 & & 6 & \multicolumn{2}{c}{ Total } \\
\hline $\mathrm{N}$ & $\%$ & $\mathrm{~N}$ & $\%$ & $\mathrm{~N}$ & $\%$ & $\mathrm{~N}$ & $\%$ \\
\hline 272 & 214.2 & 343 & 248.6 & 224 & 238.3 & 1,373 & 203.4 \\
\hline
\end{tabular}

Leve 1 of measurement is ratio

Test statistic used is the Product-Moment Coefficient of Correlation

An $r$ of +.871 was obtained and this was found to exceed the .05 level of confidence using the $F$ distribution.

Therefore, $\mathrm{Ho}_{1}$ is rejected and the alternate hypothesis is accepted:

The overall morbidity rate is positively related to anomie.

Difficulty is encountered in exploring the relationship between anomie on the social system level and morbidity, as anomie on this level has not been quantified. Further complicating this task is the fact that anomie on the social system level may not be ubiquitous to all social systems. Consequently, it is possible that some individuals may be members of a variety of social systems some of which are anomic 
and others of which may not be. To explore the relationship between social system anomie and illness, systems were selected ranging on a continuum of intimacy to the individual. Anomic conditions among these were then defined in qualitative terms based on the assumption that anomie on this level can be considered to be the breakdown of normative social structure. The social systems selected included: the family, the neighborhood, the church, and the community.

At the level of the family, it is recognized that the breakdown of norms can be manifested in a number of ways. However, it is assumed that a family in some stage of dissolution will tend to be more likely to be anomic than one with all positions filled. Operationally anomic prone families, then, are considered to be: families with a single parent, families without a natural parent and single adults. This relationship was tested by the following hypothesis, expressed in the nu11.

$\mathrm{Ho}_{2}$ : Members of families in which one or more positions are vacant do not tend to experience a higher morbidity rate than do those families with all nuclear positions filled. Level of measurement is nominal.

TABLE XXIV

OVERALL MORBIDITY RATES SHOWN BY COMPLETENESS OF COMPOSITION IN A PREDOMINENTLY INDIGENT POPULATION OF SOUTH BATON ROUGE, HAMMOND, AND NEW ROADS, 1971

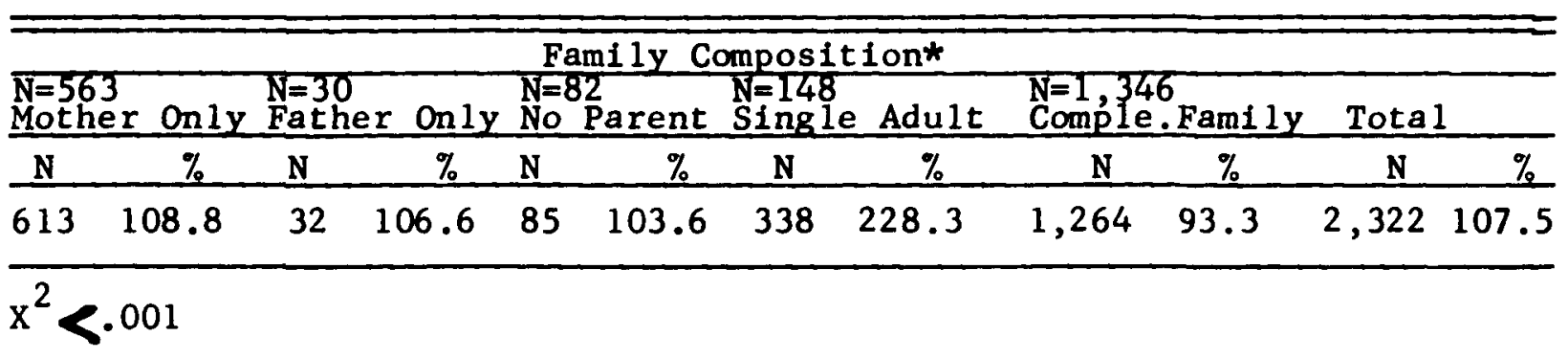


Test statistic used is Chi Square with the rejection range being .05 or less

$A \mathrm{X}^{2}$ of 61.62 was obtained. This is significant at less than the .05 level of confidence. Therefore, the $\mathrm{Ho}_{2}$ is rejected and the alternate hypothesis is accepted:

Although the Chi Square Value is obtained is highly significant and the null hypothesis is appropriately rejected, the apparent strength of this value may be misleading because of the large $N$. To determine the strength of this relationship a contingency coefficient was run with a $C$ value of .166 being obtained. This suggests that the tendency for members of incomplete families to experience higher rates of morbidity is not particularly strong.

Some question arises as to the appropriateness of the use of the $\mathrm{x}^{2}$ test statistic with these data since the independence between the frequencies of the several disease categories is not insured, thus, threatening the possibility of an inflated $x^{2}$ value. That is to say, a single individual may be a multiple pathology bearer causing him to be counted in more than one disease category. This apparently violates independentness of the sample. However, there are two conditions which tend to reduce this defect. First, the frequencies which are sought are not the frequencies with which individuals are found to appear in designated disease categories, but rather the frequencies with which the designated disease categories appear in specified populations. This being the case, independentness is violated only to the extent that one pathological condition might induce others. Secondly, this possibility was minimized, if not eliminated, by collapsing the pathology categories so that any multiple disease conditions which might bear an etiological relationship are counted in only one category. Thus, the resulting inflation of the $x^{2}$ value is reduced and it was decided that 
the use of this test statistic was not contraindicated. 22

It should be noted that $x^{2}$ is significant for each type of incomplete family structure. Another possible source of anomie occurs at the level of the family. This is the possibility that the norms may be made less clear to some individual members of the family. Thus, within the family constellation some members may be exposed to nomic structure while other members, because of some type of marginality, may be exposed to anomic conditions. In an effort to explore this, the parents were asked to designate which child they felt to be most unlike the rest of the family. Considering this to be the most atypical child and therefore, the one with the greatest likelihood to be marginal or, at least, related to differently by the other family members a comparison was made between the morbidity rates of such children and the rest of the children population as follows:

$\mathrm{Ho}_{3}$ : The overall morbidity rate of children is not positively associated with the quality of being "atypical."

TABLE XXV

OVERALL MORBIDITY RATES FOR ATYPICAL AND NORMAL CHILDREN IN A PREDOMINENTLY INDIGENT POPULATION OF SOUTH BATON ROUCF, HAMMOND, AND NEW ROADS, 1971

\begin{tabular}{ccccccc}
\hline & \multicolumn{1}{c}{ Status of ohild* } & & \\
\hline At ypica 1 & $\mathrm{N}=138$ & Norma 1 & $\mathrm{N}=918$ & \multicolumn{2}{c}{ Tota 1 } \\
\hline $\mathrm{N}$ & $\%$ & $\mathrm{~N}$ & $\%$ & $\mathrm{~N}$ & $\%$ \\
\hline 83 & 60.1 & 364 & 34.5 & 447 & 42.3 \\
\hline$* \mathrm{x}^{2}<.001$ & & & & &
\end{tabular}

${ }^{22}$ This decision was made in conference with Prentiss E. Schilling, Associate Professor, Experimental Statistics, Loulsiana State University, Baton Rouge, Louisiana, October 29, 1971. 
Leve 1 of measurement is nominal.

Test statistic used is Chi Square with the rejection range of .05 or less.

A $\mathrm{X}^{2}$ value of 12.261 was obtained. This is significant at the .05 level of confidence. Therefore, the nul1 hypothesis is rejected and the alternative hypothesis is accepted: The overall morbidity rate of children is positively associated with the quality of being "atypical." A C value of .107 was obtained, indicating that this relationship is not strong.

Other situations in which members of an "intact" family struc-

ture might experience anomic conditions is in those instances in which a member of the family is forced to attempt to fill a position for which he has not been socialized and for which society does not communt cate a set of norms to cover the deviance from the normal. The female head of household and male non-head of household are such positions. The relationship between morbidity and this type of anomie at the level of the social system is explored through the following set of hypotheses:

$\mathrm{Ho}_{4}$ : Morbidity rates are not significantly associated with the position of female head of household.

TABLE XXVI

OVERALL MORBIDITY RATES FOR HEAD OF HOUSEHOLD SHOWN BY SEX

IN A PREDOMINENTLY INDIGENT POPULATION OF SOUTH BATON ROUGE, HAMMOND, AND NEW ROADS, 1971

\begin{tabular}{ccccccc}
\hline & & Head of Household & & \\
\hline Ma le & $\mathrm{N}=330$ & Fema le* & $\mathrm{N}=235$ & \multicolumn{2}{c}{ Tota 1} \\
\hline $\mathrm{N}$ & $\%$ & $\mathrm{~N}$ & $\%$ & $\mathrm{~N}$ & $\%$ \\
\hline 515 & 156.1 & 577 & 245.5 & 1,092 & 193.3 \\
\hline $\mathrm{x}^{2}<.001$ & & & & &
\end{tabular}

$\mathrm{Ho}_{5}$ : The morbidity rate of the female head of household does not exceed that of the generally accepted female family position of wife of the head of household. 
TABLE XXVII

OVERALL MORBIDITY RATES FOR ADULT FEMALES SHOWN BY HOUSEHOLD POSITION IN A PREDOMINENTLY INDIGENT POPULATION OF SOUTH BATON ROUGE, HAMMOND, AND NEW ROADS, 1971

\begin{tabular}{|c|c|c|c|}
\hline \multicolumn{4}{|c|}{ Adult Female } \\
\hline Head of & Household* $\mathrm{N}=235$ & Nonhead & of Household $\mathrm{N}=296$ \\
\hline $\mathrm{N}$ & $\%$ & $\mathrm{~N}$ & $\%$ \\
\hline 577 & 245.5 & 508 & 171.6 \\
\hline
\end{tabular}

$\mathrm{Ho}_{6}$ : Morbidity rates are not significantly associated with the position of adult male non-head of household.

TABLE XXVIII

OVERALL MORBIDITY RATES FOR HUSBAND AND WIFE NON-HEAD OF HOUSEHOLD IN A PREDOMINENTLY INDIGENT POPULATION OF SOUTH BATON ROUGE, HAMMOND, AND NEW ROADS, 1971

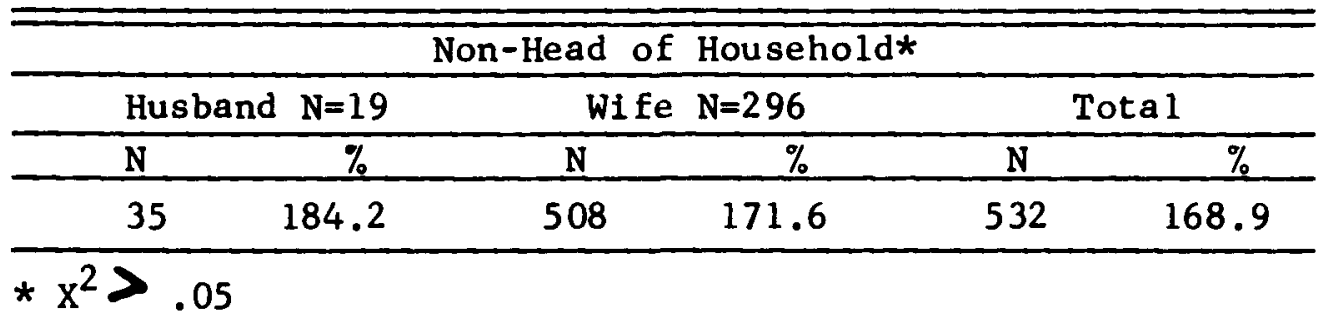

$\mathrm{Ho}_{7}$ : The morbidity rate of the adult male non-head of household does not exceed that of the generally accepted male family position of head of house hold.

TABLE XXIX

OVERALL MORBIDITY RATES FOR HUSBANDS SHOWN BY HOUSEHOLD POSITION IN A PREDOMINENTLY INDIGENT POPULATION OF SOUTH BATON ROUGE, HAMMOND, AND NEW ROADS, 1971

\begin{tabular}{ccccc}
\hline \hline \multicolumn{5}{c}{ Husbands $*$} \\
\hline Head of Household & $\mathrm{N}=330$ & Non-Head of & Household & $\mathrm{N}=19$ \\
\hline $\mathrm{N}$ & $\%$ & $\mathrm{~N}$ & $\%$ \\
\hline 515 & 156.1 & 35 & 184.2 \\
\hline $\mathrm{x}^{2}>.05$ & & &
\end{tabular}


Level of Measurement is nominal.

Test statistic used is Chi Square with the rejection range of .05 or less.

The following $\mathrm{X}^{2}$ and $\mathrm{C}$ values were obtained:

$\mathrm{Ho}_{4}$ : 57.07 and .303

$\mathrm{Ho}_{5}$ : 35.31 and .249

$\mathrm{Ho}_{6}$ : .288 and .094

Ho7: .115 and .054

All null hypotheses of this set, except $\mathrm{Ho}_{6}$ and $\mathrm{Ho}_{7}$ are rejected, the alter-hypotheses are accepted and it is assumed that high morbidity rates are associated with the atypical family position of female head of household. In the case of the male head of household, however, the association is not strong enough to produce a significantly higher morbidity rate than that found in the traditional role of female non-head of household or in the male nonhead of household.

In addressing the effect that anomic neighborhood social structure might have on morbidity rates it is recognized that, perhaps, the most valid approach would be to determine the level of anomie existing within neighborhoods and compare this level with morbidity rates. There appears to be no readily available instrument with which to accomplish this however. The approach taken in this study is to assume that geographically mobile families should be less well integrated into the normative structure of the community and thus should experience greater anomie on the neighborhood level. Predicated on this primitive, the families in this study were classified by the number of moves that they had made carrying them into new neighborhoods during the past year and the number of moves was then correlated with the overall morbidity rates of the family members.

Ho $_{8}$ : Overall morbidity rates are positively correlated with the number of interneighborhood moves made by a family. 
TABLE XXX

OVERALL MORBIDITY RATES SHOWN BY GEOGRAPHIC STABILITY OF FAMILIES IN A PREDOMINENTLY INDIGENT POPULATION OF SOUTH BATON ROUGE, HAMMOND, AND NEW ROADS, 1971

\begin{tabular}{|c|c|c|c|c|c|c|c|c|c|}
\hline \multicolumn{10}{|c|}{ Geographic Stability of Families* } \\
\hline No & Moves & One & or Two & Three & to Five & & er Five & & \\
\hline N & $\%$ & $\mathrm{~N}$ & $\%$ & $\mathbf{N}$ & $\%$ & $\mathrm{~N}$ & $\%$ & $\underline{N}$ & $\%$ \\
\hline 1,196 & 199.3 & 194 & 153.9 & 61 & 169.4 & 10 & 250.0 & 1,461 & 190.7 \\
\hline
\end{tabular}

Leve 1 of measurement is ordinal (since frequency of moves is expressed in unequal and in one case, open ended categories)

Test statistic selected is Kendall Rank Correlation Coefficient

A value of -.33 was obtained which is not significant at the .05 leve 1 of measurement. Therefore, the null hypothesis cannot be rejected and it must be concluded that the overall morbidity rate is not positively correlated with the number of interneighborhood moves made by a family.

Once the relationship of morbidity is extended beyond the level of the neighborhood two types of anomic conditions can be expected to exert an influence. One of these is the degree of anomie existing in the larger society. The other is the extent to which the individual is integrated into the larger social system. Addressing the latter condition first, it is not possible to measure this degree of integration at this time, but it is possible to select, a priory, those conditions that might mitigate such an integration and thus, prevent the individual from becoming a part of the normative social structure. Among such conditions might be a poverty of formal organization membership; low income, since much integration is purchased in our private enterprise 
society, and race. The formal organizational membership available to all the subjects of this study is church membership. Assuming, then, that the extent to which individuals participate in this available organization integrate them, at least partly, into the normative structure of the community an effort was made to compare overall morbidity rates for active and non-active church attenders and church contributors.

Hog: Overall morbidity rates are not negatively associated with regular church attendance.

TABLE XXXI

OVERALL MORBIDITY RATES SHOWN BY QUALITY OF CHURCH ATTENDANCE IN A PREDOMINENTLY INDIGENT POPULATION OF SOUTH BATON ROUGE, HAMMOND, AND NEW ROADS, 1971

\begin{tabular}{|c|c|c|c|}
\hline \multicolumn{4}{|c|}{ Quality of Church Participation* } \\
\hline $\mathbf{R e}$ & 761 & Nol & $\mathrm{N}=381$ \\
\hline $\mathrm{N}$ & $\%$ & $\mathbf{N}$ & $\%$ \\
\hline 1,833 & 104 & 470 & 123 \\
\hline
\end{tabular}

Ho $_{10}$ : Overall morbidity rates are not negatively associated with regular church contributions of time or money.

TABLE XXXII

OVERALL MORBIDITY RATES SHOWN BY QUALITY OF CHURCH CONTRIBUTION

IN A PREDOMINENTLY INDIGENT POPULATION OF SOUTH BATON ROUGE, HAMMOND, AND NEW ROADS, 1971

\begin{tabular}{|c|c|c|c|}
\hline \multicolumn{4}{|c|}{ Quality of Church Contribution* } \\
\hline \multicolumn{2}{|c|}{ Active $\mathrm{N}=1,084$} & \multicolumn{2}{|c|}{ Inactive $\mathrm{N}=461$} \\
\hline $\mathrm{N}$ & $\%$ & $\mathrm{~N}$ & $\%$ \\
\hline 1,766 & 105 & 538 & 117 \\
\hline
\end{tabular}


Level of measurement is nominal.

Test statistic is Chi Square and the rejection range of .05 or less.

A $X^{2}$ value of 8.820 was obtained for $\mathrm{Ho}_{9}$ and 48.588 for $\mathrm{Ho}_{10}$.

Both are significant at less than the .05 level of confidence.

Therefore, the null hypotheses are rejected and the alternate hypotheses are accepted. It is concluded, then, that overall morbidity rates are negatively associated with regular church attendance and the making of regular contributions of time or money to the church. The $\mathrm{C}$ values are .064 and .147 respectively.

In examining the relationship of overall morbidity rates and

income the highest income range was dropped as it is, an open ended range.

Ho11: There is no negative correlation between income range and overall morbidity rates.

TABLE XXXIII

OVERALL MORBIDITY RATES SHOWN BY LEVEL OF INCOME IN A PREDOMINENTLY INDIGENT POPULATION OF SOUTH BATON ROUGE, HAMMOND, AND NEW ROADS, 1971

\begin{tabular}{|c|c|c|c|c|c|c|}
\hline \multicolumn{7}{|c|}{ Levels of Income } \\
\hline $\begin{array}{l}\text { Under } \\
\$ 1,000\end{array}$ & $\begin{array}{r}1,00 \\
2,1\end{array}$ & 00 & $\begin{array}{r}2,0 \\
3,0\end{array}$ & & $\begin{array}{r}3,001- \\
4,000\end{array}$ & $\begin{array}{r}4,001- \\
5,000\end{array}$ \\
\hline $\mathbf{N}$ & $\mathrm{N}$ & $\%$ & $\mathrm{~N}$ & $\%$ & $\mathrm{~N} \quad \%$ & $\mathrm{~N} \quad \%$ \\
\hline $189 \quad 171.8$ & 667 & 151.2 & 508 & 104.3 & $238 \quad 96.7$ & 20093.5 \\
\hline $\begin{array}{r}5,001- \\
6,000 \\
\end{array}$ & $\begin{array}{r}6,00 \\
7,0 \\
\end{array}$ & 000 & $\begin{array}{r}7,0 \\
8, \\
\end{array}$ & & $\begin{array}{l}\text { Over } \\
8,000 \\
\end{array}$ & \\
\hline $\mathbf{N}$ & $\mathbf{N}$ & $\%$ & $\mathbf{N}$ & $\%$ & $\mathrm{~N} \quad \%$ & \\
\hline 77.8 & 59 & 61.4 & 100 & 75.2 & 18979.1 & \\
\hline
\end{tabular}

*Excluding the open ended category, $r=.9198<.001$.

Level of measurement is interval.

Measure of correlation is the Product-Moment Coefficient of Correlation. 
The measure of significance is the $F$ distribution with the rejection range of .05 or less.

An $r$ value of -.9198 was obtained producing an $F$ value of 63.29.

This is significant at less than .001 level of confidence. Therefore, the null hypothesis is rejected and the alternate hypothesis accepted. Overall morbidity rates tend to vary inversely with the family income range.

In examining the relationship between race and morbidity it

would seem reasonable to suspect that a member of any race denied entrance into the mainstream of social structure will suffer an anomic condition. Contemporary, liberal thinking suggests that Negroes suffer such a disadvantage. The Negro is constantly bombarded with messages depicting the desirable, ostensibly available material products of society yet frequently meets with fallure when he attempts to qualify for these goods. It would appear, then that membership in the Negro race might be an anomic condition and, as such, might be associated with high morbidity rates. This supposition is somewhat strengthened by the high correlation between income and perceived morbidity since the Negro family tends to have a lower income than the white family. This possible relationship is tested through the following null hypotheses:

Ho $_{12}$ : There is not a positive relationship between membership in the Negro race and overall perceived morbidity.

TABLE XXXIV

OVERALL MORBIDITY RATES SHOWN BY RACE IN A PREDOMINENTLY INDIGENT POPULATION OF SOUTH BATON ROUGE, HAMMOND, AND NEW ROADS, 1971

\begin{tabular}{cccc}
\hline & & Race* & \\
\hline & & White & $\mathrm{N}=470$ \\
\hline $\mathrm{N}$ & $\mathrm{N}=1691$ & $\mathrm{~N}$ & $\%$ \\
\hline 1809 & 107.0 & 520 & 110.6 \\
\hline $\mathrm{x}^{2}<.001$ & & &
\end{tabular}


Leve 1 of measurement is nominal.

Test statistic used is Chi Square with a rejection range of .05 or less.

A Chi Square value of 35.749 was obtained. This value is significant at the .05 level of confidence, but it is in the opposite direction of the hypothesis. Therefore, the null hypothesis cannot be rejected and it is concluded that there is no positive relationship between membership in the Negro race and morbidity.

It appears that perceived morbidity is significantly associated with anomie on a personality system level and on a social system level at the level of the family. Interneighborhood moves apparently are not associated with perceived morbidity while the quality of potential integration at a higher social system level is somewhat uncertain. Family income level is negatively correlated with perceived morbidity and church participation is negatively associated with perceived morbidity. Racial membership, however, does not appear to make a difference in terms of perceived morbidity. Although an attempt was made to relate perceived morbidity to anomie through these several variables, it is obvious that only on the level of the personality system is a direct measure of anomie used. At each of the other system levels the conditions ascribed to be anomic are complex and influence many areas of life style such as diet, sanitary conditions, and use of preventive health care practices, each of which may influence morbidity. Thus, where the nu11 hypotheses are rejected, it cannot be concluded that the relationship is with anomie, but only that it is not incompatible with the existence of anomie.

These relationships can be depicted in the conceptional framework of system levels as follows: 
FIGURE 2

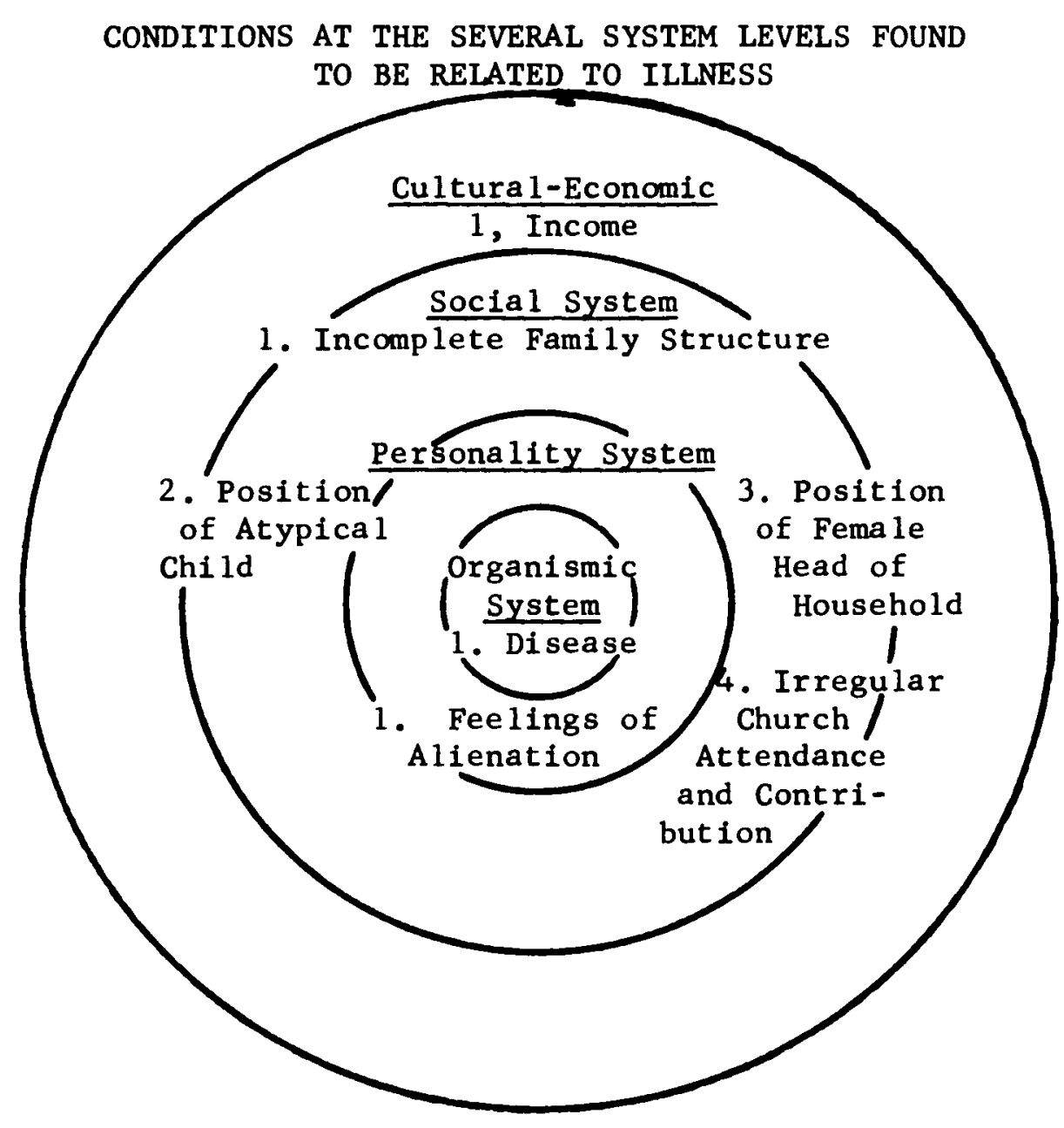

At this point sufficient information is available to provide the first logical test for the system model developed in Chapter II. This is a cybernetic model. Consequently it is only when it is behaving, that is producing out-puts and adjusting to feed back, that al1 of the components are functioning. The data presented in this chapter does not permit an examination of the system in operation. If the proposed system model is viable, however, it must be demonstrated that there is a relationship between the system internal monitors. This is necessary because even when the system is not behaving toward 
its environment it is still receiving stimuli from the environment. Since the internal monitors are assumed to influence each other stimuli recelved by each are ultimately transmitted to the others. Thus, pathogenic stimuli interpenitrating the organismic system monitor should disrupt the homeostasis of this system monitor, producing disease. This stress should, in turn, be transmitted to the personality system because of the interpenetration of the two systems. Stress in the personality system monitor is manifested by feelings of alienation. This stress, modifying the behavior of the individual personality systems, is transmitted to the social system structure. This transmission again results from the interpenetration of the two systems. The force of this stress on the soclal system ultimately results in a strain or distortion of social system structure. If this strain persists over time, alterations occur in the cultural system monitor.

of course this transmission of stress does not always proceed in this direction. Simultaneously it may be eminating from each of the other system monitors and radiating in all directions. Applying the relationships determined to exist in this chapter to the proposed system model produces the paradigm appearing in diagram 3 . 


\section{FIGURE 3}

\section{RELATIONSHIP OF CONDITIONS FOUND TO BE POSITIVELY ASSOCIATED WITH MORBIDITY TO SYSTEM PARADIGM}

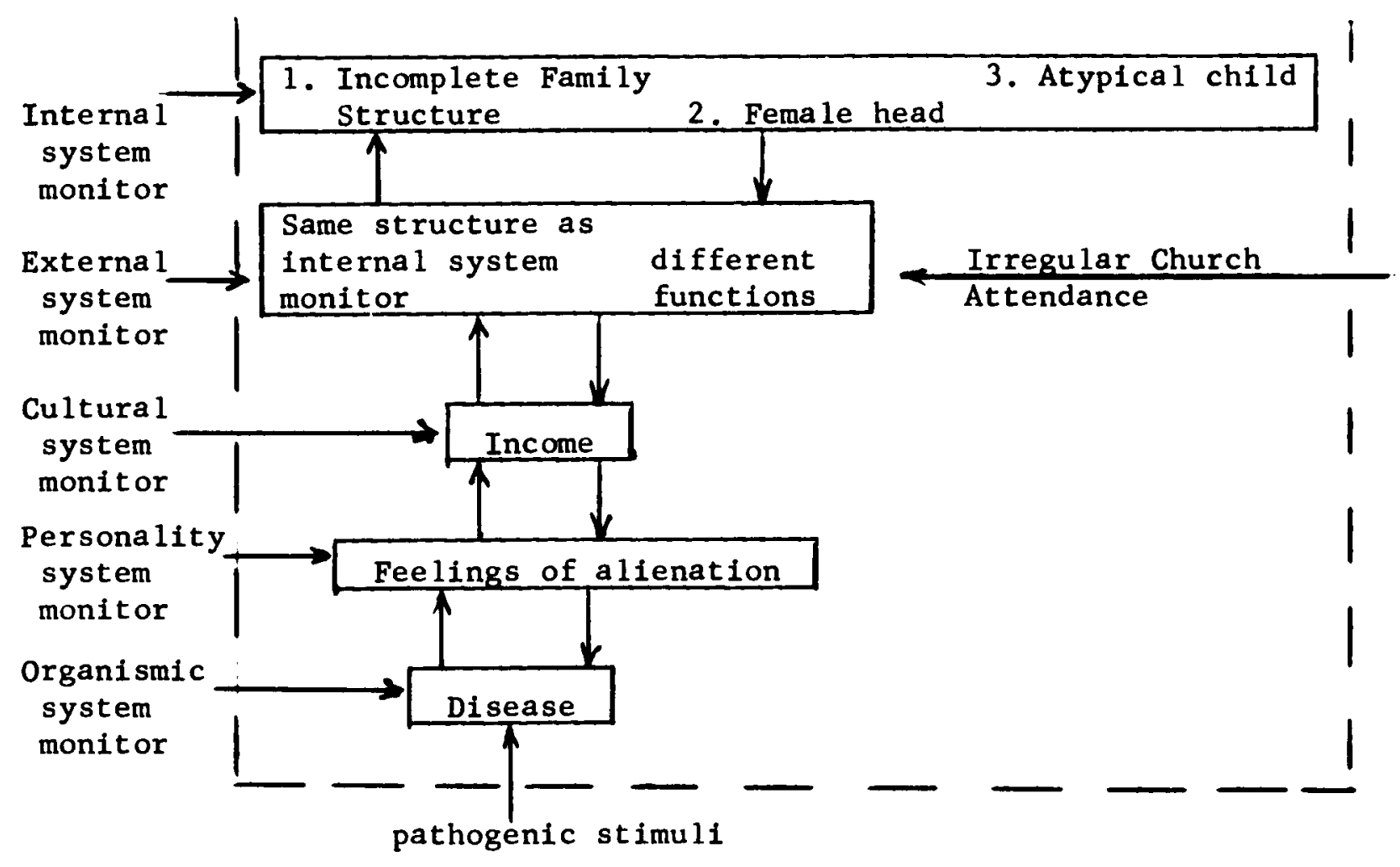

If interpreted from the perspective of a micro social structure such as a family system, this diagram suggests that the pathogenic stimuli entering the family system produces disease in one or more of its members. The environment, then, has been monitored for potentially noxious stimuli to the organismic and such a stimuli has been detected. Ultimately the system will react to this stimuli. First, however, stress occurs in the personality system monitor. Our specific data indicate that disease detected by the organismic monitor is positively associated with feelings of anomie in the personality system monitor either as effect, necessary but insufficient cause, or both. 
These feelings along with disease appear to be negatively related to income. Income is considered to be a parameter of the cultural system. It, itself, does not represent culture, but in a free enterprise society it represents a constraint on the quality of cultural stimuli to which the system may be exposed. The cultural system monitor provides an awareness of norms by which the symptoms (organismic monitor), the feelings (personality system monitor), and possible behaviors (internal and external system monitors) are perceived.

The internal system monitor and the external system monitor are comprised of the social structures of the system. A family system containing disease at the organismic leve 1 tends to be characterized by incomplete family structure and female head of the household. In the latter two instance it is this particular position which tends to also contain the pathology. In the case of the external system monitor it is necessary for some members of this social structure to maintain contacts with exogenous systems. These data indicate that a family system containing disease tends to be characterized by the diseased member participating in church only irregularly.

It appears that the proposed system model can accommodate the data presented in this chapter although it must be cautioned that it does not prove the model. 
CHAPTER V

HEALTH CARE UTILIZATION BY A PREDOMINANTLY

INDIGENT POPULATION

\section{Normative Utilization}

When a person is recognized as sick it is expected that he will seek competent medical treatment. In other words, he is expected to become an efficient health care consumer. With such an expectation of its members society must also have the responsibility to articulate acceptable health care consumer norms and to communicate them to its members in such a manner that all members of society have access to them. In our society this is accomplished through a variety of agents with some resulting inconsistency and confusion of articulated norms. The church is one agent which attempts to define acceptable health care utilization behavior. A cursory examination of church doctrine reveals a wide apparent variation in the orientation of religions to health care. The Catholic Church has a rather extensive body of doctrinal statements related to medical practice. For the most part these statements seem to be aimed more at the catholic health care provider than the Catholic health care consumer and are communicated through the Code of Ethical and Religious Directives for the Catholic Hospital Association. For the most part the specific directives appear to be based on the principles that direct k111ing of any innocent person, even at his own request, is always morally wrong and that every unborn child is considered as a human being with all the 
rights of a human person from the moment of conception. The Catholic Church, then, exerts its greatest influence in those areas of medicine concerned with the reproductive process and with imminent death. However, this influence does not seem to be so much a restriction of health care methods and procedures as it does a prohibition on motive. As such, it does not appear to be incompatible with existing health care practice, including that of psychotherapy, which was approved by Pope Pius XII.

Divine healing continues to be recognized in church doctrine and is very prominent in the Catholicism of parts of the world outside the United States where the healing power attributed to some shrines has become legend. There is no indication, though, that Catholicism relegates contemporary, professional, health care practice to an inferior position to devine healing.

Among the protestant churches represented in this study the doctrine of the Baptist and Methodist Churches tends to take liberal and cooperative attitudes toward present day health care behavior. The adherents of these religions, as with most Protestant groups, believe that God works through the physician in response to prayer. They recognize that the Apostle Luke was a physician and that God, therefore, holds a place for the doctor in caring for the sick. Although these church doctrines reject the belief in the efficacy of relics they, historically, embraced faith healing. Today, this belief does not remain strong in either of these churches.

The doctrine of the Mormon Church, during the time of Brigham 
Young, presented a very strong position against the use of professional medical care, preferring the laying on of hands and anointing with oil along with home remedies. The strength of this position has declined greatly since that cime. Now the doctrine of this church accepts the use of physicians. It does remain the practice, however, to call upon the elders to lay their hands upon the head of the patient and give him a blessing before he goes into surgery, requesting that the Lord's healing influence might attend him and guide and direct the surgeons and others assisting in the operation.

Seventh-Day Adventists have no formal prohibition against any form of medical treatment and leave it up to each individual to choose his own type of treatment. They do not preclude treatment by therapists other than medical doctors. The belief in modern day miracle healing is rejected. Although there is no formal prohibition against any form of health care, the Seventh-Day Adventists, as a group, strongly oppose blood transfusions, hypnosis and psychotherapy. 1

Formally, the doctrine of the Pentacostal Churches rejected professional health care. Even today some ultra-conservative sects continue to reject such medical care. A rather typical statement from the doctrine of one of these sects is, "let the unbeliever, who knows not God and has not faith in Him, turn to the sclence of man but to us who know God these things are a curse."2 The Pentecostal movement has

${ }^{1}$ Richard T. Barton, Religious Doctrine and Medical Practice, Springfield: Charles C. Thomas, 1958, Pp. 50-59, 65-67, 72-73, 75-76, and 77-79.

${ }^{2}$ H. Black, The Pentecosta 1 Movement, New York: Humanities Press, 1964, p. 149 . 
also revived the custom of using arpons or handkerchiefs as a means of healing. Even more restricting of health care consumption than the Pentecostal Church is the Christian Scientist Church which offers a viable system of health care through the church. ${ }^{3}$

As significant as the church's potential is in influencing the norms of health care utilization it is far from being the only such agent. Various patented medicines are advertised through the several mass media. Some marginal medical practitioners, such as the Chiropracter, may advertise through the media also, especially through the newspaper. Many of the cultural media may devote some attention to the norms of health care consumption. For example, novels, stories, and television and radio programs may include such content. Special agencies, such as the Departments of Public Welfare and Public Health, also provide the function of disseminating information regarding health care resource utilization to the potential consumer. Finally, the norms of health care utilization are often passed on by word of mouth from experienced consumers to potential consumers.

This variety of sources of information related to health care utilization probably results in a varlety of expected behavior patterns. However, it seems to be generally accepted that the most desirable source of health care is the medical profession. Although there are numerous reasons for not using a medical doctor the extent to which this is the case is some indication of the degree of deviation from expected health care utilization. 


\section{Quality of Medical Doctor Utilization}

Since the medical profession occupies such a prominent place in the provision of health care, it is appropos to begin the exploration of patterns of health care utilization with the patterns of use of the medical doctor. The first question that arises is whether there are some groups who enjoy an advantage in their relationship with the medical doctor. To gain insights into the nature of the relationship, the subjects in this sample were asked whether they felt that they had a particular medical doctor whom they could consider their family physician, the length of time since a member of their family last went to the doctor, whether this visit was to a physician located in the town in which they live, and the cost of this visit. These data were then tabulated by community, race, religion, family income and age. There is speculation in the literature that many members of ethnic groups may avoid seeking medical care because they fear the manner in which they will be treated or because they feel that because of their ethnic identity the doctor will charge prices far beyond the normal costs. ${ }^{4}$ Several factors have been found to influence geographic differences in the utilization of medical doctors. One of the most important factors is the distribution of physicians, who in turn are influenced by the availability of hospitals and other medical facilities. These facilities are most readily avallable in the more populous areas. 5 In view of these two relationships, it might be expected that

${ }^{4}$ Oscar N. Serbeen, Jr., Paying for Medical Care in the United States, New York: Columbia University Press, 1953, p. 215.

$5_{\text {Ibid. , p. } 217 .}$ 
the rural Negro would experience the poorest relationship with the medical doctor. The data in Table XXXV do not entirely support this contention. In terms of cost the Hammond Community offers the greatest advantage to the Negro. In all other categories, the urban area, Baton Rouge, does apparently provide the most advantage for the Negro. However, it is not Hammond, the community in transition, but the more rural community, New Roads, which offers the second greatest advantage to the Negro.

In view of the influence that religion has been assumed to have on the perception of illness and health care, it is possible that it might also exert an influence on the utilization of health care resources including the physician. In Table XXXVI, data reflecting the relationship between quality of utilization of physicians and religious affiliation are presented.

It appears from these data that there is some difference in the quality of utilization of physicians among the various religions included in the sample. Because the number of subjects in the Jewish, None, and other categories is so small it is impossible to make generalizations concerning them. This leaves only the Catholic, Non-medically Constricted Protestants and Medically Constricted Protestants. Among the members of these categories the Medically Constricted are the least likely to have a medical doctor with whom they relate closely enough to consider a family doctor. The Catholics are the most likely to have such a relationship. The Catholic religion is also the religious group whose members are the most likely to have family members 
TABLE XXXV

QUALITY OF UTILIZATION OF MEDICAL DOCTORS OF A PREDOMINENTLY INDIGENT POPULATION AS SHOWN BY COMMUNITY OF RESIDENCE AND RACE, 1971

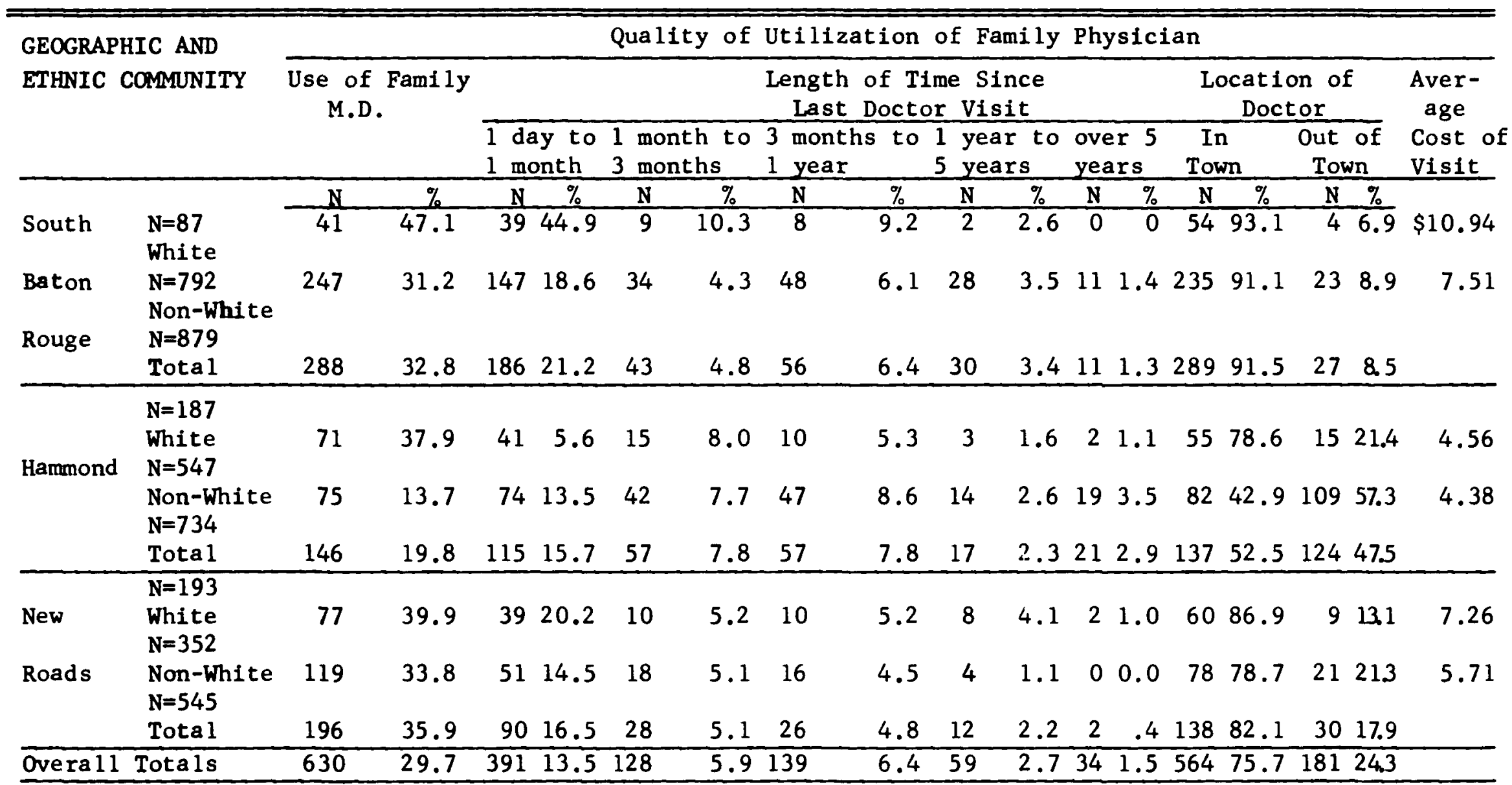


TABLE XXXVI

QUALITY OF UTILIZATION OF MEDICAL DOCTORS OF A PREDOMINENTLY INDIGENT POPULATION OF SOUTH BATON ROUGE, HAMMOND, AND NEW ROADS AS SHOWN BY RELIGIOUS

AFFILIATION, 1971

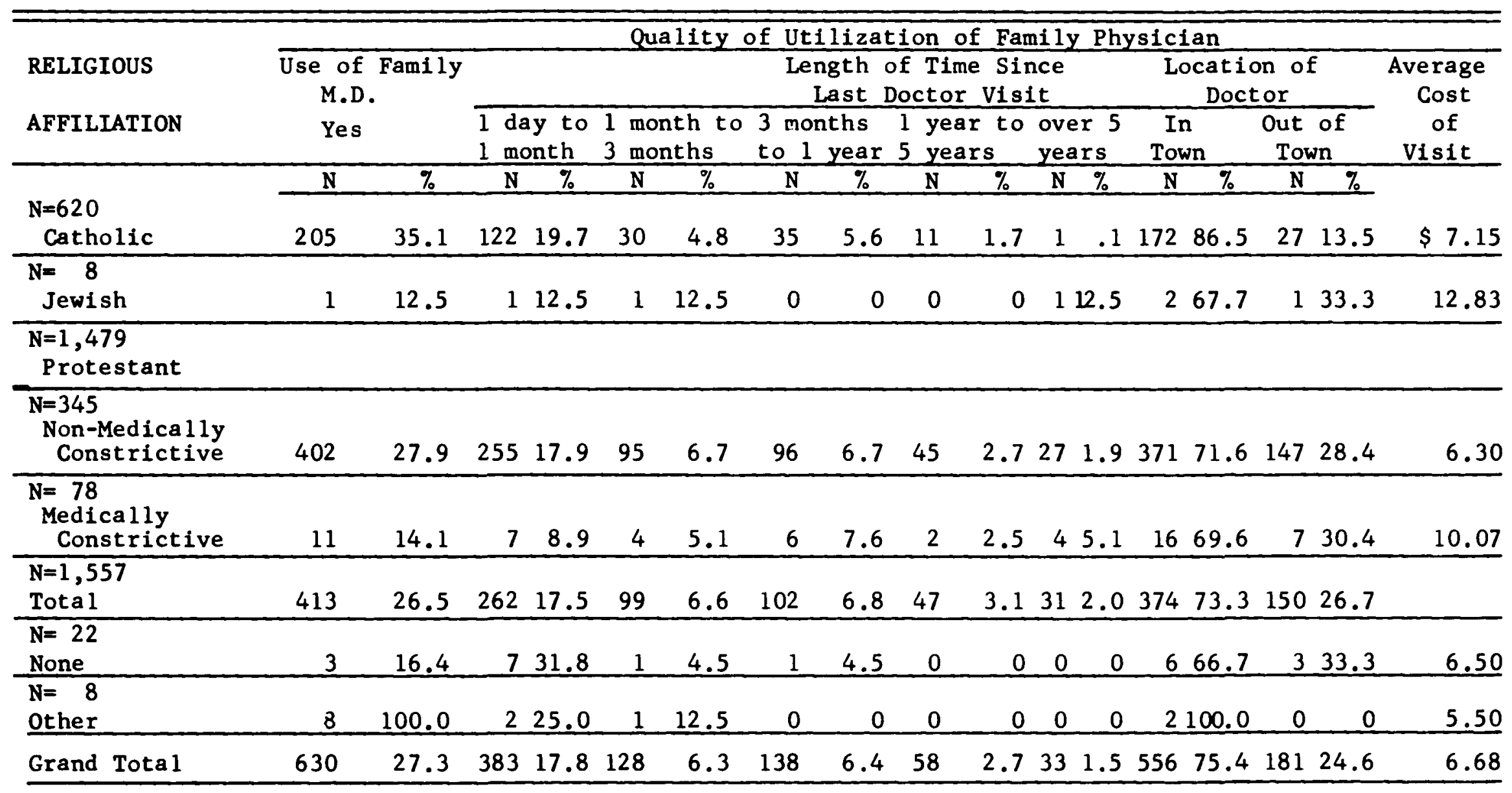


who have received recent medical care from a doctor while the members of the Medically Constricted groups are least likely. However, this latter group tends to pay the highest average cost per visit and to utilize out of town medical doctors at a higher rate. The members of the Catholic religion tend to use in-town medical doctors at a higher rate than either of the other two religious groups.

Morbidity rates are known to be related to age with a tendency to be high in the first years of $11 \mathrm{fe}$, minimal in the ages between 15-19, and to increase with advancing years. The average charge for medical care on a national basis falls along a curve which is only partly similar: the charges are lowest in the first years of life when morbidity rates are highest. However the charges are highest in the most advanced years when morbidity tends to increase again. Persons under the age of twenty years experience charges less than the average of those over twenty. The members of the age group between 25 and 34 experience charges about one third again as high as the average and those persons 65 years of age experience charges that are about twice as high as the average. 6

It might be expected that if health care utilization is efficient its rate should follow the general morbidity curve. The data in Table XXXVII suggest that this is not the case in the sample drawn for this study.

\footnotetext{
${ }^{6}$ Paul A. Dodd and E. F. Penrose, Economic Aspects of Medica 1 Services, Washington, D. C.: Graphic Arts Press, Inc., 1953, Pp. $103-104$.
} 
TABLE XXXVII

QUALITY OF UTILIZATION OF MEDICAL DOCTORS AS SHOWN BY AGE IN A PREDOMINENTLY INDIGENT POPULATION OF SOUTH BATON ROUGE, HAMMOND, AND NEW ROADS, 1971

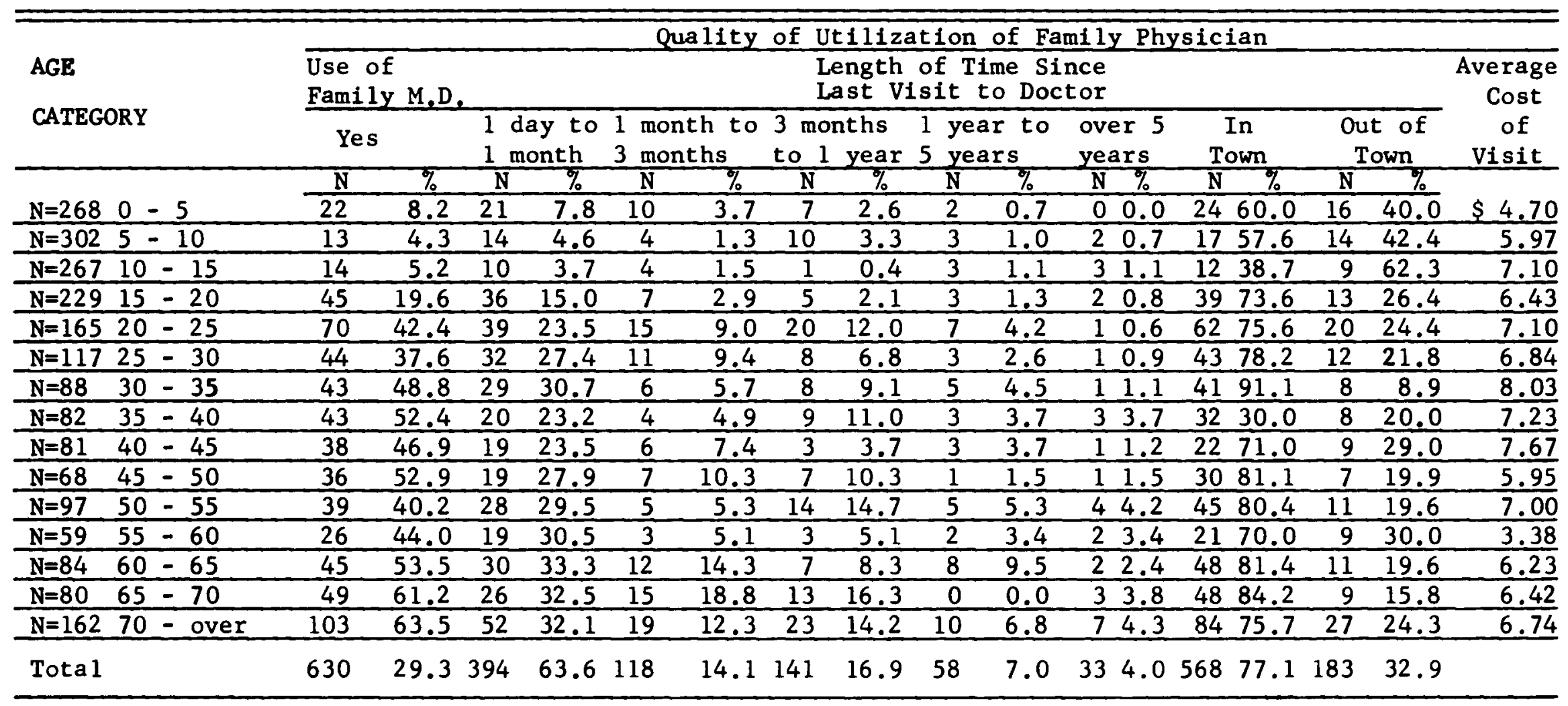


From these data it appears that, in general, the likelihood that the family member having made the most recent visit to a doctor did so within the past month increases with age. The highest average cost of doctor visits is found in the 30-35 year age group. There is a tendency for the very young person not to be identified with a family physician, while there is a stronger tendency for the age groups above 60 to have a family doctor. The members of the younger age groups, $0-15$, tend to be more likely to utilize an out of town doctor than those of the higher age groups.

Since most health care must be purchased, the possibility of income influencing its quality must be considered. Table XXXVIII shows the relationship between income and the quality of medical doctor utilization.

First, looking at the average cost of doctor visits, it is fortunately noted that, in general, as the family income is lower so also does the average cost of doctors visits tend to be lower. One feature of these data is the fact that level of family income is seen to show a relationship with the use of a family doctor. of those persons with an income of $\$ 1,000.00$ or less only 30.9 per cent use a physician which they identify as a family doctor. At the other end of the income range, however, over 42 per cent of the population with an income between $\$ 7,000-8,000$ use a family doctor. Actually all income ranges above the level of $\$ 6,000.00$ show a greater tendency than those below this level to use a family doctor. There is also a tendency for those persons with a family income of less than $\$ 6,000.00$, generally, to make 
TABLE XXXVIII

QUALITY OF UTILIZATION OF MEDICAL DOCTORS AS SHOWN BY LEVELS OF INCOME IN A PREDOMINENTLY INDIGENT POPULATION OF SOUTH BATON ROUGE, HAMMOND, AND NEW ROADS, 1971

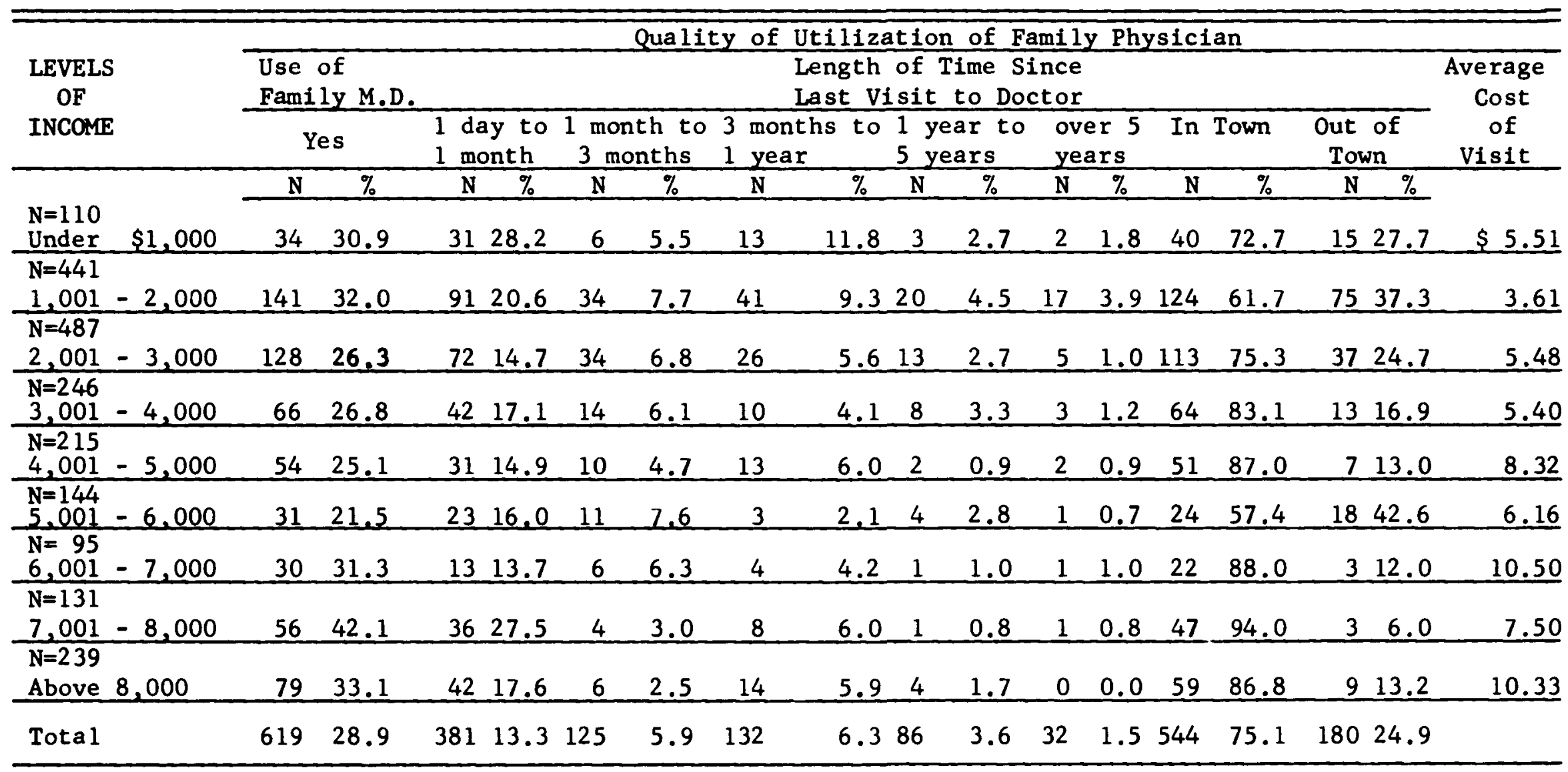


greater use of out-of-town doctors. It is also notable that persons with an income in excess of $\$ 7,000.00$ tend to have a higher rate of recent visits to a medical doctor than do any of the persons in the lower income levels. Since persons in the lower income levels tend to have a higher morbidity rate, the tendency for persons in the upper income levels to show a higher rate of recent doctor visits suggests that some of the pathology of the lower income groups may go untreated. Another possibility exists, however. That is that members of lower income groups may tend to use community health caretakers other than medical doctors.

Tables XXXIX, XL, and XII attempt to explore this above possibility. In Table XXXIX are data on the rate of use of various community caretakers by income range. These data were gathered by asking each member of the family who had decisional jurisdiction over the selection of community caretakers, which ones they went to first and then second. Since the number of such persons does not conform perfectly with the total number of subjects the percentages computed using the number of subjects as the base are not precise, but should provide a relatively valid measure.

These data do not support the belief that members of the lower income groups prefer to seek out community caretakers other than the medical doctor as a first effort in seeking medical care. Indeed, the members of the lower income ranges preferred to go to a medical doctor as a first or second choice more frequently than did the members in the higher income ranges. This is true when the income ranges above 
TABLE XXXIX

RATE OF USE OF VARIOUS COMMUNTTY CARETAKERS AS FIRST OR SECOND CHOICES BY PERSONS OF DIFFERENT INCOME RANGES IN A PREDOMINENTLY INDIGENT POPULATION OF SOUTH BATON ROUGE, HAMMOND, AND NEW ROADS, 1971

\begin{tabular}{|c|c|c|c|c|c|c|c|c|c|c|c|}
\hline \multirow{3}{*}{$\begin{array}{l}\text { COMMUNITY } \\
\text { CARETAKER }\end{array}$} & \multicolumn{11}{|c|}{ Income Range } \\
\hline & $\begin{array}{l}\mathrm{N}=110 \\
0- \\
1,000\end{array}$ & $\begin{array}{l}\mathrm{N}=441 \\
1,001- \\
2,000\end{array}$ & $\begin{array}{l}\mathrm{N}=487 \\
2,001- \\
3,000\end{array}$ & $\begin{array}{l}\mathrm{N}=246 \\
3,001- \\
\quad 4,000\end{array}$ & $\begin{array}{l}N=215 \\
4,001- \\
5,000\end{array}$ & \multirow[t]{2}{*}{$\begin{array}{l}\mathrm{N}=144 \\
5,001- \\
6,000\end{array}$} & \multirow[t]{2}{*}{$\begin{array}{l}N=95 \\
6,001- \\
7,000 \\
N\end{array}$} & \multirow[t]{2}{*}{$\begin{array}{l}N=131 \\
7,001- \\
8,000 \\
N\end{array}$} & $\begin{array}{l}\mathrm{N}=239 \\
\text { over } \\
8,000\end{array}$ & \multicolumn{2}{|c|}{ Tota 1} \\
\hline & $\mathrm{N} \%$ & $\mathrm{~N} \%$ & $\mathrm{~N} \%$ & $\mathrm{~N} \%$ & $\mathrm{~N} \%$ & & & & $\mathrm{~N} \%$ & $\mathrm{~N}$ & $\%$ \\
\hline $\begin{array}{l}\text { No } \\
\text { Response* }\end{array}$ & 0.0 & 0.7 & 0.6 & 0.8 & 2.3 & 2.1 & 0.0 & 0.0 & 0.0 & 16 & 1.6 \\
\hline $\begin{array}{l}\text { Medica } 1 \\
\text { Doctor }\end{array}$ & $46 \quad 41.8$ & $136 \quad 30.9$ & $122 \quad 25.1$ & 6124.8 & 4822.3 & $26 \quad 18.1$ & 2121.9 & 3324.8 & $50 \quad 20.9$ & 543 & 55.0 \\
\hline $\begin{array}{l}\text { Friend or } \\
\text { Neighbor }\end{array}$ & 1.8 & 6.3 & 4.3 & 1.2 & 1.0 & 3.5 & 2.1 & 0.0 & 1.2 & 66 & 6.7 \\
\hline Spouse & $5 \quad 4.5$ & 2.0 & 5.3 & 2.8 & 3.3 & 4.9 & $14 \quad 14.6$ & 1410.6 & 5.4 & 102 & 10.3 \\
\hline Druggist & .9 & 0.2 & 0.4 & 0.0 & 10.5 & 0.0 & $0 \quad 0.0$ & 0.0 & 0.0 & 5 & .5 \\
\hline Relative & 1715.4 & 5312.0 & 7.8 & 8.9 & $18 \quad 8.4$ & 9.1 & $8 \quad 8.3$ & 9.1 & 9.2 & 203 & 20.5 \\
\hline God & 1.8 & 2.2 & 0.8 & 2.0 & 1.4 & 0.0 & 0.0 & 0.8 & 0.0 & 25 & 2.5 \\
\hline Other & 1.8 & 2.8 & 0.8 & 0.8 & 0.5 & 2.1 & 2.1 & 0.0 & 0.8 & 28 & 2.8 \\
\hline Tota 1 & $75 \quad 68.2$ & $252 \quad 57.1$ & $220 \quad 45.2$ & 10241.5 & $85 \quad 39.5$ & 5739.6 & 4749.0 & 6045.1 & $90 \quad 37.7$ & 988 & 46.8 \\
\hline
\end{tabular}

*Does not include persons without decisional jurisdiction for health care. 
TABLE XL

RATES OF USE OF SELECTED COMMUNITY CARETAKERS DURING COURSE OF ILLNESS BY PERSONS

OF DIFFERENT INCOME RANGES IN A PREDOMINENTLY INDIGENT POPULATION

OF SOUTH BATON ROUGE, HAMMOND, AND NEW ROADS, 1971

\begin{tabular}{|c|c|c|c|c|c|c|c|c|c|c|c|c|c|c|c|c|c|c|c|c|}
\hline \multirow{3}{*}{$\begin{array}{l}\text { COMMUNITY } \\
\text { CARETAKER }\end{array}$} & \multicolumn{20}{|c|}{ Income Range } \\
\hline & \multicolumn{2}{|c|}{$\begin{array}{l}0- \\
1,000\end{array}$} & \multicolumn{2}{|c|}{$\begin{array}{l}1,001- \\
2,000\end{array}$} & \multicolumn{2}{|c|}{$\begin{array}{r}2,001- \\
3,000\end{array}$} & \multicolumn{2}{|c|}{$\begin{array}{r}3,001- \\
4,000\end{array}$} & \multicolumn{2}{|c|}{$\begin{array}{l}4,001- \\
5,000\end{array}$} & \multicolumn{2}{|c|}{$\begin{array}{l}5,001- \\
6,000\end{array}$} & \multicolumn{2}{|c|}{$\begin{array}{l}6,001- \\
7,000\end{array}$} & \multicolumn{2}{|c|}{$\begin{array}{l}7,001- \\
8,000\end{array}$} & \multicolumn{2}{|c|}{$\begin{array}{l}\text { over } \\
\quad 8,000\end{array}$} & \multicolumn{2}{|c|}{ Tota 1} \\
\hline & $\mathrm{N}$ & $\%$ & $\mathrm{~N}$ & $\%$ & $N$ & $\%$ & $\mathrm{~N}$ & $\%$ & $\mathrm{~N}$ & $\%$ & $\mathrm{~N}$ & $\%$ & $\mathrm{~N}$ & $\%$ & $\mathrm{~N}$ & $\%$ & $\mathrm{~N}$ & $\%$ & $\mathrm{~N}$ & $\%$ \\
\hline $\begin{array}{l}\text { Friend or } \\
\text { Neighbor }\end{array}$ & 12 & 10.0 & 59 & 13.4 & 34 & 7.0 & 23 & 9.3 & 15 & 7.0 & 11 & 7.6 & 6 & 6.3 & 8 & 6.0 & 15 & 6.3 & 183 & 34.3 \\
\hline $\begin{array}{l}\text { Minister } \\
\text { or Priest }\end{array}$ & 6 & 5.5 & 36 & 8.2 & 20 & 4.1 & 7 & 2.8 & 8 & 3.7 & 7 & 4.9 & 3 & 3.1 & 7 & 5.3 & 9 & 3.8 & 103 & 19.3 \\
\hline Druggist & 15 & 13.6 & 58 & 13.2 & 57 & 11.7 & 30 & 12.2 & 13 & 6.0 & 16 & 11.1 & 14 & 14.6 & 16 & 12.0 & 29 & 12.1 & 248 & 46.4 \\
\hline Tota 1 & 33 & 30.0 & 153 & 34.7 & 111 & 22.8 & 60 & 24.4 & 36 & 16.7 & 34 & 23.6 & 23 & 24.0 & 31 & 23.3 & 53 & 22.2 & 534 & 25.3 \\
\hline
\end{tabular}


TABLE XLI

RATE OF USE OF SELECTED COMMUNITY CARETAKERS BY PERSONS OF DIFFERENT INCOME RANGES IN A PREDOMINENTLY INDIGENT POPULATION OF BATON ROUGE, HAMMOND, AND NEW ROADS, 1971

\begin{tabular}{|c|c|c|c|c|c|c|c|c|c|c|c|c|c|c|c|c|}
\hline \multirow{3}{*}{$\begin{array}{l}\text { COMMUNITY } \\
\text { CARETAKER }\end{array}$} & \multicolumn{16}{|c|}{ Income Range } \\
\hline & $0-$ & \multicolumn{2}{|c|}{$\begin{array}{r}1,001- \\
2,000 \\
\end{array}$} & \multicolumn{2}{|c|}{$\begin{array}{r}2,001- \\
3,000 \\
\end{array}$} & \multicolumn{2}{|c|}{$\begin{array}{r}3,001- \\
4,000 \\
\end{array}$} & \multicolumn{2}{|c|}{$\begin{array}{r}4,001- \\
5,000 \\
\end{array}$} & $\begin{array}{r}5,001- \\
6,000 \\
\end{array}$ & $\begin{array}{r}6,001- \\
7,000\end{array}$ & $\begin{array}{r}7,001- \\
8,000\end{array}$ & \multicolumn{2}{|c|}{$\begin{array}{l}\text { over } \\
8,000\end{array}$} & \multicolumn{2}{|c|}{ Tota 1} \\
\hline & $\mathrm{N} \%$ & $\mathrm{~N}$ & $\%$ & $\mathbf{N}$ & $\%$ & $\mathbf{N}$ & $\%$ & $\mathbf{N}$ & $\%$ & $\mathrm{~N} \%$ & $\mathrm{~N} \%$ & $\mathrm{~N} \%$ & $\mathbf{N}$ & $\%$ & $\mathrm{~N}$ & $\%$ \\
\hline $\begin{array}{l}\text { Faith } \\
\text { Healer }\end{array}$ & 0.0 & 5 & 1.1 & 3 & .6 & 1 & .4 & 2 & .9 & 0.0 & 0.0 & .8 & 0 & 0.0 & 12 & 1.2 \\
\hline Other & 1311.8 & 41 & 9.3 & 18 & 3.7 & 23 & 9.3 & 9 & 4.2 & 2.1 & 5.2 & 4.5 & 13 & 5.4 & 131 & 12.8 \\
\hline No One & 5045.5 & 219 & 49.7 & 199 & 40.9 & 70 & 28.5 & 84 & 39.1 & $65 \quad 45.1$ & 3233.3 & 6246.6 & 87 & 36.4 & 868 & 84.8 \\
\hline
\end{tabular}


$\$ 7,000.00$ are contrasted with the levels below $\$ 3,000.00$. The informants in the upper income levels tended to turn to their spouse first at a higher rate than the members of the lower income levels did. Because the data in Table XXXIX reflects desired behavior rather than actual behavior, an effort was made to explore the actual utilization of community caretakers. This was done by asking the subjects if they ever went to any one of several identified community care takers. The responses to this item are recorded in Table XL.

These data provide a somewhat different configuration and, seemingly, suggest that the members of the lower income levels tend to utilize each of tha community health caretakers at a higher rate than do the members of the income ranges above $\$ 7,000.00$. This finding seems to imply that the members of the lower income levels utilize a wider range of caretakers.

The above discovery offers one possible explanation of how the greater pathology of the lower income levels are accommodated to a lower frequency of medical doctor utilization. In an effort to expand this inquiry to include health care providers that were not anticipated in the enumeration of providers contained in the previously discussed item, the subjects were asked to give any other types of help which they might seek when they are sick. Table XLI contains the results of this query.

Only two additional types of providers were mentioned in response to the above query in significant numbers. These were faith healers and chiropractors, with members of the lower income groups being slightly 
more inclined to utilize faith healers and members of the higher income ranges slightly more inclined to use the chiropractor. However, there is the possibility that the lower income group subjects may not be as sensitive to the distinction between the chiropractor and the medical doctor. Surprisingly few subjects tended to utilize these two health care providers, suggesting a rather sophisticated utilization of health care resources by the sample population.

It is entirely possible that influences other than level of income are associated with health care utilization. One of the most obvious constraints on such behavior is the existence of health care facilities. A wider variety of such facilities exist in urban areas than in rural areas. Consequent ly, regardless of the effectiveness with which health care consumption norms are articulated if the resources are not available the norms cannot be executed. This should lead to a different pattern of utilization between rural and urban areas, with urban residents tending to use more technologically sophisticated services and rural residents attempting to "make do" with the limited services available to them.

Table XLII shows the various sources of help to which the indigent populations of South Baton Rouge Neighborhood, Hammond, and New Roads turned to immediately for health care. These data are shown by race and were obtained from each member of the family having decisional jurisdiction over health care consumption. Since each person who responded to this item was asked to list the "two" sources of help that he would consult immediately upon becoming 111 in the sequence that he 
TABLE XLII

RATE OF USE OF VARIOUS COMMUNITY CARETAKERS AS FIRST OR SECOND CHOICE BY PREDOMINANTLY INDIGENT POPULATIONS OF THREE COMMUNITIES SHOWN BY RACE, 1971

\begin{tabular}{|c|c|c|c|c|c|c|c|c|c|c|c|c|c|c|c|c|}
\hline \multirow{3}{*}{$\begin{array}{l}\text { COMMUNITY } \\
\text { CARETAKER }\end{array}$} & \multicolumn{16}{|c|}{ Communities } \\
\hline & \multicolumn{2}{|c|}{ White } & \multicolumn{2}{|c|}{ Black } & \multicolumn{2}{|c|}{ White } & \multicolumn{2}{|c|}{ Black } & \multicolumn{2}{|c|}{ White } & \multicolumn{2}{|c|}{ Black } & \multicolumn{2}{|c|}{ White } & \multicolumn{2}{|c|}{ Black } \\
\hline & $\mathrm{N}$ & $\%$ & $\mathrm{~N}$ & $\%$ & $\mathrm{~N}$ & $\%$ & $\mathrm{~N}$ & $\%$ & $\mathrm{~N}$ & $\%$ & $\mathrm{~N}$ & $\%$ & $\mathrm{~N}$ & $\%$ & $\mathrm{~N}$ & $\%$ \\
\hline & \multicolumn{2}{|c|}{$\mathrm{N}=87$} & \multicolumn{2}{|c|}{$\mathrm{N}=792$} & \multicolumn{2}{|c|}{$\mathrm{N}=187$} & \multicolumn{2}{|c|}{$\mathrm{N}=547$} & \multicolumn{2}{|c|}{$\mathrm{N}=193$} & \multicolumn{2}{|c|}{$\mathrm{N}=352$} & \multicolumn{2}{|c|}{$\mathrm{N}=467$} & \multicolumn{2}{|c|}{$\mathrm{N}=1,691$} \\
\hline No Response & 1 & 1.1 & 14 & 1.8 & 0 & 0.0 & 0 & 0.0 & 0 & 0.0 & 2 & 0.6 & 1 & 0.2 & 16 & 0.9 \\
\hline $\begin{array}{l}\text { Friend or } \\
\text { Neighbor }\end{array}$ & 6 & 6.9 & 21 & 2.7 & 9 & 4.8 & 14 & 2.6 & 9 & 4.7 & 9 & 2.6 & 24 & 5.1 & 44 & 2.6 \\
\hline Spouse & 11 & 12.6 & 22 & 2.8 & 14 & 7.5 & 30 & 5.5 & 13 & 6.7 & 14 & 4.0 & 38 & 8.1 & 66 & 3.9 \\
\hline Relative & 23 & 26.4 & 58 & 7.3 & 22 & 11.8 & 56 & 10.2 & 20 & 10.4 & 30 & 8.5 & 65 & 13.9 & 144 & 8.5 \\
\hline God & 1 & 1.1 & 7 & 0.9 & 2 & 1.1 & 15 & 2.7 & 0 & 0.0 & 1 & 0.3 & 3 & 0.6 & 23 & 1.3 \\
\hline Other & 2 & 2.2 & 9 & 1.1 & 3 & 1.6 & 9 & 1.6 & 2 & 1.0 & 4 & 1.1 & 7 & 2.4 & 22 & 1.3 \\
\hline Total & 70 & 80.5 & 327 & 41.3 & 120 & 64.2 & 253 & 46.3 & 99 & 51.3 & 142 & 40.3 & 289 & 61.4 & 722 & 42.6 \\
\hline
\end{tabular}


would consult them, the column totals represent the total number of frequencies with which all categories of caretakers were mentioned. These data reveal that it is not in the most urban area that the most frequent use of the medical doctor is made as an initial source of health care. Instead, it is the community in transition that possesses this characteristic. In each community, however, the medical doctor was selected either as the first or second choice of health care provider at a much higher rate than any other health caretaker. The next most frequently listed caretaker was "relative," followed by "spouse," "friend or neighbor," "God," and "druggist" in al1 communities.

The differences between races is much greater than the differences between communities. The Negroes displayed a tendency to utilize the druggist and God at a higher rate than did the Whites. The Whites tended to utilize the spouse, relative, medical doctor, and friend or neighbor at a higher rate than did Negroes.

Table XLIII contains data on the rate of use of several community caretakers over the course of an $i 11$ ness.

Here we see that the rank order of the frequency of use of each of these caretakers is the same for the communities of South Baton Rouge Neighborhood and Hammond with the residents of each tending to use the druggist most, a friend or neighbor next most frequently and the minister or priest third most frequently for medical advice when they are i11. In New Roads, the most frequently used source of help is the friend or neighbor, the second most frequently used is the druggist 
TABLE XLIII

RATE OF USE OF VARIOUS COMMUNITY CARETAKERS DURING COURSE OF ILLNESS BY THE INDIGENT POPULATIONS OF THREE COMMUNITIES SHOWN BY RACE, 1971

\begin{tabular}{|c|c|c|c|c|c|c|c|c|c|c|c|c|c|c|c|c|}
\hline \multirow{5}{*}{$\begin{array}{l}\text { COMMUNITY } \\
\text { CARETAKER }\end{array}$} & \multicolumn{16}{|c|}{ Communities } \\
\hline & \multicolumn{4}{|c|}{ South Baton Rouge } & \multicolumn{4}{|c|}{ Hammond } & \multicolumn{4}{|c|}{ New Roads } & \multicolumn{4}{|c|}{ Total } \\
\hline & \multicolumn{2}{|c|}{ White } & \multicolumn{2}{|c|}{ Black } & \multicolumn{2}{|c|}{ White } & \multicolumn{2}{|c|}{ Black } & \multirow{2}{*}{\multicolumn{2}{|c|}{$\begin{array}{l}\text { White } \\
\mathrm{N}=193\end{array}$}} & \multirow{2}{*}{\multicolumn{2}{|c|}{$\begin{array}{r}\text { Black } \\
\text { N }=352\end{array}$}} & \multirow{2}{*}{\multicolumn{2}{|c|}{$\begin{array}{l}\text { White } \\
\mathrm{N}=467\end{array}$}} & \multicolumn{2}{|c|}{ Black } \\
\hline & \multicolumn{2}{|c|}{$\mathrm{N}=87$} & \multicolumn{2}{|c|}{$\mathrm{N}=792$} & \multicolumn{2}{|c|}{$\mathrm{N}=187$} & \multicolumn{2}{|c|}{$N=547$} & & & & & & & \multicolumn{2}{|c|}{$\mathrm{N}=1,691$} \\
\hline & $\mathrm{N}$ & $\%$ & $\mathrm{~N}$ & $\%$ & $\mathrm{~N}$ & $\%$ & $\mathrm{~N}$ & $\%$ & $\mathrm{~N}$ & $\%$ & $\mathrm{~N}$ & $\%$ & \multicolumn{2}{|c|}{$\begin{array}{rr} & \mathrm{N}=461 \\
\mathrm{~N} & \% \\
\end{array}$} & $\mathrm{~N}$ & $\%$ \\
\hline $\begin{array}{l}\text { Friend or } \\
\text { Neighbor }\end{array}$ & 12 & 13.7 & 63 & 7.9 & 22 & 11.7 & 45 & 8.2 & 15 & 7.7 & 30 & 8.5 & 49 & 10.4 & 138 & 8.1 \\
\hline $\begin{array}{l}\text { Minister } \\
\text { or Priest }\end{array}$ & 3 & 3.4 & 24 & 3.0 & 24 & 12.8 & 32 & 5.8 & 5 & 2.5 & 16 & 4.5 & 32 & 6.8 & 72 & 4.2 \\
\hline Druggist & 12 & 13.7 & 91 & 11.4 & 28 & 14.9 & 76 & 13.8 & 21 & 10.8 & 19 & 5.3 & 61 & 13.0 & 186 & 10.9 \\
\hline Total & 27 & 31.0 & 178 & 21.4 & 74 & 39.5 & 153 & 27.9 & 41 & 21.2 & 65 & 18.4 & 142 & 30.4 & 396 & 23.4 \\
\hline
\end{tabular}


and, again, fewer subjects in this community tend to go to the minister or priest than any of the other of these several caretakers.

In terms of patterns of utilization of these several sources of help the people in the most rural community, New Roads, tended to turn to friends or neighbors at a much higher rate than the residents in the other two communities. The subjects in Hammond tended to make greatest use of the minister or priest, and the residents of South Baton Rouge Neighborhood tended to utilize the druggist at a higher rate than the residents of either of the other two communities. The difference between races in the utilization of these particular health care resources is not remarkable, as the rank order remains the same in each. It does appear that the Whites tended to utilize friends or neighbors, and ministers or priests at a somewhat higher rate while the Negroes tended to turn to the druggist at a higher rate than did the Whites. of some interest is the fact that the rate at which the Negroes utilized the minister or priest in relation to the other two listed categories of caretaker tends to decrease progressively with the stage of urbanization of these three communities while the rate at which they turned to the druggist varied in the opposite direction. This latter condition is true of the Whites as well.

The responses to the item asking the subjects whether they ever use any other source of help when they are 111 are tabulated in Table XLIV, by community and race.

According to these data the residents of the most rural community, New Roads, had the lowest rate of utilization of faith healers. 
TABLE XLIV

RATE OF USE OF VARIOUS COMMNITY CARETAKERS BY PREDOMINANTLY INDIGENT POPULATIONS OF THREE COMMUNITIES SHOWN BY RACE, 1971

\begin{tabular}{|c|c|c|c|c|c|c|c|c|c|c|c|c|c|c|c|c|}
\hline \multirow{2}{*}{$\begin{array}{l}\text { COMMUNITY } \\
\text { CARETAKER }\end{array}$} & \multicolumn{2}{|c|}{$\begin{array}{l}\text { White } \\
\mathrm{N}=87\end{array}$} & \multicolumn{2}{|c|}{$\begin{array}{l}\text { Black } \\
\mathrm{N}=792\end{array}$} & \multicolumn{2}{|c|}{$\begin{array}{l}\text { White } \\
\mathrm{N}=187\end{array}$} & \multicolumn{2}{|c|}{$\begin{array}{l}\text { Black } \\
\mathrm{N}=547\end{array}$} & \multicolumn{2}{|c|}{$\begin{array}{l}\text { White } \\
\mathrm{N}=193 \\
\end{array}$} & \multicolumn{2}{|c|}{$\begin{array}{l}\text { Black } \\
\mathrm{N}=352\end{array}$} & \multicolumn{2}{|c|}{$\begin{array}{l}\text { White } \\
\mathrm{N}=467\end{array}$} & \multicolumn{2}{|c|}{$\begin{array}{l}\text { Black } \\
\mathrm{N}=1,691\end{array}$} \\
\hline & $\mathrm{N}$ & $\%$ & $\mathrm{~N}$ & $\%$ & $\mathrm{~N}$ & $\%$ & $\mathrm{~N}$ & $\%$ & $\mathbf{N}$ & $\%$ & $\mathrm{~N}$ & $\%$ & $\mathrm{~N}$ & $\%$ & $\mathrm{~N}$ & $\%$ \\
\hline $\begin{array}{l}\text { Faith } \\
\text { Hea ler }\end{array}$ & 1 & 1.1 & 4 & 9.5 & 1 & 0.5 & 4 & 0.7 & 0 & 0.0 & 2 & .5 & 2 & 0.4 & 10 & 0.5 \\
\hline Chiropractor & 1 & 1.1 & 1 & 0.1 & 7 & 3.7 & 0 & 0.0 & 2 & 1.0 & 0 & 0.0 & 10 & 2.1 & 1 & 0.0 \\
\hline Other & 13 & 25.2 & 51 & 6.4 & 9 & 4.8 & 22 & 4.0 & 9 & 4.6 & 29 & 8.2 & 31 & 6.6 & 102 & 6.0 \\
\hline Tota 1 & 59 & 67.8 & 297 & 37.5 & 148 & 79.1 & 246 & 44.9 & 75 & 38.8 & 207 & 58.8 & 282 & 60.3 & 750 & 44.3 \\
\hline
\end{tabular}


The subjects residing in Baton Rouge used this resource at the highest rate of the three communities. However, this relationship is not so much due to the geographic difference, but to the fact that the Negroes tend to turn to this source of help and the sample drawn in Baton Rouge has the largest proportion of Negroes. The residents of Hammond tended to utilize the Chiropractor at a higher rate than did the residents of either Baton Rouge or New Roads. This practice is almost unique to the white members of the sample with only one black subject reporting such utilization.

Another interesting area to explore is the relationship of anomie to the utilization of health care resources. Intuitively it might be predicted that subjects with a low level of anomie will tend to present a higher rate of utilization of such resources as spouse and relative. This is true because anomie tends to be lower when there exists a viable family structure. Thus when anomie is low there is a greater probability that there are family members to call on. On the other hand, since anomie on an intrapersonal level is manifested by feelings of alfenation, it is possible that those persons who are not in the mainstream of the health care system might be expected to be more likely to experience feelings of alienation, isolation, and rejection. If this is the case, then those subjects tending to think first about seeking treatment from the medical doctor when they are 111 may also be expected to have a low level of anomie.

Table XLV gives the data obtained in the item asking who the subjects seek help from first or second when they feel ill. These 
TABLE XLV

RATES OF USE OF VARIOUS CARETAKERS AS FIRST OR SECOND CHOICE BY PERSONS OF VARYING LEVELS OF ANOMIE IN A PREDOMINENTLY INDIGENT POPULATION OF SOUTH BATON ROUGE, HAMMOND, AND NEW ROADS, 1971

\begin{tabular}{|c|c|c|c|c|c|c|c|c|c|c|c|}
\hline \multirow{3}{*}{$\begin{array}{l}\text { COMMUNITY } \\
\text { CARETAKER }\end{array}$} & \multicolumn{11}{|c|}{ Anomie Leve 1} \\
\hline & \multirow{2}{*}{$\begin{array}{c}0 \\
N=29 \\
N \quad \%\end{array}$} & $\begin{array}{r}1 \\
N=75 \\
\end{array}$ & $\begin{array}{r}2 \\
N=96 \\
\end{array}$ & $\frac{3}{N=116}$ & \multicolumn{2}{|c|}{$\frac{4}{N=127}$} & \multicolumn{2}{|c|}{$\frac{5}{N=138}$} & $\begin{array}{r}6 \\
N=94\end{array}$ & \multicolumn{2}{|c|}{ Overall Total } \\
\hline & & $\mathrm{N} \%$ & $\mathrm{~N} \%$ & $\mathrm{~N} \%$ & $\mathbb{N}^{-}$ & $\%$ & $\mathrm{~N}$ & $\%$ & $\mathrm{~N} \%$ & $\mathbf{N}$ & $\%$ \\
\hline No Response & $0 \quad 0.0$ & 34.0 & 2.1 & 0.0 & 1 & 0.8 & 3 & 2.2 & 3.2 & 12 & 1.8 \\
\hline $\begin{array}{r}\text { Medica } 1 \\
\text { Doctor }\end{array}$ & 2068.9 & 4965.3 & 7376.1 & 8875.9 & 87 & 68.5 & 94 & 68.2 & 5962.8 & 470 & 69.6 \\
\hline $\begin{array}{l}\text { Friend or } \\
\text { Neighbor }\end{array}$ & 13.4 & $4 \quad 5.4$ & $5 \quad 5.2$ & 8.6 & 9 & 7.1 & 15 & 6.8 & 8.5 & 52 & 7.7 \\
\hline Spouse & 620.6 & 912.0 & 1111.4 & 1311.2 & 19 & 15.0 & 21 & 15.2 & 1313.9 & 92 & 13.6 \\
\hline Druggist & $0 \quad 0.0$ & $0 \quad 0.0$ & 0.0 & 21.8 & 0 & 0.0 & 1 & 0.7 & 11.1 & 4 & 0.6 \\
\hline Relative & 1344.8 & 2026.7 & 1313.5 & 2925.0 & 40 & 31.5 & 32 & 23.2 & 2223.4 & 169 & 25.0 \\
\hline God & $0 \quad 0.0$ & 22.7 & 3.1 & 10.9 & 7 & 5.5 & 7 & 5.0 & 33.2 & 23 & 3.4 \\
\hline Other & 13.4 & 34.0 & 2.1 & 4.3 & 4 & 3.2 & 7 & 5.0 & 44.3 & 26 & 3.9 \\
\hline Total & 4114.1 & 9012.0 & 10911.4 & $\begin{array}{ll}148 & 12.8\end{array}$ & 167 & 13.1 & 180 & 13.0 & 11312.0 & 848 & 12.6 \\
\hline
\end{tabular}


data are broken down by levels of anomie.

These data bring out that those subjects with the lowest level of anomie tended to utilize these resources at a higher rate than those subjects with any other level of anomie. There was a slight tendency for those subjects with high levels of anomie to utilize the medical doctor at a lower rate than did those with a lower level of anomie. However, there was also a tendency for those subjects with the lowest two levels of anomie to turn to the medical doctor at a lower rate than did those subjects with the middle ranges of anomie. In the case of the spouse, the relationship is somewhat different with those subjects experiencing the lowest level of anomie showing the highest rate of utilization. Those subjects experiencing the two lowest levels of anomie also had a higher rate of utilization of a relative as either the first or second source of help to which they turned in the event of 11lness. There was a tendency for the rate of utilization of friends or neighbors to increase with the level of anomie. Also there was a tendency for the subjects with a low level of anomie not to turn to the druggist as an initial source of help in sickness while those with a high level of anomie did occasionally utilize this source.

When these subjects were asked whether they ever went to a friend or neighbor, a minister or priest, or a druggist for help when they were sick the response pattern was somewhat different than the response pattern to the previous item. Table XLVI shows the tabulation of these responses by levels of anomie.

From these data it appears that subjects with high levels of 
TABLE XLVI

RATES OF USE OF VARIOUS CARETAKERS DURING COURSE OF ILLNESS BY PERSONS OF VARYING LEVELS OF ANOMIE IN A PREDOMINENTLY INDIGENT POPULATION OF SOUTH BATON ROUGE, HAMMOND, AND NEW ROADS, 1971

\begin{tabular}{|c|c|c|c|c|c|c|c|c|c|c|c|c|c|c|c|c|}
\hline \multirow{2}{*}{$\begin{array}{l}\text { SELECTED } \\
\text { COMMUNITY } \\
\text { CARETAKERS }\end{array}$} & \multicolumn{16}{|c|}{ Anomie Leve 1} \\
\hline & \multicolumn{2}{|c|}{$\frac{0}{N=29}$} & \multicolumn{2}{|c|}{$\frac{1}{N=75}$} & \multicolumn{2}{|c|}{$\begin{array}{c}2 \\
\mathrm{~N}=96\end{array}$} & \multicolumn{2}{|c|}{$\frac{3}{N=116}$} & \multicolumn{2}{|c|}{$\begin{array}{c}4 \\
N=127\end{array}$} & \multicolumn{2}{|c|}{$\begin{array}{c}5 \\
N=138\end{array}$} & \multicolumn{2}{|c|}{$\frac{6}{N=94}$} & \multicolumn{2}{|c|}{ Total } \\
\hline $\begin{array}{l}\text { Friend or } \\
\text { Neighbor }\end{array}$ & 8 & 27.6 & 12 & 16.0 & 21 & 21.9 & 25 & 21.6 & 29 & 22.8 & 41 & 29.7 & 22 & 23.4 & 158 & 35.1 \\
\hline $\begin{array}{l}\text { Minister or } \\
\text { Priest }\end{array}$ & 1 & 3.4 & 7 & 9.3 & 11 & 11.5 & 9 & 7.8 & 18 & 14.2 & 22 & 15.9 & 13 & 13.8 & 81 & 18.0 \\
\hline Druggist & 7 & 24.1 & 20 & 26.7 & 30 & 31.3 & 29 & 25.0 & 36 & 28.3 & 52 & 37.7 & 37 & 39.4 & 211 & 46.9 \\
\hline
\end{tabular}


anomie tended to resort to these resources over the course of their illness at a higher rate than did those with a low level of anomie. Since this is inconsistent with the rates observed in Table XLV in which the subjects with the higher rates of utilization tended to be those with the lowest levels of anomie, it appears that the subjects with the lowest levels of anomie may have been less inclined to desert their initially selected sources of help or to enlist additional help. Among these several resources, the subjects with higher levels of anomie tended to have higher rates of utilization for two of them, the minister or priest and the druggist. There was not a remarkable difference in the utilization of friends or neighbors. Table XLVII shows that there was no notable differences in the patterns of utilization of the faith healer and chiropractor associated with high or low levels of anomie. 


\section{TABLE XLVII}

RATES OF USE OF VARIOUS CARETAKERS BY PERSONS OF VARYING LEVELS OF ANOMIE IN A PREDOMINENTLY INDIGENT POPULATION OF SOUTH BATON ROUGE, HAMMOND, AND NEW ROADS, 1971

\begin{tabular}{|c|c|c|c|c|c|c|c|c|c|c|c|c|c|c|c|c|}
\hline $\begin{array}{l}\text { COMMUNITY } \\
\text { CARETAKER }\end{array}$ & \multicolumn{2}{|c|}{$\mathrm{N}=29$} & \multicolumn{2}{|c|}{$\mathrm{N}=75$} & \multicolumn{2}{|c|}{$\mathrm{N}=96$} & \multicolumn{2}{|c|}{$\mathrm{N}=116$} & \multicolumn{2}{|c|}{$\mathrm{N}=127$} & \multicolumn{2}{|c|}{$\mathrm{N}=138$} & \multicolumn{2}{|c|}{$\mathrm{N}=94$} & & \\
\hline Faith Healer & 1 & 3.4 & 0 & 9.9 & 3 & 3.1 & 2 & 1.7 & 0 & 0.0 & 1 & 0.7 & 2 & 2.1 & 9 & 1.4 \\
\hline Other & 6 & 20.7 & 8 & 10.7 & 8 & 8.3 & 12 & 10.3 & 20 & 15.7 & 22 & 15.9 & 20 & 21.3 & 96 & 15.1 \\
\hline No One & 20 & 69.0 & 58 & 77.3 & 76 & 79.2 & 95 & 81.9 & 95 & 74.8 & 112 & 81.2 & 68 & 72.3 & 524 & 82.5 \\
\hline
\end{tabular}




\section{Reasons for Use of Medical Care}

At this point, it appears that there are some differences in the patterns of utilization of health care caretakers among various categories of the sample. The major effort of this chapter, however, is not to examine these differences in detail, but to examine the nature of the decision making process which precedes the utilization of health care resources. Since the medical doctor is by far the most frequent ly resorted to health caretaker by the subjects in this sample, he can be considered the key to entrance into the health care delivery system. The decision to enter this system, then, is usually initiated by a decision to visit a physician.

In an effort to gain some insight into how this decision is arrived at the system model described in Chapter II was used as a conceptual framework. It is assumed that the decision making process is a function of the interaction occurring within the family as a social system. However, if there is a quality of interpenetration of other system levels into the social system structure of the family then these too should influence the decision making process. The resulting configuration should be a clustering of reasons for either seeking the help of a medical doctor or not seeking such help. Such clusterings would result from the fact that influences on the decision that derive from the same system level tend to be more closely related to each other than to those influences arising from other system levels. An attempt was made in this study to explore this possibility. To do this, the respondents were asked to select the symptoms from a prepared list which they considered to be serious enough to warrant 
going to a physician. They were then asked whether they or anyone in the family under their decisional jurisdiction had had any of these symptoms during the past year. Those who did were asked if they or the symptomatic member of the family had, in fact, gone to the doctor. Those who did go to a physician were asked their reasons for going. These reasons were selected by the subjects from a list that was developed largely from Mechanic's "Triggers."7 Those who did not go to a physician, even though they had one or more symptoms that they considered serious enough to require medical attention, were asked their reasons for not going to a physician. The results of the latter group are tabulated in Table XLVIII, and shown in rank order of their rate of selection.

TABLE XLVIII

REASONS FOR NON USE OF MEDICAL DOCTOR BY SYMPTOM BEARING PERSONS SHOWN BY RANK ORDER

\begin{tabular}{lcr}
\hline Reasons & Frequency & Rate \\
\hline Felt symptom was not serious enough & 34 & 13.0 \\
Was able to continue functioning & 32 & 12.3 \\
Lack of transportation & 32 & 12.3 \\
Could not afford to & 27 & 10.3 \\
Knew reasons for symptoms & 26 & 10.0 \\
Symptom was intermittant & 21 & 8.0 \\
Accustomed to feeling bad & 18 & 6.9 \\
Subject was told not to & 17 & 6.5 \\
Symptom ceased & 16 & 6.1 \\
Lack of confidence in health care system & 13 & 5.0 \\
Fear of discourteous treatment & 10 & 3.8 \\
Lack of time & 7 & 2.7 \\
Lack of knowledge of symptom & 6 & 2.3 \\
Discussed it with someone and decided against going & 2 & .8 \\
& & \\
\hline Total & 261 & \\
\hline
\end{tabular}

7 David Mechanic, Medical Sociology, New York: Free Press of Glencoe, 1968, PP. 130-31. 
The most frequently mentioned reason for not going to a doctor was that the person did not feel the symptom was serious enough. Mentioned almost as frequently were the lack of transportation and the fact that the person felt he remained able to continue functioning. The most infrequently mentioned reasons were the lack of time and having discussed the possibility of going to the doctor and deciding against it. The responses of the subjects who had gone to a medical doctor for the symptoms they experienced are recorded in rank order of their frequency of selection in Table XLIX.

\section{TABLE XLIX}

REASONS FOR USE OF MEDICAL DOCTOR BY SYMPTOM BEARING PERSONS SHOWN BY RANK ORDER

\begin{tabular}{lcc}
\hline \hline Reasons & Frequency & Rate \\
\hline Felt symptoms were serious enough & 362 & 19.5 \\
Felt that it would prevent more serious & & \\
difficulty & 357 & 19.2 \\
The symptom persisted & 355 & 19.1 \\
Inability to continue functioning & 252 & 13.6 \\
Knew what the symptom meant & 202 & 10.9 \\
Discussed with someone and decided & 120 & 6.5 \\
Told to & 106 & 5.7 \\
It did not require much effort to go & 72 & 3.9 \\
It was easily affordable & 33 & 1.8 \\
\hline Total & 1,859 & \\
\hline
\end{tabular}

Three reasons were offered at a considerably higher rate than others for the decision to utilize a medical doctor. These were the seriousness of the symptom, the possibility that it might become worse if allowed to continue, and the fact that the symptom did persist. The 
most infrequently mentioned reasons for deciding to see a medical doctor were the affordability of the behavior and the convenience of utilizing the doctor.

To determine whether the responses to these items cluster at what might approximate system levels a factor analysis was run. Recalling the social system model suggested in Chapter II, four system levels should be expected to exist. These are: the organismic, the personality, the cultural and the social. Each of these system levels exists as a monitoring system within the social system. The social system monitoring system actually exists in two components, the internal system monitor and the external system monitor. To explore this condition the hypotheses become:

$\mathrm{H}_{1}$ : The reasons for deciding not to seek medical care from a physician by the pathology bearing members of a family system will fall into four underlying factors approximating the four system levels.

$\mathrm{H}_{2}$ : The reasons for deciding to seek medical care from a physician by the pathology bearing members of a family system will fall into four underlying factors approximating the four system leve $1 \mathrm{~s}$.

In testing these hypotheses complications are encountered. Relying on verbal responses is tantamount to eliciting responses from a single system level. This is the personality system. Thus, the relationship of these responses to system levels other than the personality system is indirect and can be inferred only from the semantics of the statements. Such a condition raises the question of validity and reliability. Neither is consifered to be a serious methodological problem in this instance. Validity, the quality of an instrument 
measuring what it purports to measure, is not relevant because the hypotheses assume that this quality is not established. In fact, it is this quality that the hypotheses are designed to test. Reliability, consistency over time and between subjects, is not crucial because it is not the actual reason for seeking or not seeking medical care but the factors involved in the decision making process that is being explored.

The rotated factor matrix appears in Table $L$.

TABLE L

ROTATED FACTOR MATRIX OF REASONS FOR NOT SEEKING MEDICAL CARE

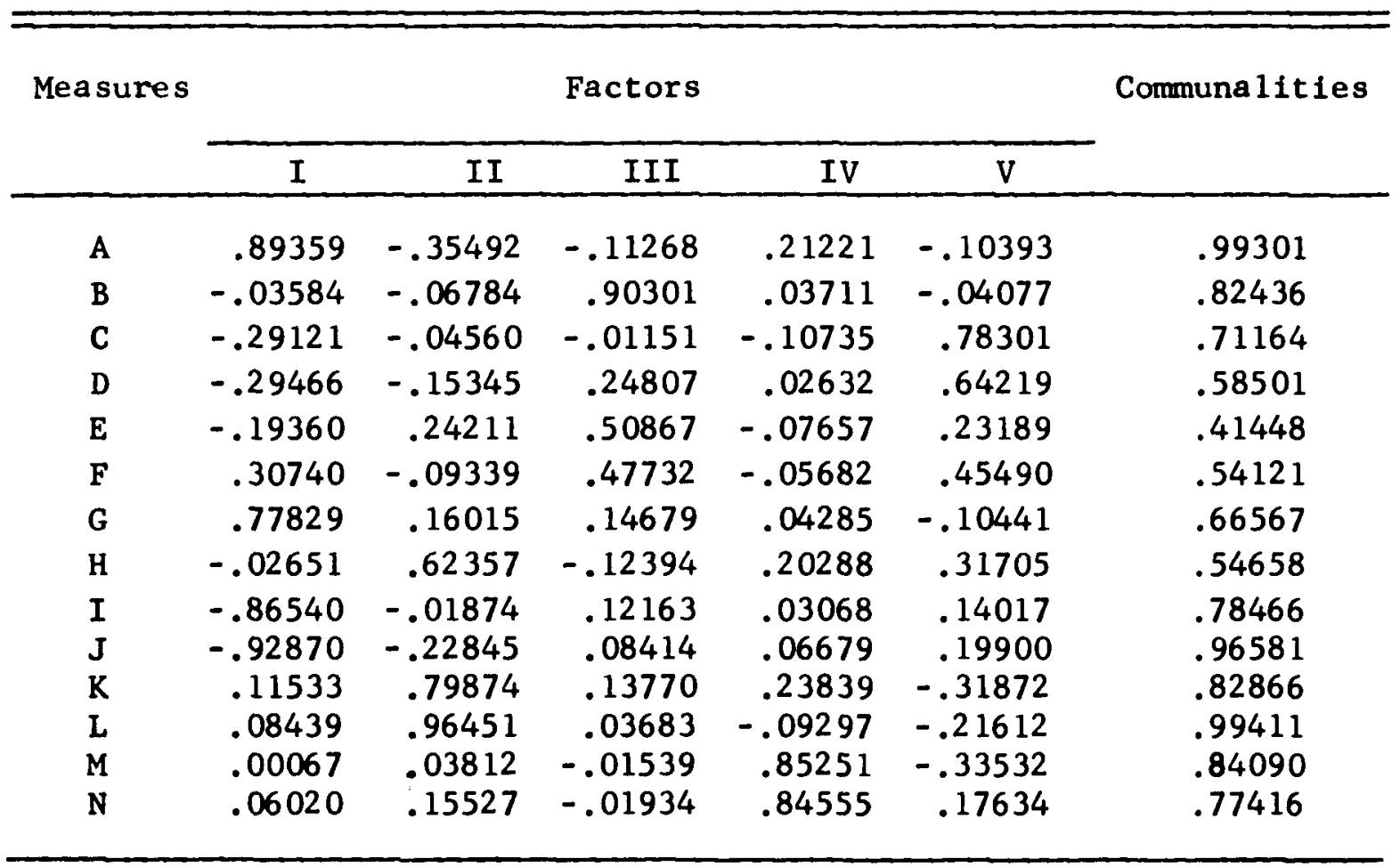

From this rotated factor matrix the following factor compositions were decided upon: 
Factor

I

II

III

IV

V
Measure

A: Subject was told not to go to a medical doctor.

G: Subject is accustomed to feeling bad.

H: No way to tell whether symptoms were serious

K: Too difficult to arrange transportation.

L: Could not afford medical care.

B: Talked it over with someone and decided against.

E: The condition appeared to be going away by itself.

F: The condition would go and come.

M: Subject was afraid that he would not be treated we 11 .

$N$ : Subject felt that it wouldn't do much good to go to the doctor.

C: Subject did not feel that it was important enough to seek medical care.

D: Subject was still able to do the things that he needed to do.

I: Subject couldn't take time off to seek medical care.

$\mathrm{J}$ : Thought that he knew reason for the symptom.

It appears that the reasons for the decision not to go to the doctor reduce to five factors. This is one factor in excess of the number expected if the factors clustered around the several system levels. It also appears that each of the five factors contain measures relating to more than one system level. Factor $I$, for example, is composed of two measures. One, being told not to go to the doctor, appears to relate to social system level while the second, that the subject is accustomed to feeling bad, appears to more appropriately relate to the personality system level. However, when it is accepted that the measures contained in a factor are present together because they possess a common quality and this common quality is identified a different relationship emerges. These particular two measures suggest a passive, resigned abdication of decision making. This might be 
thought of as a cultural quality. Taking this approach each of the factors might be described as follows:

Factor

I

II III

IV

$\mathrm{V}$

\section{Description}

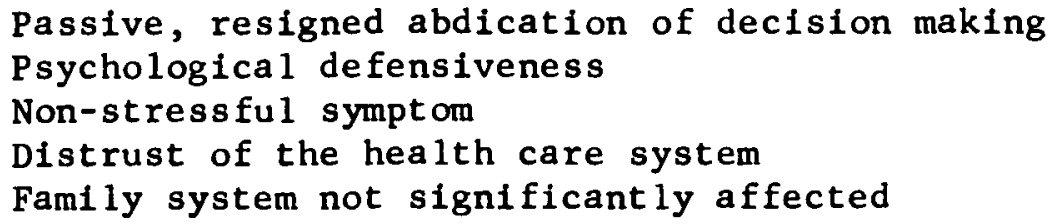

Describing the factors in this way it appears that Factor I is related to the cultural system, Factor II is related to the personality system, Factor III is related to the organismic system leve1, Factor IV is related to the social system level, and Factor $V$ is also related to the social system level. There is a difference in Factors IV and $V$ even though each is related to the social system level. This difference appears to be that Factor IV reflects a relationship external to the family while Factor $V$ relates to the social system structure internal to the family. These findings cannot be considered incompatible to Hypothesis $\mathrm{H}_{1}$.

In examining the second Hypothesis only four factors were identifiable among those reasons given for deciding to seek treatment from a medical doctor. The rotated factor matrix appears in Table LI. 
TABLE LI

ROTATED FACTOR MATRIX OF REASONS FOR SEEKING MEDICAL CARE

\begin{tabular}{|c|c|c|c|c|c|}
\hline \multirow[t]{2}{*}{ Measures } & \multicolumn{4}{|c|}{ Factors } & \multirow[t]{2}{*}{ Communalities } \\
\hline & I & II & III & IV & \\
\hline $\mathbf{A}$ & -.03642 & .79589 & .03372 & -.03890 & .63742 \\
\hline $\mathrm{B}$ & .14443 & .68203 & -.03944 & -.01132 & .48771 \\
\hline $\mathrm{C}$ & .52369 & -.43090 & .00453 & -.16091 & .48584 \\
\hline D & .64216 & .18544 & .10243 & -.07137 & .46235 \\
\hline $\mathrm{E}$ & .59456 & -.14842 & -.08133 & .18622 & .41682 \\
\hline $\mathrm{F}$ & .79353 & .16089 & -.01936 & .05373 & .65884 \\
\hline G & .01246 & -.03585 & .02995 & .92755 & .86269 \\
\hline $\mathrm{H}$ & .26382 & .14967 & -.69230 & .36569 & .70500 \\
\hline I & .20108 & .09735 & .81592 & .25110 & .77868 \\
\hline
\end{tabular}

This rotated factor matrix produces the following factor compositions :

Factor

Measure

I C: Felt symptoms were serious enough

D: Knew symptoms were serious enough

$E$ : Could no longer function

F: Symptoms would not let up

II A: Told to go to doctor

B: Talked it over and felt the need

III I: Felt that it wouldn't cost too much

IV G: Felt that it would save time in the long run

$H$ : Felt that it wouldn't require much effort

Seemingly four factors underly the reasons for deciding to go to a medical doctor. The first factor relates to the serfousness of the symptoms and, thus, represents the organismic system level. Factor II contains the item, "told to go," which was interpreted to imply a passive abdication of decision making in the decision not to go to a 
doctor. However, in that decision this measure was combined with the subject's being resigned to feeling bad. In the decision to go to a doctor, it is combined with the measure, "talked it over with someone and decided on the need to go." In this context, it involves some degree of social interaction, although in a passive manner. This apparent1y indicates a suggestability on the part of the subject and falls at the social system level. In Factor III, concern about the possible stress on the internal social system structure is indicated. The final factor is composed of two measures implying an effort to justify or rationalize the decision to go to the doctor. This appears to represent the personality system level.

In summary, the several factors underlying the decision to seek medical care from a physician may be described as follows:

Factor Description

I: $\quad$ Stressful symptom

II: $\quad$ Suggestibility

III: $\quad$ System concern

IV: $\quad$ Justification

Again, these findings are not incompatible with the hypothesis. However, it cannot be assumed that these findings prove the stated hypotheses. Although the number of underlying factors associated with the decision to use or not to use the medical doctor, approximates the number of system levels, it is not possible to say with certainty that these factors do, indeed, represent these system levels. This uncertainty probably results from two sources. First, the observations used were verbal responses to schedule items. Verbal responses must, by their 
nature, reflect the perception, thought processes, and communication processes of the personality system. At best then the responses can only reflect the personality system's perception and articulation of other system level influences. Secondly, the interpenetration of the several system levels precludes the existence of boundary integrity between the system levels. As a result diffusion must exist between these systems making it difficult to classify measures or factors at any one system level.

\section{Summary}

Health care resource utilization is a rather complex phenomenon reflecting multiple influences. The most frequently utilized health care personnel by the subjects of this study was the medical doctor. Differences were found in the quality of relationship between the medical doctor and various types of patients. The negro residing in the urban area of Baton Rouge tended to enjoy a better relationship than did the negro from the more rural areas of Hammond and New Roads. Religion, too, appeared to exert an influence on the quality of medical doctor relationship. As might be expected, the members of the medically constricted religions tended to visit the medical doctor less frequent $1 y$ than did members of other religious groups. Catholics tended to frequent the medical doctor at a higher rate than did members of the other religious groups and were the most likely to designate a family physician. On the other hand, the members of the medically constricted religions tended to pay higher fees and to visit out of town doctors. 
Age and income also influenced the quality of medical doctor relationship. It appears that, although the members of the lower income groups expressed a stronger preference for the medical doctor as first treatment choice, they, in reality, tended to utilize a wider range of health caretakers and to utilize the medical doctor at a lower rate than did members of the upper socio-economic groups. The subjects from the rural areas tended to select a medical doctor as first treatment source at a higher rate than did those from the urban area. The differences in utilization patterns between members of the Black and White races appeared to be greater than that between residents of different geographic locations.

Anomie was also found to be related to health care resource utilization patterns. Those subjects with the lowest level of anomie tended to utilize health caretakers at a higher rate than did those with higher levels of anomie. However, there was a tendency for those subjects with a middle range of anomie to turn to a medical doctor at a higher rate than did either those with high levels or low levels of anomie. Subjects with a low level of anomie tended to turn to a spouse or relative at a higher rate. There was a tendency for those with higher levels of anomie to turn to a friend or neighbor at a higher rate. Subjects with lower levels of anomie appeared to be somewhat more loyal to their initially selected sources of help.

In examining the decision making process involved in deciding either to go to a medical doctor or not to go, a limited number of factors were found to be involved. These factors appear to be roughly 
analogous to the several system levels. Relating them to the system model described in Chapter II, the following paradygm is obtained:

FIGURE 4

MEDICAL DOCTOR UTILIZATION PARADYGM

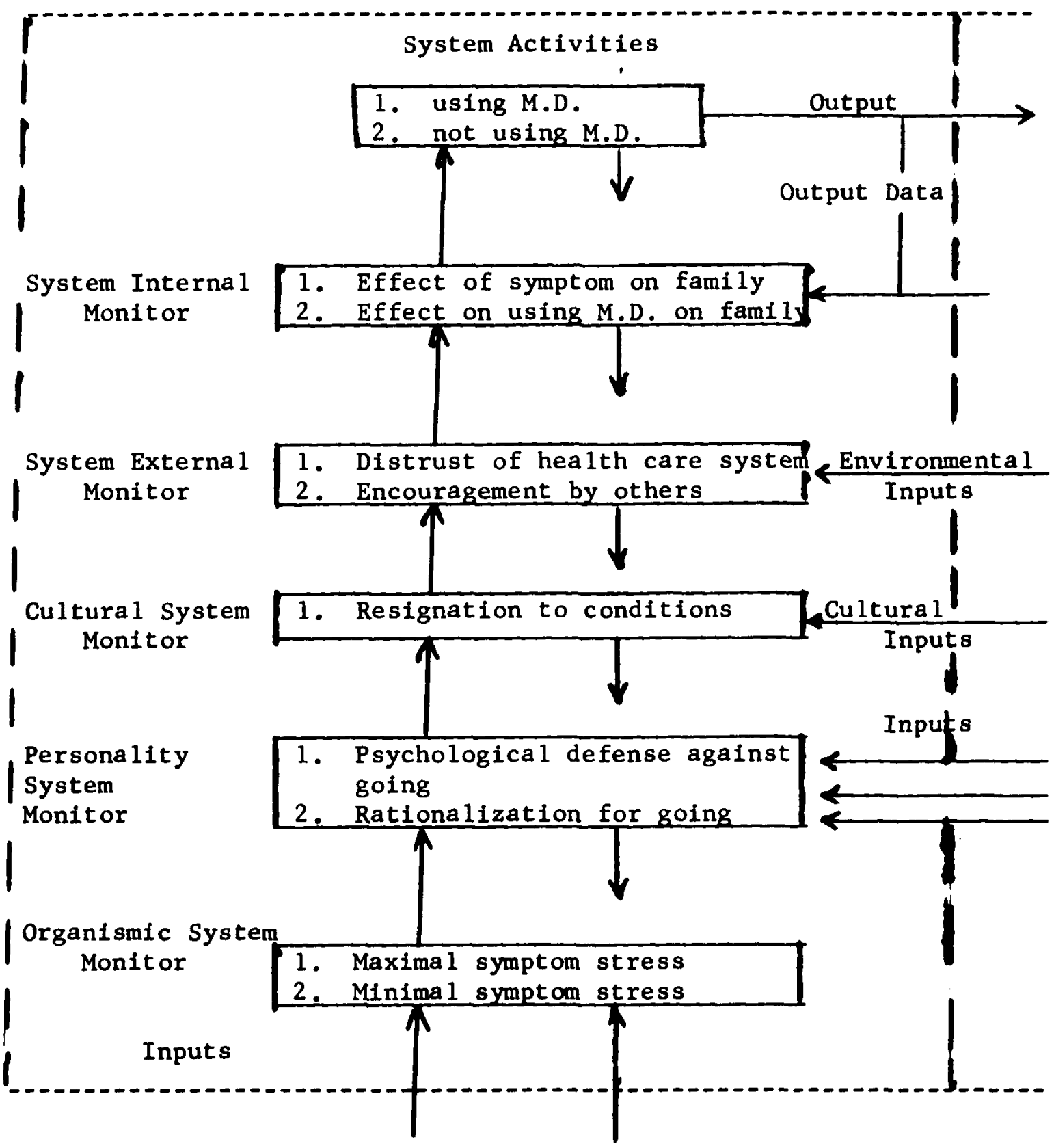




\section{CHAPTER VI}

\section{ATTITUDE TOWARD HEALTH CARE FACILITIES}

A number of definitions of attitude exist. W. I. Thomas suggests that an attitude is a process of individual consciousness which determines real or possible activity of the individual in the social world. 1 MacIver also saw attitudes as states of consciousness within a person with respect to objects. ${ }^{2}$ For our purpose, however, an attitude may be defined as a relatively stable system of organization of the behavior displayed by a person toward a particular object or set of objects. ${ }^{3}$ To be useful the concept must be anchored by reference to some particular object or set of objects and must show direction. Since there is a tendency to organize behavior around attitudes it should be expected that a positive attitude toward an object would lead to the embracing of that object while a negative attitude should lead to the rejection of that object. Translated to health care facilities the implication is that those facilities toward which the consumer has a negative attitude should be rejected in favor of one for which the consumer has a positive attitude.

${ }^{1}$ William I. Thomas and Florian Znaniecki, The Polish Peasant in Europe and America, Boston: Gorham Press, 1918, Vol. 1, P. 22. 1949 , p. 24 .

${ }^{2}$ Robert M. MacIver, Society, New York: Farrar and Rhinehart,

3Join W. McDavid and Herbert Harari, Social Psychology: Individua 1s, Groups, Societies, New York: Harper and Row, Publishers, 1968, p. 129 . 
There is a complication, however, factors other than consumer volition influence the selection of health care facilities. The public utility quality of many health care resources, for example, makes it impossible for the patient not to utilize them provided he cannot forego treatment altogether. Other factors such as age, income, and geographic location may also restrict freedom of choice of health care facilities at least to some extent. This eliminates the possibility of using health care behavior as an indication of consumer attitudes toward health care resources.

This condition actually increases the importance of examining attitudes toward health care resources in any exploration of health care patterns, for consumers who are forced to patronize facilities for which they have a negative attitude may be expected to become restive. This possibility may influence the extent to which consumers may remain loyal to existing health care resources.

In exploring attitudes toward health care facilities in this study the subjects were asked to name the most recent public hospital and private hospital which they had visited. They were then asked whether the care they received was poor, fair, or good. Their response to this item was assumed to be their attitude toward the care offered by that facility. It is recognized that this response actually represents an appraisal of a specific service. However, since the respondents usually have no way of making an objective evaluation of the quality of medical service received, it is assumed that their appraisal of this service is based on an attitude. The advantage of addressing 
the subjects' response to a specific service rather than to diffused qualities of the facility is that it indicates to the client that he is not expected to make a technical evaluation and also serves to reduce noncommita 1 responses.

In our material society, it is sometimes assumed that a person is more inclined to value something if he has invested money in it. If this assumption is valid in the consumption of health care, then we might expect the most negative attitudes to be manifested toward charity hospitals; provided, of course, that other things remain equal. Any inequality that might be anticipated in other factors would intuitively be expected to produce a bias in favor of the private hospital. These conditions might include more attractive physical plant, less crowding, and better trained medical staffs, due to the use of externs and interns in the public hospitals. The contention that a person may feel more positive toward health care for which he has paid is supported by a study made in Baltimore. In this study it was found that clients in a medical care program for the indigent made wider use of physician services and reduced complaints following the replacement of a capitation method of payment with a fee-for service method. It was speculated that the decrease in clients' complaints was due to the freedom of choice conferred by the fee-for-service plan. 4

In exploring the possibility that patients who pay for the health care that they receive may tend to have a more positive attitude Preferred," Public Health Reports, LXXXII (March, 1967), 192. 
toward the care than those subjects who did not pay for their care, the hospitals utilized by the subjects of this study were divided into two groups. One was comprised of public general hospitals. The second group included the private general hospitals utilized by the subjects. The responses of the respondents to the question relative to their opinion of the care which they received were recorded as poor, fair, or good. Table III presents these data tabulated by hospital and income range.

Contrary to the notion that people tend to value most highly that which they have paid for, these data suggest that there is no appreciable difference between the attitudes of the subjects who utilized the charity hospitals and those of the subjects who were patients at the private hospitals. The rate of "good" responses for the former subjects was found to be $82.8 \%$ while the rate of "good" responses for the latter subjects was $82.6 \%$.

An interesting relationship is seen when the responses by income ranges are examined. In the case of the private hospitals, attitudes appeared to remain relatively constant over income ranges. However, the responses of the subjects who utilized the charity hospitals demonstrated a somewhat different patterı. The members of the lower and middle income ranges present an attitude equally positive with that of the private hospital users. In the income ranges above $\$ 6,001$, on the other hand, the attitude of the respondents toward the charity hospitals is much less positive than their attitude toward private hospitals. 
TABLE LII

ATTITUDES TOWARD PUBLIC AND PRIVATE HOSPITAL CARE SHOWN BY RANGE OF INCOME IN A PREDOMINENTLY INDIGENT POPULATION OF SOUTH BATON ROUGE, HAMMOND, AND NEW ROADS, 1971

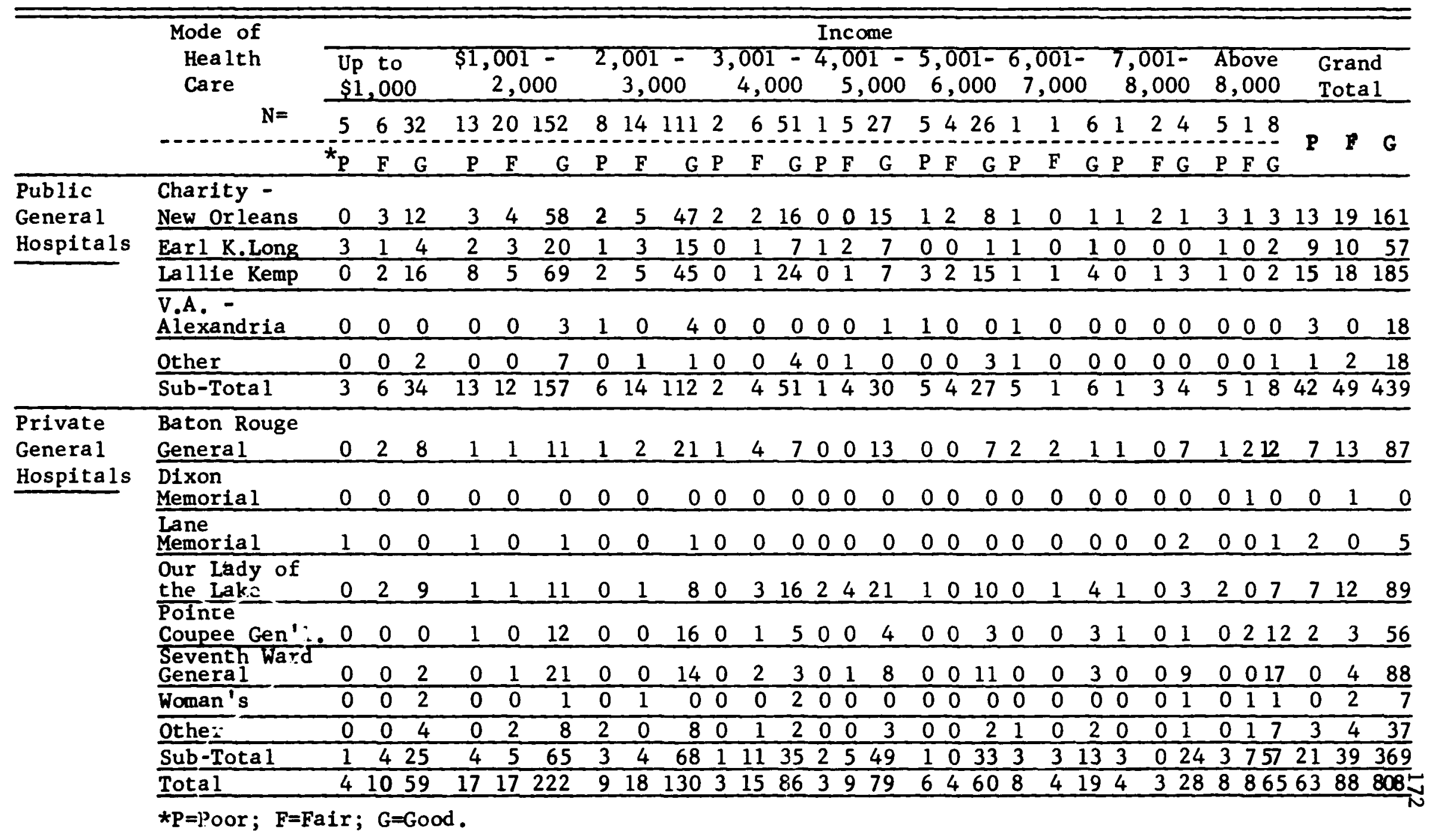


The above finding has some reinforcement in the literature. Rosenblatt, pointed out that it has been observed the urban poor tend to have a negative attitude toward the total societal health care delivery system. It is possible that this attitude develops because this class of consumers receive uniformly poor treatment. However, another possibility is brought out by Rosenblatt, who points out that these consumers may not be accustomed to the degree of impersonal care that they receive in the bureaucratic and complex, urban health care system. 5 By negative implication this may mean that the more technological oriented middle class consumer might be expected to form a more positive attitude toward the more bureaucratic, aseptic, impersonal atmosphere of the private hospital. By the same token he might be expected to form a more negative attitude toward the less rigid, less formal atmosphere of the charity hospital with its lines of patients waiting for service. This possibility is consistent with the data in Table LII. On the other hand, Rosenblatt's explanation is inconsistent with the fact that the low income consumer had an equally positive attitude toward both the charity hospital and the private hospital.

The question arises, then, of whether Rosenblatt's finding is an artifact or, perhaps, a nuance of a circumscribed population. To explore this possibility the attitudes toward both charity and private hospitals were tabulated by geographic area. See Table LIII.

5 Daniel Rosenblatt, "Barriers to Medical Care for the Urban Poor," in Arthur B. Shostah and William Gromberg (eds.), New Perspectives on Poverty, Englewood Cliffs: Prentice-Hall, Inc., 1965, Pp. 69-76. 
TABLE LIII

ATTITUDES TOWARD PUBLIC AND PRIVATE HOSPITAL CARE AMONG THE PREDOMINENTLY INDIGENT POPULATION OF THREE COMMUNITIES, 1971

\begin{tabular}{|c|c|c|c|c|c|c|c|c|c|c|c|c|c|c|c|c|}
\hline \multirow{3}{*}{\multicolumn{2}{|c|}{$\begin{array}{cc} & \begin{array}{c}\text { Mode of } \\
\text { Hea 1th } \\
\text { Care }\end{array} \\
\text { Public } \quad \text { Charity - }\end{array}$}} & \multicolumn{15}{|c|}{ Attitudes by Community } \\
\hline & & \multicolumn{4}{|c|}{ Baton Rouge } & \multicolumn{4}{|c|}{ Hammond } & \multicolumn{4}{|c|}{ New Roads } & \multicolumn{3}{|c|}{ Grand Total } \\
\hline & & Poor & Fair & Good & Total & Poor & Fair & Good & Tota 1 & Poor & Fair & r Good & Tota 1 & Poor & Fair & Good \\
\hline $\begin{array}{l}\text { Public } \\
\text { Genera } 1\end{array}$ & $\begin{array}{l}\text { Charity - } \\
\text { New Orleans }\end{array}$ & 5 & 13 & 59 & 77 & 4 & 5 & 46 & 55 & 3 & 1 & 62 & 66 & 12 & 19 & 167 \\
\hline \multirow[t]{5}{*}{ Hospitals } & Ear1 K.Long & 0 & 0 & 3 & 3 & 1 & 0 & 0 & 1 & 1 & 0 & 5 & 6 & 2 & 0 & 8 \\
\hline & $\begin{array}{l}\text { V.A. - } \\
\text { Alexandria }\end{array}$ & 7 & 8 & 35 & 50 & 1 & 1 & 0 & 2 & 0 & 1 & 0 & 1 & 8 & 10 & 35 \\
\hline & Lallie Kemp & 0 & 1 & 2 & 3 & 14 & 17 & 194 & 225 & 0 & 0 & 0 & 0 & 14 & 18 & 196 \\
\hline & Other & 0 & 2 & 4 & 6 & 0 & 0 & 9 & 9 & 0 & 0 & 5 & 5 & 0 & 2 & 18 \\
\hline & Sub-Total & 12 & 24 & 103 & 139 & 20 & 23 & 249 & 292 & 4 & 2 & 72 & 78 & 36 & 49 & 424 \\
\hline $\begin{array}{l}\text { Private } \\
\text { General }\end{array}$ & $\begin{array}{l}\text { Bat on Rouge } \\
\text { Genera } 1\end{array}$ & 6 & 13 & 78 & 97 & 1 & 0 & 2 & 3 & 0 & 0 & 10 & 10 & 7 & 13 & 90 \\
\hline \multirow[t]{9}{*}{ Hospitals } & $\begin{array}{l}\text { Dixon } \\
\text { Memorial }\end{array}$ & 0 & 1 & 0 & 1 & 0 & 0 & 0 & 0 & 0 & 0 & 0 & 0 & 0 & 1 & 0 \\
\hline & $\begin{array}{l}\text { Lane } \\
\text { Memorial }\end{array}$ & 1 & 0 & 4 & 5 & 1 & 0 & 0 & 1 & 0 & 0 & 0 & 0 & 2 & 0 & 4 \\
\hline & $\begin{array}{l}\text { Our Lady of } \\
\text { the Lake }\end{array}$ & 6 & 13 & 73 & 92 & $\underline{0}$ & 0 & 7 & 7 & 1 & 0 & 12 & 13 & 7 & 13 & 93 \\
\hline & $\begin{array}{l}\text { Pointe } \\
\text { Coupee Gen'1. }\end{array}$ & 0 & 0 & 0 & 0 & 1 & 0 & 0 & 1 & 1 & $1+$ & 58 & 63 & 2 & 4 & 58 \\
\hline & $\begin{array}{l}\text { Seventh Ward } \\
\text { Genera } 1\end{array}$ & 0 & 1 & 0 & 1 & 0 & 3 & 88 & 91 & 0 & 0 & 0 & 0 & 0 & 4 & 88 \\
\hline & Woman's & 0 & 0 & 2 & 2 & 0 & 1 & 2 & 3 & 0 & 1 & 3 & 4 & 0 & 2 & 7 \\
\hline & Other & 1 & 3 & 5 & 9 & 2 & 1 & 19 & 22 & 0 & 0 & 13 & 13 & 3 & 4 & 37 \\
\hline & Sub-Tota 1 & 14 & 31 & 162 & 201 & 5 & 5 & 118 & 1.28 & 2 & 7 & 96 & 103 & 21 & 41 & 377 \\
\hline & Total & 26 & 44 & 265 & 346 & 25 & 28 & 267 & 420 & 6 & 9 & 168 & 181 & 57 & 90 & 801 \\
\hline
\end{tabular}


According to the tabulations in Table LIII, Rosenblatts' finding is replicated. In the present study the urban health care consumer did tend to form a more negative attitude toward both the public and private hospital as evidenced by the fact that the Baton Rouge sample manifested only a $74.1 \%$ "good" response for public hospitals and a $78.3 \%$ "good" response for private hospitals. At the other end of the ruralurban continuum, however, the New Roads sample showed a $93.2 \%$ "good" response for public hospitals and a $92.3 \%$ "good" response for private hospitals. Hammond, the transition community, showed $85.3 \%$ and $92.1 \%$ "good" responses respectively. From this finding we cannot say that the urban poor, health care consumer is reacting against the bureaucratic, aseptic environment because they are lower class and react to the impersonality of the hospital. The data in Table LII contradict such a premise. It is apparent, though, that the urban health care consumer did present a more negative attitude.

Another area of interest in exploring attitudes toward health care facilities is the relationship between age and attitudes. Much attention has been directed, especially in the current, popular literature, to the lack of confidence which many of the youth in our society have in the "establishment" and with the adults who are identified with the establishment. In view of this, the question must be raised whether this lack of confidence extends to the health care delivery system and, if it does, then to what age limit does this lack of confidence extend.

A review of the literature failed to shed any light on this question. In fact the single study found indicated that it was the 
older people (65 years and over) who indicated some dissatisfaction with treatment from medical doctors. It is uncertain whether this dissatisfaction resulted from experiences or from stereotyped beliefs. ${ }^{6}$ No studies were found addressed to the relationship of age to attitudes toward hospitals.

To gain some understanding of this relationship the responses to the items eliciting attitudes toward both public and private hospitals were tabulated by age ranges and presented in Table LIV. The lowest age range considered was the 15-25 year range. Below this age most of the attitude responses were proxy responses by the parent.

It appears from these responses that there is a tendency for the subjects in the age ranges between 15 years and 35 years to have a less positive attitude toward public hospitals than any other age groups. A similar relationship does not obtain for attitudes toward private hospitals. Unlike the study cited by Shanas, the present data seemingly suggest that the older age groups, that is over 55 years, tend to have positive attitudes toward both the public and private hospitals.

Table LV, provides information of relationship between race and attitude toward health care.

There appeared to be a slight tendency for the Negro population to have a stronger, positive attitude toward hospital care. The tendency, though, is slight and does not obtain at all for private hospitals.

${ }^{6}$ Ethel Shanas, "Family Relationships of Older People," New York: Health Information Foundation Research Series 20, 1961, pp. 60-61. 
TABLE LIV

ATTITUDES TOWARD PUBLIC AND PRIVATE HOSPITAL CARE SHOWN BY AGE RANGE IN A PREDOMINENTLY INDIGENT POPUIATION FOR SOUTH BATON ROUGE, HAMMOND, AND NEW ROADS, 1971

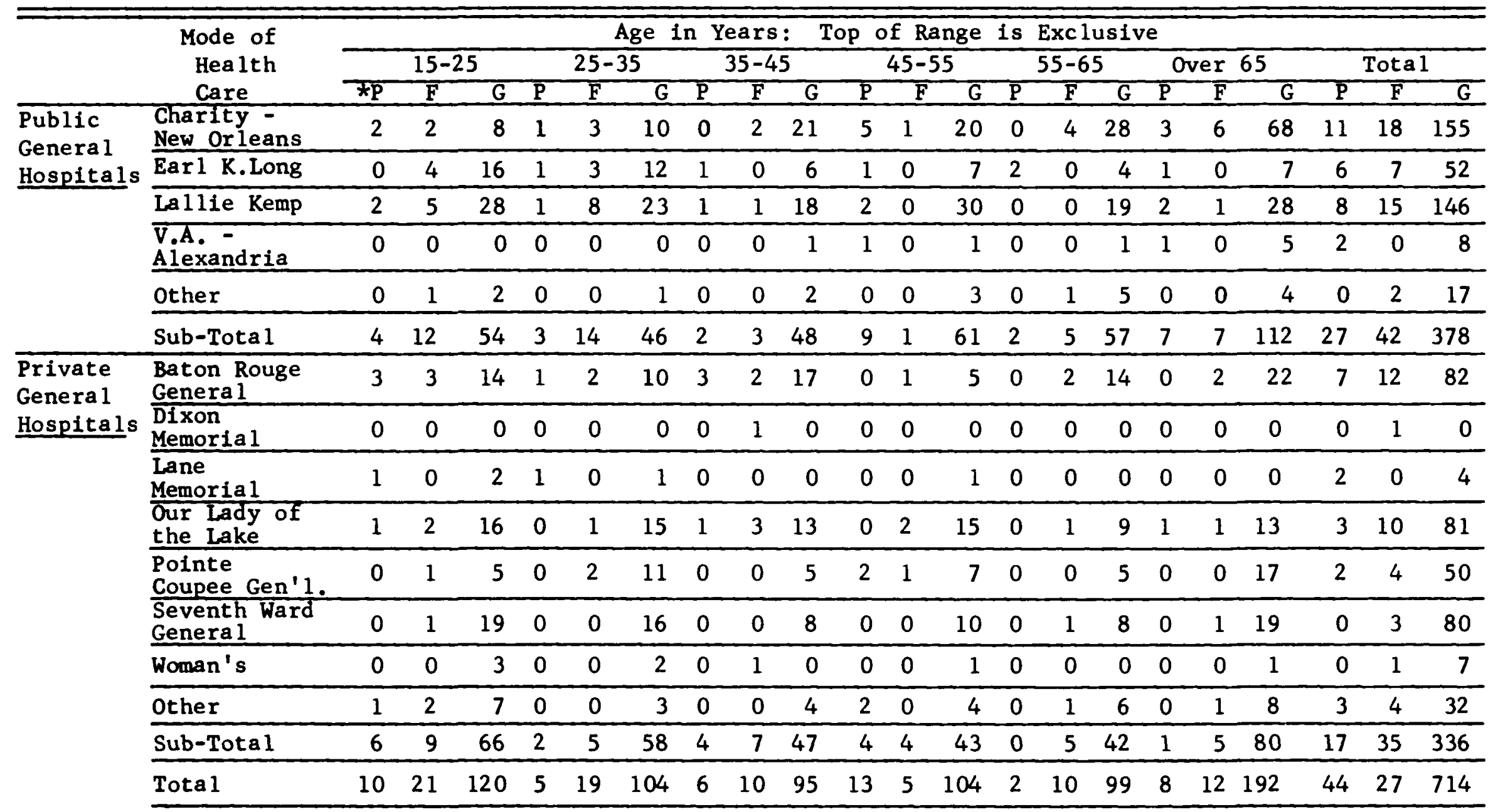

*P=Poor; F=Fair; G=Good. 
TABLE LV

ATTITUDES TOWARD PUBLIC AND PRIVATE HOSPITAL CARE SHOWN BY RACE AND ETHNIC GROUP IN A

PREDOMINENTLY INDIGENT POPULATION FOR SOUTH BATON ROUGE, HAMMOND, AND NEW ROADS, 1971

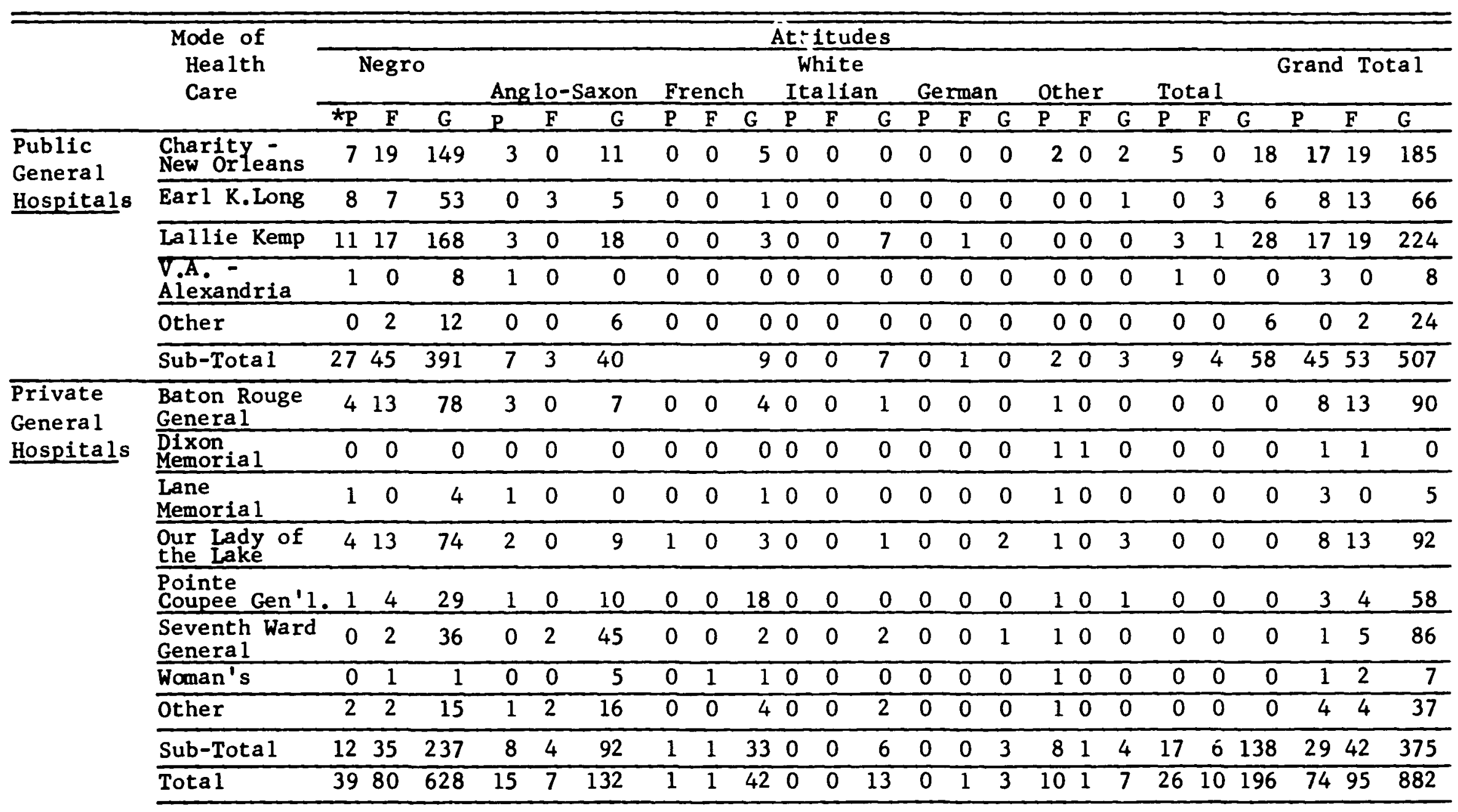

*P=Poor; $F=$ Fair; $G=$ Good. 
Another characteristic that may be expected to influence attitudes toward hospital care is anomie. No studies were found in the literature that brought out a direct relationship between anomie and attitudes toward hospital care. One study was found that did bring out a rather indirect relationship. In this study, reported by Rosenblatt and Suchman, four vocational categories were delineated. Two were blue collar. These were operatives and kindred workers and domestic and service workers. The remaining two categories were white collar occupations, including professional, managers, and officials; and clerical and kindred workers. Members of all categories were administered an att1tude test, in which the blue collar workers scored higher with regard to skepticism of medical care. ${ }^{7}$ If we assume that the members of the blue collar categories in this study represent the group with the highest level of anomie then it appears that there may be a negative relationship between level of anomie and strength of positive attitudes toward hea1th care.

Although there is some merit in making this assumption, the data collected in this study permit a quantitative exploration of this relationship. Table LVI contains these data.

It can be seen that for the public hospitals there is a distinct tendency for those subjects experiencing a lower level of anomfe to be more likely to have a positive attitude toward hospital care. It also

7 Daniel Rosenblatt and Edward A. Suchman, "Blue-Collar Attitudes and Information Toward Health and Illness," in Arthur B. Shostak and William Gomberg, op. cit., pp. 325-29. 
TABLE LVI

ATTITUDES TOWARD PUBLIC AND PRIVATE HOSPITAL CARE SHOWN BY LEVEL OF ANOMIE IN A PREDOMINENTLY INDIGENT POPULATION FOR SOUTH BATON ROUGE, HAMMOND, AND NEW ROADS, 1971

\begin{tabular}{|c|c|c|c|c|c|c|c|c|c|c|c|c|c|c|c|c|c|c|c|c|c|c|c|c|c|}
\hline \multirow{3}{*}{\multicolumn{2}{|c|}{$\begin{array}{c}\text { Mode of } \\
\text { Hea 1th } \\
\text { Care } \\
\end{array}$}} & \multicolumn{24}{|c|}{ Anomie } \\
\hline & & \multicolumn{3}{|c|}{0} & \multicolumn{3}{|c|}{1} & \multicolumn{3}{|c|}{2} & \multicolumn{2}{|r|}{3} & \multicolumn{4}{|c|}{4} & \multicolumn{3}{|c|}{5} & \multicolumn{3}{|c|}{6} & \multicolumn{3}{|c|}{ Tota 1} \\
\hline & & *P & $F$ & G & $\mathbf{P}$ & $\mathbf{F}$ & G & $\mathrm{P}$ & $F$ & G & $\mathrm{P}$ & $F$ & G & $\mathbf{P}$ & $F$ & G & $\mathrm{P}$ & $F$ & G & $\mathrm{p}$ & $F$ & G & $\mathrm{P}$ & $\mathbf{F}$ & $\bar{G}$ \\
\hline \multirow{6}{*}{$\begin{array}{l}\text { Public } \\
\text { General } \\
\text { Hospital } \\
\end{array}$} & $\begin{array}{l}\text { Charity - } \\
\text { New Or leans }\end{array}$ & 0 & 0 & 5 & 0 & 0 & 9 & 1 & 0 & 14 & 3 & 0 & 14 & 1 & 2 & 24 & 1 & 5 & 28 & 1 & 2 & 23 & 7 & 9 & 117 \\
\hline & Lallie Kemp & 0 & 0 & 3 & 0 & 0 & 7 & 0 & 2 & 12 & 1 & 2 & 22 & 1 & 1 & 29 & 2 & 5 & 23 & 2 & 3 & 13 & 6 & 13 & 109 \\
\hline & Earl K.Long & 0 & 0 & 2 & 0 & 0 & 5 & 1 & 1 & 4 & 1 & 1 & 4 & 0 & 0 & 9 & 3 & 3 & 9 & 1 & 1 & 8 & 6 & 6 & 41 \\
\hline & Alexandria & 0 & 0 & 0 & 0 & 0 & 0 & 0 & 0 & 1 & 0 & 0 & 0 & 0 & 0 & 1 & 1 & 0 & 3 & 0 & 0 & 1 & 1 & 0 & 6 \\
\hline & Other & 0 & 0 & 0 & 0 & 0 & 1 & 0 & 0 & 3 & 0 & 0 & 1 & 0 & 1 & 2 & 0 & 0 & 2 & 0 & 0 & 1 & 0 & 1 & 10 \\
\hline & Sub-Total & 0 & 0 & 10 & & & 22 & 2 & 3 & 34 & 5 & 3 & 41 & 2 & 4 & 65 & 7 & 13 & 65 & 4 & 6 & 46 & 20 & 29 & 283 \\
\hline \multirow{9}{*}{$\begin{array}{l}\text { Private } \\
\text { General } \\
\text { Hospital }\end{array}$} & $\begin{array}{l}\text { Baton Rouge } \\
\text { General }\end{array}$ & 0 & 0 & 6 & 0 & 1 & 6 & 1 & 1 & 10 & 1 & 1 & 13 & 1 & 2 & 9 & 1 & 3 & 12 & 2 & 0 & 10 & 5 & 8 & 66 \\
\hline & $\begin{array}{l}\text { Dixon } \\
\text { Memorial }\end{array}$ & 0 & 0 & 0 & 0 & 0 & 0 & 0 & 0 & 0 & 0 & 0 & 0 & 0 & 1 & 0 & 0 & 0 & 0 & 0 & 0 & 0 & 0 & 1 & 0 \\
\hline & $\begin{array}{l}\text { Lane } \\
\text { Memorial }\end{array}$ & 0 & 0 & 0 & 1 & 0 & 0 & 0 & 0 & 1 & 0 & 0 & 0 & 0 & 0 & 0 & 1 & 0 & 0 & 0 & 0 & 0 & 2 & 0 & 1 \\
\hline & $\begin{array}{l}\text { Our Lady of } \\
\text { the Lake }\end{array}$ & 1 & 1 & 4 & 1 & 1 & 3 & 0 & 1 & 5 & 1 & 2 & 9 & 0 & 1 & 11 & 1 & 2 & 14 & 0 & 1 & 11 & 4 & 9 & 57 \\
\hline & $\begin{array}{l}\text { Pointe } \\
\text { Coupee Gen'1 }\end{array}$ & 0 & 0 & 0 & 0 & 1 & 6 & 0 & 0 & 7 & 0 & 1 & 9 & 0 & 0 & 6 & 1 & 1 & 7 & 0 & 0 & 2 & 1 & 3 & 37 \\
\hline & $\begin{array}{l}\text { Seventh Ward } \\
\text { Genera l }\end{array}$ & 0 & 0 & 2 & 0 & 0 & 6 & 0 & 0 & 8 & 0 & 1 & 7 & 0 & 1 & 8 & 0 & 1 & 14 & 0 & 0 & 0 & 0 & 3 & 45 \\
\hline & Woman's & 0 & 0 & 0 & 0 & 1 & 3 & 0 & 0 & 0 & 0 & 0 & 1 & 0 & 0 & 1 & 0 & 0 & 1 & 0 & 0 & 0 & 0 & 1 & 6 \\
\hline & other & 1 & 1 & 1 & 0 & 1 & 4 & 0 & 0 & 5 & 1 & 1 & 0 & 0 & 0 & 5 & 0 & 1 & 3 & 1 & 0 & 5 & 2 & 4 & 23 \\
\hline & $\frac{\text { Sub-Total }}{\text { Total }}$ & $\frac{2}{2}$ & $\frac{2}{2}$ & $\frac{13}{23}$ & $\frac{2}{2}$ & $\frac{5}{5}$ & $\frac{28}{50}$ & $\frac{1}{3}$ & $\frac{2}{5}$ & $\frac{36}{70}$ & $\frac{3}{8}$ & $\frac{6}{0}$ & $\frac{39}{80}$ & $\frac{1}{2}$ & $\frac{5}{0}$ & $\frac{40}{105}$ & $\frac{4}{11}$ & $\frac{7}{20}$ & $\frac{51}{116}$ & $\frac{3}{7}$ & $\frac{2}{8}$ & $\frac{28}{74}$ & $\frac{14}{34}$ & $\frac{29}{58}$ & $\frac{235}{518}$ \\
\hline
\end{tabular}


appears that there is a slight tendency for this likelihood to vary inversely with the level of anomie. In the case of the subjects utilizing private hospitals it is difficult to detect such a relationship.

One final potential influence on attitudes that should be explored is that of type of payment. This is an area of increasing concern in the health care field, as rising costs are forcing attention to be directed to the consideration of alternate plans for payment of hospital fees. As mentioned earlier there is some indication that the authors of the fee-for-service plan inaugurated in Baltimore's medical care program speculated that the reduction in complaints may have been due to the freedom of choice conferred by the plan.

To gain some understanding of the relationship between method of payment and attitude toward hospital care among the subjects in this sample, a questionnaire item was designed to determine how the costs of the subjects' latest hospitalization were paid. The responses from approximately 200 subjects included in the pretest of the instrument were collapsed into nine categories. These categories are: employer, insurance, cash, medicine, none, welfare, cash and medicare, cash and insurance, and cash and welfare. Responses to the item on the final schedule were recorded by a code indicating the most appropriate "method of payment." This information is found in Table LVII.

Since only one subject responded to the types: cash and medicare and cash and insurance in both the private hospital and public hospital categories, these responses were discarded. Examining the remaining payment types, it is seen that cash is the type of payment associated with 
TABLE LVII

ATTITUDES TOWARD PUBLIC AND PRIVATE HOSPITAL CARE SHOWN BY MANNER OF PAYMENT IN A PREDOMINENTLY

INDIGENT POPULATION FOR SOUTH BATON ROUGE, HAMMOND, AND NEW ROADS, 1971

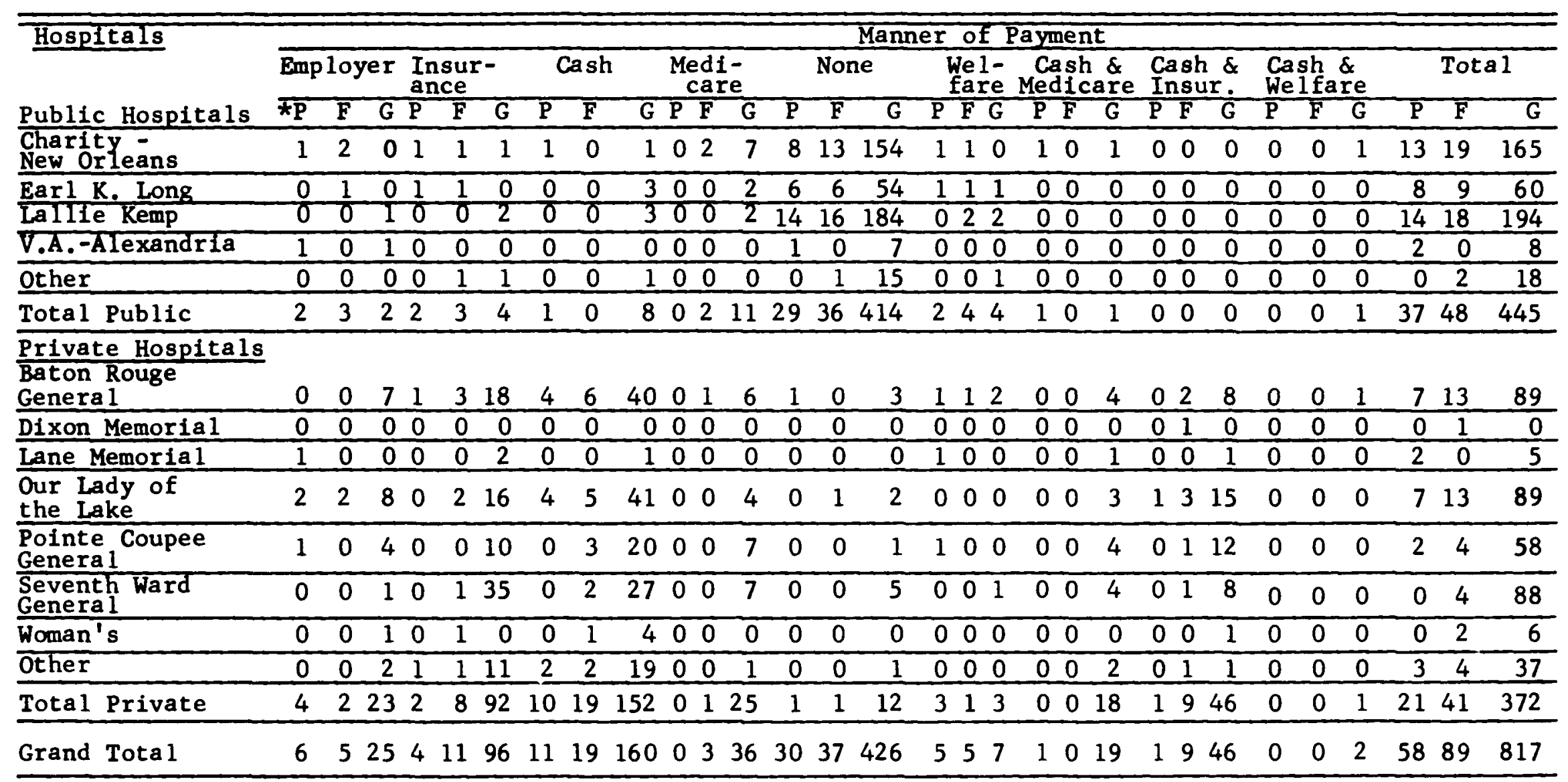

*P=Poor; F=Fair; G=Good . 
the highest rate of positive attitude for public hospitals while medicare is the type of payment associated with the highest rate of positive response for private hospitals. Insurance is associated with the lowest rate of positive response for public hospitals and welfare is associated with the lowest rate of positive response for private hospitals.

The relative rank of the various types of payments in relation to their association with rates of positive attitude toward hospital care can be accomplished by examining their rank order. This rank order for both private and public hospitals is presented in Table LVIII.

TABLE VIII

TYPE OF PAYMENT FOR HOSPITAL CARE SHOWN IN RANK ORDER FOR PRIVATE AND PUBLIC HOSPITALS

\begin{tabular}{ll}
\hline \multicolumn{1}{c}{ Private Hospital } & \multicolumn{1}{c}{ Public Hospital } \\
\hline 1. Medicare & 1. Cash \\
2. Insurance & 2. No payment \\
3. Cash & 3. Medicare \\
4. No payment & 4. Welfare \\
5. Cash and Insurance & 5. Employer \\
6. Employer & 6. Insurance \\
7. Welfare &
\end{tabular}

These rank order listings do not reveal a loglcal order. In the private hospital list medicare, insurance, and cash occupy the three highest ranks while the combination of cash and insurance unexplainably falls to the fifth rank. No payment occuples the fourth rank. However, payment by the employer, which must resemble "no payment" more than cash and insurance do, rests at sixth place. One 
possible intuitive explanation for this arrangement of ranks is that the first three ranks include payment types which suggest a quality of economic independence. The fifth rank, cash and insurance, also possesses this quality. However, in this case the insurance apparently was insufficient to cover the full expense. This may have made the patient feel that he had been exploited. Ranks 6 and 7, employer and welfare respectively, suggest a quality of economic dependence. Rank number 4, no payment, also suggests such a quality, but the discomfort of the individual may have been tempered by the implication that the hospital had excused them from paying the bill. Thus, it is possible to develop an intuitive explanation consistent with these data that does not embrace the position that the attitudes varied because the subjects were treated differently in the hospitals.

Such speculation is interesting. Unfortunately, the resulting explanations are not necessarily reliable. In fact, if the explanation developed above is applied to the rank order of the methods of payment in the public hospitals, it is found that the three type of payment involving the quality of economic independence do not occupy the first three ranks, but are almost equally spaced from the very highest rank to the very lowest rank.

It appears from these data that cash payment is associated with a high rate of positive attitude toward hospital care, but by no means assures positive attitudes. A striking feature of these data is the apparent difference which exists between the public and private hospitals. 
Summary

The intent in this chapter was to determine whether there existed any differences in attitudes toward hospital care manifested by varfous categories of health care consumers studied such as type of hospital (public vs. private), income range, geographic residence, age range, racial identity, lavel of anomie, and method of payment. Certain apparent differences were found to exist. Subjects in income ranges above $\$ 6,001$ tend to have a lower rate of positive responses toward public hospital care than do those subjects with incomes beneath this level. The urban sample showed a lower "good" response rate to the attitude item than did the more rural areas of Hammond and New Roads. This tendency is more pronounced for the attitudes toward public hospitals than for private hospitals. Similarly, subjects being treated in public hospitals tended to be the younger age groups (15 years to 35 years) to have a lower rate of positive responses than did persons in the higher age groups. Again, there appeared to be some difference between the public hospital and private hospital populations as measured by the responses of members of the two major racial groups. The Negro response was slightly more positive than the white response for public hospital care, but the reverse was true in the case of private hospitals. A tendency is seen for public hospital patients having lower levels of anomie to have higher rates of positive attitude responses. Finally, a tendency for rates of positive responses to be related to types of payment is apparent from these data. For the most part the relationships are obvious enough to be 
seen by inspection. However, there is the suggestion of an underlying relationship which is not completely obvious. We have seen that there is no essential difference in the rates of positive attitude responses between the public hospital users and the private hospital users as overall populations. That is, overall, it appears that the public hospital patients and the private hospital patients have an equally positive attitude toward the care they receive. Yet, when attention is directed toward various characteristics of these populations it appears that different attitude patterns may be emerging. This possibility merits some explanation. This is accomplished by testing a series of hypotheses.

Ho $_{1}$ : There is not a tendency for the rank order of the positive attitude responses of the public hospital patient population to vary in the same direction as the private hospital patient population when ordered on income ranges.

TABLE LIX

RANKS OF POSITIVE RESPONSE RATES TOWARD PUBLIC AND

PRIVATE HOSPITAL CARE OF A PREDOMINENTLY INDIGENT POPULATION OF SOUTH BATON ROUGE, HAMMOND, AND NEW ROADS SHOWN BY LEVEL OF INCOME, 1971

\begin{tabular}{|c|c|c|c|c|c|c|c|c|c|}
\hline & & & & Leve & 1 of In & come & & & \\
\hline & $\begin{array}{l}\text { Up to } \\
\$ 1,000\end{array}$ & $\begin{array}{l}\$ 1,001 \\
-2,000 \\
\end{array}$ & $\begin{array}{l}\$ 2,001 \\
-3,000 \\
\end{array}$ & $\begin{array}{r}\$ 3,001 \\
-4,000 \\
\end{array}$ & $\begin{array}{r}\$ 4,001 \\
-5,000 \\
\end{array}$ & $\begin{array}{l}\$ 5,001 \\
-6,000 \\
\end{array}$ & $\begin{array}{l}\$ 6,001 \\
-7,000 \\
\end{array}$ & $\begin{array}{r}\$ 7,001 \\
-8,000 \\
\end{array}$ & $\begin{array}{l}\text { Over } \\
8,000\end{array}$ \\
\hline $\begin{array}{l}\text { Public } \\
\text { Hospitals }\end{array}$ & 5 & 2 & 4 & 1 & 3 & 6 & 8.5 & 8.5 & 7 \\
\hline $\begin{array}{l}\text { Private } \\
\text { Hospitals }\end{array}$ & 6.5 & 5 & 3 & 8 & 4 & 1 & 9 & 2 & 6.5 \\
\hline
\end{tabular}

$\star_{r}=-.083>.05$

Level of Measurement: Ordinal

Test Statistic: Kendall Rank Correlation Coefficient with a rejection leve 1 of .05 or less. 
Decision: A value of -.083 was obtained. This is not significant at the .05 level of confidence. Therefore, the null hypothesis cannot be rejected and it is concluded that there is no tendency for the rank order of the positive responses of the public and private hospital patients to vary directly when ordered on income range.

$\mathrm{Ho}_{2}$ : There is no difference in the frequency of positive attitude responses between the urban, public hospital patients and the urban private hospital patients.

TABLE LX

FREQUENCY OF POSITIVE AND NEGATIVE ATTITUDE RESPONSES FOR PUBLIC AND PRIVATE HOSPITAL CARE IN A PREDOMINENTLY INDIGENT POPULATION FOR SOUTH BATON ROUGE AND HAMMOND, 1971

\begin{tabular}{|c|c|c|c|}
\hline $\begin{array}{l}\text { Type of } \\
\text { Response }\end{array}$ & Public & $\begin{array}{l}\text { ital* } \\
\text { Private }\end{array}$ & Tota 1 \\
\hline Positive & 352 & 280 & 632 \\
\hline Negative & 79 & 55 & 134 \\
\hline Total & 431 & 335 & 766 \\
\hline
\end{tabular}

Leve 1 of Mea surement: Nomina 1

Test Statistic: Chi Square with a rejection level of .05 or less.

Decision: A Chi Square value of .487 was obtained.

This is not significant. The null hypothesis cannot be rejected and it is concluded that there is not a significant difference in the positive response rate of these two groups.

$\mathrm{Ho}_{3}$ : There is no difference in the positive attitude responses between the rural, public hospital patients and the rural, private hospital patients. 
TABLE LXI

FREQUENCY OF POSITIVE AND NEGATIVE ATTITUDE RESPONSES FOR PUBLIC AND PRIVATE HOSPITAL CARE IN A PREDOMINENTLY INDIGENT POPULATION FOR NEW ROADS, 1971

\begin{tabular}{lccr}
\hline $\begin{array}{l}\text { Type of } \\
\text { Response }\end{array}$ & Public & Type of Hospital* & Private \\
Positive & 72 & 96 & 168 \\
Negative & 6 & 7 & 13 \\
\hline Total & 78 & 103 & 181 \\
\hline$x^{2}>.05$ & & &
\end{tabular}

Leve1 of Measurement: Nomina 1

Test Statistic: Chi Square with a rejection level of .05 or less.

Decision: A Chi Square value of .058 was obtained which is much higher than the established rejection level. Therefore, the null hypothesis is not rejected and it is concluded that there is not a significant difference in the frequency of positive responses toward their hospital care of these two groups.

$\mathrm{Ho}_{4}$ : There is not a significant tendency for the frequency of positive responses toward hospital care of the private hospital and public hospital patients to vary in the same direction when ordered on age.

TABLE LXII

RANKS OF POSITIVE RESPONSE RATES TOWARD PUBLIC AND PRIVATE HOSPITAL CARE OF A PREDOMINENTLY INDIGENT POPULATION OF SOUTH BATON ROUGE, HAMMOND, AND NEW ROADS SHOWN BY AGE CATEGORIES, 1971

\begin{tabular}{|c|c|c|c|c|c|c|}
\hline & & Age in & Top & Range is & xclusive* & \\
\hline & $15-25$ & $25-35$ & $35-45$ & $45-55$ & $55-65$ & Over 65 \\
\hline Public & 5 & 6 & 1 & 4 & 3 & 2 \\
\hline Private & 4 & 3 & 6 & 5 & 2 & 1 \\
\hline
\end{tabular}


Leve 1 of Measurement: Ordinal

Test Statistic: Kendall Rank Correlation Coefficient with a rejection level of .05 or less.

Decision: A value of -.056 was obtained which is not significant at the .05 leve 1. Therefore, the null hypothesis cannot be rejected and it is concluded that when ranked on age there is not a significant tendency for the frequency of positive responses of these two groups to vary in the same direction.

$\mathrm{Ho}_{5}$ : There is no difference in the frequency of positive attitude responses between the Negro, public hospital patients and the Negro, private hospital patients toward the care they receive.

TABLE LXIII

FREQUENCY OF POSITIVE AND NEGATIVE ATTITUDE RESPONSES OF NON WHITES FOR PUBLIC AND PRIVATE HOSPITAL GARE IN A PREDOMINENTLY INDIGENT POPULATION FOR SOUTH BATON ROUGE, HAMMOND AND NEW ROADS, 1971

\begin{tabular}{lccc}
\hline \hline Type of & & Type of Hospital* & \\
Response & Public & Private & Total \\
\hline Positive & 391 & 237 & 628 \\
Negative & 72 & 138 & 210 \\
\hline Total & 463 & 375 & 838 \\
\hline $\mathrm{x}^{2}<.001$ & & &
\end{tabular}

Leve 1 of Measurement: Nomina 1

Test Statistic: Chi Square with a refection level of .05 or less.

Decision: A Chi Square value of 49.83 was obtained, dictating the rejection of the null hypothesis and the conclusion that there is a difference in the frequency of positive attitude responses between the Negro, public hospital patients and Negro, private hospital patients. An inspection of the data reveals that this difference is in the direction of the Negro, public hospital patient being the most likely to have a positive attitude toward hospital care.

The Contingency Coefficient for this relationship is .236 .

$\mathrm{Ho}_{6}$ : There is no difference in the frequency of positive attitude responses between the white, public hospital patients and white, private hospital patients toward hospital care. 


\section{TABLE LXIV}

FREQUENCY OF POSITIVE AND NEGATIVE ATTITUDE RESPONSES OF WHITES FOR PUBLIC AND PRIVATE HOSPITAL CARE IN A PREDOMINENTLY INDIGENT POPULATION FOR SOUTH BATON ROUGE, HAMMOND AND NEW ROADS, 1971

\begin{tabular}{lccc}
\hline Type of & & & \\
Response & Public & Type of Hospitalt & Total \\
\hline Positive & 58 & 138 & 196 \\
Negative & 13 & 23 & 36 \\
\hline Total & 71 & 161 & 232 \\
\hline
\end{tabular}

$* x^{2}>.05$

Level of Mea surement: Nomina l

Test Statistic: Chi Square with a rejection level of .05 or less.

Decision: A Chi Square value of .621 was obtained which is not significant dictating that the null hypothesis be accepted and the conclusion drawn that there does not exist a significant difference between the frequency of positive attitude responses of the white, public hospital patients and the white, private hospital patients. Inspection of the data reveals that the difference which does exist is in the direction of the white, private hospital patient being the most likely to express a positive attitude.

$\mathrm{Ho}_{7}$ : The relationship between anomie and rate of positive attitude response among those persons utilizing public hospitals is not the same as among those utilizing private hospitals.

TABLE LXV

RATE OF POSITIVE ATTITUDE RESPONSE FOR PUBLIC HOSPITAL AND PRIVATE HOSPITAL CARE SHOWN BY LEVEL OF ANOMIE IN A PREDOMINENTLY INDIGENT POPULATION OF SOUTH BATON ROUGE, HAMMOND AND NEW ROADS, 1971

\begin{tabular}{cccc}
\hline \multicolumn{4}{c}{ Positive Response Ratest } \\
\hline Leve 1 of Anomie & Public & Hospitals & Private Hospitals \\
\hline 0 & .900 & .847 \\
1 & 1.000 & .800 \\
2 & .825 & .923 \\
3 & .745 & .848 \\
4 & .910 & .867 \\
5 & .772 & .841 \\
6 & .768 & .833 \\
\hline
\end{tabular}


Leve 1 of Measurement: Interval

Test Statistic: Product moment correlation coefficient to determine the strength of the relationship in each sample and the $Z$ test to determine the significance of the difference between these two relationships. A rejection leve 1 of .05 or less is used to reject the null hypothesis.

Decision: The correlation coefficients of -.627 and -.033 were computed for the public hospital and private hospital samples respectively. The $Z$ value obtained for the difference between these two correlations is .8405 . This value is not significant at the .05 leve1. Thus, the null hypothesis cannot be rejected and it must be assumed that the relationship between anomie and rate of positive attitude response of those persons utilizing public hospitals is not significantly different from those utilizing private hospitals.

$\mathrm{Ho}_{8}$ : The rate of positive attitude response toward hospital care does not bear the same rank order relationship to methods of payment in both public hospital and private hospital populations.

TABLE LXVI

RANKS OF POSITIVE ATTITUDE RESPONSE TO HOSPITAL CARE SHOWN BY TYPE OF PAYMENT FOR PUBLIC AND PRIVATE HOSPITALS IN A PREDOMINENTLY INDIGENT POPULATION OF SOUTH BATON ROUGE, HAMMOND AND NEW ROADS, 1971

\begin{tabular}{lcccccc}
\hline $\begin{array}{l}\text { Type of } \\
\text { Hospital }\end{array}$ & Medicare & Insurance & Cash & None & Emp loyer & We 1fare \\
\hline \multirow{2}{*}{$\begin{array}{l}\text { Private } \\
\text { Public }\end{array}$} & 1 & 2 & 3 & 4 & 5 & 6 \\
& 3 & 6 & 1 & 2 & 5 & 4 \\
\hline
\end{tabular}

$r=.067>.05$

Level of Measurement: Ordinal

Test Statistic: Kendall rank correlation coefficient with a rejection leve 1 of .05 .

Decision: A Kendall rank correlation coefficient of .067 was obtained. This is not significant at the .05 level. Therefore, 
the null hypothesis cannot be rejected and it is concluded that the rate of positive attitude response toward hospital care does not bear the same rank order relationship to methods of payment in both public hospital and private hospital populations.

It appears that there are both differences and similarities in the attitude behavior of public hospital and private hospital populations. When the proportion or rate of positive responses to hospital care are considered there is not a tendency for these rates to vary in the same direction with respect to age. In public hospital consumer populations there is a tendency for the younger age groups to have a lower rate of positive responses and for the upper age groups to be more divided. In the private hospital consumer population, there is a tendency for the older age groups to have a stronger positive response rate and for the positive response rate of the two younger age groups to rest at about the mean.

Type of residence, whether rural or urban, is also associated with a difference in attitude response patterns. The rural population tends to have a stronger positive response rate than does the urban population. However, there is no significant difference between the two groups in relation to the distribution of positive responses between public and private hospitals.

There is also a relationship between race and expressed attitude toward hospital care. This pattern shows the Negro tending to present a higher rate of positive responses in the public hospital group than in the private hospital group and the white population evidencing the opposite relationship, although the relationship for the white 
population is not significant. When positive attitude response rates are ranked by type of payment different patterns also emerge for the public and private hospitals. When income is considered it is found that there is a tendency for the public hospital consumer and the private hospital consumer to again present different patterns of attitude responses with the higher income groups of the public hospital patients tending to have the lowest positive response rates. of those characteristics explored, only anomie and rural-urban residence present a relationship to attitudes toward hospital care which cannot be said to be significantly different between the public hospital consumer and the private hospital consumer. 
CHAPTER VII

SUMMARY AND CONCLUSION

\section{Background}

This investigation began as an exploratory study designed to determine the health care patterns of the medically indigent persons in three selected communities. However, as planning for the study progressed, it was discovered that a knowledge of health care behavior of the medically indigent does not provide maximum insights for health care planning. A knowledge of the health care patterns of all persons living in indigent areas is of more value. Consequently, this became the objective of the study.

To accomplish this exploration, three population centers were selected representing a range of population types. One was a trade center depending on a farm economy and having little industry which is not farm related. A second community was somewhat larger. It was formally a farming area and produce shipping center, but is now beginning to industrialize. The third population center was located in an industrial, urban area. These population centers offered varying degrees of industrialization and urbanization, two ubiquitous influences in our society.

The sampling procedure used was adapted to each communtty. In the urban center, census data were used to locate low income census 
districts. A sampling procedure described by Kish was employed to generate the sample. ${ }^{1}$ In the transiticn community a great deal of difficulty was encountered in gathering the sample. Census tracts proved to be too large in proportion to the size of the community to be sensitive to concentrations of poverty populations. That is to say, each census tract covers such a large portion of the community that no single tract is limited to a predominantly low income population. Efforts to locate a previous poverty study proved to be unproductive. As a result of these complications it was necessary to improvise. Th1s was done by revisiting the low income occupied homes in the other two communftes and observing their characteristics then arriving at an approximation of the "usual low income home." With this "type" in mind a team drove through the community and marked the location of such homes on a map from which the sample was drawn. Although this method did not result in a completely precise location of the low income homes, it did prove to be more efficient in this respect than did the method of utilizing a poverty survey which had previously been completed by the office of Economic Opportunity Agency in the smallest community.

Having accomplished the sampling, attention was directed to gathering data. A schedule was developed for this purpose. The development of this instrument was a somewhat awkward process and was accomplished in several stages. Inputs were obtained from a medical survey instrument developed by Mulford at the University of Iowa, from a

$1_{\text {Leslie Kish, "Two Stage Sample of a City," American Socio- }}$ logical Review, XVII (December, 1952), 761-69. 
committee of professional persons, including medical doctors and social workers, and from a lay group representing the low income population. A great deal of the content of the schedule was dictated by its health planning purpose. The pretesting was accomplished in two stages. The first, devoted to the health and demographic items, was accomplished with an $\mathrm{N}$ of 200 . The second stage was devoted to items pertaining to health care utilization. The $\mathrm{N}$ for this stage was approximately half as large as that used in the first stage.

The profound sociological Importance of health care should not be underestimated. In the early history of inan, illness must have been a threat to the very existence of the species. Even as late as 1348 one nation, England, lost one-third of its population from the Black Death in a single year. Society could not ignore such a serious threat. Consequently a large body of norms developed to regulate the condition as well as possible. Obviously, medical care is such a body of norms. In addition, society developed norms related to symptom perception, the behavior of the sick person and the behavior of the non-sick toward the sick.

In exploring phenomena with such a wide range of influence, it is necessary to have a conceptual model that can accommodate to relationships at several different levels. To accomplish this a systems model was decided upon. The literature suggests that systems exist at 
several levels.2,3,4 Each of these levels are thought to interpenetrate. Thus, influences must be transmitted from one system level to another if such an interpenetration does exist.

It was felt to be necessary to establish whether such a condition does obtain before constructing the system model. If it does, then no social system model can be adequate if it does not provide for the simultaneous consideration of influences from the organismic, personality, social, and cultural system levels.

In approaching the problem of establishing the possibility of the existence of system level interpenetration, it was assumed that if a condition existing on one system level could be demonstrated to be significantly related to analogous conditions on each of the several other system levels this would be compatible with the possibility. It was also assumed that disease is a disruption of the homeostasis on the organismic system level. Analogous conditions at each of the other system levels must be related to the disruption of equilibrium or homeostases at each of the respective levels. At the personality system level this was assumed to be manifested in feelings of not belonging or in feelings of alienation. A breakdown of equilibrium at the social

2 Robin M. Williams, "The Sociological Theory of Talcott Parsons," in Max Black (ed.), The Social Theories of Talcott Parsons: A Critical Examination, Englewood Cliffs: Prentice-Ha11, Inc., 1961, pp. 69-72.

Marvin E. 01sen, The Process of Social Organlzation, New York: Ho1t, Rinehart and Winst on, 1968, p. 236 .

${ }^{4}$ James G. Miller, "Toward a General Theory for the Behavioral Sciences," American Psychologist, X (September, 1955), 521. 
system level was assumed to be conditions suggesting a breakdown in social structure. More difficulty was experienced in deciding on the manifestation of disequflibrium at the cultural system level. It was finally decided that a fundamental characteristic of American culture is the emphasis on purchasing goods and services. Although it may be argued that this emphasis is diminishing at the present time, it still remains true that this concept is communicated through the abundant advertising to which the American public is constantly exposed. One disequilibrium condition which can be anticipated to exist at the cultural system level, then, is the fact that some segments of society that are exposed to the theme that it is American, desirable, good, or expected for people to purchase goods and services may not be financially able to conform to this expectation. Thus, the shopper who must use food stamps, the health care consumer who must seek free medical care, or the family provider who can not afford to purchase may be considered to be existing in anomie to some extent because they cannot practice the norms which are communicated to them as being most desirable.

In operationalizing these various levels of system disequilibrium readily available variables were selected. At the organismic system level the rates of perceived pathology were used. The srole Anomie Scale was used at the personality system level. Observed or reported incompleteness in social structure was used to represent disequilibrium at the social system level. At the cultural system level, it proved difficult to locate a system variable. Consequently, an 
effort was made to locate an appropriate parameter. Income was the parameter decided upon, as it was reasoned that the American culture emphasizes the purchase of goods and services and an inability to conform to this expectation may be conducive to anomie.

The resulting calculations from this scheme indicate a strong relationship between disruption of homeostasis on the organismic system level and analogous conditions at each of the several higher system levels. Although it is not claimed that this proves the existence of system interpenetration, since this was not the intent, it does suggest that the possibility of such a condition existing is demonstrated to the extent that any model developed to explore health care behavior must accommodate to such a possibility.

A second condition that was felt to be essential for the system model is that of a cybernetic structure since any system which endures over time in the face multiple influences must be a self adjusting system. These qualities were incorporated into a modification of a system model developed by Holder. ${ }^{5}$ After constructing the model it was tested by applying it to two decision making behaviors. These were the decision of pathology bearing persons to seek treatment from a medical doctor and the decision of pathology bearing persons not to seek treatment from a medical doctor. A factor analysis of these responses produced factors which were consistant with the system model in both number and content.

5 Harold D. Holder, "Evaluation Methods and Dynamics in Program Planning," (Source unknown-reprint on file at the L.S.U. School of Social Welfare), p. 36. 
Having established the conceptual framework, attention must now be directed to the specific findings of the study. Although no effort was made to test out further the viability of the system model in the study, it does provide a framework for reviewing the findings. Three areas of dependent variables were explored. These were pathology, health care utilization, and attitudes toward hospital facilities. of these, pathology represents the organismic system, utilization the social system level and attitude a reaction to the behavior of the environment. Several independent variables were explored in various combinations. These were anomie, race and ethnicity, age, family composition, geographic location, religion, and income.

\section{Pathology}

The survey approach used in this study offers many advantages. Unfortunately, it also provides some disadvantages. One potentially serious disadvantage is the possibility that in using this approach to estimate morbidity rates those groups who are more sensitive to symptoms may tend to over report morbidity. These groups were determined to be: Hammond residents, members of medically constricted religious groups, people in the over $\$ 8,000.00$ per year income category, and members of the "American" ethnic group.

The morbidity data were tabulated according to several of these classifications including: place of residence, income, and ethnicity. These tabulations indicate that the perceived morbidity rate in Hammond is higher than either of the other communities. If the tendency to be symptom sensitive inflates the perceived morbidity rates than we would 
expect Hammond, which has the highest symptom response, to also have the highest perceived morbidity response. When the other two population classifications are examined, however, it is found that in neither of them do perceived morbidity rates and symptom response rates vary in the same direction. Although we cannot say from this comparison that the tendency to think of symptoms as important enough to require treatment does not inflate perceived morbidity rates, it is possible to say that it does not inflate these rates to the extreme of nullifying other influences, presumably including the presence of morbidity. Assuming, then, that the data obtained through this survey provided a relatively accurate estimate of morbidity the following relationships were found to obtain. The overall morbidity rate of the sample population was positively related to anomie, incomplete family structure, atypical family status of children, female head of household status, and non-regular church attendance. In addition, it was negatively related to family income.

Taken individually, these findings are not exceptionally exciting. In fact, with the possible exception of two of these relationships, the findings closely approximate the expected. These unexpected findings are the high morbidity rates for the female head of household and for the "atypical" child. In the former instance, it would be expected that any difference in rates would be biased toward the non-head of household since, in addition to being influenced by probability, the head of household status could not be held by persons experiencing serious pathology. The latter situation, that involving 
the "atypical" child, is unexpected simply because it apparently has not been explored previously.

Collectively, the implications of these findings are somewhat more significant, for they are not inconsistent with the concept of interpenetration of system levels. If, as has been suggested, living systems exist at several different system levels which interpenetrate each other then any condition existing at one system level must exert an influence at each of the other system levels.

It is doubtful that this influence is in the nature of a defused impact. A greater likelihood is that the influence is channeled from one system level to another through some common structure. From this point of entrance the influence may then spread out through the system. This common structure between systems suggests any condition at one system level must be related to an analogous structure at each of the other system levels.

If disease is assumed to be the disruption of the homeostasis of the organismic system level, then it must be related to some systematic disruption of equilibrium at each of the higher system levels. In this study, it was demonstrated that the following analogous conditions could be assumed to exist at the several system levels. Organismic System Level

1. Disease

Personality System Level

1. Feelings of Alienation 
Social System Leve 1

1. Incomplete family structure

2. Position of atypical child

3. Position of female head of household

4. Irregular church attendance

Cultural-Economic System Leve 1

1. Income

These relationships should be received with certain reservations. First, they cannot be considered to exhaust the possible intersystem relationships which might exist. Secondly, no cause and effect relationship can be assumed to obtain between these conditions on the basis of the data which are available from this study.

\section{Hea1th Care Utilization}

As pathology intrudes upon a population, its members become health care consumers. The Health care consumer is made aware of health care utilization norms through a variety of sources including: the church, the mass advertising media, the cultural media, agencies such as the Departments of Public Welfare and Public Health, and by word of mouth from the experienced consumer to the inexperienced consumer. Each of these sources tend to reach different sectors of the population. On occasion, this is by design, but at other times, it is because of the selectivity with which the population exposes itself to these various sources.

As a consequence of this differential exposure to health care utilization information, there exists a wide range of knowledge and understanding of health care utilization. This condition along with 
other influencing factors produces different patterns of health care utilization. An examination of these different patterns of utilization revealed that the medical doctor is, by far, the most frequently resorted to health care resource by all groups within this sample, including those persons belonging to the medically constricted religious groups. Entrance into the health care system is usually initiated, then, through the medical doctor.

Since this is the case, the decision making process involved in deciding whether or not to visit a medical doctor is important. An exploration of this process through factor analysis suggests that it is far more complex than symptom determinism. In fact the process seemingly conforms to a rather complex system model with organismic, personality, cultural and social components. The symptomatic person is aware of the discomfort of the symptom. He interprets this discomfort within a cultural context and either reconciles himself to it or begins to rationalize the decision to go to a medical doctor. There also occurrs a determination of the effects upon the family of either going or not going to the doctor. Finally, feedback is sought from the environment and the potential health care consumer is either encouraged or develops a distrust of the health care system. The process may not occur in this temporal sequence, however.

Many influences impinge upon this process. Persons living in a rural area tended to conform to the most conventional utilization. Members of the medically constricted religions tended to visit the medical doctor less frequently, but this tendency was rewarded by their 
having illness of a more serious nature.

Although place of residence is associated with differences in quality of physician utilization, it cannot be assumed from these data that the differences are related to the extent of urbanization or industrialization. Hammond, the community in transition, presented the lowest rate of families having a family physician as well as the highest rate of persons utilizing out of town doctors.

Income, also, is associated with the decision to utilize a medical doctor. Despite the fact that the low income groups expressed a stronger preference for the medical doctor as a first or second treatment choice, they actually tended to utilize the medical doctor at a lower rate than did the upper socio-economic groups. They also tended to utilize a wider range of comminity caretakers.

The subjects having the highest level of anomie tended to select the medical doctor as a first or second choice at a lower rate than did subjects with lower levels of anomie. However, the middle ranges of anomie appeared to be associated with higher rates of medical doctor selection as first or second choice than were either the highest or lowerest levels of anomie.

Although the medical doctor was the most frequently selected health caretaker as the initial contact in entering the health care system, he was by no means the only caretaker thus utilized. The spouse and other relatives were frequently the first source of help sought. Both of these rources were turned to at the greatest rate by subjects with lower rates of anomie. This is partly explained by the fact that 
subjects with high rates of anomie were less likely to have a spouse or close relatives.

\section{Attitudes}

The sensitivity of American institutions to the people they serve, while certainly not perfect, is remarkable enough that Carl Marx, in a speech at the Hague, observed that the United States was one of two mentioned nations which may not need to experience the proletariat revolution because of the nature of its institutions. 6 Perhaps one of the most feasible explanations for this sensitivity is the fact that there are two nearly ubiquitous feedback mechanisms built into institution behavior in the United States. These are the competitive model and the right to vote.

The competitive model serves as a feedback mechanism because with the existence of multiple, comparable outputs and a client system which can exercise freedom of choice there is a tendency for the members of the client system to gravitate toward the provider system which they feel to be most desirable. The loss of consumers by the competing provider systems is interpreted as negative feedback and adjustments are made to reduce this negative feedback by more closely accomodating to the interests of the consumers.

The feedback quality of voting on tax supported agencies and services is obvious. However, in the case of the provision of health

${ }^{6}$ Hans Kelsen, The Political Theory of Bolshevism (Berkeley: University of California Press, 1948), p. 41. 
care services both of these feedback mechanisms have been greatly dampened. The right to vote has not been effective because health care delivery has been effectively held out of the political sector until recently. Competition has also been muted in health care delivery. This results partially from the monopolistic like dominance of the medical profession in the field. A reinforcing condition is the vast numerical superiority of consumers to providers.

Such a condition is potentially explosive, for without an open feedback channel the only avenue available to consumers to express their attitudes may be consumer revolt. Thus, an awareness of consumer attitudes toward health care facilities can be of benefit to both the provider system as well as the consumer system.

For the purpose of this study the subjects' attitudes toward the medical facility to which they most recently went for care were elicited. Of these the medical hospital was selected for comparison because it offered a clear dichotomy between the public and private types. The responses were recorded as: poor, fair, or good. These responses were then tabulated by income range, geographic location, age range, racial and ethnic identity, level of anomie, and method of payment .

Essentially, 1ittle difference was found in the rate of "good" responses for public and private hospital patients. In fact, it appeared that there may have been some partitioning of hospital patients with consumers tending to gravitate to that type of hospital for which they had a preference. That income alone was not the 
determining factor, is seen by the fact that $38.7 \%$ of the subjects with an income of less than $\$ 5,001.00$ per year ut 11 ized a private hospital. There is a difference in attitude behavior by income groups with the higher income groups tending to produce a lower "good" response rate for public hospital care. In keeping with this partitioning possibility is the fact that of the several independent variables listed above only the behavior of anomie and attitude and place of residence and attitude were not significantly different for both public and private hospitals.

The fact that over $80 \%$ of the population expressed a "good" response to hospital care should not be interpreted as an overwhelming vote of confidence for the present health care system. Although this preponderance of "good" responses suggests that there may not be a danger of imminent consumer revolt in the health care field, there are some ominous indications. First, the nearly $20 \%$ of the population who expressed less than a "good" response is sizeable and cannot really be written off until the behavior of this segment over time is determined. Before a decision is made about this ratio, it is necessary to know whether the segment responding with less than a "good" attitude is increasing, decreasing, or remaining static over time. There is some indication in the available data that this population segment might be expected to increase. One reason for this prediction is the fact that the urban population tends to have a lower rate of "good" responses than does the more rural population. Since there is a trend toward urbanization in the area it must be assumed possible that, as 
urbanization increases, attitudes toward hospital care may become less positive. Another potential influence which must be considered with the public hospital is that the younger age groups in this sample tended to have less positive attitudes toward public hospital care. It is, of course, possible that this is a characteristic of the age group. Another possibility, however, is that these subjects, having experienced a different socialization, may have a different attitude set which may endure as they progress into the higher age groups. If this occurs, it should depress the attitudes in the higher age groups.

\section{Limitations of the Study}

One limitation of this study is somewhat characteristic of exploratory studies. This is the tendency to explore horizontally rather than vertically resulting in some lack of depth. Usually this results from a calculated trade off in an effort to achieve maximum utilization of the avallable data. In some instances, the opposite condition results and some data are not explored to the extent which their importance warrants.

This occurs in two specific instances in this study. One of these is in the exploration of pathology where attention is directed primarily to the overall pathology rates. A productive area of exploration would be the relationship of each category of pathology to the various independent, socio-economic variables. A second area of potentially productive exploration that was given only cursory attention is the area of attitude, especially as it relates to types of pathology and patterns of utilization. Unfortunately, the purposes and 
resources of this study did not permit an exhaustive exploration of these areas at this time.

A second limitation embodied in this study is the nature of the sampling methods used. In each geographic area the sample was generated differently. Although in each instance an effort was made to preserve the quality of randomness, it cannot be assumed that this quality was perfectly preserved in any of the samples nor can it be assumed that this quality was preserved to the same extent in each of the samples. This defect results largely from two constraints imposed by the grant under which the study was undertaken. One of these constraints was that the sample should be drawn from the predominently poverty areas of the communities. The second constraint was that the sampling should be accomplished in a manner that would demonstrate a feasible way to proceed in the future studies of the various types of population centers existing in the Louisiana Capital Area Health Planning Council's jurisdiction.

As a result of these sampling nuances the samples generated in Hammond and New Roads are representative only of the poverty sectors of the communities while the South Baton Rouge Neighborhood Area sample is representative of that entire neighborhood, which is a preponderantly indigent neighborhood.

A difficulty was encountered in the sampling. Originally, it was intended that the sampling unit would be the family, but that the data would be recorded and tabulated on the Individual when ever appropriate. It was expected that, on occasion, a parent would answer as 
proxy for minor children on many items. These arrangements were maintained throughout the study. However, as a result of a policy of having as many members of the family together as possible during the interviewing it was learned that frequently the late adolescent children disagreed on some items such as who they considered their doctor to be and what their attitudes were toward the care which they received. Under these circumstances units of decisional jurisdiction over their own or others' health care decisions were considered to be the data source. This condition, along with a tendency not to respond to some items, such as income, and the fact that some items were not appropriate to all family members, resulted in an apparently bounding $N$. This condition is not uncommon in surveys and there is no reason to believe that any errors resulting from this condition are systematic.

It was claimed earlier that a compeling need for this study was produced by the absence of morbidity data at any level other than the national level. Although this claim is approximately accurate at this time there are some indications that this condition may not endure indefinitely. There is one source of data which may relieve this condition in the future. This is the National Health Survey. This survey was designed to represent the civilian, noninstitutional population of the United States. Estimates relate to the nation as a whole. The sample size and structure permit the extension of some of these statistics to four broad geographical regions and for selected large metropolitan areas, but the design was not intended to yield state estimates. However, an experimental technique for utilizing these data to 
produce crude state estimates has emerged. This technique, by relating the statistics to the variables of color, sex, age, residence, family income, family size and industry of head of household, reduces the sample variability and bias. 7 In view of this development there is a possibility that increased sophistication in data manipulation may permit the estimation of morbidity at a geopolitical level other than the state at some time in the future.

Despite these several limitations this study does provide important insights into the health care needs, utilization patterns, and consumer attitudes. The attempt to relate the study to systems theory enhances its potential contribution.

Recommendations

A characteristic of exploratory studies is that they frequently raise more questions than they answer. This study is no exception. It provided some insights into the relationships between pathology, health care patterns, and attitudes toward hospital care to several socioeconomic variables. It also tended to support the sociological significance of the health field.

However, the most exciting outcomes of this study are the identification of two potentially productive areas for further explorations. One of these is the relationship between pathology and analogous

$7_{U}$. S. Department of Health, Education and Welfare, Public Health Service, Synthetic State Estimates of Disability: Derived from the National Health Survey, PHS Publication No. 1759, Washington, D.C.: U.S. Goverment Printing Office, 1968, pp. 1 and 9. 
structure at each of the several system levels. This relationship apparently obtains for overall pathology rates, but another possibility that exists is that the several pathologies may each bear a different relationship to the other system levels. A detailed examination of these relationships offers to provide an expansion of the understanding of multiple causation as we 11 as the sociological implications of illness.

A second area meriting further exploration is that of the decision making process involved in seeking health care. The data gathered in this study suggest that this process is less a function of the organismic system level than it is a function of the several other system levels. Thus, the symptom itself is less important in making the decision to seek treatment from a medical doctor than is the meaning of the symptom to the individual and the meaning of the decision to the family system. However, these data were obtained from verbal responses. Consequent $1 y$, they may not accurately reflect the dynamics at each level. A better understanding of these decision making dynamics could lead to more effective mobilization of the morbid populations. Several, more specific, recommendations can be made on the basis of this study. In view of the demonstrated relationship between morbidity, family dissolution, and anomie, it should be predicted that perceived morbidity can be expected to increase in the future at a rate greater than the rate of general population increase, since both family dissolution and anomie are thought to be increasing in our society. The relation between family dissolution also offers a possible focus for prevention, especially in locating high risk populations. of special 
interest in this area is the high morbidity rate experienced by the "atypica1" child. A team approach that offers the capability of improving the integration of this child into the supportive structure of the family might effectively reduce this high morbidity rate.

The usual mode of entrance of a person into the health care delivery structure is through the medical doctor. This proves to be uneconomical both in terms of cost to the consumer and in the deployment of health care manpower. The spouse is frequently the first person turned to by persons experiencing pathology while, less frequently, the minister, druggist, chiropractor, and faith healer are resorted to. There is, then the possibility of mobilizing these caretakers to provide a more effective gate keeping function. One other quality which should not be overlooked is the fact that in this sample, the nursing profession plays no role at all in the entrance of the consumer into the health care structure.

There are some indications that the low income consumer, as represented by this sample, is becoming restive and that this restiveness can be expected to increase in the future. Because of the public utility nature of health care it should be more responsive to the interest of its consumer. If an effort is made to reduce this restiveness, it should not be assumed that the public hospital should be modified to more closely resemble the private hospital. This is true because, first both populations are approximately equally positive in their attitudes. Secondly, the two populations are unique and may be expected to respond differently to different types of health care 
delivery. Apparently a structural defect which persists in the health care system is the absence of a viable feedback mechanism. Some attention, then, should be directed toward designing and developing such a structure. It is the writer's belief that the study provides an excellent base for further exploration and suggests several innovative methodological procedures to utilize in any such studies. 


\section{SELECTED BIBLIOGRAPHY}

\section{A. BOOKS}

Ackerknecht, Erwin. History and Geography of the Most Important Diseases. New York: Hafner Publishing Co., Inc., 1965.

Apple, D., editor. Sociological Studies of Health and Sickness. New York: McGraw-Hi11 Book Company, Inc., 1960.

Bales, Robert F. Interaction Process Analysis: A Method for the Study of Sma11 Groups. Cambridge: Addison-Wesley, 1949.

Barton, Richard T. Religious Doctrine and Medical Practice. Springfield: Charles C. Thomas, 1958.

Black, H. The Pentecostal Movement. New York: Humanities Press, 1964.

Black, Max, editor. The Social Theories of Talcott Parsons: A Critical Examination. Englewood Clifts: Prentice-Hall, Inc., 1961 .

Buckley, Walter. Sociology and Modern Systems Theory. Englewood Clifts: Prentice-Ha11, Inc., 1967.

Commission on Chronic Illness. Chronic Illness in the United States: Chronic Illness in a Large City. Cambridge: Harvard University Press, 1959.

Dodd, Paul A. and E. F. Penrose, Economic Aspects of Medical Services. Washington, D.C.: Graphic Arts Press, Inc., 1953.

Dubos, Rene. Man Adapting. New Haven: Yale University Press, 1965. - Mirage of Hea1th. New York: Harper, 1959.

Durkheim, Emile. The Division of Labor in Society. George Simpson, translator. New York: The Free Press, 1933.

- Suicide, A Study in Sociology. John A. Spaulding and George Simpson, translators. Glencoe: Free Press, 1951.

Ford, Thomas R. Hea1th and Demography in Kentucky. Lexington: University of Kentucky Press, 1964.

Freeman, Howard E., et al., editors. Handbook of Medical Sociology. Englewood Cliffs: Prentice-Ha11, Inc., 1963. 
Grinker, Roy., editor. Toward a Unified Theory of Human Behavior. New York: Basic Books, Inc., 1956.

Hawkins, Norman G. Medical Sociology. Springfield: Charles C. Thoma s, 1958 .

Herbert, Hyman. Survey Design and Analysis. Glencoe: The Free Press, 1955.

Jaco, E. G. Patients, Physicians and Illness. Glencoe: The Free Press, 1958 .

Kelsen, Hans. The Political Theory of Bolshevism. Berkeley: University of California Press, 1948.

Koos, Earl L. The Health of Regionville. New York: Columbia University Press, 1954.

Kosa, John, et a1., editors. Poverty and Health: A Sociological Analysis. Cambridge: Harvard University Press, 1969.

Lief, H. I., et al., editors. The Psychological Basis of Medica1 Practice. New York: Harper and Row, 1963.

MacIver, Robert M., editor. Conflict of Loyalties. New York: Harper and Bros., 1952.

- The Ramparts We Guard. New York: The Macmillan Company, 1950 .

- Society. New York: Farrar and Rhinehart, 1949.

McDavid, John W. and H. Harari. Social Psychology: Individua 1s, Groups, and Society. New York: Harper and Row, Publishers, 1968 .

Mechanic, David. Medical Sociology. New York: The Free Press of Glencoe, 1968 .

Mott, Frederick D. and M. I. Roemer. Rural Health and Medical Care. New York: McGraw-Hill Book Co., Inc., 1948.

O'Brien, Patrick. Moral Problems in Hospital Practice. St. Louls: B. Herder Book Co., 1956.

Olsen, Marvin E. The Process of Socia1 Organization. New York: Holt, Rinehart and Winston, 1968.

Parsons, Talcott. The Social System. New York: The Free Press of Glencoe, Inc., 1951 . 
Parsons, Talcott, and R. F. Bales. Family, Socialization and Interaction Process. New York: The Free Press, 1955.

Pittman, David J, and Charles R. Snyder, editors. Society, Culture, and Drinking Patterns. New York: John Wiley and Sons, Inc., 1962.

Roessler, R., and N. Greenfield, editors. Physiological Correlates of Paychological Disorder. Madison: The University of Wisconsin Press, 1962 .

Saunders, Lyle. Cultural Difference and Medical Care: The Care of the Spanish-Speaking People of the Southwest. New York: Russell Sage Foundation, 1954.

Serbeen, Oscar N., Jr. Paying for Medical Care in the United States. New York: Columbia University Press, 1953.

Shostack, A., and W. Gomberg, editors. Blue-Collar World: Studies of the American Worker. Englewood C11ffs: Prentice-Ha11, 1965.

, and , editors. New Perspectives on Poverty. Prentice-Ha11, Inc., 1965.

Smelser, Neil.T., and J. A. Davis, editors. Sociology. Englewood Cliffs: Prentice-Ha11, Inc., 1969.

Spencer, Herbert. The Principles of Sociology. Vo1. II. New York: D. Appleton and Co., 1898 .

Sydenstricker, Edgar. Health and Environment. New York: McGraw-Hil1 Book Company, Inc., 1933.

Thomas, William I., and F. Zaniecki. The Polish Peasant in Europe and America. Vol. I. Boston: Gorham Press, 1918.

Thorton, Janet. The Social Component in Medical Care. New York: Columbia University Press, 1937.

Wolff, H. Stress and Disease. Springfield, Illinois: Thomas, 1968.

\section{B. PERIODICALS}

Alpert, Joel J. et al. "Types of Families that Use an Emergency Clinic," Medical Care, VII (Jan.-Feb., 1969), 56-61.

Aycock, W. L. and J. W. Hawkins. "Regiona1, Racial and Familial Relationships in Leprosy in the United States," Public Health Reports, LVI (June, 1941), 1323-1336. 
Bailey, M. B., et a1. "The Epidemiology of Alcoholism in an Urban Residential Area," Quarterly Journal of Studies on Alcohol, XXVI (March, 1965), 19-40.

Bertrand, Alvin L. "The Stress-Strain Element of Social Systems: A Micro Theory of Conflict and Change," Social Forces, XLII (October, 1963), 1-9.

Calabresi, M. "The Relation of Country of Origin to Mortality for Various Causes in New York State," Human Biology, XVII (1945), 340-365.

Curet, Bernard. "Pointe Coupee: Her Economic Progress," Acadiana Profile - A Magazine for Bi-Lingual Louisiana, I (SeptemberOctober).

Dorn, Harold F. 'Method of Measuring Incidence and Prevalence of Disease," American Journal of Public Hea1th, XLI (March, 1951), 271-278.

Emerson, Haven. "Significant Differences in Racial Susceptibility to Measles, Diphtheria, and Scarlet Fever: Statistical Study of Case Incidence and Deaths Among Treatment Dwellers in New York City, 1921-1925, Inclusive," Journal of Preventive Medicine, V (September, 1931), 317-350.

Epstein, Frederick H., et al. "The Epldemiology of Atherosclerosis among a Random Sample of Clothing Workers of Different Ethnic Origins in New York City, I," Journal of Chronic Disease, V (September, 1957), 300-328.

Graham, Saxon. "Disability in Butler County," Public Health Reports, LXXI (November, 1956), 115-118.

- "Ethnic Background and Illness in a Pennsylvania County," Social Problems, IV (July, 1956), 76-82.

Kish, Leslie. "Two Stage Sample of a City," American Sociological Review, XVII (December, 1952), 761-769.

Kosa, John. "Crisis and Stress in Family Life," Wisconsin Sociologist, IV (Summer, 1965), 11-19.

Miller, James G. "Toward a General Theory for the Behavioral Sciences," American Psychologist, X (September, 1955), 513-531.

Redlich, F. C., et al. "Social Class Differences in Attitudes Toward Psychiatry," American Journal of Orthopsychtatry, XXV (1955), 60-70. 
Richardson, William C. "Poverty, Illness, and Use of Health Services in the United States Hospitals," Journal of the American Hospital Association, XIIII (July 1, 1969), 34-40.

Sauer, H. I. "Epidemiology of a Cardiovascular Mortality - Geographic and Ethnic," American Journal of Public Health, LII (January, $1962), 94-105$.

Simmons, 0zzie. "Implications of Social class for Public Health," Human Organization, XVI (Fa11, 1957), 7-14.

Smith, F. R. "Nationality and Carcinoma of the Cervix," American Journa 1 of obstetrics and Gynecology, XLI (March, 1941), 424-430.

Srole, Leo. "Social Integration and Certain Corollaries: An Exploratory Study," American Sociological Review, XXI (December, 1956), 709-716.

Zborowski, M. "Cultural Components in Responses to Pain," Journal of Social Issues, VIII, 非 (1952), 16-30.

Zola, Irving K. "Culture and Symptoms - An Analysis of Patients' Presenting Complaints," American Sociological Review, XXXI (October, 1966), 615-630.

\section{OTHER SOURCES}

Alleger, Danie1. A Southern Rural Paradox: Social Change and Dispair. Tallahassee: Florida State University, Agricultural Experimental Station, Research Report, II, No. 1 (January, 1966).

American Public Health Association. The Maryland Medical Care Program. New York: A Report of the American Public Health Association, 1948.

Anderson, Odin W. and Paul B. Sheatsley. Comprehensive Medical Insurance - A Study of Costs, Use, and Attitudes Under Two Plans, Health Information Foundation Research Series No. 9, New York: Health Information Foundation, 1959.

Baton Rouge Area Chamber of Commerce. A Decade of Progress: Economic Resume, Baton Rouge, Louisiana. Baton Rouge: Chamber of Commerce, 1971 .

Bertrand, Alvin L, and Homer L. Hitt. Parental Attitudes and Denta 1 Care for Children in Selected Rural Areas of Loulsiana. Baton Rouge: Louisiana State University Press, 1948 . 
Hamption, H. P. Report of Governors' Conference on Health Care Cost. Austin, Texas: Governor's Office of Comprehensive Health Planning, 1971 .

Hawkins, N. G. and T. H. Holmes. "Environmental Considerations in Tuberculosis: Ecologic Factors in Tuberculosis Morbidity," Transactions of the Fiftieth Anniversary Meeting of the National Tuberculosis Association, 1954, 233-238.

Holder, Harold D. "Evaluation Methods and Dynamics in Program Planning," (Source unknown-reprint on file at the L.S.U. School of Social Welfare).

Shanas, Ethe1. Family Relationships of older People. New York: Health Information Foundation Research Series 20, 1961.

United States Department of Commerce: Bureau of the Census. 1968 County Business Patterns, Louisiana. U. S. Government Printing office: Washington, D.C., 1969. - Census of Population: 1960, Vol. I: Characteristics of the Population, Part 20, Louisiana. U.S. Government Printing Office: Washington, D.C., 1961.

United States Department of Health, Education and Welfare, Public Health Service, Synthetic State Estimates of Disability: Derived from the National Health Survey. P.H.S. Publication No. 1759, Washington, D.C.: U.S. Goverment Printing office, 1968 .

\section{UNPUBLISHED WORKB}

Feldman, Jacob J. "What Americans Think About Their Medical Care," Paper read at the annual meeting of the American Statistical Association. Chicago, December 27-30, 1958.

Hammond Chamber of Commerce. Economic Facts About Hammond. An unpublished report with aceograph copies on file in the office of the Hammond Chamber of Commerce, 1971. 
A P P E N D I C E S 


\section{APPENDIX A}

1971

LOUISIANA CAPITAL AREA HEALTH PLANNING COUNCIL PERCEIVED HEALTH NEEDS, ATTITUDES TOWARD HEALTH CARE, AND HEALTH CARE CONSUMPTION PATTERNS OF THE MEDICALLY INDIGENT

\begin{tabular}{lll}
\hline (1) & (2) Functional Dwelling Type & Questionnalre \\
Name & 1. Single family dwelling unit & \\
Address & 2. Duplex & of \\
\hline 3. Baton Rouge & 3. Rooming house & Questionnaires \\
2. Hotel & \\
3. New Roads & & \\
\hline
\end{tabular}

PERSONAL DATA ON OCCUPANTS

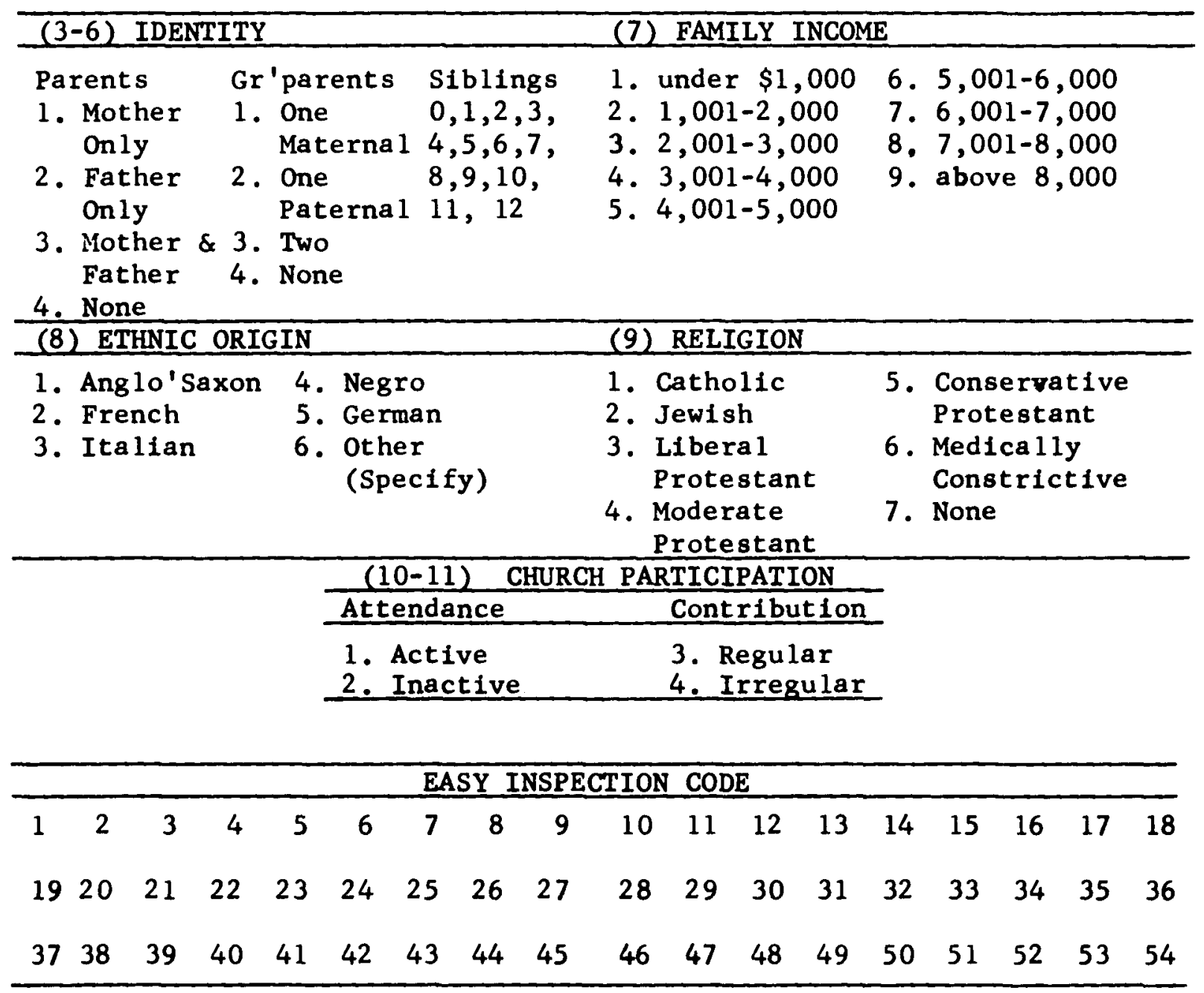


1. (a) What is the name of the head of this household? ENTER IN 1st COLUMN

(b) What are the names of all other persons 21 and over who live here? ENTER

(c) I have listed (READ NAMES). Is there anyone else now staying here such as friends, relatives, or roomers? 1 - Yes 2 - No

(d) Do any of these people have a home elsewhere?

1 - Yes APPLY HOUSEHOLD MEMBERSHIP RULES. IF NOT MEMBER, DELETE (12)

2 - No LEAVE ON LIST.

(e) What are the names of your children? IF ANY ADULT MALES LISTED, ASK:

(f) Are any of the persons in this household now on full-time active duty with the Armed Forces or living away from home?

1 - Yes DELETE 2 - No

2. How are you related to the head of this household?

(son, daughter, father, mother, mother-in-law,

roomer, step-son, spouse, etc.

WRITE IN RELATIONSHIP

(13)

3. How old are you?

4. What are the ages of the other members of the family?

5. Sex (Write in code in each column)

1 - male

2 - female

6. Are you now married, widowed, divorced, separated, or never married? (ask for each appropriate member of the family) CODE EACH COLUMN

1 - married* 4 - separated

2 - widowed 5 - single

3 - divorced

*IF "MARRIED" (1), ASK:

How long have you been married?

DETERMINE WHICH ADULTS ARE AT HOME AND RECORD THIS INFORMATION. BEGINNING WITH 非, YOU ARE TO INTERVIEW FOR HIMSELF OR HERSELF OR HAVE PRESENT EACH ADULT WHO IS AT HOME (EXCEPT WHEN OTHERWISE INDICATED)

CODE EACH COLUMN

1 - At home

2 - Not at home 
7. Were you or any member of the family, sick at any time

last week or the week before? (That is, the 2-week

period which ended this past Sunday night?)

1 - Yes

2 - No

(a) What was the matter?

(b) Anything else?

8. Last week or the week before, did you or any member of your family, take any medicine or treatment for any condition (besides... which you told me about?)

1 - Yes

2 - No

(a) What was the condition?

(b) Do you have anything else that bothers you?

(23)

9. Since this time last year, have you (your--, etc.) had any injuries from accidents that interfered with things you usually do for a half day or more or for which you had treatment?

1 - Yes

2 - No

(a) What was the accident and injury?

(b) Anything else?

10. Did you ever have an (any other) accident or injury that still bothers you or affects you in any way?

1 - Yes

2 - No

$(26)+\cdots$

(a) In what way does it bother you?

RECORD PRESENT EFFECTS

(b) Anything else?

11. Has anyone in the family--you, your--, etc. had any of these conditions during the past 12 months?

1 - Yes

2 - No

READ CARD "A," CONDITION BY CONDITION: RECORD IN HIS COLUMN ANY CONDITION (BY NUMBER) MENTIONED FOR THAT PERSON, 
12. Does anyone in the family have any of these conditions?

READ CARD "B," CONDITION BY CONDITION: RECORD IN HIS COLUMN ANY CONDITIONS (BY NUMBER) MENTIONED FOR THE PERSON.

1 - Yes

2 - No

13. Do you or your family have anyone that you go to get help when you feel bad (elicit responses other than medical doctors)?
1 - Yes
2 - No

What type of person?--List

14. Which of these symptoms do you think are serious enough to cause a person to go to a doctor?

USE CARD C

15. Did you or anyone in your family have any of these symptoms over the past year and not go to the doctor? (if yes, go to item 16)

1 - Yes

2 - No

16. If yes to 15 , we would like to know why you did not go to the doctor.

USE CARD D

17. Did you or anyone in your family go to a

doctor during the past year (if yes, go to 18)?

1 - Yes

2 - No

18. Now we would like to know what helped you to decide to go to the doctor. 
When you feel sick whom do you go to for advice or help? (first, second, etc.) WRITE IN

19. Do you ever go to a friend or neighbor?

1 - Yes

2 - No

20. Do you ever go to a minister or priest?

1 - Yes

2 - No

21. Do you ever go to a druggist for advice when you are sick?

1 - Yes

2 - No

22. Are you taking medicine at this time?

1 - Yes, prescription

2 - No

3 - Yes, non-prescription

23. (if yes to 22) About how much did your

family pay for this medicine last

month (July)?

WRITE IN AMOUNT

(43)

24. How is it paid for?

1 - the person or company you work for

2 - insurance

3 - cash

4 - Medicare

5 - no payment

6 - welfare

25. Do you have an "usual" or "family" doctor that you do to?

1 - Yes

2 - No

26. How long has it been since you or any member of your family last went to a doctor? 
27. Where is the doctor located?

WRITE IN HOSPITAL OR CLINIC AND TOWN

(47)

28. Approximately how much did the visit cost?

WRITE IN AMOUNT IN THE APPROPRIATE COLUMN

29. How was the visit paid for?

1 - the person or company you work for

2 - insurance

3 - cash

4 - Medicare

5 - no payment

6 - we lfare

30. During the past six months about how many

days have the members of your family been

sick enough to have to put off what they

ordinarily do, i.e., work, school, etc.

RECORD IN THE APPROPRIATE COLUMN

31. Have you or any member of your family

been treated at a public general

hospital? (if yes, list them)

1 - Yes

2 - No

32. How long has it been?

1 - during the past month

2 - one to three months

3 - three months to one year

4 - one to five years ago

5 - over five years ago

Ask items 33-34 for each hospital listed

33. How was the bill paid?

1 - the person or company you work for

2 - insurance

3 - cash

4 - Medicare

5 - no payment

6 - wellare 
34. How do you feel that you were treated?

1 - with courtesy and respect

2 - with indifference

3 - with open irritation or unpleasantness

35. Have you or any member of your family been

treated at a private hospital?

(if yes, list them)

1 - Yes

2 - No

36. How long has it been?

1 - during the past month

2 - one to three months

3 - three months to one year

4 - one to five years ago

5 - over five years ago

Ask items 38-39 for each hospital listed

37. How was the bill paid?

1 - the person or company you work for

2 - insurance

3 - cash

4 - Medicare

5 - no payment

6 - welfare

38. How do you feel that you were treated?

1 - with courtesy and respect

2 - with indifference

3 - with open irritation or unpleasantness

(58)

39. Have you or any member of your family

been to any clinic such as (suggest

examples and list clinics revisited)?

1 - Yes

2 - No 
40. How long has it been?

1 - during the past month

2 - one to three months

3 - three months to one year

4 - one year to five years ago

5 - over five years ago

Ask items 41 - 42 for each clinic visited

41. How was the bill paid?

1 - the person or company you work for

2 - insurance

3 - cash

4 - Medicare

5 - no payment

6 - wel fare

42. How do you feel that you were treated?

1 - with courtesy and respect

2 - with indifference

3 - with open irritation

43. In genera1, how good do you feel the medical care is that you get?

1 - poor

2 - fair

3 - good

44. What type of arrangement do you make for transportation when you seek medical care?

1 - own car

2 - relative's car

3 - friend's or neighbor's car

4 - taxi

5 - city bus

6 - volunteers

45. How many times have you moved during the past

three years? (Count only those moves that

carried the family into an unfamiliar neighborhood)

1 - none

2 - one or two

3 - three to five
4 - over five 
46. (Ask for those moves counted in 1tem 45.)

Were there any cases of sickness in your family

following any of these moves?--- How many?

1 - None

2 - one or two

3 - three to five

4 - over five

Now we would like to ask you whether you agree

with some statements about life.

47. Nowadays a person has to live pretty much for today and let tomorrow take care of itself.

1 - Agree

2 - Disagree or don't know

48. In spite of what some people say the lot of

the average man is getting worse, not better.

1 - Agree

2 - Disagree or don't know

(68)

49. It's hardly fair to bring children into the world with the way things look for the future.

1 - Agree

2 - Disagree or don't know

50. These days a person doesn't really know on whom he can count.

1 - Agree

2 - Disagree or don't know

(70)

51. There's little use writing to public officials because often they aren't really interested in the problems of the average man.

1 - Agree

2 - Disagree or don't know

52. Things have usually gone against me in 1 ife.

1 - Agree

2 - Disagree or don't know 
53. Which of your children do you consider to be the most different from the rest of the family?

(write in name)

54. How long has it been since you or a member of your family went to a dentist?

1 - during the past month

2 - one to three months

3 - three months to one year

4 - one to five years ago

5 - over 5 years ago

6 - none

Your Age 


\section{APPENDIX B}

\section{MORBIDITY INVENTORY LIST}

1. Asthma

2. Tuberculosis

3. Chronic Bronchitis

4. Repeated Attacks of Sinus Trouble

5. Rheumatic Fever

6. Hardening of the Arteries

7. High Blood Pressure

8. Heart Trouble

9. Stroke

10. Hemorrhoids or Piles

11. Hay Fever

12. Tumor, Cyst or Growth

13. Chronic Ga11 Bladder Trouble

14. Chronic Liver Trouble

15. Stomach Ulcer

16. Any Other Chronic Stomach Trouble

17. Kidney Stones or Chronic Kidney Trouble

18. Mental Illness

19. Arthritis or Rheumatism

20. Diabetes

21. Alcoholism

22. Thyroid Trouble or Goiter

23. Any Allergy

24. Epilepsy

25. Chronic Nervous Trouble

26. Cancer

27. Chronic Skin Trouble

28. Hernia or Rupture

29. Deafness or Serious Trouble Hearing with One or both Ears

30. Serious Trouble Seeing with One or both Eyes Even When Wearing Glasses

31. Missing Fingers, Hand, Arm, Toes, Foot, or Leg

32. Palsy

33. Paralysis of any Kind

34. Repeated Trouble with Back or Spine

35. Club Foot

36. Permanent Stiffness or any Deformity of the Foot, Leg, Fingers, Arm or Back 


\section{VITA}

The author was born in New Orleans, Louisiana on May 14, 1928. He attended public schools in Hamond, graduating from Hammond High School in 1945. His college education was interrupted by two periods of active duty in the United States armed service. However, a Bachelor of Science degree was obtained at Louisiana State University in January, 1956. This was followed by a Master of Social Work degree in August, 1960, which was also obtained from Louisiana State University.

From 1956 to 1958 the author was employed as a Welfare Visitor with the Louisiana State Department of Public Welfare. From 1960 to 1964 he served with the Louisiana State Department of Hospitals, first as a psychiatric social worker in an alcoholism treatment center, then as director of an alcoholism treatment center, and finally as director of the Louisiana State Alcoholism Program.

In September, 1964, the author accepted a position on the faculty of the School of Social Welfare, Louisiana State University. He has continued in this capacity since then. In January, 1965, he began graduate studies in sociology at Louisiana State University where he is present ly a candidate for the $\mathrm{Ph} . \mathrm{D}$. degree. 
EXAMINATION AND THESIS REPORT

Candidate: Robert A. Perkins

Major Field: $\quad$ Sociology

Title of Thesis: Health Care Patterns, Attitudes, and Resource Utilization of a Predominantly Indigent Population in Three Communities

Approved:

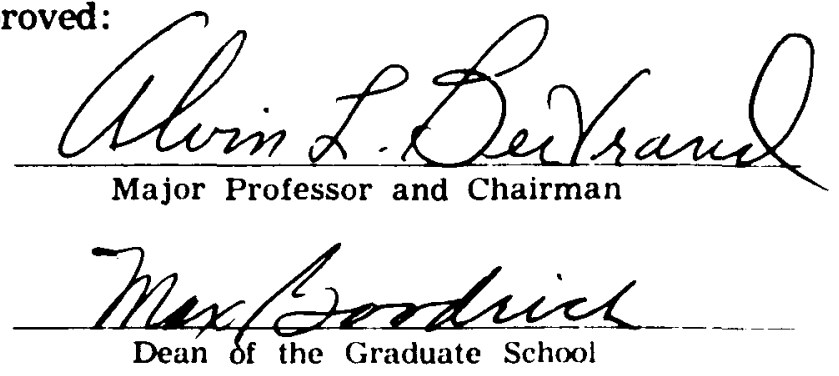

EXAMINING COMMITTEE:
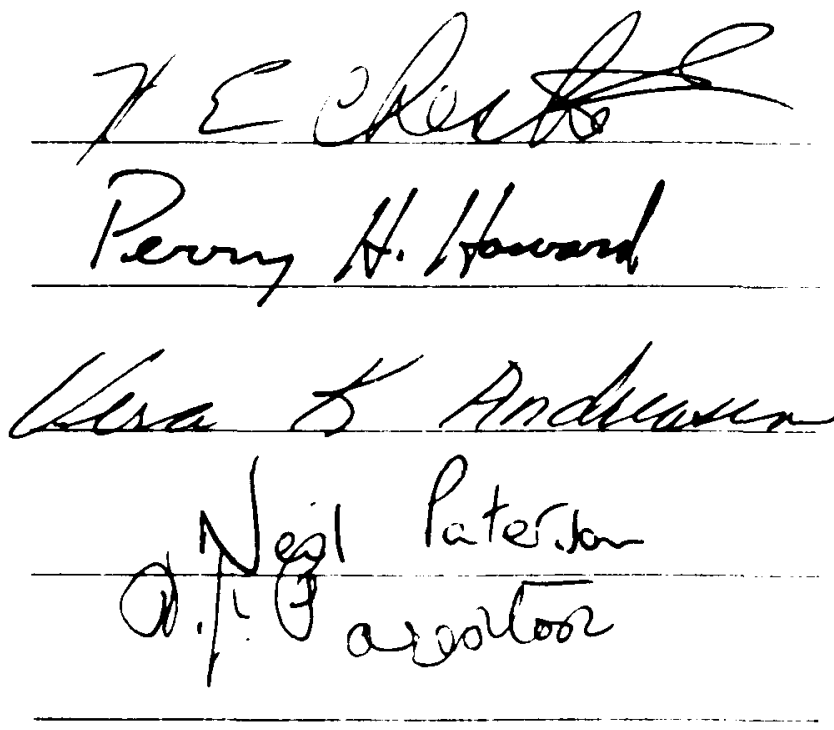

Date of Examination:

April 28, 1972 